UNIVERSITY OF BELGRADE

Faculty of Philosophy

Ljiljana B. Lazarević

\title{
RELATIONS BETWEEN IMPLICIT AND EXPLICIT MEASURES OF PERSONALITY- PROSPECTS OF IMPLICIT ASSOCIATION TEST (IAT) IN ASSESSMENT OF BASIC PERSONALITY TRAITS
}

Doctoral Dissertation

Belgrade, 2012 


\section{UNIVERZITET U BEOGRADU}

Filozofski fakultet

Ljiljana B. Lazarević

\section{ODNOS IZMEĐU IMPLICITNIH I EKSPLICITNIH MERA LIČNOSTI- MOGUĆNOSTI TESTA IMPLICITNIH ASOCIJACIJA (IAT) U PROCENI BAZIČNIH DIMENZIJA LIČNOSTI}

Doktorska disertacija

Beograd, 2012 
Supervisor:

1. Associate Professor Goran Knežević, PhD

Department of Psychology, Faculty of Philosophy, Belgrade, Serbia

Board members:

2. Assistant Professor Goran Opačić, PhD

Department of Psychology, Faculty of Philosophy, Belgrade, Serbia

3. Associate Professor Dejan Lalović, $\mathrm{PhD}$

Department of Psychology, Faculty of Philosophy, Belgrade, Serbia

4. Associate Professor Brian Nosek, PhD

Department of Psychology, University of Virginia, USA

Date: 
During work on this study, I had great support of my colleagues and friends. First, I would like to thank to all students of Department of Psychology, at the Faculty of Philosophy, Belgrade that participated in research. Without them, I would not be able to conduct this study. In addition, I thank Faculty staff and Slobodanka Đurković for assistance in organization of data collecting.

I thank my friends and colleagues Jovana Bjekić, Milica Erić and Elena Stojimirović for enormous help and energy they invested in collecting behavioural data. To my dear friend Branislava Džida, I thank for the help in technical preparation of the text. Also, I thank my dear friends and colleagues Natalija Radivojević and Boban Petrović for their suggestions and support.

I owe much gratitude to my colleagues from the Institute of psychology and to the former director of the Institute prof. Bora Kuzmanović, PhD for supporting me and providing me with the opportunity to work in a very pleasant surroundings.

To my professors at the Department of Psychology prof. Vasilije Gvozdenović, $\mathrm{PhD}$, prof. Dejan Lalović, PhD, asis. prof. Goran Opačić, PhD and asis. prof. Iris Žeželj, $\mathrm{PhD}, \mathrm{I}$ thank for useful suggestions they made in preparatory phase of this research.

To prof. Anthony Greenwald, PhD, prof. Konrad Schnabel, PhD, and prof. James Pennebaker, $\mathrm{PhD}$, I owe gratitude for suggestions they made during preparatory phase of research.

I thank prof. Mitja Back, $\mathrm{PhD}$ for his permission to use protocol for collection of behavioural data and on suggestions he made.

Special gratitude goes to prof. Brian Nosek, $\mathrm{PhD}$ for dedicating his time and for making available his expertise in the field of implicit measurement to me.

Deepest gratitude I owe to my supervisor prof. Goran Knežević, PhD. I thank you for your unselfish support, immense energy you invested, and for sharing your knowledge throughout all these years with me.

Last, but not least, I thank my parents Dušanka and Branko Lazarević and my family for their unselfish love and support. 


\title{
Relations between Implicit and Explicit Measures of Personality- Prospects of Implicit Association Test (IAT) in Assessment Of Basic Personality Traits
}

\begin{abstract}
Introduction. The core idea behind the Implicit Association Test (IAT) is to obtain information that are not the result of controlled processes. Therefore, it is considered a technique with the potential to overcome some disadvantages of explicit measures, such as socially desirable responding. IAT consists of a task of double categorization whereby the respondents have to sort the stimuli belonging to superordinated categories.

Study objective. The main objective of the study was to investigate the convergent and discriminative validity of IAT in the assessment of basic personality traits.

Method. To investigate the relations between the implicit and explicit measures, Implicit Association Tests, several self-report measures, ratings by close others, and measures of cognitive abilities were administered to a sample of 224 university students at Belgrade University. Ratings by experts and linguistic measures were collected from a subsample of 99 subjects. The respondents completed the personality IAT, NEO-PIR and DELTA10 ( $\mathrm{S}$ and $\mathrm{R}$ form), a short scale of attributes (DOCEAN), a short questionnaire for the assessment of relevant moderator variables, KOG9 battery test for the assessment of intellectual abilities, and self-assessment of intellectual abilities. In addition, they were observed by experts in structured interviews, in which linguistic parameters were collected through an automatic text analysis (LIWC).

Results. The correlations between the self-reported and IAT Neuroticism (0.17) and Extraversion (0.16) were found to be small but significant $(\mathrm{p}<0.05)$. However, none of the paths from the personality IAT to the corresponding latent traits in SEM Correlated-Traits-Correlated-Uniqueness-MTMM-Model was significant. The model had the excellent fit: $\chi^{2}=338.18, p=0.00$; RMSEA=0.042 (90\% CI RMSEA 0.0310.053), SRMR=0.066 and CFI=0.96. The MTMM analyses on a subsample of 99 respondents, from which behavioural measures were collected, demonstrated relations
\end{abstract}


between IAT and the parameters collected with automatic text analysis (LIWC). Subsequent analyses demonstrated a strong divergence between implicit and explicit method factors.

Conclusion. Study has shown that the personality IAT measures have little in common with personality traits measured by the traditional self-report inventories or rating scales. However, MTMM analysis provides evidence about the predictive validity of IAT in spontaneous verbal behaviour.

Key words: Implicit Association Test (IAT), self-report, rating by close others, rating by experts, basic personality traits, Multi-Trait-Multi-Method (MTMM) approach Scientific topic: Psychology

Narrow scientific topic: Individual differences.

UDK: 159.923 
Odnos između implicitnih i eksplicitnih mera ličnosti - mogućnosti Testa Implicitnih Asocijacija (IAT) u proceni bazičnih dimenzija ličnosti

\section{Rezime}

Uvod. Ideja koja stoji u osnovi Testa Implicitnih Asocijacija (IAT) je prikupljanje informacija koje nisu pod uticajem kontrolisanih procesa, zbog čega se smatra da ova tehnika pruža mogućnost prevazilaženja nedostataka eksplicitnih mera, kao što je socijalno poželjno odgovaranje. IAT predstavlja zadatak dvostruke kategorizacije u kojem ispitanici svrstavaju stimuluse koji pripadaju nadređenim kategorijama.

Cilj. Glavni cilj istraživanja je bio da se utvrdi konvergentna i diskriminativna validnost IAT-a u proceni bazičnih dimenzija ličnosti.

Metod. Kako bi se utvrdile relacije između implicitnih i eksplicitnih mera, na uzorku od 224 studenta beogradskog univerziteta, prikupljeni su podaci sa Testa Implicitnih Asocijacija, nekoliko mera samo-izveštaja, procene od strane bliskih drugih i mere kognitivnog funkcionisanja. Na poduzorku od 99 ispitanika prikupljene su i mere procene od strane eksperta, kao i lingvistički parametri. Primenjeni su sledeći instrumenti: IAT za procenu bazičnih dimenzija ličnosti, NEO PIR (S i R forma) i DELTA 10 (S i R forma), kratka skala atributa (DOCEAN), kratak upitnik za procenu relevantnih moderatorskih varijabli, KOG9 baterija za procenu intelektualnih sposobnosti i upitnik za samo-procenu intelektualnih sposobnosti. Dodatno, prikupljene su i ekspertske procene na osnovu posmatranja u strukturisanom intervjuu i lingvistički parametri na osnovu automatske analize teksta (LIWC).

Rezultati. Korelacije između Neuroticizma merenim NEO PIR i IAT (0.17) i Ekstraverzije (0.16) su bile male ali značajne ( $\mathrm{p}<0.05)$. Međutim, nijedno od zasićenja sa IAT na korespodentnim latentnim faktorima u strukturnom MTMM modelu nije bilo značajno. Model je imao odlične indekse podesnosti: $\chi^{2}=338.18, \quad \mathrm{p}=0.00$; RMSEA $=0.042$ (90\% CIRMSEA 0.031-0.053), SRMR $=0.066$ i CFI $=0.96$. MTMM analiza na subuzorku od 99 ispitanika, na kojem su prikupljene i bihejvioralne mere, je kazala na relacije između IAT i parametara prikupljenih automatskom analizom teksta 
(LIWC). Naknadne analize su pokazale jako razmimoilaženje metodskih faktora izolovanih iz implicitnih i eksplicitnih mera.

Zaključak. Istraživanje je pokazalo da mere prikupljene pomoću IAT imaju malo zajedničkog sa merama samoizveštaja ili procena od strane drugih. Ipak, MTMM analiza je ukazala na mogućnosti IAT u predviđanju spontanog verbalnog ponašanja.

Ključne reči: Test Implicitinih Asocijacija (IAT), mere samoizveštaja, procena od strane bliskih drugih, procena od strane eksperta, bazične dimenzije ličnosti, multicrta multi-metod pristup (MTMM)

Naučna oblast: Psihologija

Uža naučna oblast: Individualne razlike

UDK: 159.923 


\section{Contents}

1. INTRODUCTION ......................................................

1.1. Explicit Measures in the Assessment of Individual Differences............. 2

1.1.1. The Self-report Method....................................... 2

1.1.2. Observer Ratings of Personality - Ratings by Close Others...... 4

1.1.3. Behavioural Observation................................................ 6

1.2. Implicit Measures in Assessment of Individual Differences................. 13

1.2.1. Theoretical Foundations of Implicit Measures.................... 14

1.2.2. Nature of Processes Underlying Implicit Measures................ 16

1.2.3. Implicit Association Test (IAT) ................................. 17

1.3. Basic Personality Traits................................................ $\quad 30$

1.4. Cognitive Abilities- Cybernetic Model of Intellectual Functioning.... $\quad 34$

1.5. An Overview of Advantages and Shortcomings of Different Assessment Methods in Personality Psychology ....................... $\quad 35$

1.6. Study Objective................................................. 38

1.7. Research Hypotheses............................................. 40

2. METHOD ............................................................ 42

2.1. Sample ........................................................ 42

2.2. Variables in research............................................... 43

2.3. Instruments in Research........................................ 45

2.3.1. Implicit Association Test (IAT) .............................. 45

2.4. Explicit Measures of Basic Personality Traits........................ 53

2.4.1 Inventory for the Assessment of Basic Personality Traits NEO PI

$\mathrm{R}$ ( $\mathrm{S}$ and $\mathrm{R}$ form)

2.4.2. Inventory for the Assessment of General Proneness to Psychosis

- DELTA 10 (S form and R form) ..............................................

2.4.3. Short Scale for the Assessment of Basic Personality Traits (SSA-DOCEAN) ................................................ 55

2.4.4. Battery for the Assessment of Intellectual Abilities KOG9....... 56

2.4.5. Self-assessment of Intellectual Abilities.......................... 58

2.4.6. Visibility of Traits (Self-reported) .......................... 58

2.4.7. Consistency of Traits (Subjective and Objective Measures)........ 58

2.4.8. Ipsatized S Measures............................................ 59

2.4.9. Behavioural Observation (Ratings by Experts) ................... 59

2.5. Language Composition in LIWC .......................................... 64

2.5.1. Transcription and Linguistic Analysis................................ 64

2.6. Data Analysis - Algorithms for Data Analysis......................... 67

2.6.1. Implicit Measures - Computation of D Measure (IAT

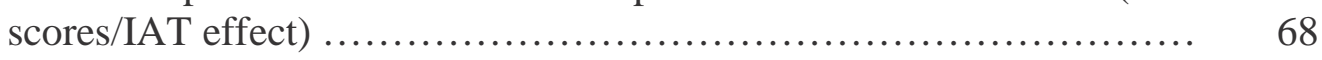

3. RESULTS ............................................................... 71

3.1. First Research Phase............................................. 71

3.1.1. Results of Exploratory Factor Analyses (EFA) for Selection of IAT Stimuli....................................................... 71

3.1.2. PSIHO Software Testing..................................... 76

3.1.3. Training of Research Assistants for Behavioural Observation and Assessment of Prototypicality of Indicators...................................... $\quad 78$

3.2. Second Research Phase............................................... 82

3.2.1. Psychometric Properties of Implicit and Explicit Measures........ 82 
3.3. Descriptive Statistics for Implicit and Explicit Measures................... $\quad 89$

3.3.1. Implicit Measures - "Data Trimming" in IAT....................... 89

3.3.2. Implicit Measures - Descriptive Statistics............................. 90

3.3.3. Explicit Measures - Descriptive Statistics........................... 91

3.4. Relations of IATs with Various Explicit Measures................... 95

3.4.1. Exploratory Factor Analysis - Latent Structure of Personality

Traits Assessed by IAT........................................ 95

3.4.2. Within method intercorrelations of personality traits............ 98

3.4.3. Correlations of IATs and Self-report Measures for Seven Basic Personality Domains.

101

3.4.4. Correlations of IATs and Ratings by Close Others for Six basic Personality Domains..............................................

3.4.5. Correlations of IAT and Measures of Intellectual Abilities.........

3.4.6. Correlations of IATs and Behavioural Measures...................

3.4.7. Correlations of IATs and LIWC Parameters.................... 107

3.5. Correlations of Explicit Measures................................. 107

3.5.1. Correlations of Self-reports and Ratings by Close Others........... 107

3.5.2. Correlations of Self-reports and Ratings by Experts............... 109

3.5.3. Correlations of Ratings by Close Others and Ratings by Experts. 112

3.5.4. Correlations of LIWC Measures and Self-reports.................... 113

3.5.5. Correlations of LIWC Measures and Ratings by Close Others.... 114

3.5.6. Correlations of LIWC Measures and Ratings by Experts......... 115

3.6. Multi-Trait Multi-Method Validation................................... 116

3.6.1. Multi-Trait Multi-Method Validation of IAT -first part.......... 116

3.6.2. Multi-trait Multi-method Validation of IAT- second part........... 120

3.6.3. Model Testing Only Method Factors............................. 125

4. DISCUSSION .................................................. 128

4.1. On the Quality of IAT Stimuli and Relations between IAT and Explicit Measures in Assessment of Basic Personality Traits...............

4.2. On the Effect of Moderators on Correlations between IAT and Explicit Measures..................................................

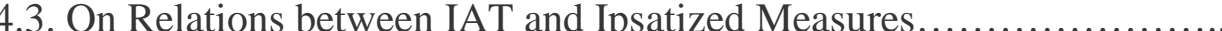

4.4. On Relations between Explicit Measures in Assessment of Basic Personality Traits

4.4.1. On Behavioural Indicators......................................... 134

4.5. On Relations between IAT and Spontaneous Verbal Behaviour....... 136

4.6. On Aspects of Verbal Behaviour Explaining Individual Differences in Personality

4.7. On Possibilities of IAT in Assessment of Basic Personality Traits..... 138

4.7.1. Automatic Self-associations are Predominately Positive........ 141

4.8. On the Strength and Shortcomings of this Study..................... 143

5. CONCLUSION ..................................................... 145

6. References....................................................... 147

7. Appendices...................................................... 165 


\section{Tables}

Table 1 Structure of female sample on which observer ratings were collected........ 42

Table 2. Structure of male sample on which observer ratings were collected........... 43

Table 3. Tests used for data collection.......................................... 43

Table 4. Scheme of IAT on example of assessment of one personality trait.......... 49

Table 5. Description of segments of structured interview for behavioural 60

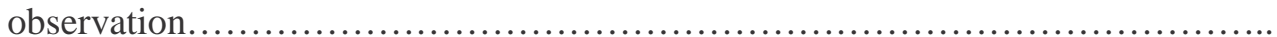

Table 6. Behavioural indicators for assessment of big six personality traits...........

Table 7. Questionnaire in the form of debriefing for assessment of interview..........

Table 8. Pattern matrix - PCA with Promax rotation with Kaiser Normalization - 6 factor solution..................................................

Table 9. Pattern matrix - PCA with Promax rotation with Kaiser Normalization - 5 factor solution.....

Table 10. Results of D measures in IAT Gay-Straight, preliminary testing on 71 respondents.

Table 11. Results of D measures in IAT personality traits, preliminary testing on 83 respondents.

Table 12. Correlations between IATGay-Straight and two explicit measures of attitude, 71 respondents.

Table 13. Correlations between personality IAT and self-report NEO PIR and DELTA 10, 83 respondents....

Table 14. Behavioural Criteria for Each of the Big Five Personality Dimensions.......

Table 15. Reliability of indicators and intraclass coefficient of correlations of behavioural indicators.

Table 16. Psychometric properties of IAT scores of seven personality domains.......

Table 17. Psychometric properties of self-report measures of six basic personality domains

Table 18. Psychometric properties of female observer ratings measures of six basic personality domains.

Table 19. Psychometric properties of male observer ratings measures of six basic personality domains.

Table 20. Psychometric properties of Short Attribute Scale (DOCEAN) of six basic personality domains.

Table 21. Intraclass correlation coefficients for behavioural criteria..................

Table 22. Composite LIWC measures for each of big six personality domains.........

Table 23. Psychometric properties of composite linguistic measures of six basic personality domains, subsample of 99 subjects.

Table 24. Descriptive statistics for main seven domains on IAT, sample 224 respondents.

Table 25. Descriptive statistics for main six domains on self-reports, sample 224 respondents.

Table 26. Descriptive statistics for main six domains on female observer ratings, sample 224 respondents.

Table 27. Descriptive statistics for six main domains on male observer ratings, sample 224 respondents.

Table 28. Descriptive statistics of KOG9 scores, sample 224 respondents............

Table 29. Descriptive statistics for main six domains on behavioural composite measures, subsample 99 respondents

Table 30. Descriptive statistics of self-assessment measure of intellectual abilities,

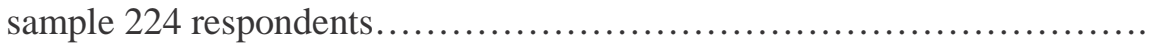

Table 31. Descriptive statistics of self-reported global trait score on TSPROC for six main domains. 
Table 32. Descriptive statistics of self-reported consistency measures on TSPROC for six main domains.

Table 33. Descriptive statistics of objective measures of basic six personality trait consistencies.

Table 34. Descriptive statistics of ipsatized scores for six personality traits, sample 224 respondents.

Table 35. Pattern matrix - PCA with Promax rotation with Kaiser Normalization - 6 factor solution

Table 36. Correlation matrix for IAT measures.................................. 98

Table 37. Correlation matrix for self-report measures............................ 98

Table 38. Correlation matrix for ratings by close female others...................... 99

Table 39. Correlation matrix for ratings by close male others....................... 99

Table 40. Correlation matrix for short scale of attributes......................... $\quad 100$

Table 41. Correlations matrix for ratings by experts............................. 100

Table 42. Correlations matrix for linguistic measures............................ 101

Table 43. Correlations of IATs and self-report measuring corresponding personality traits.............................................................

Table 44. Partial correlations of IATN and IATE and self-reports measuring corresponding traits, controlled for Openness (self-report) .................

Table 45. Correlations of IATs and dimensions from Short Scale of Attributes (SSA) DOCEAN on 224 respondents.................................

Table 46. Correlations of IATs and female observer ratings measuring corresponding traits...................................................

Table 47. Correlations of IATs and male observer ratings measuring corresponding traits.

Table 48. Correlations of Self-assessment of intellectual abilities with principal component on KOG9 and $\mathrm{IAT}_{\mathrm{I}}$....

Table 49. Correlations of IATs and composite behavioural measures (behavioural indicators and LIWC), sample 99 respondents.

Table 50. Correlations of IATs and standardized composite LIWC measures, sample of 99 respondents.

Table 51. Correlations of self-report and female observer ratings, sample of 224 respondents.........................................................

Table 52. Correlations of self-report and male observer ratings, sample of 224 respondents.

Table 53. Correlations of female and male observer ratings, sample of 224 respondents.

Table 54. Correlations of self-reports and composite behavioural measures, sample of 99 respondents.

Table 55. Correlations of self-report Neuroticism and behavioural indicators, sample of 99 respondents.

Table 56. Correlations of self-report Extraversion and behavioural indicators, sample of 99 respondents.

Table 57. Correlations of self-report Openness and behavioural indicators, sample of 99 respondents.

Table 58. Correlations of self-report Agreeableness and behavioural indicators, sample of 99 respondents............................................

Table 59. Correlations of self-report Conscientiousness and behavioural indicators, sample of 99 respondents................................................

Table 60. Correlations of self-report Disintegration and behavioural indicators, sample of 99 respondents.

Table 61. Correlations of female observer ratings and composite behavioural measures. 
Table 62. Correlations of male observer ratings and composite behavioural

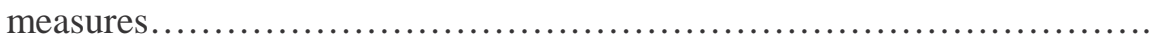

Table 63. Correlations of LIWC composite measures and self-reports...............

Table 64. Correlations of LIWC composite measures and ratings by close female others.

Table 65. Correlations of LIWC composite measures and ratings by close male others.

Table 66. Correlations of LIWC composite measures and ratings by experts..........

Table 67. Factor loadings of self-reports on corresponding latent factors, sample 224 respondents

Table 68. Factor loadings of female ratings on corresponding latent factors, sample 224 respondents.

Table 69. Factor loadings of male ratings on corresponding latent factors, sample 224 respondents.

Table 70. Factor loadings of IATs on corresponding latent factors, sample 224 respondents.

Table 71. Factor loadings of intellectual abilities measures on latent factor of intellectual abilities, sample 224 respondents...........................

Table 72. Inter-correlations of latent factors, sample 224 respondents.

Table 73. Factor loadings of self-reports on corresponding latent factors, sample 99 respondents.

Table 74. Factor loadings of female ratings on corresponding latent factors, sample 99 respondents.

Table 75. Factor loadings of male ratings on corresponding latent factors, sample 99 respondents.

Table 76. Factor loadings of IATs on corresponding latent factors, sample 99 respondents.

Table 77. Factor loadings of behavioural measures on corresponding latent factors, sample of 99 respondents.

Table 78. Factor loadings of linguistic measures on corresponding latent factors, sample 99 respondents.

Table 79. Factor loadings of KOG9 processors on corresponding latent factor, sample 99 respondents.

Table 80. Inter-correlations of latent factors, sample 99 respondents................. 124

Table 81. Correlations of latent method factors, sample 99 respondents............ 127 


\section{Figures}

Figure 1 Computer Screen in the First Block (Ja-I, Drugi-Others, Moj-Mine)

Figure 2. Computer Screen in the Second Block (Stabilan-Stable, Nestabilan-Unstable, Relaksiran-Relaxed)

Figure 3. Computer Screen in third Block (Ja ili Stabilan-I or Stable, Drugi ili Nestabilan-Others or Unstable, Relaksiran-Relaxed)...................... $\quad 50$

Figure 4. Computer Screen in the Fourth Block.................................. 50

Figure 5. Computer screen in fifth block (Drugi-Others, Ja-I, Moj-Mine)............... 51

Figure 6. Computer Screen in the Sixth Block (Drugi ili Stabilan-Others or Stable, Ja ili Nestabilan-I or Unstable, Relaksiran-Relaxed) ....................... 52

Figure 7. Computer Screen in the Seventh Block................................. 52

Figure 8. Structural Model Tested on 224 Subjects................................................... 117

Figure 9. Structural Model Tested on 99 subjects................................. 121

Figure 10. Structural Model Testing Only Latent Method Factors on 99 subjects......... 126

\section{Appendices}

Appendix 1 Questionnaire for self-assessment of intellectual abilities

Appendix 2 Questionnaire for assessment of consistency and visibility of basic personality traits.

Appendix 3 Metrical characteristics of self-report measures - facets and main domains. Appendix 4 Metrical characteristics of female observer ratings measures - facets and main domains.

Appendix 5 Metrical characteristics of male observer ratings measures - facets and main domains

Appendix 6 List of parameters and their abbreviations in LIWC.

Appendix 7 Basic descriptive statistics of IAT data - different error-correction treatments.

Appendix 8 Descriptive statistics for facets of six basic personality traits - self-reports.

Appendix 9 Descriptive statistics for facets of six basic personality traits - female observer ratings.....................................................

Appendix 10 Descriptive statistics for facets of six basic personality traits - male observer ratings....

Appendix 11 Hierarchical linear regression analyses- testing of effects of moderator variables on correlations between implicit and explicit measures.

Appendix 12 Exploratory factor analysis- Principal component analysis on IAT differential scores.....................................................

Appendix 13 List of abbreviations of behavioural criteria........................... 183

Appendix 14 Goodness of Fit statistics - MTMM model tested on 224 respondents...... 184

Appendix 15 Goodness of Fit statistics - MTMM model tested on 99 respondents...... 185

Appendix 16 Goodness of Fit statistics - model testing only method factors............. 186 


\section{INTRODUCTION}

There is a consensus in the literature about the nature of at least five basic personality dimensions (Ashton \& Lee, 2008; Costa \& McCrae, 1995; Goldberg, 1990; Tupes \& Christal, 1992). In addition, over the years, scholars in the field of personality assessment have conducted extensive researches about assessment methods and possibilities of traditional explicit measures, e.g. self-reports, ratings by close others, and behavioural observations by experts (Barrick \& Mount, 1991; Borkenau \& Liebner, 1993; McCrae \& Weiss, 2007; Vazire, 2006; Vazire, 2010; Vazire \& Mehl, 2008; Vazire \& Carlson, 2010). However, continuous research aimed at overcoming known problems in personality assessment (e.g., acquiescent and socially desirable responding), has led researchers in recent years to develop new, implicit, methods (Greenwald \& Banaji, 1995; Greenwald \& Farnham, 2000; Greenwald, McGhee \& Schwartz, 1998). One of the widely used implicit methods is the Implicit Association Test (IAT), initially developed for the assessment of implicit attitudes (Greenwald \& Banaji, 1995; Greenwald, Banaji, Rudman, Farnham, Nosek \& Mellott, 2002; Greenwald, Nosek \& Banaji, 2003). In the field of individual differences, some researchers have tried to test whether implicit measures can be valid assessment methods, but their results have not provided enough evidence to fully support the convergent and discriminative validity of IAT in personality assessment (Back, Schmukle \& Egloff, 2010; Steffens \& Schulze-König, 2006).

While discussing the assessment of cognitive and affective constructs in the field of psychology of individual differences, the general viewpoint is that multi-method assessment is more reliable and valid (Greenwald et al., 2002; Hofstee, 1994; McCrae \& 
Weiss, 2007; Vazire, 2006). This study was conducted with the objective of assessing the possibilities of the Implicit Association Test in the assessment of basic personality traits. By using various assessment methods, both implicit and explicit, it tries to unfold the prospects of implicit measures, specifically the Implicit Association Test, in the assessment of basic personality traits.

The introductory section of the study discusses the major explicit and implicit assessment methods in personality psychology along with their advantages and shortcomings. The second part is dedicated to empirical research and provides data on the possibilities and limitations of implicit measurement in the field of personality. The third and concluding part analyzes all the results and points to some of the possible directions for future research in this field.

\subsection{Explicit Measures in the Assessment of Individual Differences}

\subsubsection{The Self-report Method}

In personality assessment, researchers mostly use self-report measures (S-data or $\mathrm{S}$ measures) and observer ratings (R-data or $\mathrm{R}$ measures). However, the dominant source of data collection is self-report (Craik, 2007; Larsen \& Buss, 2008; Paulhus \& Vazire, 2007; Vazire, 2006).

The use of self-reports has several advantages (Paulhus \& Vazire, 2007; Vazire $\&$ Mehl, 2008). First, the data collected through self-reports are very rich in information and the researcher has the opportunity to observe a wide range of behaviours and mental states (e.g., thoughts, feelings and sensations). Secondly, people are motivated to respond about themselves, which increases the validity of data. Finally, this way of data 
collection is very practical and its use is efficient and inexpensive. However, the accuracy of such self-perceptions of personality is always questionable and it is difficult to say to what extent it is possible and recommendable to trust self-reports.

The existing literature indicates that self-reports "suffer" from several disadvantages (Paulhus, 2002; Paulhus \& Vazire, 2007). First, some people show a tendency to respond in a way that interferes with the validity of their answers, for example socially desirable responding, acquiescent responding, or extreme responding. When these tendencies are specific to the situation, they are termed response sets, but when they are consistent over time and across different assessment contexts, they are named response styles. Secondly, even the most honest self-assessors do not have an infinite ability to recall all the relevant information. Thirdly, cultural limitations can influence data validity. This means that respondents from different cultures may treat self-reports in ways different from those expected by people of western cultures (e.g. subjects of Asian origin show a moderate bias or ambivalence). Additionally, the data quality depends on the respondents' willingness to report about their inner states, and their ability to express those states adequately.

Self-reports are the most popular and most frequently used measures of personality. Naturally, therefore, attempts have been made to find out possible solutions to the problem of validation of self-reports. Since there are no absolute criteria as to how self-reports can be evaluated, proofs about the construct-validity are collected from various sources (usually by correlating self-reports with observer ratings, but also with behavioural and life-outcome data) (Paulhus \& Vazire, 2007; Vazire \& Carlson, 2010). 


\subsubsection{Observer Ratings of Personality - Ratings by Close Others}

There is a great deal of empirical evidence in the literature that personality assessments made by well-acquainted observers can provide fairly reliable information about the subject (Kolar, Funder \& Colvin, 1996; Oh, Wang \& Mount, 2001; Vazire, 2006). Observer ratings have several advantages. First, they offer a more objective view, and collecting several observer ratings on one person increases the reliability of assessment, as the observers have had the opportunity to observe a diverse spectrum of the subject's behaviour in various situations (Conolly, Kavanagh \& Viswesvaran, 2007). A great deal of empirical evidence advocates observer ratings as reliable, stable, and valid measures in personality traits assessment (Costa \& McCrae, 2008; Johnson, 1997; McCrae \& Weiss, 2007). The second advantage of the use of $\mathrm{R}$ measures ( $\mathrm{R}$ stands for rating by close others $-\mathrm{F}$ if the rater is a female, and $\mathrm{M}$ if the rater is a male) is the avoidance of socially desirable answers. Some researches show that observer ratings are less susceptible to exaggeration (in both directions) as compared to selfreport measures, and the level of agreement between the ratings of observers and selfreports is higher when more easily observed domains are measured, such as Extraversion or Conscientiousness (more than Agreeableness, for example) (Gosling, John, Craik \& Robins, 1998; John \& Robins, 1993; Heyes \& Dunning, 1997; Szarota, Zawadzki \& Strelau, 2002). Besides the observability of traits, researchers have showed that self-rating correlations rise with a high trait relevance and high trait consistency (Bem \& Allen, 1974; Zuckerman, Koestner, DeBoy, Garcia, Maresca \& Sartoris, 1988).

However, data collected from observer ratings also have several disadvantages (McCrae \& Weiss, 2007). First, no matter how close and intimate the observed is to the observer, the observer can never provide as much information (e.g., thoughts, emotions, 
motives) as the subject him/herself through a self-report (Paulhus \& Vazire, 2007). Secondly, as in the case of self-reports, observer ratings suffer from some biases in responding (e.g., acquiescence, extreme responses etc.). In addition, although in general the bias of social desirability does not exist in observer ratings, if the subject is very "close" and/or important to the observer, the observer's tendency to describe him in a more positive light cannot be ruled out. In addition, it is possible to make the fundamental attribution error, i.e. the tendency to exaggerate the impact of dispositions over the situational factors in explaining someone's behaviour (Gilbert, 1998). Finally, observers are not often available to report on someone's behaviour in some particular situations.

As for the relations between self-reports and observer ratings, researches show that $\mathrm{S}$ and $\mathrm{R}$ data correlate moderately. Several meta-analyses show that self-reports and observer ratings correlate moderately, in the range of $0.40-0.60$, and the results are consistent across the domains of personality (e.g., the "big five" personality traits) (Vazire, 2006; Vazire \& Carlson, 2010; Watson, Hubbard \& Weise, 2000). Based on these results, we can conclude that there is no complete overlap between self-reports and observer ratings, and people's self-views are not identical to the reputation they have among those who know them very well (e.g., parents, spouses, or close friends) (Vazire, 2006; Costa \& McCrae, 2008; Watson et al., 2000). The moderate correlations indicate that a maximum of 35 per cent of the variance can be attributed to the measured traits. 


\subsubsection{Behavioural Observation}

Besides self-reports and observer ratings, another legitimate way of collecting data is by observing someone's behaviour, which is often considered to be a gold standard for evaluating the accuracy of self-reports (Vazire \& Carlson, 2010). As compared to observer ratings, behavioural assessments are usually performed by trained observers, and are not affected by certain response biases that influence other forms of personality assessment. Despite several weaknesses of the behavioural observation (e.g., there is no single behavioural coding system, costs are high, and larger amounts of information can be gathered through other forms of explicit measures), its use in assessment of personality has some very important benefits. Yet, a prediction of behaviour is considered to be the ultimate goal in psychology, and there is a lack of sufficient empirical data about the links between personality traits and behaviour (Furr \& Funder, 2007).

However, obtaining an objective measure of personality through behavioural observation is more difficult than it appears at the first glance, and can often be quite cumbersome (Vazire \& Carlson, 2010). In behavioural assessments of personality, the general concern is coping with the specificity of responses (especially in experimental conditions), because different people manifest the same trait differently (for example, some people express anxiety by crying, others by laughing). Asendorpf (1988) concludes that it is difficult to rate someone's personality traits on the basis of specific behavioural manifestations. It is widely accepted that the behavioural assessment should be conducted with multiple indicators and multiple observers. Therefore, after deciding the particular behaviour associated with each trait, the researcher has to record and code 
it by multiple observers, and then to average all the indicators after making them comparable by z-transformation (Asendorpf, 1998).

A study by Mehl, Gosilng \& Pennebaker (2006) indicated that it might be possible to distinguish stable patterns of behaviour caused by basic personality traits. It showed that Emotional stability was reliably manifested in calmness, and in less time spent on arguing. Extraverted people were sociable, talkative, enthusiastic, engaged more in conversations, and spent less time alone. People with higher scores on Openness to experience on the BFI scale spent more time in public places like restaurants, bars, etc. Sympathy, warmth, and unconfrontational behaviour were related to Agreeableness, while behaving responsibly, carefully and with self-discipline was associated with Conscientiousness. In addition, people who scored higher on Conscientiousness in self-reports (on the BFI scale) spent more time in class, at work, and in public places other than restaurants, bars, etc. (Mehl et al., 2006).

One can always ask how well self-perceptions correspond to the actual behaviour of a person. So far, meta-analyses report that, on an average, self-reports and laboratory behaviour have a correlation of 0.34 (Vazire \& Carlson, 2010). Research has showed that, on the basis of physical appearance, and both static (e.g., clothing style) and dynamic (e.g., facial expression, posture) clues, we can collect valuable information about the personality of the observed, and these judgements are very accurate for a variety of traits. Empirical data demonstrates that the accuracy of judgement increases when visual inputs (i.e., physical appearance) as well as verbal and other nonverbal sources of information are available (e.g., facial expression, posture) (Borkenau \& Liebler, 1993; Naumann, Vazire, Rentfrow \& Gosling, 2009). Verbal output is a very important aspect of behavioural observation. Individuals vary in the words they use, and 
scholars think that this variation would reflect stable psychological differences (Fast \& Funder, 2008). In subsequent sections, this aspect will be discussed more thoroughly.

\subsubsection{Linguistic Styles and Their Relation with Individual Differences}

The idea that the words people use can be tapped to assess their mental, social, and physical states has been present since the beginning of the development of psychology. Early psychologists, and specially psychoanalysts, have provided examples that personality, and unconscious are encoded in language (Frojd, 1969). This viewpoint is still present in the personality psychology. Personality involves particular thoughts and feelings that appear in language and it has a top-down influence on language production by forming and modulating our ideas into words (Fast \& Funder, 2008; Frojd, 1969; Hirsh \& Peterson, 2009; Mairesse \& Walker, 2006; Pennebaker, Mehl \& Neiderhoffer, 2003). The semantic content of verbal (i.e., vocal) expression conveys a large amount of information about the person speaking, and some part of that information certainly speaks about personality traits, which are probably the most fundamental dimensions of variation between humans (Mairesse, Walker, Mehl \& Moore, 2007).

Depending on the focus of language analysis (i.e., deciding what would be the appropriate unit of language analysis), methods for language assessment are divided into qualitative and quantitative approaches (Pennebaker et al., 2003). The first stream derives from psychoanalytic orientation (Pennebaker \& King, 1999) while the second approach assumes that it is possible to capture individual differences from the expression of psychological states, ideas, and concepts in different words. The basic idea is that the vocabulary people habitually use represents their stylistic behaviour, 
which stands for "one's manner of performing adaptive acts", and is unintentional, spontaneous, and difficult to change (Allport, 1961, p. 461, also see Pennebaker \& King, 1999). Thus, according to Allport, each individual has their own unique stylistic behaviour, such as the way they walk or smile, and in accordance with this view, the presumption is that people have their own characteristic ways of expressing themselves in language. These stylistic differences are considered as stable individual differences (Pennebaker \& Graybeal, 2001; Pennebaker et al., 2003). This approach focuses on various semantic and grammatical features of the verbal output, such as frequency of words representing positive or negative emotions, frequency of personal pronouns, prepositions, verbs, etc. Therefore, a very important part of the word-count approach is to decide which words should be counted, and how they should be coded. Based on a review of available literature (Hart, 2001; Pennebaker et al., 2003), we can make certain assumptions that justify this approach in language analysis. These are:

- the selection of words we use in everyday life is rarely controllable (i.e., it is highly difficult to think about single words we use when speaking);

- selection of words is psychologically relevant (i.e., it reflects our inner states, feelings, attitudes, etc);

- context is not crucial (i.e., the words people use convey psychological information, over and above their literal meaning, and independent of their semantic context);

- pragmatics is more important than semantics (i.e., the usual contexts in which a certain word is used is incorporated when the words are pre-categorized in software dictionary in automatic text analysis, for example the word-stem 
active can be categorized as a word belonging to the categories Affective, Cognitive, Relative, and Motion).

One way to overcome the problem of content is to pay attention to "function words", such as pronouns, articles, conjunctions, auxiliary verbs, and even "junk words", since these serve as the "building material" holding the content of the words together (Chung \& Pennebaker, 2007). In other words, the content words (i.e., the nouns and regular verbs) are very important in communication, but it is not possible to reduce communication only to content. Empirical evidence suggests that changing the communication goals, and the context, implies changes in the use of function words, indicating the underlying cognitive processes (Chung \& Pennebaker, 2007).

Researchers have provided empirical evidence on the stability and consistency of language use over time. Several studies have shown that the spontaneous word use remains stable over time (with the average test-retest correlation for standard linguistic variables 0.41 , and for psychological processes 0.24 ), and consistent across social contexts (Mehl, Pennebaker, Crow, Dabbs, \& Price, 2001; Mehl \& Pennebaker, 2003; Pennebaker \& King, 1999).

Although it is generally accepted that people differ in the way they talk and write, sufficient attention has not been paid to language use in the field of individual differences and personality studies. Only some studies have investigated relations between linguistic parameters and basic personality traits.

A research by Mairesse et al. (2007) gives an overview of relations among the "big five" personality traits and personality markers in language. Emotional stability was found to be related to a lesser use of concrete and frequent words (Gill \& 
Oberlander, 2003, also see Mehl et al., 2006). Pennebaker \& King (1999) found that Neuroticism was positively correlated with negative emotions and first person singular pronouns correlated negatively with positive emotions. Mehl et al. (2006) found that this dimension was related to a higher number of uttered words. Extraversion was positively related with positive emotion words and words indicating social processes (Pennebaker \& King, 1999), and with the number of words used in the observational period (Mehl et al., 2006). It was also related to a higher rate of contextuality (i.e. use of pronouns, verbs, adverbs and interjections) (Heylighen \& Dewaele, 2002), and with word count. In addition, it was related to a lower type/token ratio (which reflects the diversity of the language the person uses, and is calculated as a ratio of the number of different words and the total number of words) and a less formal language, while the introverts used a broader language (Mairesse et al., 2007). Openness to experience was negatively correlated with the use of third-person pronouns and past-tense verbs (Mehl et al., 2006). Agreeableness was positively related to positive emotion words, and negatively to negative emotion words (Pennebaker \& King, 1999). Another research showed that Agreeableness was negatively related to the use of swear words, and positively with the use of first-person singular pronouns (Mehl et al., 2006). An amount of sighing was indicative of a lack of Conscientiousness, while a lesser use of swearwords and more frequent use of second-person pronouns were positively related to this trait (Mehl et al., 2006). In addition, the same study revealed some gender differences in language markers of Conscientiousness, where the males perceived as conscientious produced more filler words, while the females did not.

Possible reasons for the status of the topic (i.e., language use in the field of individual differences) may be related to various practical and conceptual issues. First, 
the word-based analysis faces some problems - e.g., it is very difficult to grasp someone's irony, or sarcasm, considering the context or the multiple meanings of words. Secondly, word-based analysis is dependent on a predefined dictionary, which makes this kind of analysis inflexible to some extent (Mehl \& Gill, 2010; Pennebaker et al., 2003). However, these problems do not mean discarding automatic text analysis completely, because if the extracted linguistic information unambiguously answers research questions, the validity of the method is proved. Besides that, as already mentioned, the use of function words enables us to distinguish between different mental states and psychological processes.

In addition, automatic text analysis has some very important psychometric advantages that lead to a possibility of generalization and ecological validity. The data derived from automatic text analysis do not share common method variance with explicit methods. These measures are objective: they ensure measurement equivalence across researches and their metrics is not arbitrary (Mehl \& Gill, 2010).

The word-count approach distinguishes between "manual" and automatic data analysis. In automatic data analysis, units of analysis are single words, and counting is performed within predefined categories (Pennebaker, Francis \& Booth, 2001). In spite of the disadvantages that this kind of word-analysis entails, this stream has produced some very efficient software for word-based analysis that provides objective measures (Pennebaker \& King, 1999). One of the latest, which is fairly developed, is Linguistic Inquiry and Word Count or LIWC (Pennebaker, Chung, Ireland, Gonzales \& Booth, 2007). Several qualities of LIWC contribute to its wide use in psychology (Mehl \& Gill, 2010; Tausczik \& Pennebaker, 2010). First, it analyses the basic grammatical features of texts and provides information about psychological processes. Secondly, the software 
is psychometrically tested on several world languages. Thirdly, various studies have contributed to the construct validity of its categories. Finally, the software is user friendly.

In order to assess the efficiency of language use, the makers of LIWC have developed more than 80 output variables of language use. The basic principle is that each word, or word stem, defines one or more word categories or subcategories, and very often many of the categories in LIWC are hierarchically arranged (e.g., the word sad is coded as sadness > negative emotion > affect) (Pennebaker et al., 2007). In this kind of text analysis, a large number of words are coded using several criteria. Besides this, the output provides information about various function words. LIWC output will be discussed in greater detail in the section Method.

\subsection{Implicit Measures in Assessment of Individual Differences}

In order to overcome the limitations of explicit measures, especially self-reports, researchers have started developing new techniques known as "implicit techniques" (Greenwald et al., 1998). The main idea underlying all implicit techniques is to allow the assessment of desired constructs without directly asking for verbal report from the subject. The introduction of implicit measures in the psychology of individual differences offers new possibilities for additional validation of explicit measures. However, it is important to mention that the scholars who predominantly use implicit measures do not advocate an abandonment of the explicit measures. They are still trying to answer the numerous questions about the theoretical foundations of implicit measures, nature of processes underlying them, methodological issues, and relationship between implicit and explicit measures. 


\subsubsection{Theoretical Foundations of Implicit Measures}

The theoretical foundations of implicit measurement can be traced in the work of pioneers in psychology (see Nosek, Hawkins \& Frazier, in press). For example, Freud advocated that many mental processes could occur without conscious awareness (Frojd, 1970). However, only after several decades and new insights about conscious and unconscious processes this topic was revived (Greenwald \& Banaji, 1995). Namely, researches in the field of cognitive psychology investigating mental processes related to judgement alterations (Nisbett \& Wilson, 1977) and functioning of declarative and procedural memory (Roediger, 1990) had significant influence on development of new, implicit, assessment methods and accelerated development of research related to implicit cognition (Nosek, et al., in press).

In spite of the growing number of researches in the last couple of decades, and more precise methodology, some scholars state that "research concerning implicit measures has been surprisingly atheoretical" (Fazio \& Olson, 2003, p.301). However, it would be more precise to say that, even though the researchers start from different ground points, they all use the same methodological tool. Scholars agree that the object of measurement are automatic processes (evaluations or self-evaluations) in which the influence of dual theories can be recognized (Wilson, Lindsey, \& Schooler, 2000).

The paradigms of measurement in implicit processes come from social cognition, and therefore the theories and models are initially directed towards the investigation of implicit attitudes (Fiske \& Taylor, 2008). In these methods, the socalled dual theories are dominant, which were developed in field of: a) attitudes Elaboration likelihood model (Petty \& Caccioppo, 1986; Petty \& Wegener, 1999), Heuristic-systematic model (Chen \& Chaiken, 1999), Model of dual attitudes (Wilson et 
al., 2000), b) behaviour - Motivation and Opportunity as Determinants (MODE) model (Fazio \& Towles-Schwen, 1999), and c) attributions - A dual process model of overconfident attributional inferences (Trope \& Gaunt, 1999). The core of most models of dual processes is based on a recognition of two qualitatively different modes in cognitive processing - "systematic" (central), which implies a higher investment of cognitive energy in activities, as well as more a rational thinking and behaviour, and "heuristic" (peripheral), which implies being cognitively economic, relying more on shortcuts in thinking, concluding, and in behaviour (Fiske \& Taylor, 2008; Moskowitz, 2005). Besides, the assumption is that people are more often in heuristic mode of processing. Only in certain situations they are motivated and able to process in the central mode, when they process information systematically, scrutinize outcomes and make rational decisions.

The special models of dual processes, compared to other models, focus more on the aspects of automatic activation of associative connections. These models were developed in the field of formation and changing of attitudes - Fazio's MODE model (Fazio \& Towles-Schwen 1999), and in individual differences (Greenwald \& Farnham, 2000).

In accordance with dual model approach and early empirical evidence indicating distinction between implicit and explicit operations of the self (e.g., Bargh \& Tota, 1988; Rogers, Kuiper, \& Kirker, 1977), researchers supposed that it was also possible to distinguish between the implicit and explicit self-associations (Greenwald \& Farnham, 2000; Asendorpf, Banse, \& Mücke, 2002). Self-associations represent the totality of all associations of self-concept and attributes that describe the personality. Explicit selfassociations are based on the information that the subject gives about him/herself, 
usually through self-reports. This information consists of valid (introspectively available) and non-valid (consequence of impression management, socially desirable answering, or measurement error) information. Implicit self-associations are based on the information processed automatically, meaning that they are available only after applying certain methodological tools to assess them. As such, it is expected that the implicit measures are more robust in comparison with explicit measures, when it comes to impression management and other distortions that characterize the explicit measures (Greenwald et al., 1998; Wilson et al., 2000).

\subsubsection{Nature of Processes Underlying Implicit Measures}

In spite of the growing popularity of implicit measurement of attitudes, stereotypes and other cognitive constructs, and the development of different implicit techniques, it is still not clear exactly what measures are considered under the implicit measures, and which processes form their base (DeHouwer, 2006; DeHouwer, TeigeMocigemba, Spruyt \& Moors, 2009). There has been an extensive discussion on the nature of processes forming implicit measures. At first, scholars tried to equate the implicit and unconscious processes. In spite of the fact that researches have showed that the implicit measures can register unconscious processes and cognition, it cannot be assumed that the outcomes of implicit measurement are the direct measures of unconscious cognition (DeHouwer, 2006).

The recent literature relates the concept of implicit with the functional properties of the concept of automatic. As such, it is thought that the implicit can be described with attributes like unwilling, goal independent, uncontrollable, stimulus driven, autonomous and fast (DeHouwer, 2006; DeHouwer \& Moors, 2007). In support of the 
conceptual analysis which DeHouwer has developed, there are numerous research results, stemming from dual theories, which show that the implicit and explicit aspects of attitudes and cognitions can be distinguished both by the nature of the implicit processes (i.e., whether they are different from controlled, explicit processes) and by the adequacy of methods that would be used for the assessment (DeHouwer, 2006). In other words, the nature of the underlying processes influences the selection of the best assessment method.

It is possible to conclude that the results of conceptual analyses (DeHouwer, 2006; DeHouwer \& Moors, 2007), and numerous researches relying on statistical analyses (e.g., Nosek, 2005; Nosek \& Smyth, 2007) give enough basis to differentiate implicit and explicit evaluations which, when taken together, can give a more comprehensive view of the experiences of individuals.

\subsubsection{Implicit Association Test (IAT)}

The implicit techniques that are considered to be the most developed and best founded are based on the measurement and analysis of reaction times (RT) in certain tasks (the so-called group of implicit RT) (Wittenbrink \& Schwarz, 2007). A set of these relatively new implicit measures evaluates the automatic evaluative responses on object measurement. Thus, the task of the respondent is not to directly evaluate the object representing measured construct, but to do some simple tasks in which they have to react very fast (i.e., about few hundreds milliseconds) on stimuli representing categories of measured constructs presented to them. Based on indirectedness of the respondents' responses and on the speed of response, the researchers suppose that the 
responses are at least partially determined with unintentional, unconscious, and uncontrollable processes (DeHouwer \& Moors, 2007).

The group of RT implicit techniques includes various standard priming procedures and response competition procedures, of which the most well known is Implicit Association Test (IAT) (Greenwald et al., 1998). Researchers consider IAT as potentially useful in the identification of a wide spectrum of socially important associative structures. Its basic use is to assess the strength of associations between concepts and attributes in terms of the relative strength of associations between pairs of concepts (i.e., categories and attributes).

Primarily, IAT was designed for measuring the evaluative association underlying the implicit attitudes. Implicit attitudes manifest themselves as actions or judgements that are under the control of automatically activated evaluations, when the respondent is not aware of that causal relation (Greenwald et al., 1998). In recent years, the focus of researchers using IAT has shifted from implicit attitudes to the domain of personality (personality traits, identity, self-associations) (Bosson, Swann, \& Pennebaker, 2000; Greenwald \& Farnham, 2000; Stefens \& Schulze-König, 2006; Schnabel, Asendorpf \& Greenwald, 2007).

The main idea in IAT is that it would be easier to map two concepts on the same response when those concepts are similar, or associated in a similar manner in the memory, than when they are more disconnected or less similar. Namely, on the screen are displayed names of the categories (concepts) and stimuli (e.g., attributes) and respondent has to perform two opposite tasks of double categorisation. The basic assumption is that the subject would respond faster and more easily in the tasks in which the poles of attributes and target-concepts (or pairs of the poles of target- 
concepts, and poles of some other concept) are highly associated (Schmukle \& Egloff, 2005; Steffens \& Schulze-König, 2006). In other words, the subject would react faster if one pair of the associated categories requires one response, and another pair requires some other response (Steffens \& Plewe, 2001).

When stimulus is presented on the left side of the screen, it will automatically activate the representations of answers associated with the left spatial position (e.g., pressing left button). When the automatically activated answer representations differ from the representations of correct answers (e.g., pressing right button when the stimulus corresponds to the left screen side), choosing the correct answer will be slower in comparison with the situations when the representation of the correct answer is automatically activated (DeHouwer, 2003). The measurement of a trait is achieved through an assessment of the trait self-associations, and it is presumed that these are related to cognition and behaviour, independent of the explicit personality measures (Asendorpf et al., 2002). For example, we can think of a situation in which we measure RT in a task in which the stimuli representing category $I$ (e.g., mine) and the stimuli representing category Conscientious (e.g., organized) require the same response button (e.g., pressing the left button), and the stimuli representing category Others (e.g., theirs) and the ones representing the category Unconscientious (e.g., lazy) require some other response button (e.g., pressing the right button).

The average RT in this task is compared with the one in which the stimuli representing categories "I and Unconscientious" require one button, and responses to the stimuli representing categories "Others and Conscientious" require the other button. The subjects who respond faster to the task "I or Conscientious" compared to the task 
"Others and Unconscientious" more strongly associate the self with conscientiousness (i.e., show implicit acceptance of conscientiousness).

Scholars stress that IAT is potentially valuable because it allows us to investigate attitudes and other automatic associations even when the respondents are not willing to demonstrate them (Greenwald \& Banaji, 1995; Greenwald et al., 1998). This quality of IAT, that it allows the researchers to avoid (at least partially) the tendency of the respondents to give socially desirable answers, hesitation in answering, or any other simulation of attitudes (or statements), is what makes it highly attractive in social cognition and in the psychology of individual differences (Wittenbrink \& Schwarz, 2007; Schnabel, Asendorpf, \& Greenwald, 2008).

Although researches show that IATs are not immune to faking, they are still considered less susceptible to it in comparison with self-reports (Asendorpf et al., 2002; Banse, Seise, \& Zerbes, 2001; Boysen, Vogel, \& Madon, 2006; Egloff \& Schmukle, 2002; Steffens, 2004). However, it is important to stress that the possibilities to simulate results have been found to be higher when the subjects are instructed in advance to fake (Kim, 2003). As in other methods, faking effects in average IAT scores is a potential problem in the assessment of the validity of individual differences only if differential faking is present (i.e., if different subjects fake at different levels). Researches have shown that compared to self-reports, IATs are more robust when it comes to the average and differential effects of faking.

The main advantage of IAT and other implicit techniques is that they offer a solution to the problems present when the researcher is dealing with subjects who are not able to articulate their attitudes, or not motivated to express them (e.g., while dealing with children), or the less educated or less capable people (Thomas, Burton 
Smith, \& Ball, 2007). In addition, it has become a useful tool in the assessment of less conscious components of attitudes. Implicit techniques enable researchers to avoid testretest effect when the experimental group is aware of the research goals. Therefore, implicit techniques are widely used in the experimental research of attitude changes. Because the basic assumption is that the implicit measures capture automatic processes, they are considered to be context-free, not affected by the person who is asking the questions, or the manner in which the questions are being asked, nor by other variables that are related to the social context (Wittenbrink \& Schwarz, 2007).

\subsubsection{How to "Make" IAT - Selection of Super-ordinate Categories and Stimuli}

While on the one hand, the flexibility of IAT allows researchers to investigate a large range of constructs, it also "tempts" them to declare any four categories as good representatives of measured constructs. Because the name of the category and the stimuli itself influence the way the subject interprets the concept, it is important to pay special attention to the selection of superordinate categories, and representing stimuli (Lane, Banaji, Nosek, \& Greenwald, 2007).

In order to select category (i.e., its title), it is important to define precisely the object of measurement (i.e., the desired construct). Sometimes, it is very simple because many categories have their natural antonyms, i.e., comparison categories (e.g., conscientious-unconscientious, male-female, etc.). According to Lane et al (2007), when IAT is used with categories that have no natural antonyms, the categories should be simple, mutually exclusive and, if possible, from the same domain.

Several researches have shown that both, the selection of category labels and the stimuli representing them, can have impact on IAT results (Nosek, Greenwald, \& 
Banaji, 2005). In other words, the label of the category influences the interpretation of the stimuli and, at the same time, the stimuli can affect the construal of the target category (e.g., the selection of stimulus items representing the superordinate category Gay in Gay-Straight IAT, makes it ambiguous whether gay refers to a gay man, a lesbian, or both) (Govan \& Williams, 2004; Mitchell, Nosek, \& Banaji, 2003; Nosek et al., 2005). Nosek, Greenwald, \& Banaji (2007, p.282) report that "changing just two stimulus items in the "gay people" category, from the representations of gay women to gay men, resulted in stronger pro-straight preferences in the latter representation, compared to the former. An optimal number of stimuli representing each category is also important (Nosek et al., 2005). On one side, an increase in the number of stimuli can allow a precise representation of the superordinate categories, and decrease the possibility of the subjects learning to categorize the stimuli based on recognition. On the other side, a decrease in the number of stimuli by not including those only vaguely related to the category, leads to a lower possibility of diluting the superordinate category. Besides, a decrease in the number of stimuli poses less restrictive demands when designing IAT, especially when there are no good category representatives.

Although Greenwald et al. (1998) have noticed that there are no dramatic changes in IAT results whether 5 or 25 stimuli represent the categories, Nosek et al. (2005) state that after the pioneering work of Greenwald et al., researchers have not paid adequate attention to this problem. Therefore, Nosek et al. (2005) conducted an extensive study to determine the optimal number of stimuli. Their study showed that using a very small number of stimuli per category (e.g., one) has a strong influence on the reliability of IAT results, or their correlation with explicit measures. 
Based on this discussion, it is possible to draw some conclusions about the selection of categories and stimuli (Nosek et al., 2005). The selection of category names should directly reflect the desired construct and allow the subject to easily identify the category to which the stimulus belongs. Regarding the number of stimuli, the optimal situation is to choose a smaller number of good representatives. In other words, it is desirable to select a smaller number of stimuli that cannot be classified wrongly, and represent the construct well. By following these recommendations, a significant increase in the construct validity of IAT can be ensured.

\subsubsection{Psychometric Properties of IAT}

A differential treatment of variables and their metric properties reflects differences in the experimental and correlational paradigms. Researchers on correlational paradigm are interested in the assessment of individual differences, where the procedural variance is considered as error variance. In comparison, the experimental psychology focuses on the internal validity of the procedure itself, and the individual differences are considered as error variance (Schnabel et al., 2007).

With respect to these paradigms, the evaluation of psychometric properties, and especially validity, is slightly different in IAT than in self-reports. Although Greenwald et al. (1998) have used the term "test" for IAT, it can be misleading. Strictly observed, this term can be used only for the standardized and validated instruments designed for the assessment of specific constructs. IAT is the procedural format for implicit cognition assessment, and not a unique measure of a specific construct. There is no unique "formula" that has to be validated. Two IATs have little in common except the 
procedure. Therefore, there are general (related to format) and specific (related to construct) topics that should be addressed while assessing its reliability and validity ${ }^{1}$

Specific IAT procedures, designed for different researches, are usually very different, and due to this fact, the coefficients of psychometric properties (different coefficients of reliability, validity, etc.) vary significantly. The implicit measures are based on RT measures and, in general, less reliable compared to the explicit measures of attitudes (Buchner \& Wippich, 2000; Perruchet \& Baveaux, 1989, also see Lane et al., 2007). A significant amount of error variance is easily observed in studies with RT measurements. For example, even the slightest changes in the respondents' surroundings, or in the respondent himself (e.g., loud noise, blinking or sneezing) during the stimuli presentation, can result in irrelevant variability in the RTs. Metaanalysis shows that the internal consistency of IAT (expressed with Cronbachs' alpha), on an average, is 0.79 (Hofmann, Gawronski, Gschwender, Le, \& Schmitt, 2005). Testretest reliability of IAT ranges from 0.25 to 0.69 , depending on the specific attitude that is measured (e.g., political views, or attitudes towards minorities), while meta-analysis show that most often reliability is around 0.50 (Bosson et al., 2000).

Validity of IAT is often assessed through criterion validity. Usually two different variants of the criterion validity are used: one, through group membership, and the other, through relations of implicit and explicit measures.

Testing of the criterion validity through group membership is based on the generally accepted social-psychological law that people prefer their own group compared to other groups. Accordingly, the criterion validity of implicit measures is

\footnotetext{
${ }^{1}$ It is important to mention that since a significant number of studies using IAT are from the field of social cognition (i.e., research and assessment of attitudes), results on psychometric properties come mostly from that field.
} 
tested by checking the assumption that the subjects belonging to certain groups (e.g., Americans of Korean origin) would show preference for their own group compared to the group they do not belong to (e.g., Americans of Japanese origin). A large number of studies (Lane et al., 2007) confirm this successful discrimination between the members of groups determined by certain behaviour, and groups defined by socio-demographic characteristics of the subjects.

Scholars have tested criterion validity through correlations between the implicit and explicit measures in a large number of studies. One research showed that these correlations (based on 17 studies) ranged from 0.13 to $0.75\left(\mathrm{r}_{\mathrm{Mdn}}=0.22\right)$ (Lane et al., 2007). Numerous studies have shown small to moderate correlations between the implicit and explicit measures of the same constructs, but a large number of studies have also indicated strong and robust correlations between IATs and explicit measures (Lane et al., 2007). A meta-analysis conducted on 126 independent studies demonstrated that the correlations between implicit and explicit measures range from 0.25 to $0.60\left(\mathrm{r}_{\mathrm{Mdn}}=0.19\right)$ (Hofmann et al., 2005).

Although a large number of studies report relatively low correlations between the implicit and explicit measures, it has been demonstrated that correlations depend on a variety of factors, e.g., when, how, under what conditions, and among which people, these measures have been tested (Lane et al., 2007). As stated by Hofmann et al. (2005), theoretically these low correlations are a consequence of several reasons - bias in responding on self-reports, lack of introspective insight, factors influencing memory retrieval, characteristics of methods, and complete independence of the measured constructs. 
However, until we consider the extent to which this relationship is dependent on specific conditions, it is unlikely to bring any constructive conclusions. According to Fazio \& Olson (2003), when the expression of attitudes is determined more by automatic processes (which are dependent on the specific situation in which they will be expressed), the correlation of implicit and explicit measures is significant. However, this does not have to be the case when the controlled processes play the main role in attitude expression (Fazio \& Olson, 2003). Therefore, when the motivation to process something deliberately, and/or the opportunities for it are low (or not existing), a higher concordance between the implicit and explicit measures is more probable.

Nosek (2007) states that it is possible to draw parallels between mental processes (which represent the operations of the mind) and mental experiences (i.e., the subjective phenomena resulting from those operations) on the one hand, and the implicit and explicit attitudes on the other. He further says that although the differences are not completely clear, we should consider these to be different constructs. Nosek (2005, 2007) indicates that different factors moderate the relationship between implicit and explicit measures (i.e., influence the correlations between these measures), and suggests several reasons for the wide range of validity coefficients, as follows:

a) Impression management (lower correlations are present when the respondents are concerned not to show negative attitudes, and when the fear of potential social condemnation is present),

b) Strength of attitude (important and highly elaborated attitudes imply higher correlations), 
c) Polarity of attitudes, i.e., the level of preference for one option implies a dislike of the contrasting category (higher polarity implies higher correlations),

d) Distinctiveness of attitude, i.e., the perception of the respondents that their attitude is different from the attitudes of others (personal attitudes perceived as more distinct compared to normative attitudes that result in higher correlations between the implicit and explicit attitudes).

When it comes to the discriminative validity of IATs, the level of overlap of conceptually related IAT measures would be a strong evidence of validity, but only if conceptually different IATs do not correlate. The research of Cunningham, Johnson, Raye, Gatenby, Gore, \& Banaji (2004) provides evidences for discriminative validity. In it, the attitudes towards social objects had saturations on one factor, while the non-social attitudes had loadings on another factor. Besides, other studies (Mierke \& Klauer, 2003) have shown that the method-specific variance is removed or diminished when the improved scoring algorithm of Greenwald et al. (2003) is used. This result suggests that when the method-variance is controlled, better evidences of the discriminative validity of implicit measures are obtained.

Several researches show that convergent validity of IAT is not yet proved and correlations are not satisfying (Bosson et al., 2000; Fazio \& Olson, 2003). One of the reasons for it is thought to be the lower internal consistencies of RT measures. Because of it, the true relations of implicit and explicit measures are often masked with error of measurement (Cunningham, Preacher, \& Banaji, 2001). Therefore, scholars suggest that, in order to explain the true nature of relations between these measures, the future research should focus on large samples with correction of measurement errors using latent variable analysis (Lane et al., 2007). 
Researches show that the implicit measures predict behaviour better in comparison with the explicit measures and offer proofs of predictive validity (Arcuri, Castelli, Galdi, Zogmaister \& Amadori, 2008; Greenwald, Poehlman, Uhlmann \& Banaji, 2009).

Some authors suppose that the implicit measures grasp those aspects that influence the behaviour of a person in an automatic and unconscious manner, while the explicit measures entangle those aspects that the person accepts willingly as characteristics visible in everyday life and behaviour (Bornstein, 1995).

Meta-analyses show that IAT predicts a wider range of variable criteria, e.g., social attitudes, physiological responses, and social actions (Greenwald et al., 2009). A recent research by Arcuri et al. (2008) indicates that the implicit measures are better, and the main predictor of the voting behaviour of politically undecided subjects (i.e., those who do not know who they will vote for).

Fazio \& Olson (2003) carried out comparative studies of the predictive validity of priming measures in general, and IAT in particular, and found that IAT was better in the prediction of behaviour at the category level, while other priming techniques were better at the level of specific members of the categories. This finding was in accord with the conclusions of DeHouwer (2001) that IAT assesses the strength of associations between the labels of categories while priming assesses the automatic responding to concrete examples. However, it is accepted that the implicit measures are predictive only for those situations that function under relatively analogous conditions of processing. In other words, it is thought that automatic processes underlie the implicit measures, and are predictive only for situations in which people react automatically, or when evaluations are not conscious and intentional (Wittenbrink, 2007). 
Some authors have suggested a classification of the prediction models of implicit and explicit measures - additive, multiplicative, and the model of double dissociation (Perugini, 2005). In all three groups of models, the basic assumption is that the implicit measures have incremental validity, which is very important in the assessment of personality constructs. The additive model presumes that the implicit and explicit measures explain different portions of variance of the criterion. Researches have shown that in the prediction of the anxious, shy, and angry behaviours, IAT has an incremental validity in case of the anxious and shy behaviours (Schnabel, Banse, \& Asendorpf, 2006a, 2006b).

The multiplicative model implies that the implicit and explicit measures interact in the prediction of behaviour. For example, interaction effects are found in the field of self-respect (Jordan, Spencer, Zanna, Hoshino-Browne, \& Correll, 2003; McGregor, Nail, Marigold, \& Kang, 2005; Schröder-Abé, Rudolph, Wiesner, \& Schütz, 2007).

Empirical evidences, demonstrating that the implicit measures predict spontaneous behaviour while the explicit measures predict controlled behaviour, support the model of double dissociation. However, the validation of this model is difficult due to the complexity of identification of relevant indicators of both the kinds of behaviour. In the field of social phenomena, researches show that IATs concerning racial prejudice correlate with the indicators of spontaneous behaviour, while the explicit measures do not (McConnell \& Liebold, 2001, also see Schnabel et al., 2007). Researches investigating the predictive validity in the domain of personality have also shown correlations between implicit measures and the indicators of spontaneous behaviour, and provide evidence to support the model of double dissociation (Asendorpf et al., 2002; Egloff \& Schmuckle, 2002; Steffens \& Schulze-König, 2006). 
However, it is important to mention that, when it comes to predicting behaviour in the domain of self-associations, all IATs used so far have included attributes confounded with valence (e.g., anxious - self-confident). Keeping in mind that it is still not clear how many of the responses are based on the semantics of attribute categories (i.e., on positive and negative valence), researchers still have to prove the construct validity of the specific semantic content as different from the general positive or negative evaluation (Schnabel et al., 2007).

\subsection{Basic Personality Traits}

There are several ways to conceptualize personality from various perspectives, and on different levels of abstraction. One of the most researched levels is the level of personality traits (see John \& Srivastava, 1999). In this field, the dominant viewpoint is based on the five basic personality traits, and the idea is conceptually as well as empirically elaborated in the Five Factor Model (FFM) (Knežević, Džamonja-Ignjatović \& Đurić-Jočić, 2004; Matthews, Deary, \& Whiteman, 2003).

The Five Factor Model assumes the existence of five basic personality dimensions: Neuroticism (N), Extraversion (E), Openness to experience (O), Agreeableness (A), and Conscientiousness (C) (Costa \& McCrae, 1995; Đurić-Jočić, Knežević, \& Džamonja-Ignjatović, 2004; Knežević et al., 2004).

Neuroticism is a domain describing the adjustment and emotional stability of a person, i.e., his general tendency to experience negative emotions. People high in neuroticism are emotionally reactive and they interpret even the ordinary situations as threatening, and minor frustrations as difficult. At the other end of the dimension are individuals who score low in Neuroticism; they are less easily upset and emotionally 
less reactive. They tend to be relatively calm and emotionally stable. It contains facets anxiety (N1), hostility (N2), depression (N3), self-consciousness (N4), impulsiveness (N5) and vulnerability (N6).

Extraversion implies more sociability and higher energy level. Extraverted people are described as talkative, outgoing, and active, with positive emotions, and developed social network. They tend to be enthusiastic, action-oriented and responsive to opportunities for excitement. On the other hand, introverted people lack the exuberance, energy, and activity levels of the extraverts; they are less engaged in the social world and prefer to be alone. This domain includes warmth (E1), gregariousness (E2), assertiveness (E3), activity (E4), excitement seeking, (E5) and positive emotions (E6).

Openness to experience reflects the tendency to be tolerant for differences, openmindedness, unconventional attitude, and being receptive to others' emotions and ideas. People with higher scores on this scale are more prone to artistic tendencies, are intellectually curious, and sensitive to beauty. This domain consists of fantasy (O1), aesthetics (O2), feelings (O3), actions (O4), ideas (O5), and values (O6).

Agreeableness is related to interpersonal relations and the level to which a person is concerned with cooperation and social harmony. People with higher scores on this scale are altruistic, capable of being emphatic, "soft-hearted", and willing to help others, and believe that others are also willing to help. Disagreeable individuals place their own interests above getting along with others. These people are often described as unfriendly, aggressive, and uncooperative. This domain consists of trust (A1), straightforwardness (A2), altruism (A3), compliance (A4), modesty (A5) and tendermindedness (A6). 
Conscientiousness reflects the individual's level of persistence, motivation and organization. People with higher scores on this scale are goal-oriented, possess a strong will, and are punctual and reliable. Conscientious people are usually successful, thorough, and persistent. On the other end of this dimension are individuals who are often described as unreliable and less effective with a lack of ambition. This domain consists of competence (C1), order (C2), dutifulness (C3), achievement striving (C4), self-discipline (C5), and deliberation (C6). Time and cross-cultural stability of the basic personality traits has been confirmed in a large number of studies (Larsen \& Buss, 2008; McCrae \& Costa, 2003; McCrae \& Costa, 2008; McCrae, Terracciano \& 78 members of personality profiles of cultures project, 2005).

However, in recent years, scholars have expressed doubts over whether basic personality can be described with only five personality factors (Knežević, 2003; Knežević et al., 2004; Knežević, Savić, Kutlešić, Jović, Opačić, \& Šaula, submitted; Larsen \& Buss, 2008; McAdams, 1992; Saucier, 2008; Waller, 1999).

Some researchers, both from the field of lexical paradigm and hierarchical FFM, think that at least one essential domain is not included in FFM (Ashton \& Lee, 2008; Knežević et al., submitted; Saucier, 2008), namely, the dimension that would correspond to Eysenk's concept of psychoticism or Momirovic's system for coordination of regulative functions (Đurić-Jočić et al., 2004). In other words, this model is insensitive to a large set of psychopathological phenomena founded on both discrete pathological processes, and diverse forms of maladaptive behaviours. However, one of the reasons why FFM does not include the dimensions that would describe the dissociative phenomena is that most of the markers are so-called evaluative adjectives. These words describe the permanent personality dispositions and the regularities in 
behaviour (e.g., crazy, weird, "dark", normal, "wacky" etc.), and are discarded from further analyses in the first phases of researches in FFM (Đurić-Jočić et al., 2004).

Keeping in mind that the results of numerous researches point out that it is better to think of psychotic behaviours as the end points on a continuum of maladaptation in the general population, and not as qualitatively separate entities (Knežević et al., submitted), this research includes the basic personality trait of Disintegration or proneness to psychosis, besides the "big five" personality traits. Disintegration is considered to be the basis of various aspects of maladaptation and, at the same time, creativity and achievement. Proneness to psychosis consists of ten facets (Knežević et al., submitted):

a) general executive dysfunction (GEI), i.e., memory problems, concentration problems, attention, and problems with coordination of mental functions;

b) perceptive distortions (PD), i.e., deep disorders in the body scheme, hallucinations and dissociative phenomena;

c) enhanced awareness (EA), i.e., absorption phenomena;

d) depression (D);

e) paranoia $(\mathrm{P})$;

f) mania (M);

g) social anhedonia (SA), i.e., lack of enjoyment in social interaction, and avoidance of it;

h) flattened affect (FA), i.e., emotional numbness and insensitivity; 
i) somatoform disregulation (SD), i.e., experience of disturbances in functioning of bodily organs;

j) magical thinking (MT).

\subsection{Cognitive Abilities-Cybernetic Model of Intellectual Functioning}

There are differences among researchers as to whether the constructs of cognitive psychology and the psychology of intelligence should be considered as personality constructs or not. If under traits, we presume relatively permanent dispositions, based on which we can differentiate the behaviours of individuals (John \& Srivastava, 1999), it is justifiable to include the construct of intelligence into a wider personality construct. Therefore, we can consider intelligence as an important construct of individual differences. This research adopts, as the theoretical frame for intelligence, the cybernetic model of Momirovic and colleagues (Wolf, Momirović, \& Džamonja, 1992). This model is based on the work of Luria (1983) and is congruent with the cybernetic model of Das, Kyrbi, and Jarman (1975). It defines intelligence as the efficiency of systems for processing information when intelligent reactions are required.

The core of the model is the assumption of existence of four latent dimensions: processor for decoding and structuring of information, processor for serial processing, processor for parallel processing, and the amount of efficiently used information in long-term memory (Wolf et al., 1992). Empirical data confirm these four latent dimensions while, on the secondary level, one general cognitive factor $(G)$ is extracted which is interpreted as the efficiency of central processor for information analysis and decision making (Wolf et al., 1992). 
These factors represent the different forms of unique cognitive ability. A large body of evidence supports this model of cognitive functioning and the possibility to reliably assess the efficiency of cognitive processors. This model is congruent with the model of Dass, Kirby and Jarman, and is based on Luria's work (Lazarević \& Knežević, 2008; Wolf et al., 1992).

\subsection{An Overview of Advantages and Shortcomings of Different Assessment Methods in Personality Psychology}

The use of self-reports is quite widespread in personality psychology. According to Vazire (2006), the vast majority of research has used the self-report method. One strong argument for the use of self-reports is that information about someone's inner states and feelings is best obtained by asking the person themselves, about everything one would like to know. Paulhus \& Vazire (2007) state that people have the best view into their inner states, the information provided by them is very rich in introspective details, and they are usually highly motivated to speak about themselves. In addition, Kline (1993) says that administering self-reports is advantageous because of its ease of scoring and interpretation. Finally, this kind of assessment is time- and cost-efficient.

However, a certain caution is necessary when using self-reports. Schwarz (1999) states that the question format, wording, and even the context of the questionnaire, influence responses. Other problems are biases in responding (e.g., socially desirable, acquiescent, and extreme responding) (Paulhus, 1991). John \& Robins (1994) also find self-perceptions as potentially problematic in providing self-report, because they are often distorted. In other words, people are predisposed towards self-enhancement, and try to give a positive self-perception (Fiske \& Taylor, 2008). In addition, people 
sometimes lack self-information and do not always possess the necessary level of selfawareness (Kagan, 2007).

Observer ratings are usually collected from people who know the observed well (e.g., spouse, partner, friends, parents, etc.). The rationale behind collecting data from them is that other people can offer different, alternative perspectives on someone's personality. These data are rich sources of information as the informants have had the opportunity to observe behaviour across situations. Besides, the process is inexpensive, and time-efficient (Vazire, 2006). Hofstee (1994) says that by collecting several ratings, the reliability of assessment is increased. However, in spite of the fact that response biases are lower in observer ratings, we cannot negate the possibility of the informants providing favourable answers, especially if the observed is intimate to them, for example, the romantic partner or a close friend (McCrae and Weiss, 2007). Further, in spite of all the advantages of observation, the observers are not competent to rate someone's inner states and feelings. Besides, other people are not able to report on how someone would react in more specific situations.

Behavioural assessment is considered very important because the personality is easily observed in someone's behaviour. One important advantage is that we can simulate certain situations and observe people's reactions. Another advantage is the bypassing of problems associated with the retrospective assessment of personality (e.g., with self-reports). Furr \& Funder (2007), however, point out several aspects that make behavioural observation difficult; e.g., it is expensive and time consuming, development of coding schemes demands a great deal of effort, and it is easier to use questionnaires and inventories. Another shortcoming is related to the assessment of personality in artificial situations (as the data collected usually reflect only one situation). 
Since self-serving biases influence many aspects of human behaviour, finding a way to overcome these tendencies would be of great importance in personality assessment. Implicit measures were developed in an attempt to overcome the disadvantages of self-report measures, which are particularly prone to be influenced by these tendencies. Because of that, implicit measures are expected to improve validity of explicit measures. In addition, implicit assessment enables measuring information not available to the consciousness, which would improve prediction of various forms of spontaneous behaviour. It also enables researchers to test subjects who are less able, or willing, to report about their inner states (Greenwald et al., 1998). In addition, it is efficient in terms of both time and costs. However, a major drawback is the lack of a theory that could completely explain the underlying processes (DeHouwer, 2006; DeHouwer \& Moors, 2007; DeHouwer et al., 2009; Fazio \& Olson, 2003).

In spite of some shortcomings of multi method approach (e.g., it requires more effort, money, resources, etc.), researchers support multi-method assessment in personality psychology because it improves the construct validity, and offers very rich information (John \& Soto, 2007; Pervin, 1999). The multi-method approach enables us to obtain different but complementary data about the same construct and to assess the accuracy of research methods. 


\subsection{Study Objective}

The study objective of this research, which is designed to comprehensively measure important personality dimensions (including Disintegration and Intelligence, apart from the "Big Five"), is to investigate the relationship between some implicit and several explicit personality measures. The focus is on testing the convergentdiscriminative validity of the implicit (i.e., IAT) measures of basic traits by relating them to various explicit measures (i.e., self-reports, ratings by close others, and ratings by experts). It aims at expanding the spectrum of personality assessment methods with those capturing behaviour through less controllable methods than self-report measures, thus increasing the possibility of extracting the latent trait factors with higher loadings on implicit measures. Apart from that, the moderating influence of behavioural consistency and trait visibility on the relations between implicit and explicit measures will also be investigated. The results should provide information on whether it is possible to supplement, or possibly substitute, explicit measures, which would have significant consequences for solving practical problems, such as selection processes in the methods of personality assessment.

In spite of the growing interest in studies in the field of individual differences based on implicit measurement, researches with a comprehensive approach to the measurement of personality characteristics are still scarce. The available studies usually have a narrow scope, and measure only one or two personality traits, or certain aspects of personality domains (Schnabel, Banse, \& Asendorpf, 2006a; Schnabel, Asendorpf \& Greenwald, 2008). Besides, most of the researches deal with the possibilities of predicting behaviour based on the implicit and self-report measures (Steffens \& 
Schulze-König, 2006). It is important to mention that, when researchers make their decisions regarding the explicit measures they would use, they usually choose the shorter versions of the Big Five inventories (e.g., NEO-FFI, BFI) with poor psychometric properties, or some behavioural criteria (Steffens \& Schulze-König, 2006).The observer ratings ( $\mathrm{R}$ measures) remain neglected as valid explicit measures, and are rarely used. 


\subsection{Research Hypotheses}

Moderate correlations between the implicit and explicit measures (Bornstein, 1995; Hofmann et al., 2005; Lane et al., 2007) suggest that both tap stable individual differences. Thus, we can assume that these measures assess different aspects of basic personality characteristics. Based on this, we can hypothesise that:

H1: Positive correlations exist between implicit and explicit ( $\mathrm{S}$ and $\mathrm{R}$ ) measures of certain traits.

Correlations of self-reports and observer ratings are moderate (Vazire, 2006; Costa \& McCrae, 2008). Therefore, we can conclude that these explicit measures, to a certain extent, assess different aspects of basic personality traits. Evidence about differences between automatic (implicit) and highly elaborated (explicit) descriptions of the self are already presented. We assume that automatic associations are based on explicit self-associations formed through life-time experience. However, since the task in IAT is based on differential RT, it does not allow mechanisms of distortions present in highly elaborated self-descriptions (such as self-deception or impression management) to influence differential RT. Based on that, we assume that automatic associations in higher extent reveal "the true trait level", that is more visible to observers (assuming that they are more objective in assessment). Based on that, we can assume following:

H2: Correlations of implicit and explicit $\mathrm{R}$ measures will be equal or higher than correlations of implicit and explicit S measures of a trait. 
Implicit measures reflect the automatic associations (resulting from long-term experience of a person with their own intellectual abilities); so, we can expect that they will share a common variance with that of the objective measures, independently of the processes underlying self-assessment of intellectual abilities. In other words, we can expect that:

H3: Implicit measures will have incremental validity in the objective score of intellectual abilities in comparison with self-assessment of intellectual abilities.

Research shows that the consistency in the behavioural indices of a trait (either objective or self-reported) leads to higher correlation between $\mathrm{S}$ and $\mathrm{R}$ measures of the trait (Bem \& Alen, 1974; Zuckerman et al., 1988). Similarly, we can suppose that consistency in behaviour related to specific trait would lead to stronger automatic associations, which would effect correlations between implicit and corresponding explicit S measure. Therefore, we can hypothesise that:

H4: Trait consistency (self-reported and objective) will moderate the relations between implicit and explicit measures, whereby the correlations will be higher for consistent $\underline{\text { traits. }}$

Since ipsatized measures are expected to be less sensitive to socially desirable responding than normative measures, we can assume that:

H5: Implicit measures will have higher correlations with ipsatized S measures than with normative measures. 


\section{METHOD}

\subsection{Sample}

The sample consisted of 224 psychology students from the Faculty of Philosophy, Belgrade, Serbia. All participants agreed to participate and signed an informed consent. They participated in the research in exchange for research participation credits. The average age of the respondents was $20.43(\mathrm{SD}=1.60)$. The sample consisted of 186 female and 38 male students. For every subject in the sample, Implicit Association Test data, self-reports, rating measures from two close observers (NEO PI R and DELTA 10), and measures of cognitive functioning on KOG9 battery were collected. Further, $91.5 \%$ female observers were mothers of the subjects, while 77.2\% male observers were fathers of the subject (Table 1 and Table 2).

Table 1 Structure of female sample on which observer ratings were collected

\begin{tabular}{|c|c|c|}
\hline \multirow{2}{*}{} & \multicolumn{2}{|c|}{ Female observers } \\
\cline { 2 - 3 } & $\mathrm{F}$ & $\%$ \\
\hline mother & 205 & 91.5 \\
\hline female friend & 14 & 6.3 \\
\hline sister & 3 & 1.3 \\
\hline girlfriend & 2 & 0.9 \\
\hline $\mathrm{N}$ & 224 & 100 \\
\hline
\end{tabular}

Table 2.Structure of male sample on which observer ratings were collected

\begin{tabular}{|c|c|c|}
\hline \multirow{2}{*}{} & Male observers \\
\cline { 2 - 3 } & $\mathrm{F}$ & $\%$ \\
\hline father & 173 & 77.2 \\
\hline male friend & 14 & 6.2 \\
\hline boyfriend & 12 & 5.3 \\
\hline brother & 18 & 8.0 \\
\hline stepfather & 6 & 2.6 \\
\hline uncle & 1 & 0.05 \\
\hline $\mathrm{N}$ & 224 & 100 \\
\hline
\end{tabular}

The Average age of female observers was 46.87 years $(\mathrm{SD}=8.77)$, and of male observers 46.54 years $(\mathrm{SD}=12.18)$. From a smaller subsample of 99 subjects, behavioural data were also collected. These subjects participated in structured interviews. 


\subsection{Variables in research}

Variables in research, and the instruments measuring them, are presented in Table 3. Six basic personality traits have been assessed, viz. Neuroticism, Extraversion, Openness to experience, Agreeableness, Conscientiousness, and Disintegration. These were assessed both with implicit (IAT and implicit objective measures, i.e. LIWC) and explicit measures (self-reports, ratings by close others, behavioural observation-expert ratings). The intellectual abilities were measured with explicit (self-assessment of intellectual abilities and objective cognitive tests) and implicit measures (IAT). In addition, for each of the six personality traits, self-report measures of consistency and visibility in behaviour were collected.

Table 3 Tests used for data collection

\begin{tabular}{|c|c|c|c|}
\hline Test $^{2}$ & $\begin{array}{l}\text { Form of } \\
\text { measurement }\end{array}$ & Domain of measurement & Domain \\
\hline $\begin{array}{l}\text { NEOPIR Self } \\
\text { Report }\end{array}$ & $\begin{array}{l}\text { Explicit: self- } \\
\text { report }\end{array}$ & $\begin{array}{c}\text { Neuroticism, Extraversion, Openness to experience, } \\
\text { Agreeableness, Conscientiousness }\end{array}$ & $\begin{array}{l}\text { Personality } \\
\text { traits }\end{array}$ \\
\hline $\begin{array}{l}\text { DELTA } 10 \\
\text { Self Report }\end{array}$ & $\begin{array}{l}\text { Explicit: self- } \\
\text { report }\end{array}$ & Disintegration & $\begin{array}{l}\text { Personality } \\
\text { trait }\end{array}$ \\
\hline $\begin{array}{c}\text { NEOPIR } \\
\text { Observer } \\
\text { ratings }\end{array}$ & $\begin{array}{l}\text { Explicit: } \\
\text { rating by close } \\
\text { others }\end{array}$ & $\begin{array}{c}\text { Neuroticism, Extraversion, Openness to experience, } \\
\text { Agreeableness, Conscientiousness }\end{array}$ & $\begin{array}{l}\text { Personality } \\
\text { traits }\end{array}$ \\
\hline $\begin{array}{c}\text { DELTA } 10 \\
\text { Observer } \\
\text { ratings }\end{array}$ & $\begin{array}{l}\text { Explicit: } \\
\text { rating by close } \\
\text { others }\end{array}$ & Disintegration & $\begin{array}{l}\text { Personality } \\
\text { trait }\end{array}$ \\
\hline $\begin{array}{l}\text { SSA short } \\
\text { scale of } \\
\text { attributes }\end{array}$ & $\begin{array}{l}\text { Explicit: self- } \\
\text { report }\end{array}$ & $\begin{array}{c}\text { Neuroticism, Extraversion, Openness to experience, } \\
\text { Agreeableness, Conscientiousness }\end{array}$ & $\begin{array}{l}\text { Personality } \\
\text { traits }\end{array}$ \\
\hline $\begin{array}{l}\text { TS PROC- } \\
\text { Consistency of } \\
\text { traits in } \\
\text { behaviour }\end{array}$ & $\begin{array}{l}\text { Explicit: self- } \\
\text { report }\end{array}$ & $\begin{array}{c}\text { Neuroticism, Extraversion, Openness to experience, } \\
\text { Agreeableness, Conscientiousness }\end{array}$ & $\begin{array}{l}\text { Personality } \\
\text { trait }\end{array}$ \\
\hline $\begin{array}{l}\text { Ipsatized S } \\
\text { measures }\end{array}$ & $\begin{array}{l}\text { Explicit: self- } \\
\text { report }\end{array}$ & $\begin{array}{c}\text { Neuroticism, Extraversion, Openness to experience, } \\
\text { Agreeableness, Conscientiousness }\end{array}$ & $\begin{array}{l}\text { Personality } \\
\text { trait }\end{array}$ \\
\hline $\begin{array}{l}\text { IQ self- } \\
\text { assessment }\end{array}$ & $\begin{array}{l}\text { Explicit: self- } \\
\text { report }\end{array}$ & General intellectual achievement & Intelligence \\
\hline IT1 & $\begin{array}{l}\text { Explicit: } \\
\text { objective }\end{array}$ & Perceptual identification & $\begin{array}{l}\text { Perceptive } \\
\text { processing }\end{array}$ \\
\hline
\end{tabular}

\footnotetext{
${ }^{2}$ Detailed description of all instrument is provided in section Instruments in research.
} 


\begin{tabular}{|c|c|c|c|}
\hline Test $^{2}$ & $\begin{array}{c}\text { Form of } \\
\text { measurement }\end{array}$ & Domain of measurement & Domain \\
\hline $\mathrm{CF} 2$ & $\begin{array}{l}\text { Explicit: } \\
\text { objective }\end{array}$ & Perceptive analysis & $\begin{array}{l}\text { Perceptive } \\
\text { processing }\end{array}$ \\
\hline GT7 & $\begin{array}{l}\text { Explicit: } \\
\text { objective }\end{array}$ & Perceptive synthesis & $\begin{array}{l}\text { Perceptive } \\
\text { processing }\end{array}$ \\
\hline AL4 & $\begin{array}{l}\text { Explicit: } \\
\text { objective }\end{array}$ & Verbal opposites & $\begin{array}{c}\text { Verbal } \\
\text { processing }\end{array}$ \\
\hline AL7 & $\begin{array}{l}\text { Explicit: } \\
\text { objective }\end{array}$ & Verbal analogies & $\begin{array}{c}\text { Verbal } \\
\text { processing }\end{array}$ \\
\hline GSN & $\begin{array}{l}\text { Explicit: } \\
\text { objective }\end{array}$ & Synonyms & $\begin{array}{c}\text { Verbal } \\
\text { processing }\end{array}$ \\
\hline $\mathrm{S} 1$ & $\begin{array}{l}\text { Explicit: } \\
\text { objective }\end{array}$ & Visual spatialization & $\begin{array}{c}\text { Parallel } \\
\text { processing }\end{array}$ \\
\hline IT2 & $\begin{array}{l}\text { Explicit: } \\
\text { objective }\end{array}$ & General visualization & $\begin{array}{c}\text { Parallel } \\
\text { processing }\end{array}$ \\
\hline D48 & $\begin{array}{l}\text { Explicit: } \\
\text { objective }\end{array}$ & Domino test & $\begin{array}{c}\text { Parallel } \\
\text { processing }\end{array}$ \\
\hline KOG9 & $\begin{array}{l}\text { Explicit: } \\
\text { objective }\end{array}$ & General intellectual achievement & Intelligence \\
\hline IAT & Implicit & $\begin{array}{c}\text { Neuroticism, Extraversion, Openness to experience, } \\
\text { Agreeableness, Conscientiousness, Disintegration, } \\
\text { Intelligence }\end{array}$ & $\begin{array}{l}\text { Personality } \\
\text { traits+ } \\
\text { intelligence }\end{array}$ \\
\hline $\begin{array}{l}\text { Structured } \\
\text { Interview }\end{array}$ & $\begin{array}{l}\text { Explicit: } \\
\text { rating by } \\
\text { experts }\end{array}$ & $\begin{array}{l}\text { Neuroticism, Extraversion, Openness to experience, } \\
\text { Agreeableness, Conscientiousness, Disintegration }\end{array}$ & $\begin{array}{l}\text { Personality } \\
\text { traits }\end{array}$ \\
\hline LIWC & $\begin{array}{l}\text { Implicit: } \\
\text { objective }\end{array}$ & Verbal behaviour & $\begin{array}{c}\text { Personality } \\
\text { traits }\end{array}$ \\
\hline
\end{tabular}

Conventionally, explicit measures are taken before the implicit measures (Egloff \& Schmuckle, 2002; McDaniel, Beier, Perkins, Goggin, \& Frankel, 2009). This study also first carried out assessment with explicit measures (i.e., NEO PI R and DELTA 10, KOG9), and then IAT assessment. The explicit measures were assessed during practicals on the course of individual differences (during $2 \mathrm{~h}$ practicals NEO PI R and DELTA 10 self-reports were collected). The assessment of intellectual abilities with KOG9 was carried out during the 2-hour practicals next week. The participants completed their IAT individually (in separate rooms) after all explicit measures were collected. IAT testing lasted several weeks. 


\subsection{Instruments in Research}

\subsubsection{Implicit Association Test (IAT)}

For the assessment of personality traits, a complete IAT consists of seven IATs designed for the assessment of seven personality dimensions: Neuroticism, Extraversion, Openness to experience, Agreeableness, Contentiousness, Disintegration and Intelligence. As per the recommendations of scholars, each IAT measuring one personality domain consists of seven blocks (Greenwald et al., 2003).

\subsubsection{IAT - Stimuli}

Dimension of attributing personality traits. In Implicit Association Test designed for the assessment of self-associations, it is important to determine the category that contrasts with the category $I$. The majority of scholars decide to use the category Others. However, Karpinski (2004) gives a very harsh critique on it and says that the pole of category defined in this manner cannot be used in the assessment of selfassociations. However, subsequent research which has carried out a thorough methodological examination of the questions concerning the valence of contrasting categories, has shown that the category Others has a neutral valence, and is adequate for the assessment of self-associations (Pinter \& Greenwald, 2005). Apart from choosing a contrasting category, the second important question in the construction of IAT is the selection of stimuli that will represent the different dimensions of personality traits. There are two ways to determine the stimuli to represent the categories I-Others generic and idiographic. Although some researches indicate that the correlations of the implicit and the corresponding explicit measures are higher when idiographic IAT is 
used (Greenwald \& Farnham, 2000; Nosek \& Hansen 2008, Olson \& Fazio, 2004), the results of the confirmatory factor analyses show that the generic format better defines the latent variables. Besides, the use of generic format has an additional advantage, as it does not require gathering information specific to each subject (Greenwald \& Farnham, 2000).

Keeping in mind that researches (Greenwald \& Farnham, 2000; Steffens \& Schulze-König, 2006) indicate that the generic IAT format adequately assesses the implicit self-associations, five pronouns representing each category of dimension $I$ Others were chosen for this research ${ }^{3}$.

Dimension of personality domains. The basic task of the respondent in IAT is to sort stimuli in the subordinate categories. Therefore, it is crucial that the subjects are able to identify the stimuli and to recognize them as representatives of dimensions. For dimension labels, these were chosen: Stable-Unstable, Extraverted-Introverted, Openminded-Close-minded, Agreeable-Non-agreeable, Conscientious-Unconscientious, Integrated-Disintegrated, and Capable-Incapable. For each dimension, 10 stimuli were chosen, out of which five were of positive valence and five of negative valence.

In order to select the best stimuli for each trait dimension, 174 attributes for seven personality traits were selected. The selection was based on an extensive literature review, and the sources examining adequate markers of basic personality traits (ĐurićJočić et al., 2004; John \& Srivastava, 1999; John, Naumann, \& Soto, 2008; Knežević et al., submitted; Smederevac \& Mitrović, 2006). The analysis of natural languages shows a disproportion in the number of attributes representing each pole of the personality

3. In Serbian, nouns and pronouns have seven different declinations, but some forms are the same, and all forms are single words - moj, moje, mene, mnome i moga (for category "I" these are "my, mine, of me, with me, of mine"), and njihov, njihovo, njih, njima i njihovih (for category "Others" these are "their(s), theirs, of them, with them, to them) 
dimensions; a larger number of attributes is present for dimensions that are important for interpersonal relations (e.g., Extraversion and Agreeableness), compared to the dimensions important for the persons themselves and their adjustments (e.g., Neuroticism) (Đurić-Jočić et al., 2004). Therefore, the number of attributes for each dimension in the preliminary list was not equal - Openness to experience (12 positive and 13 negative), Conscientiousness (13 positive and 12 negative), Agreeableness (13 positive and 12 negative), Disintegration (12 positive and 13 negative), Intelligence (12 positive and 13 negative), Extraversion (12 positive and 12 negative) and Neuroticism (12 positive and 12 negative).

\subsubsection{IAT Procedure - Design of Implicit Association Test}

The basic task of the respondent in IAT is to categorise the stimuli presented. While assessing attitudes, a categorization of the concepts representing two different attitude categories (i.e., the target concept and the attributes of clear positive and negative valence, such as good and bad) is combined. By comparing the average categorization times in different situations of combining attributes and concepts, the associative strength between certain concepts and attributes of positive or negative valence is measured.

By combining target concepts I-Others with attributes of different dimensions (e.g. stable vs. unstable; strong vs. week; science vs. art; family vs. career), the possibilities for the assessment of individual differences (in personality traits, selfconcept) are opened. In addition, it is possible to determine the extent to which each person attributes some trait with a certain aspect of the self (Lane et al., 2007; Schnabel et al., 2008; Steffens and Schulze-König, 2006). 
The basic idea of IAT is to compare the average reaction times (RTs) when the respondent sorts out stimuli in two opposite tasks of double categorization. In the first task, the respondent is asked to press one button when the stimuli representing one of the two categories of the target concept or attribute is presented, and another one when the other target concept or attribute is presented. For example, when assessing personality, the respondents are asked to press the left button every time the stimuli representing the category $I$ or the attributes of positive valence are presented, and to press the right button every time the stimuli representing the category Others or the attributes of negative valence are presented. In another, opposite sorting task, the respondent has to press the left button when the stimuli representing the category $I$ or the attributes of negative valence are presented, and to press the right button every time the stimuli representing the category Others or the attributes of positive valence are presented. Categorization in IAT is based on the assumption that it should be easier to make a particular behavioural response (i.e., to press one key) when the concepts are strongly associated in memory, than when they are weakly associated. A compatible assignment of categories (e.g., I + Stable) should lead to shorter response latencies than when unassociated categories share one response key (e.g., I + Unstable).

In the IATs of this research, the superordinate categories were presented at the left and upper right corners of the screen, while the target stimuli were presented at the centre. The respondents had the instruction to answer as quickly as possible while trying to make the least number of mistakes. The inter-trial interval was $150 \mathrm{~ms}$. If the subject made an error, red " $\mathrm{X}$ " was presented below the target stimuli and, in order to continue with the task, the respondent had to give the correct answer after which the next stimuli was presented. 
Keeping in mind that all the stimuli were presented in the same mode (i.e., verbal), the labels and corresponding stimuli of the target concept (I-Others) were presented in one colour (i.e., black), and the labels and corresponding stimuli of personality traits were presented in another colour (i.e., green) (Nosek, Greenwald, \& Banaji, 2007). Remaining labels (i.e., category names), positioned at the upper left and right corner of the screen, remained on the screen during each block.

Researches show that the most optimal structure of IAT makes seven blocks or phases (Greenwald et al., 2003; Nosek et al., 2005). Table 4 presents the structure of IAT blocks, as an example of the assessment of one personality trait (Steffens \& Schulze-König, 2006).

Table 4 Scheme of IAT on example of assessment of one personality trait

\begin{tabular}{|c|c|c|c|}
\hline Blocks & Left button & Right button & Number of trials $^{4}$ \\
\hline 1. & I & Others & 20 \\
\hline 2. & Stable & Unstable & 20 \\
\hline 3. & I or Stable & Others or Unstable & 20 \\
\hline 4. & I or Stable & Others or Unstable & 40 \\
\hline 5. & Others & I & 40 \\
\hline 6. & Others or Stable & I or Unstable & 40 \\
\hline 7. & Others or Stable & I or Unstable & 40 \\
\hline
\end{tabular}

The first two blocks gave the respondents practice in categorizing the target and attribute stimuli respectively (i.e., pronouns representing categories $I-$ Others in the first, and the attributes representing personality traits in the second).

These two blocks were designed so that the respondents could practice locating dimensions and adjust to the task itself. In these blocks, the subjects had to work on a single categorization task, which meant that in the first block they had to categorize the stimuli representing the target concept (i.e., to press the left button when the stimuluspronoun, representing category $I$ was displayed, and to press the right button, when the

\footnotetext{
${ }^{4}$ In each block, set of predefined number of stimuli is presented so that in total block consist of 20 (and 40) trials, not of completely different stimuli
} 
stimulus representing category Others was presented), and in the second they had to categorize the stimuli of positive or negative valence in the corresponding superordinate category (e.g., Stable-Unstable) (Figure 1 and Figure 2).

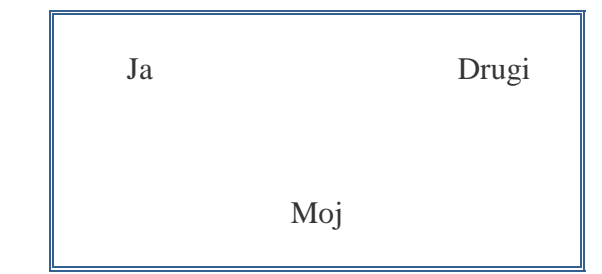

Figure 1. Computer Screen in the First Block (Ja-I, Drugi-Others, Moj-Mine)

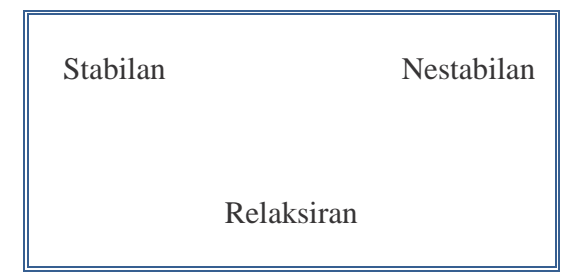

Figure 2. Computer Screen in the Second Block (Stabilan-Stable, Nestabilan-Unstable, Relaksiran-Relaxed)

These blocks consisted of 20 trials each. In the third and fourth block, the subjects had to press the left button when the stimuli representing categories I or Stable were displayed, and the right button when the stimuli representing categories Others or Unstable were presented (Figure 3 and Figure 4).

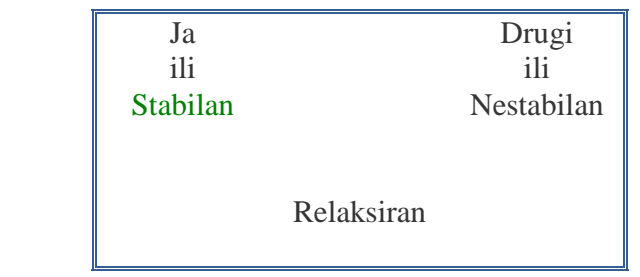

Figure 3. Computer Screen in third Block (Ja ili Stabilan-I or Stable, Drugi ili Nestabilan-Others or Unstable, Relaksiran-Relaxed)

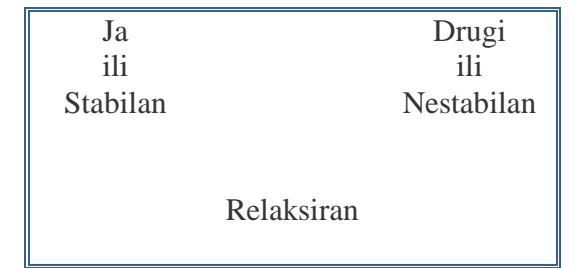

Figure 4. Computer Screen in the Fourth Block

The third block consisted of the first double discrimination task in which the subjects had to respond to 20 stimuli, and provided the respondents the opportunity to practice combined categorization. The fourth block was "critical"; the subjects had the same task, but they had to respond to 40 stimuli. The Fifth block was the practice block for target stimuli only, but with the reversed key-assignments (i.e., the position of categories I-Others was switched). The subjects again had to categorize stimuli, but now 
they had to press the left button for the stimulus representing category Others, and the right button for the stimulus representing category $I$ (Figure 5).

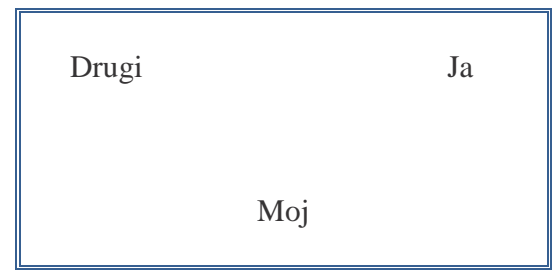

Figure 5. Computer screen in fifth block (Drugi-Others, Ja-I, Moj-Mine)

Researchers (Greenwald et al., 2003; Schnabel et al., 2007) suggest that it is optimal to present the double number of stimuli in this block, compared to the first (i.e., 40 ), in order to avoid the effect of order for the combined blocks, or the previously learned positions of dimensions. Due to the order effect, the average IAT scores show slightly stronger associations corresponding to the pairs of the first presented combined blocks. Therefore, it is recommended to introduce a higher number of trials, and to counterbalance the order of combined blocks across the subjects (Schnabel et al., 2007). The last two blocks (sixth and seventh) consisted of the second double-discrimination task, but this time in a reversed order as compared to the $3^{\text {rd }}$ and $4^{\text {th }}$ blocks - the subjects now had to press the left button for the stimuli representing categories Others or Stable, and the right button for the stimuli representing categories I or Unstable (Figure 6 and Figure 7). The sixth block was a practice block consisting of 20 trials, while the seventh block was critical and consisted of 40 trials. 


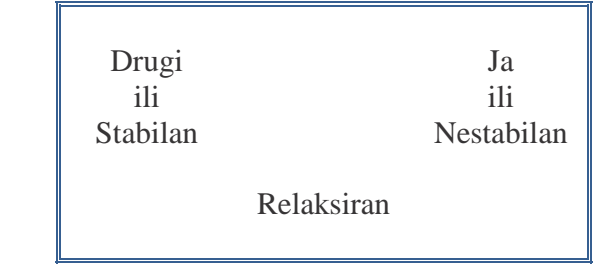

Figure 6. Computer Screen in the Sixth Block

(Drugi ili Stabilan-Others or Stable, Ja ili

Nestabilan-I or Unstable, Relaksiran-Relaxed)

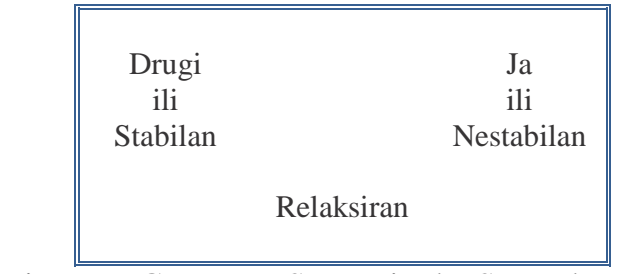

Figure 7. Computer Screen in the Seventh Block

Order of stimuli within the blocks was randomized. Besides, the blocks B3-B4 and B6-B7 were counterbalanced across subjects, regarding the position of superordinate categories. In other words, the subjects could start sorting the task with different combinations of paired super-ordinate categories (e.g., I-Stable; OthersUnstable or Others-Stable; I-Unstable). Counterbalancing of the block order was done in order to provide control for the effect due to the fact that the IAT scores tend to show stronger associations for the categories that are paired first. Also, in order to avoid the possible negative effects of fatigue on the assessment of personality traits, the order of traits (i.e. mega blocks) was also randomized. In other words, each subject received a unique order of stimuli within the blocks of each IAT, and a random order of IATs representing personality traits (i.e., mega blocks).

Between the blocks in each IAT, the subjects were given instructions about the task. After four mega-blocks (i.e., four IATs measuring four personality traits), all the subjects had to take a fixed 5 minute break.

\subsubsection{Software and Hardware for Collecting IAT Data}

Experiment design requires a high control over the experimental sequence (e.g., counterbalancing of the position of dimensions, trait orders and stimuli representing traits), and a possibility to present different kinds of stimuli - texts, images, Likert scales, questionnaire items, etc. IATs were conducted in laboratory rooms using PSIHO 
software (Knežević \& Opačić, 2009) which allows the presentation of different kinds of stimuli, and a reliable data collection with various peripheral components. The software allows reaction time measurement in milliseconds. It is very user friendly when it comes to designing the task; it allows complete randomization of trials, blocks and "mega blocks" (personality traits in this research). In addition, for each subject, the collected data are automatically imported into SPSS database. Data were collected on two notebook computers. For response recording, response pads Cedrus RB-530 were used due to their technical and ergonomic characteristics. The response pads offered a quicker reaction time resolution (1 millisecond) compared to the other peripheral components. Besides, compared with standard keyboards, they had a lesser number of buttons, and the respondents had fewer problems in finding out the correct button due to its size and colour.

\subsection{Explicit Measures of Basic Personality Traits}

2.4.1. Inventory for the Assessment of Basic Personality Traits NEO PI R (S and R form)

Inventory for the assessment of basic personality traits NEO PI R is based on Five Factor Model (FFM) of personality (Costa \& McCrae, 1995). This model assumes that the basic personality dispositions are the five dimensions: Neuroticism, Extraversion, Openness to experience, Agreeableness and Conscientiousness. Each dimension consists of six facets. The questionnaire had 240 Likert-type items, out of which 48 items assessed each dimension. Numerous researches show that this inventory represents a good operationalization of FFM and is able to assess individual differences on the highest level (Costa \& McCrae, 1995; Larsen \& Buss, 2008; McCrae \& Costa, 
1997; McCrae \& Costa, 1999; McCrae, Terracciano, \& 78 members of the Personality Profiles of Cultures Project, 2005). Also, the instrument had good psychometric characteristics (Knežević et al., 2004; Knežević, Radović, \& Opačić, 1997, Đurić-Jočić et al., 2004).

The observer ratings (ratings by close others) version of the NEO PI R ( $\mathrm{R}$ form) was formulated in the third person, but it was identical to the $\mathrm{S}$ form with respect to content. The subjects' personalities were assessed by persons who knew them very well. S and R form correlated moderately from 0.43-0.60 (Đurić-Jocić et al., 2004). For each subject, two observer ratings were collected; the observers were either their parents or close others of the opposite sex.

The questionnaire had three validity questions (Costa \& McCrae, 2008). It is generally accepted that the balanced items and validity questions are sufficient to control various response tendencies (Costa \& McCrae, 2008).

\subsubsection{Inventory for the Assessment of General Proneness to Psychosis - DELTA10 (S form and R form)}

This instrument was designed for the assessment of basic proneness to psychosis or "disintegration" (Knežević et al., submitted). It consisted of 150 Likert-type items and comprised 10 facets - GEI (general executive dysfunction), PD (perceptive distortions), P (paranoia), D (depression), FA (flattened affect), SOD (somatoform dysfunction), EA (enhanced awareness), MT (magical thinking), M (mania), and SA (social anhedonia). The instrument provided information about each facet and the general score on the trait. For each subject, besides the self-report measures on DELTA 
10, two observer ratings were collected - from their parents or two close persons of opposite sex.

\subsubsection{Short Scale for the Assessment of Basic Personality Traits (SSA-DOCEAN)}

From the attributes selected to represent six personality dimensions in IATs, a short balanced scale was designed (Knežević \& Lazarević, 2011). One hundred and seventy four psychology students (average age 20.47 years, SD=3.02, 140 females and 34 males) gave self-reports on the five-point Likert-type scale for each attribute. Results show that, for the assessment of "big five" personality traits, a short attribute scale has good psychometric properties, as each dimension has a small number of items, and all the attributes are balanced with respect to valence (Knežević \& Lazarević, 2011). The Kayser-Mayer-Olkin (KMO) measure of sampling adequacy ranges from 0.72 (Oattribute) to 0.97 (Eattribute), coefficients of internal consistencies (Cronbach $\alpha$ ) range from 0.67 (Oattribute) to 0.89 (Eattribute and Cattribute), Lord-Kaiser-Caffrey's measure of reliability of the first principal component (L-K-C $\beta$ ) ranges from 0.66 (Oattribute) to 0.89 (Eattribute), while Momirovic's coefficients of homogeneity range from 0.51 (Oattribute) to 0.82 (Eattribute). The data analysis also shows satisfying coefficients of convergent and divergent validity. The correlations of scores on the attribute scale and the NEO PIR and DELTA 10 self-reports are: Neuroticism 0.52 (0.13), Extraversion 0.70 (0.15), Openness 0.52 (0.12), Agreeableness 0.51 (0.24), Conscientiousness $0.64(0.17)$ and Disintegration -0.44 (0.19) (the average scores of absolute values of divergent correlations are displayed in parenthesis). With average observer ratings (observer ratings for males and females were averaged), the patterns of correlations reflect the convergent and divergent validity, although they are 
considerably lower: Neuroticism 0.14 (0.06), Extraversion 0.52 (0.08), Openness 0.31 (0.09), Agreeableness 0.26 (0.15), Consciousness 0.29 (0.12), and Disintegration 0.27 (0.09).

While selecting suitable attributes for Disintegration, words best describing the phenomenon of Disintegration were not chosen due to their extremely negative connotations (e.g., sick, crazy, twisted, etc.). It was thought, and reasonably so, that it would lead to skewed results, since these negative attributes were likely to be found too extreme by the respondents, and therefore difficult to be associated with the category $I$. However, it resulted in slightly lower validity coefficients for Disintegration attributes.

\subsubsection{Battery for the Assessment of Intellectual Abilities KOG9}

The battery for the assessment of intellectual abilities, KOG9, was designed to assess the efficiency of cognitive processing of information, based on the cybernetic model (Wolf et al., 1992). It was designed for an accurate and relatively systematic assessment of the intellectual abilities of adults. It consists of nine subtests, measuring the efficiency of perceptive, serial, and parallel processing (three subtests for each of the abilities). All the tests that form the KOG9 battery originally belonged to other batteries for the assessment of intellectual abilities, but some names of the tests are not identical to their original names.

For the assessment of serial processor (i.e., the assessment of the ability to identify denotative meaning of verbal symbols), the tests AL4, AL7, and GSN were used. AL4 and AL7 originally belonged to Army Alpha that was designed to measure the intellectual abilities of literate subjects in the US (Darley, Glucksberg, S \& Kinchla, 1986; Huffman, Vernoy \& Vernoy, 1994). Test AL4 has 30, and AL7 39 items. GSN is 
from the GVERTOS battery of Ignjatović, Petrović, Vučinić and Bukvić (Ignjatović \& Bukvić, 1966; Lalović, 2000). The designers of the GVERTOS battery claim that this test has good psychometric properties, moderate correlations with other tests, and high correlations with the scale in total, which makes it one of best tests in the whole GVERTOS battery (Ignjatović \& Bukvić, 1966). Test GSN has 39 items and the item content of all the three tests (AL4, AL7 and GSN) shows that they are highly saturated with verbal abilities.

For the assessment of efficiency of the parallel processor (i.e., the ability to deduct spatial relations), tests S1, IT2 and D48 were used. Test IT2 has 39 items and originates from the GATB battery, with its original name being "Three dimensional space" (Sharp \& Pickett, 1959; Pucel \& Nelson, 1969). It is designed for the assessment of general intellectual and spatial abilities. Test S1 is from the SVPN-1 battery designed by Reuchlin and Valin with 30 items, for the assessment of visual spatialization (Wolf et al., 1992). This test also provides a good measure for the eduction factor and the general cognitive factor, and is considered to be the most reliable in the SVPN-1 battery (Wolf et al., 1992). Nonverbal "Domino test-D48" is a 40 item French version of the "domino" test, and was originally designed for the assessment of general intellectual ability (Bele-Potočnik, 1983; Chissom \& Hoenes, 1976; Chissom \& Lightsey, 1971; Colom, Flores-Mendoza, Angeles-Quiroga, \& Privado, 2005; Domino, 2001; Domino \& Morales, 2000; Gough \& Domino, 1963; McLaurin, Pendergrass, \& Kennedy, 1973; Touron, 1983).

For the assessment of efficiency of the perceptive processor (i.e., the assessment of perceptive identification and discrimination), tests IT1, CF2, and GT7 were used. "Tool matching" (IT1) and "Form matching" (GT7) come from the General Aptitude 
Test Battery - GATB) of Dvorak, and are designed for the assessment of the perception of form (Bukvić, Štajberger, \& Dragićević, 1976; Pucel \& Nelson, 1969; Wolf et al., 1992). Test IT1 has 39 items, and GT7 60 items. Test CF2 was designed by Therston and Gotschald. It has 200 items and belongs to the group of the "Tests of hidden figures" (Wolf et al., 1992). A research on a large sample of Serbian respondents $(\mathrm{N}=1116)$ regarding the factor structure of the battery has shown that it is consistent with the theoretical assumptions, and provides a good assessment of the intellectual abilities (Lazarević \& Knežević, 2008).

\subsubsection{Self-assessment of Intellectual Abilities}

Besides the objective assessment of intellectual abilities with KOG9, the subjects had to provide self-assessment of their abilities. On a scale ranging from 1 to 7 , the subjects had to compare their achievements on the tests of cognitive abilities with those of other psychology students in their school generation (Appendix 1).

\subsubsection{Visibility of Traits (Self-reported)}

The visibility of a trait is assessed on the instrument TSPROC (Appendix 2). The subjects assess the visibility of each trait on a five point scale.

\subsubsection{Consistency of Traits (Subjective and Objective Measures)}

The subjective measure of the consistency of each trait was a self-assessment of consistency on a five-point scale, on the instrument TSPROC (Appendix 2). 
The objective measure of consistency is calculated by multiplying the standard deviation of S scores on the Adjective Scale (OCEAN adjectives), two observer ratings scores ( $\mathrm{R}$ scores), and cross situational stability of trait and self-report score (e.g., Nobj=zNF, zNM, zN $\left.\mathrm{SSA}_{\mathrm{Z}}, \mathrm{ZTS}_{\mathrm{PROC}}\right)$.

\subsubsection{Ipsatized S Measures}

Ipsatized $\mathrm{S}$ measures are calculated as the deviations of scores for each trait from the average scores on all six traits $(\mathrm{N}, \mathrm{E}, \mathrm{O}, \mathrm{A}, \mathrm{C}, \mathrm{D})$, divided by the standard deviations of the scores for all six traits.

\subsubsection{Behavioural Observation (Ratings by Experts)}

In order to collect behavioural data related to the basic personality dimensions, a sub sample of 99 respondents was assessed through structured interviews. The outline of the interview, and almost all parts of it, were taken from Back et al. (2009) with due permission (Table 5). However, certain segments were adapted to this research (e.g., the concentration test, and the construction of indicators for Disintegration trait).

Because of the advisability of administering a concentration test, as content and task demands usually provoke a certain level of anxiety in the observation situation, it was decided to use Digit Span from WAIS-IV (Wechsler, 2008). This test is designed to assess the attention, concentration and mental control. 
Table 5 Description of segments of structured interview for behavioural observation

\begin{tabular}{|c|c|c|}
\hline Segment & Brief description & Time \\
\hline Reception of the respondent & Welcome note & $1 \mathrm{~min}$ \\
\hline Small talk & $\begin{array}{l}\text { General introductory questions about subject (e.g. name, } \\
\text { studies, general impression about studies) }\end{array}$ & $2 \mathrm{mins}$ \\
\hline $\begin{array}{c}\text { IAT assessing } 7 \text { personality } \\
\text { dimensions }(\mathrm{N}, \mathrm{E}, \mathrm{O}, \mathrm{A}, \mathrm{C}, \mathrm{D}, \mathrm{I})\end{array}$ & Respondent is completing IAT & 40 mins \\
\hline Self-introduction (SI) & $\begin{array}{l}\text { Participants introduce themselves (interests, hobbies, } \\
\text { etc.) }\end{array}$ & 4 mins \\
\hline Vision of the future (VF) & $\begin{array}{l}\text { Participants describe how they see themselves and the } \\
\text { world in } 15 \text { years }\end{array}$ & 3 mins \\
\hline Concentration test & Administration of Digit Span (WAIS-IV) & $7 \mathrm{mins}$ \\
\hline Brick-pantomime & $\begin{array}{l}\text { Participants think about the possible usage of a brick } \\
\text { and present ideas in the form of pantomime }\end{array}$ & 3 mins \\
\hline Short story & $\begin{array}{l}\text { Participants had to write short story in which they use } \\
\text { following words: air crash, chambermaid, middle ages, } \\
\text { fireworks and supermarket }\end{array}$ & 7 mins \\
\hline Knowledge test & $\begin{array}{l}\text { General knowledge test consisted of } 19 \text { multiple choice } \\
\text { format questions and } 7 \text { open-ended questions. }\end{array}$ & 10 mins \\
\hline Waiting situation & Participants were left alone in experimental room & 2 mins \\
\hline Helping situation & $\begin{array}{l}\text { Participants were asked to help the experimenters "to } \\
\text { prepare another experiment" by distributing some } \\
\text { materials (e.g. papers, pencils, erasers) equally. }\end{array}$ & 3 mins \\
\hline Returning the questionnaire & $\begin{array}{c}\text { Participants were given a specially designed } \\
\text { questionnaire (in a form of debriefing) with explicit } \\
\text { instruction to return it to next lecture of Individual } \\
\text { differences course. }\end{array}$ & X days \\
\hline
\end{tabular}

For each of the basic personality dimensions, a number of behavioural criteria were defined a priori. For the basic personality traits from FFM, the conceptual descriptions of the big five dimensions from Back et al. (2010), and the results of previous researches on behavioural personality correlates were referred to, and a list of indicators for each of the dimensions was prepared. For Disintegration, the theoretical framework of Knežević et al. (submitted) was adopted, and a list of the behavioural indicators applicable to the tasks in the interview was prepared. In addition to various indicators rated by four experts, the number of objectively measured criteria (e.g., the delay in attendance or in returning the questionnaire, the number of errors in the short 
story, etc.), the Linguistic Inquiry and the Word Count for automatic text analysis was applied (LIWC; Pennebaker et al., 2007) (Table 6).

Table 6 Behavioural indicators for assessment of big six personality traits

\begin{tabular}{|c|c|c|c|}
\hline Item & $\begin{array}{l}\text { Typical behavioural } \\
\text { aspects }\end{array}$ & Behavioural criteria & Rating \\
\hline \multicolumn{4}{|c|}{ Neuroticism } \\
\hline \multirow{13}{*}{$\begin{array}{l}\text { Anxious, } \\
\text { nervous, fearful, } \\
\text { uncertain, afraid; } \\
\text { calm, relaxed, } \\
\text { restful, at ease, } \\
\text { balanced }\end{array}$} & \multirow{13}{*}{$\begin{array}{c}\text { Nonverbal } \\
\text { nervousness, verbal } \\
\text { uncertainty, } \\
\text { negative self-view } \\
\text { mentioned }\end{array}$} & Global behaviour SI (rating) & 12345 \\
\hline & & Global behaviour vision of the future (rating) & 12345 \\
\hline & & Global transcript SI (rating) & 12345 \\
\hline & & Gaze aversion SI (counting) & 12345 \\
\hline & & Tense body posture SI (rating) & 12345 \\
\hline & & Tense leg posture SI (rating) & 12345 \\
\hline & & Silence during SI (rating) & 12345 \\
\hline & & $\begin{array}{l}\text { Reassuring whether cell phone is switched off } \\
\text { (yes/no) }\end{array}$ & 12 \\
\hline & & $\begin{array}{c}\text { Reassuring questions in helping situation } \\
\text { (counting) }\end{array}$ & \\
\hline & & $\begin{array}{l}\text { Reassuring questions in other situations } \\
\text { (counting) }\end{array}$ & \\
\hline & & Disfluency of speech SI (filler words, LIWC) & \\
\hline & & Negations SI (LIWC) & \\
\hline & & $\begin{array}{l}\text { Words related to anxiety and depression SI } \\
\text { (LIWC) }\end{array}$ & \\
\hline \multicolumn{4}{|c|}{ Extraversion } \\
\hline \multirow{12}{*}{$\begin{array}{c}\text { Sociable, } \\
\text { talkative, active, } \\
\text { impulsive, } \\
\text { outgoing; shy, } \\
\text { reticent, passive, } \\
\text { deliberate, } \\
\text { reserved }\end{array}$} & \multirow{12}{*}{$\begin{array}{c}\text { Expressive } \\
\text { nonverbal and } \\
\text { verbal behaviour; } \\
\text { impulsive } \\
\text { behaviour; social } \\
\text { contact sought; } \\
\text { showy appearance }\end{array}$} & Global behaviour SI (rating) & 12345 \\
\hline & & Global behaviour vision of the future (rating) & 12345 \\
\hline & & Global transcript SI (rating) & 12345 \\
\hline & & Expressivity of facial expression SI (rating) & 12345 \\
\hline & & Loudness of voice SI (rating) & 12345 \\
\hline & & Stylish dress (rating) & 12345 \\
\hline & & Flashy dress (rating) & 12345 \\
\hline & & Number of words SI (LIWC) & \\
\hline & & False alarms in concentration test (counting) & \\
\hline & & Own questions during small talk (counting) & \\
\hline & & Second-person pronouns SI (LIWC) & \\
\hline & & Other references SI (LIWC) & \\
\hline
\end{tabular}




\begin{tabular}{|c|c|c|c|}
\hline \multicolumn{4}{|c|}{ Openness } \\
\hline \multirow{9}{*}{$\begin{array}{l}\text { Imaginative, } \\
\text { civilized, well- } \\
\text { educated, } \\
\text { interested, gifted; } \\
\text { unimaginative, } \\
\text { primitive, } \\
\text { uneducated, } \\
\text { indifferent, } \\
\text { limited }\end{array}$} & \multirow{9}{*}{$\begin{array}{c}\text { Intellectual } \\
\text { competence; } \\
\text { creative and } \\
\text { original ideas; } \\
\text { openness to unusual } \\
\text { situations }\end{array}$} & Global short story (rating) & 12345 \\
\hline & & Global transcript SI (rating) & 12345 \\
\hline & & Verbal eloquence SI (rating) & 12345 \\
\hline & & Open answers in small-talk situation (rating) & 12345 \\
\hline & & $\begin{array}{l}\text { General knowledge (test) - multiple choice } \\
\text { questions }\end{array}$ & \\
\hline & & General knowledge (test) - open-ended questions & \\
\hline & & Original and unusual brick categories (counting) & \\
\hline & & Pantomime-originality (rating) & 12345 \\
\hline & & Number of words in short story (LIWC) & \\
\hline \multicolumn{4}{|c|}{ Agreeableness } \\
\hline \multirow{12}{*}{$\begin{array}{l}\text { Trusting, well- } \\
\text { meaning, } \\
\text { friendly, helpful, } \\
\text { good-natured; } \\
\text { obstinate, } \\
\text { quarrelsome, } \\
\text { hostile, hard- } \\
\text { hearted, resentful }\end{array}$} & \multirow{12}{*}{$\begin{array}{c}\text { Helpfulness; } \\
\text { friendly and trustful } \\
\text { nonverbal and } \\
\text { verbal behaviour; } \\
\text { compliant } \\
\text { behaviour; non } \\
\text { aggressiveness; } \\
\text { social and selfless } \\
\text { orientation } \\
\text { mentioned }\end{array}$} & Global behaviour in helping situation (rating) & 12345 \\
\hline & & Global transcript SI (rating) & 12345 \\
\hline & & Quality of help (counting) & \\
\hline & & Friendly voice in helping situation (rating) & 12345 \\
\hline & & Friendly voice in small talk (rating) & 12345 \\
\hline & & Attentive body posture in small talk (rating) & 12345 \\
\hline & & Checking out room in waiting situation (rating) & 12345 \\
\hline & & $\begin{array}{c}\text { Aggressive-destructive brick categories } \\
\text { (counting) }\end{array}$ & \\
\hline & & Number of swear words SI (LIWC) objective & \\
\hline & & $\begin{array}{l}\text { Relative frequency of other vs. self-words SI } \\
\text { (LIWC) }\end{array}$ & \\
\hline & & Words related to social processes SI (LIWC) & \\
\hline & & Words related to family SI (LIWC) & \\
\hline \multicolumn{4}{|c|}{ Conscientiousness } \\
\hline \multirow{8}{*}{$\begin{array}{l}\text { Meticulous, } \\
\text { reliable, neat, } \\
\text { fussy, thorough; } \\
\text { careless, } \\
\text { unreliable, } \\
\text { chaotic, frivolous, } \\
\text { erratic }\end{array}$} & \multirow{8}{*}{$\begin{array}{c}\text { Common } \\
\text { arrangements } \\
\text { adhered to; } \\
\text { linguistic } \\
\text { correctness; } \\
\text { erroneous } \\
\text { behaviour avoided; } \\
\text { formal dress and } \\
\text { appearance }\end{array}$} & Global transcript SI (rating) & 12345 \\
\hline & & Understandability in small talk (rating) & 12345 \\
\hline & & Slouching body posture SI (rating) & 12345 \\
\hline & & Formal dress (rating) & 12345 \\
\hline & & $\begin{array}{l}\text { Minutes too late in attending experiment } \\
\text { (counting) }\end{array}$ & \\
\hline & & $\begin{array}{c}\text { Lateness in sending back questionnaire } \\
\text { (counting) }\end{array}$ & \\
\hline & & Number of errors in short story (counting) & \\
\hline & & $\begin{array}{l}\text { Number of errors in concentration test } \\
\text { (counting) }\end{array}$ & \\
\hline
\end{tabular}




\begin{tabular}{|c|c|c|c|}
\hline \multicolumn{4}{|c|}{ Disintegration } \\
\hline \multirow{15}{*}{$\begin{array}{l}\text { Normal, adapted, } \\
\text { ordinary, } \\
\text { balanced, } \\
\text { collected; twisted, } \\
\text { dark, weird, } \\
\text { wacky, deluded }\end{array}$} & \multirow{15}{*}{$\begin{array}{l}\text { Concentration, low } \\
\text { memory, low level } \\
\text { of abstraction, } \\
\text { proneness to } \\
\text { concrete thinking; } \\
\text { bizarre; distant; } \\
\text { paranoid; } \\
\text { despondent; organic } \\
\text { dysfunctions; } \\
\text { apathetic; flattened } \\
\text { affect; alienated; } \\
\text { manic; agitated; } \\
\text { tense; haggard; } \\
\text { unusual } \\
\text { associations; } \\
\text { superstitious; } \\
\text { inadequacy of facial } \\
\text { expression, mimic } \\
\text { and emotions; } \\
\text { tremor; bizarre } \\
\text { complaints and } \\
\text { comments. }\end{array}$} & Global behaviour SI (rating) & 12345 \\
\hline & & Global behaviour vision of the future (rating) & 12345 \\
\hline & & Global transcript SI (rating) & 12345 \\
\hline & & Facial expression - inadequacy (rating) & 12345 \\
\hline & & Body posture (rating) & 12345 \\
\hline & & Appearance- squalor, bizarreness (rating) & 12345 \\
\hline & & Pantomime - bizarreness (rating) & 12345 \\
\hline & & Helping situation (rating) & 12345 \\
\hline & & Depression - short story (rating) & 12345 \\
\hline & & Coherence - short story (rating) & 12345 \\
\hline & & Perseverance - short story (rating) & 12345 \\
\hline & & $\begin{array}{l}\text { Concentration test (discrepancy of scores higher } \\
\text { than } 2 \text {; longest string repeated shorter than 5) - } \\
\text { counting }\end{array}$ & \\
\hline & & $\begin{array}{l}\text { Short story (LIWC - total number of words, } \\
\text { content - inhibition, negative emotions, number } \\
\text { of errors in short story) }\end{array}$ & \\
\hline & & Negative emotions (anger, depression) (LIWC) & \\
\hline & & Cognitive processes (inhibitions) (LIWC) & \\
\hline
\end{tabular}

After the interview, the subjects had to complete a questionnaire regarding their impression about the interview and return it the next week (Table 7). The questionnaire consisted of 30 adjectives, of both positive and negative valence. 
Table 7 Questionnaire in the form of debriefing for assessment of interview

\begin{tabular}{|c|c|c|c|c|c|}
\hline No. & Attributes & Rating & No. & Attributes & Rating \\
\hline 1 & $\begin{array}{l}\text { Challenging } \\
\text { (Izazovno) }\end{array}$ & 12345678910 & 16 & $\begin{array}{c}\text { Disturbing } \\
\text { (Uznemirujuće) }\end{array}$ & 12345678910 \\
\hline 2 & $\begin{array}{c}\text { Unpleasant } \\
\text { (Neprijatno) }\end{array}$ & 12345678910 & 17 & $\begin{array}{c}\text { Safe } \\
(\text { Sigurno })\end{array}$ & 12345678910 \\
\hline 3 & $\begin{array}{l}\text { Motivating } \\
\text { (Motivišuće) }\end{array}$ & 12345678910 & 18 & $\begin{array}{c}\text { Pointless } \\
\text { (Besmisleno) }\end{array}$ & 12345678910 \\
\hline 4 & $\begin{array}{c}\text { Bad } \\
(\text { Loše })\end{array}$ & 12345678910 & 19 & $\begin{array}{c}\text { Useful } \\
\text { (Korisno) }\end{array}$ & 12345678910 \\
\hline 5 & $\begin{array}{l}\text { Attractive } \\
\text { (Privlačno) }\end{array}$ & 12345678910 & 20 & $\begin{array}{c}\text { Unexpected } \\
\text { (Neočekivano) }\end{array}$ & 12345678910 \\
\hline 6 & $\begin{array}{c}\text { Useless } \\
\text { (Nekorisno) }\end{array}$ & 12345678910 & 21 & $\begin{array}{c}\text { Inspiring } \\
\text { (Inspirativno) }\end{array}$ & 12345678910 \\
\hline 7 & $\begin{array}{l}\text { Necessary } \\
\text { (Potrebno) }\end{array}$ & 12345678910 & 22 & $\begin{array}{c}\text { Dangerous } \\
\text { (Opasno) }\end{array}$ & 12345678910 \\
\hline 8 & $\begin{array}{c}\text { Boring } \\
\text { (Dosadno) }\end{array}$ & 12345678910 & 23 & $\begin{array}{c}\text { Understandable } \\
\text { (Razumljivo) }\end{array}$ & 12345678910 \\
\hline 9 & $\begin{array}{l}\text { Stimulating } \\
\text { (Podsticajno) }\end{array}$ & 12345678910 & 24 & $\begin{array}{c}\text { Frustrating } \\
\text { (Frustrirajuće) }\end{array}$ & 12345678910 \\
\hline 10 & $\begin{array}{c}\text { Negative } \\
\text { (Negativno) }\end{array}$ & 12345678910 & 25 & $\begin{array}{c}\text { Original } \\
\text { (Originalno) }\end{array}$ & 12345678910 \\
\hline 11 & $\begin{array}{c}\text { Clear } \\
\text { (Jasno) }\end{array}$ & 12345678910 & 26 & $\begin{array}{c}\text { Tiring } \\
\text { (Zamorno) }\end{array}$ & 12345678910 \\
\hline 12 & $\begin{array}{l}\text { Undesirable } \\
\text { (Nepoželjno) }\end{array}$ & 12345678910 & 27 & $\begin{array}{l}\text { Complex } \\
\text { (Složeno) }\end{array}$ & 12345678910 \\
\hline 13 & $\begin{array}{l}\text { Informative } \\
\text { (Informativno) }\end{array}$ & 12345678910 & 28 & $\begin{array}{c}\text { Intrusive } \\
\text { (Intruzivno) }\end{array}$ & 12345678910 \\
\hline 14 & $\begin{array}{l}\text { Repulsive } \\
\text { (Odbojno) }\end{array}$ & 12345678910 & 29 & $\begin{array}{c}\text { Important } \\
\text { (Bitno) }\end{array}$ & 12345678910 \\
\hline 15 & $\begin{array}{c}\text { Usable } \\
\text { (Upotrebljivo) }\end{array}$ & 12345678910 & 30 & $\begin{array}{c}\text { Scary } \\
\text { (Strašno) }\end{array}$ & 12345678910 \\
\hline
\end{tabular}

Note: In parentheses are provided original attributes in Serbian.

Since the results of the analysis of this debriefing questionnaire were not in the primary focus and were not related to the objective of this study, they will not be discussed any further.

\subsection{Language Composition in LIWC}

\subsubsection{Transcription and Linguistic Analysis}

In addition to video recording, the research assistants also transcribed all of the respondents' verbal output during the interviews (the research assistants had received 
special training prior to the interviews on handling ambiguities, (e.g., fillers, nonfluencies, slang, etc.). After this, all the transcripts were translated into English by a person fluent in both English and Serbian and then submitted for a linguistic analysis using Linguistic Inquiry and Word Count (LIWC) (Pennebaker et al., 2007). This software enables text analysis by comparing all the words of a text with an internal dictionary. Words in LIWC 2007 dictionary are arranged according to various grammatical and psychological categories. LIWC output provides information on 80 categories - 4 general descriptor categories (total number of words, mean number of words per sentence, percentage of words longer than six letters, percentage of words captured by LIWC dictionary), 22 linguistic categories (percentage of pronouns broken down separately by first, second and third person, articles, auxiliary verbs, etc.), 32 word categories tapping psychological constructs (e.g., affect, cognition, biological processes), 7 personal concern categories (e.g., work, home, leisure activities), 3 paralinguistic categories (assents, fillers, non-fluencies), and 12 punctuation categories (periods, commas, etc.). Linguistic dimensions associated with the psychological processes tap the emotional, cognitive, social and sensory aspects (Pennebaker \& King, 1999; Pennebaker et al., 2007).

The Affective processes category comprised positive emotions (i.e., a broad spectrum of positive feelings, and positive valence words), negative emotions (i.e., a variety of negative feelings, and negative valence words), anxiety (e.g., worried, fearful, etc.), sadness (e.g., sad, grief, etc.) and anger (e.g., hate, kill, etc.).

The group of categories Social processes included references to other people through communication, use of pronouns (except first person pronouns) and references to family, friends and other human beings. 
The Cognitive processes captured words that tapped active thinking (e.g., insight or self-reflection, and causation) which, taken together, are found to be related to the mental and physical health. In addition, this dimension included discrepancy category (e.g., should, would, could, etc.), inhibition (e.g., block, constrain, etc.), tentative (e.g., maybe, perhaps, guess, etc.), certainty (e.g., always, never, absolute, etc.), inclusive (e.g., and, with, include, etc.) and exclusive (e.g., but, without, exclude, etc.).

The group of categories Perceptual processes refers to the extent to which people use words related to various perceptive processes (e.g., visual, auditory, tactile etc.). Current concerns in it relate to various topics, such as work, leisure, money, metaphysical issues (e.g., religion and death), physical states (e.g., body, health, sexuality, ingestion) (Pennebaker \& King, 1999; Pennebaker et al., 2007).

Pennebaker \& King (1999) were interested in the stability of results obtained with LIWC and questioned whether the language people use was consistent throughout their multiple writing samples. In three reliability studies, they showed that the language used is a reliable indicator of individual differences. Besides good results on reliability, the factor structure of LIWC has been tested, and results show that all the categories in it group into four factors with satisfactory congruence coefficients:

- Immediacy (including first-person singular words, articles, long words, present tense, and discrepancies);

- Making distinctions (including exclusive words, negations, and inclusion words);

- Social Past (including past tense words and social reference); 
- Rationalization (including causation words, insight words, and negative emotion words).

Regarding validity studies, the research revealed that all extracted factors related, to some extent, to certain personality characteristics. The Immediacy factor was negatively correlated with Openness to experience, while Making distinctions was positively correlated with Introversion and negatively with Conscientiousness (Pennebaker \& King, 1999).

\subsection{Data Analysis - Algorithms for Data Analysis}

1. Algorithms for preliminary data transformation - standardization of data obtained through several assessment methods, in order to extract maximum information while applying multivariate statistical methods;

2. Algorithms for calculation of $\mathrm{D}$ measure in Implicit Association Test (Greenwald et al., 2003)

3. Algorithms for calculation of psychometric properties RTT10G (Knežević \& Momirović, 1996). This programme, among other measures, provides:

a) Kaiser-Mayer-Olkin measure of representativeness - KMO,

b) Cronbach alpha measure of internal consistency - Cronbach $\alpha$,

c) Lord-Kaiser-Caffrey's measure of reliability of first principal component $-\beta$,

d) Momirovic's measure of homogeneity $-\mathrm{h} 2^{6}$;

\footnotetext{
${ }^{5}$ Detailed description of all steps in calculation of D measure is provided in the subsequent section Implicit measures - Computation of D Measure

${ }^{6}$ Size of the first eigenvalue, extracted on the image (Guttman) of the variables, divided by the number of variables.
} 
4. Algorithms of multivariate statistics:

a) Linear correlation analysis (for calculation of relations among variables),

b) Linear regression analysis (for calculation of relations between implicit and corresponding explicit measures),

c) Exploratory factor analysis (for exploration of latent structures in applied tests and inventories),

d) Structural equation modeling (for exploration of relationship between measures obtained through all applied assessment methods and latent factors).

\subsubsection{Implicit Measures - Computation of D Measure (IAT scores/IAT effect)}

The implicit measure (the relative strength of association of attributes and concepts) is based on latency measures, and is called IAT effect or D measure (Greenwald et al., 2003). The implicit data in this research were treated as per Greenwald et al. (2003) improved scoring algorithm:

1. Compute the standard deviations of all trials in the third and sixth blocks, and the standard deviations of all trials in the fourth and seventh block: (SD3,6) and $(\mathrm{SD} 4,7)$

2. Compute the means of trials in the third, fourth, sixth and seventh block: M6, M3, M7, and M4;

3. Compute the differences of means of the sixth and third (M6 - M3), and of the seventh and fourth blocks (M7 - M4); 
4. Compute: Diff1=(M6 - M3)/ (SD3,6) and Diff2=(M7 - M4)/(SD4,7));

5. $\quad$ D measure $=$ Mean $($ Diff1, 2*Diff2).

In other words, the IAT effect is a measure of the strength of associations between target concepts in two tasks of combined categorization (evaluative compatible combination, e.g., I-Stable, Others-Unstable, and evaluative incompatible combination e.g., I-Unstable, Others-Stable) (Schmukle \& Egloff, 2005). The size of difference in RT between easy (i.e., compatible or congruent) and difficult (i.e., incongruent or incompatible) tasks indicates individual differences in connections between the nodes of associative nets (Steffens \& Plewe, 2001). D measures with the value 0 , indicate that the strength of associations between one category and a certain concept or attribute is equal to the strength of association of other categories and certain concepts or attributes. In other words, in this case, the subject does not prefer either of the combination of paired categories. The positive values of $\mathrm{D}$ measure indicate a faster sorting speed in compatible tasks, and a positive association between the self and positive attributes (i.e., the average response latency is shorter when the dimension representing self is combined with the positive pole of attribute category).

However, since D measure is based on reaction time (RT) or response latency, it gives rise to some important questions, e.g., (a) how to treat the reaction times when the respondents make errors, and (b) how to treat the extreme values in reaction times. Greenwald et al. (2003) showed that stronger and "more precise" IAT effects are obtained when the corrected RTs are included (i.e., when the RTs on error trials are included in the calculation of D measure) (Greenwald et al., 2003). When calculated this way, the D measure enables researchers to grasp the individual differences on the strength of associations, and not on some other confounding variables. Thus, scholars 
have pointed out that more errors in responses (i.e., in categorization of stimuli) occur if the stimuli-pairs (category-attribute) are more incongruent with the explicit selfassociations.

Consistent with this, by discarding error trials, the difference in the mean reaction time in incongruent pairs of stimuli is lower and, consequently, the IAT effect is weaker. Greenwald et al. (2003) propose two possible procedures for the correction of error response latencies. First, it is possible to change error trials by taking the sum of the average RTs for a respondent for a block, and two SDs for that respondent for that block. Another option is to change error trials by taking the sum of the average RTs for a respondent for a block with $600 \mathrm{~ms}$ penalty. Besides error treatment, they propose that all response latencies longer than $10000 \mathrm{~ms}$ should be discarded from future analysis. In addition, those respondents who respond faster than $300 \mathrm{~ms}$ in more than $10 \%$ of all trials should be excluded from further analysis. 


\section{RESULTS}

Research was divided in two phases. In the preliminary phase, the attributes list (i.e., the stimuli for IAT) was constructed, the PSIHO software for stimuli presentation was developed and tested, and research assistants were trained for behavioural observation.

The second phase of the research consisted of two parts of data analysis. The first part was related to data analysis on the larger sample of 224 subjects in which the implicit measures, self-report ratings, and ratings by close others were collected. In the second part, all the analyses were performed on a sub-sample of 99 subjects whereby, besides all the previously mentioned data, behavioural ratings by expert observers were collected (behaviour was observed in structured interview).

\subsection{First Research Phase}

\subsubsection{Results of Exploratory Factor Analyses (EFA) for Selection of IAT Stimuli}

Based on the results of the Principal Component Analysis (PCA) for each of the six personality dimensions, the final selection of the stimuli for IAT was made. Selected attributes were balanced with respect to the numbers of positive and negative. In addition, wherever possible, the negation of positive attributes was avoided in order to avoid the strategy of automatic sorting of attributes beginning with "un" or "in" in the same category.

First, six factors were extracted in the PCA. However, this solution was not completely satisfying. The factors representing Extraversion (first), Conscientiousness 
(second) and Agreeableness (third) had clear loadings, but the rest of the factors were not that clear. For example, the attributes selected to represent Disintegration factor merged with the items belonging to Openness factor while, in the case of the fifth factor (Neuroticism), two adjectives (out of 10) were not loaded as expected (Table 8).

Table 8 Pattern matrix - PCA with Promax rotation with Kaiser Normalization -6 factor solution

\begin{tabular}{|c|c|c|c|c|c|c|}
\hline \multirow{2}{*}{ Item } & \multicolumn{6}{|c|}{ Component } \\
\hline & 1 & 2 & 3 & 4 & 5 & 6 \\
\hline Withdrawn (Povučen) & .838 & & & & & \\
\hline Quiet (Tih) & .791 & & & & & \\
\hline Shy (Stidljiv) & .791 & & & & & \\
\hline Passive (Pasivan) & .723 & & & & & \\
\hline Closed (Zatvoren) & .702 & & & & & \\
\hline Vivacious (Živahan) & .626 & & & & & \\
\hline Talkative (Pričljiv) & .615 & & & & & \\
\hline Friendly (Druželjubiv) & .587 & & & & & \\
\hline Happy (Veseo) & .488 & & & & & \\
\hline Cheerful (Vedar) & .480 & & & & & \\
\hline Disorganised (Neorganizovan) & & .852 & & & & \\
\hline Lazy (Lenj) & & .713 & & & & \\
\hline Irresponsible (Neodgovoran) & & .704 & & & & \\
\hline Responsible (Odgovoran) & & .696 & & & & \\
\hline Careless (Nemaran) & & .660 & & & & \\
\hline Inefficient (Neefikasan) & & .641 & & & & \\
\hline Disciplined (Disciplinovan) & & .631 & & & & \\
\hline Efficient (Efikasan) & & .608 & & & & \\
\hline Systematic (Sistematičan) & & .560 & & & & \\
\hline Practical (Praktičan) & & -.398 & & & & \\
\hline Unintrospective (Neintrospektivan) & & .324 & & & & \\
\hline Benign (Dobroćudan) & & & .790 & & & \\
\hline Well-intentioned (Dobronameran) & & & .736 & & & \\
\hline Sympathetic (Saosećajan) & & & .726 & & & \\
\hline Insensitive (Bezosećajan) & & & .700 & & & \\
\hline Cold (Hladan) & & & .659 & & & \\
\hline Undiscerning (Neuviđavan) & & & .634 & & & \\
\hline Malicious (Zlonameran) & & & .628 & & & \\
\hline Generous (Velikodušan) & & & .611 & & & \\
\hline Devout (Veran) & & & .521 & & & \\
\hline Volatile (Nepostojan) & & & .398 & & & \\
\hline Creative (Kreativan) & & & & .696 & & \\
\hline Twisted (Uvrnut) & & & & .695 & & \\
\hline Imaginative (Maštovit) & & & & .674 & & \\
\hline Weird (Čudan) & & & & .641 & & \\
\hline Curious (Radoznao) & & & & .528 & & \\
\hline Enthralled (Zanesen) & & & & .519 & & \\
\hline Ordinary (Običan) & & & & -.513 & & \\
\hline Complex (Kompleksan) & & & & .486 & & \\
\hline Dark (Mračan) & & & & .477 & & \\
\hline Wacky (Ćaknut) & & & & .477 & & \\
\hline
\end{tabular}




\begin{tabular}{|c|c|c|c|c|c|c|}
\hline \multirow{2}{*}{ Item } & \multicolumn{5}{|c|}{ Component } \\
\cline { 2 - 6 } & 1 & 2 & 3 & 4 & 5 & 6 \\
\hline Normal (Normalan) & & & & -.451 & & \\
\hline Philosophising (Filozofirajući) & & & & .394 & & \\
\hline Traditional (Tradicionalan) & & & & .358 & & \\
\hline Adapted (Adaptiran) & & & & -.324 & & \\
\hline Conventional (Konvencionalan) & & & & .239 & & \\
\hline Calm (Smiren) & & & & & .727 & \\
\hline Tense (Napet) & & & & & .687 & \\
\hline Relaxed (Relaksiran) & & & & & .678 & \\
\hline Nervous (Nervozan) & & & & & .676 & \\
\hline Worried (Zabrinut) & & & & & .626 & \\
\hline Serene (Spokojan) & & & & & .586 & \\
\hline Balanced (Uravnotežen) & & & & & .459 & \\
\hline Quarrelsome (Svadljiv) & & & & & & -.515 \\
\hline Stubborn (Tvrdoglav) & & & & & & .459 \\
\hline Tough (Čvrst) & & & & & & .449 \\
\hline Decisive (Odlučan) & & & & & & .415 \\
\hline Collected (Skockan) & & & & & & -.298 \\
\hline Dogmatic (Dogmatičan) & & & & & & \\
\hline (n) & & & & & \\
\hline
\end{tabular}

Note: In parentheses are provided attributes in Serbian

The impurities found in the six-factor solution suggested testing five-factor solution without Disintegration attributes, and it proved to be more satisfying. The five extracted factors in the Principal Component Analysis explained 46.52\% of variance. Almost all the adjectives had clear loadings on the corresponding factors (only Practical had primary loading on Conscientiousness instead of Openness factor, and Relaxed on Introversion instead of Neuroticism). The first extracted factor was interpreted as Extraversion in which all the attributes had satisfying loadings. The second factor was saturated with adjectives describing Conscientiousness. On the third factor, the highest loadings had attributes describing Agreeableness, the fourth was saturated with Neuroticism attributes, while the fifth was described with Openness attributes (Table 9). 
Table 9 Pattern matrix - PCA with Promax rotation with Kaiser Normalization -5 factor solution

\begin{tabular}{|c|c|c|c|c|c|}
\hline \multirow{2}{*}{ Item } & \multicolumn{5}{|c|}{ Component } \\
\hline & 1 & 2 & 3 & 4 & 5 \\
\hline Withdrawn (Povučen) & .829 & & & & \\
\hline Shy (Stidljiv) & .788 & & & & \\
\hline Quiet (Tih) & .766 & & & & \\
\hline Closed (Zatvoren) & .726 & & & & \\
\hline Passive (Pasivan) & .724 & & & & \\
\hline Vivacious (Živahan) & -.661 & & & & \\
\hline Talkative (Pričljiv) & -.650 & & & & \\
\hline Friendly (Druželjubiv) & -.598 & & & & \\
\hline Happy (Veseo) & -.557 & & & & \\
\hline Cheerful (Vedar) & -.536 & & & & \\
\hline Relaxed (Opušten) & -.457 & & & .430 & \\
\hline Organised (Organizovan) & & .868 & & & \\
\hline Disorganised (Neorganizovan) & & -.849 & & & \\
\hline Irresponsible (Neodgovoran) & & -.729 & & & \\
\hline Disciplined (Disciplinovan) & & .711 & & & \\
\hline Responsible (Odgovoran) & & .711 & & & \\
\hline Lazy (Lenj) & & -.692 & & & \\
\hline Systematic (Sistematičan) & & .673 & & & \\
\hline Inefficient (Neefikasan) & & -.579 & & & \\
\hline Efficient (Efikasan) & & .569 & & & \\
\hline Careless (Nemaran) & & -.563 & & & \\
\hline Practical (Praktičan) & & .498 & & & \\
\hline Benign (Dobroćudan) & & & .804 & & \\
\hline Sympathetic (Saosećajan) & & & .721 & & \\
\hline Well-intentioned (Dobronameran) & & & .707 & & \\
\hline Insensitive (Bezosećajan) & & & -.643 & & \\
\hline Generous (Velikodušan) & & & .629 & & \\
\hline Malicious (Zlonameran) & & & -.577 & & \\
\hline Undiscerning (Neuviđavan) & & & -.572 & & \\
\hline Faithful (Veran) & & & .567 & & \\
\hline Cold/reserved (Hladan) & & & -.549 & & \\
\hline Volatile(Nepostojan) & & & -.431 & & \\
\hline Tense (Napet) & & & & -.709 & \\
\hline Calm (Smiren) & & & & .699 & \\
\hline Nervous (Nervozan) & & & & -.690 & \\
\hline Serene (Spokojan) & & & & .646 & \\
\hline Relaxed (Relaksiran) & & & & .621 & \\
\hline Worried (Zabrinut) & & & & -.591 & \\
\hline Quarrelsome (Svadljiv) & & & & -.521 & \\
\hline Balanced (Uravnotežen) & & & & .503 & \\
\hline Stubborn (Tvrdoglav) & & & & -.477 & \\
\hline Creative (Kreativan) & & & & & -.675 \\
\hline Imaginative (Maštovit) & & & & & -.674 \\
\hline Traditional (Tradicionalan) & & & & & .513 \\
\hline Unintrospective (Neintrospektivan) & & & & & .458 \\
\hline Curious (Radoznao) & & & & & -.445 \\
\hline Philosophical (Filozofirajući) & & & & & -.438 \\
\hline Complex (Kompleksan) & & & & & -.426 \\
\hline Dogmatic (Dogmatičan) & & & & & .409 \\
\hline Conventional (Konvencionalan) & & & & & .347 \\
\hline
\end{tabular}

Note: In parentheses are provided original attributes in Serbian. 
The choice of the attribute markers for the "Big Five" was predominantly based on the five-factor solution. However, it was decided to include the Disintegration markers in the study in spite of the fact that the six factor solution did not confirm the existence of the independent Disintegration factor, based on the chosen markers. Actually, a trade-off was made between probably clearer factorial structures that could have been obtained if the attributes of extremely negative valence - such as crazy and insane-had been chosen (but possibly not working within the IAT context), and less extreme attributes working within the IAT paradigm (but poorer indicators of Disintegration). To summarise, the following attributes represented the dimensions of personality traits in the Implicit Association Test:

1. Neuroticism - Calm, Relaxed, Serene, Tough, Decisive, Tense, Nervous, Worried, Quarrelsome, Stubborn;

2. Extraversion - Withdrawn, Quiet, Shy, Passive, Closed, Vivacious, Talkative, Friendly, Happy, Cheerful;

3. Openness to experience - Practical, Unintrospective, Traditional, Conventional, Dogmatic, Creative, Imaginative, Curious, Complex, Philosophising;

4. Agreeableness - Amiable, Well-intentioned, Sympathetic, Generous, Devout, Insensitive, Reserved, Undiscerning, Malicious, Volatile;

5. Conscientiousness - Lazy, Unorganized, Irresponsible, Careless, Inefficient, Organised, Responsible, Disciplined, Efficient, Systematic;

6. Disintegration - Twisted, Weird, Enthralled, Dark, Wacky, Normal, Ordinary, Adapted, Collected and Balanced. 


\subsubsection{PSIHO Software Testing}

After the selection of stimuli for personality traits, the layout for IAT testing was constructed in PSIHO software. For preliminary software testing, implicit assessments for two different IATs were performed, one related to attitudes towards homosexuality (containing control Flower-Insect IAT and Gay-Straight IAT) (Bjekić, Živanović, \& Žeželj, unpublished manuscript), and one related to personality traits with attributes selected on the basis of PCA, on samples of 71 and 83 students, respectively ${ }^{7}$. Results showed that the D measures in both the IATs were in the expected range (Table 10 and Table 11).

Table 10 Results of D measures in IAT Gay-Straight, preliminary testing on 71 respondents

\begin{tabular}{|c|c|c|c|c|}
\hline & Min & Max & M & SD \\
\hline IAT $_{\text {Flower-Insect }}$ & .10 & 1.86 & .91 & .39 \\
\hline IAT $_{\text {Gay-Straight }}$ & -1.35 & 1.53 & .44 & .52 \\
\hline
\end{tabular}

Table 11 Results of D measures in IAT personality traits, preliminary testing on 83 respondents

\begin{tabular}{|c|c|c|c|c|}
\hline Domain & Min & Max & M & SD \\
\hline IAT $_{\mathrm{N}}$ & -.50 & 1.69 & .40 & .41 \\
\hline $\mathrm{IAT}_{\mathrm{E}}$ & -.71 & 1.09 & .28 & .42 \\
\hline $\mathrm{IAT}_{\mathrm{O}}$ & -.40 & 1.52 & .41 & .37 \\
\hline $\mathrm{IAT}_{\mathrm{A}}$ & -.48 & 1.30 & .47 & .43 \\
\hline $\mathrm{IAT}_{\mathrm{C}}$ & -1.02 & 1.55 & .44 & .42 \\
\hline $\mathrm{IAT}_{\mathrm{D}}$ & -.42 & 1.28 & .45 & .38 \\
\hline $\mathrm{IAT}_{\mathrm{I}}$ & -.25 & 1.37 & .59 & .39 \\
\hline
\end{tabular}

Note: IAT $_{\mathrm{N}}$ - IAT Neuroticism; IAT $\mathrm{E}_{\mathrm{E}}$ - IAT Extraversion; IAT $\mathrm{I}_{\mathrm{O}}-\mathrm{IAT}_{\text {Openness; }}$ IAT $_{\mathrm{A}}-\mathrm{IAT}$ Agreeableness; IAT $_{\mathrm{C}}$ - IAT conscientiousness; IAT $_{\mathrm{D}}-$ IAT Disintegration; IAT $_{\mathrm{I}}-\mathrm{IAT}_{\text {Intelligence. }}$

In addition, the testing did not prove to be too tiresome for the subjects in spite of the fact that it lasted, on an average, for 30 minutes (for personality IAT).

In order to carry out a more thorough test of the quality of data collected with the PSIHO software, a preliminary analysis of the implicit and explicit data was

\footnotetext{
${ }^{7}$ Subjects from these two sample were not part of the main sample for this research (i.e., sample consisting out of 224 subjects)
} 
performed, both on attitude and personality IAT. The IAT designed for measuring implicit attitudes towards homosexuality correlated significantly with two explicit measures of attitudes (scale and thermometer) (Table 12).

Table 12 Correlations between IATGay-Straight and two explicit measures of attitude, 71 respondents

\begin{tabular}{|c|c|c|c|}
\hline & & Scale $_{\text {Gay-Straight }}$ & Thermometer \\
\hline \multirow{2}{*}{ IAT $_{\text {Gay-Straight }}$} & $\mathrm{r}$ & .412 & -.415 \\
\cline { 2 - 4 } & $\mathrm{sig}$ & .000 & .000 \\
\hline
\end{tabular}

On Gay-Straight IAT, significant correlations were found which was in accordance with previous researches (Banse et al., 2001). However, the preliminary analysis of the personality IATs and self-report measures on NEO PIR and DELTA 10, showed non-significant correlations (Table 13).

Table 13 Correlations between personality IAT and self-report NEO PIR and DELTA 10, 83 respondents

\begin{tabular}{|c|c|c|c|c|c|c|c|}
\hline \multicolumn{2}{|c|}{} & $\mathrm{N}_{\mathrm{SR}}$ & $\mathrm{E}_{\mathrm{SR}}$ & $\mathrm{O}_{\mathrm{SR}}$ & $\mathrm{A}_{\mathrm{SR}}$ & $\mathrm{C}_{\mathrm{SR}}$ & $\mathrm{D}_{\mathrm{SR}}$ \\
\hline \multirow{2}{*}{$\mathrm{IAT}_{\mathrm{N}}$} & $\mathrm{r}$ & .031 & -.083 & .101 & -.021 & .072 & .046 \\
\cline { 2 - 8 } & $\mathrm{sig}$ & .784 & .456 & .368 & .853 & .518 & .691 \\
\hline \multirow{2}{*}{$\mathrm{IAT}_{\mathrm{E}}$} & $\mathrm{r}$ & .044 & .050 & -.003 & -.073 & .132 & .130 \\
\cline { 2 - 8 } & $\mathrm{sig}$ & .694 & .655 & .977 & .515 & .236 & .258 \\
\hline \multirow{2}{*}{$\mathrm{IAT}_{\mathrm{O}}$} & $\mathrm{r}$ & .083 & -.158 & .113 & -.021 & .019 & -.064 \\
\cline { 2 - 8 } & $\mathrm{sig}$ & .458 & .155 & .313 & .855 & .863 & .578 \\
\hline \multirow{2}{*}{$\mathrm{IAT}_{\mathrm{A}}$} & $\mathrm{r}$ & -.052 & -.046 & .101 & -.095 & -.152 & -.025 \\
\cline { 2 - 8 } & $\mathrm{sig}$ & .641 & .683 & .367 & .397 & .173 & .831 \\
\hline \multirow{2}{*}{$\mathrm{IAT}_{\mathrm{C}}$} & $\mathrm{r}$ & .123 & -.120 & .064 & .028 & .083 & -.083 \\
\cline { 2 - 8 } & $\mathrm{sig}$ & .273 & .283 & .565 & .805 & .461 & .468 \\
\hline \multirow{2}{*}{$\mathrm{IAT}_{\mathrm{D}}$} & $\mathrm{r}$ & -.071 & .069 & .017 & -.014 & .019 & .009 \\
\cline { 2 - 8 } & $\mathrm{sig}$ & .525 & .538 & .877 & .898 & .865 & .941 \\
\hline
\end{tabular}

Note: IAT $_{\mathrm{N}}-\mathrm{IAT}_{\mathrm{D}}$ - personality IAT measuring big six personality traits; $\mathrm{N}_{\mathrm{SR}^{-}}-\mathrm{D}_{\mathrm{SR}^{-}}$self-report measures of big six personality traits on NEO PIR and DELTA 10.

However, the finding of non-significant correlations for personality traits in the preliminary test was not discouraging as the relations between the implicit and explicit personality measures are less strong in comparison to the attitude measurement. Previous researches in implicit measurement of personality have also demonstrated small correlations (approximately 0.20) (e.g., Egloff \& Schmukle, 2002; Schmukle \& Egloff, 2005; Steffens \& Schulze-König, 2006). Effect size analysis, conducted 
previously in the phase of research preparation, for detection of population effect size of 0.20 (which is usually the maximum correlation obtained in the field of personality traits), with 0.85 power at 0.05 alpha level, suggested that a sample of at least 221 subjects was necessary.

The results of analyses from this phase (selection of IAT stimuli, software testing, and pilot testing) provided sufficient evidence to draw conclusions about the satisfying quality of the constructed Implicit Association Tests. In accordance with this, it was decided to proceed with the second phase of research.

\subsubsection{Training of Research Assistants for Behavioural Observation and Assessment of Prototypicality of Indicators}

For this part of the assessment, a group of master's level psychology students was trained to conduct interviews. Prior to testing, one volunteer (a non-psychology student) was interviewed. Master's level psychology students (who had taken the advanced course Psychology of Individual Differences) watched the video, and rated the behaviour of the volunteer on the Back et al. (2010) indicators, as well as the indicators chosen for this research.

This part of the research empirically tested the extent to which the behavioural criteria selected by Back et al. (2010) belonged to each of the five personality domains, and also the extent to which the indicators chosen for this research belonged to the Disintegration trait. A short description of each indicator and each trait was given to a group of 29 master's students who rated the extent of belonging for each indicator on a scale ranging from zero (not prototypical at all for this trait) to 5 (very prototypical for this trait). Table 14 shows the results of this analysis. 
Table 14 Behavioural Criteria for Each of the Big Five Personality Dimensions

\begin{tabular}{|c|c|c|c|c|c|c|c|}
\hline & & $\mathrm{N}$ & $E$ & $\mathrm{O}$ & $\mathrm{A}$ & $\mathrm{C}$ & $\mathrm{D}$ \\
\hline \multicolumn{8}{|c|}{ Neuroticism } \\
\hline \multirow{2}{*}{ Global behaviour } & $\mathrm{M}$ & 4.69 & 3.07 & 2.31 & 1.86 & 1.90 & 3.17 \\
\hline & Mdn & 5.00 & 3.00 & 2.00 & 2.00 & 1.00 & 3.00 \\
\hline \multirow{2}{*}{ Vision of future } & $\mathrm{M}$ & 4.28 & 1.90 & 2.24 & 1.57 & 1.62 & 3.28 \\
\hline & Mdn & 4.00 & 2.00 & 2.00 & 1.50 & 1.00 & 4.00 \\
\hline \multirow{2}{*}{ Global transcript } & $\mathrm{M}$ & 4.31 & 2.17 & 1.52 & 1.62 & 1.41 & 3.10 \\
\hline & Mdn & 5.00 & 2.00 & 1.00 & 2.00 & 1.00 & 3.00 \\
\hline \multirow{2}{*}{ Gaze aversion } & $\mathrm{M}$ & 4.14 & 3.41 & 2.17 & 2.24 & 1.34 & 3.41 \\
\hline & Mdn & 4.00 & 4.00 & 2.00 & 2.00 & 1.00 & 4.00 \\
\hline \multirow{2}{*}{ Tense body posture } & $\mathrm{M}$ & 4.52 & 2.69 & 1.48 & 1.66 & 1.24 & 3.31 \\
\hline & Mdn & 5.00 & 3.00 & 1.00 & 2.00 & 1.00 & 3.00 \\
\hline \multirow{2}{*}{ Tense leg posture } & $\mathrm{M}$ & 4.34 & 2.24 & 1.28 & 1.14 & .93 & 2.79 \\
\hline & Mdn & 4.00 & 2.00 & 1.00 & 1.00 & 1.00 & 3.00 \\
\hline \multirow{2}{*}{ Silence during SI } & $\mathrm{M}$ & 3.41 & $\underline{3.90}$ & 2.11 & 2.18 & 1.46 & 2.75 \\
\hline & Mdn & 4.00 & 4.00 & 2.00 & 2.50 & 1.00 & 3.00 \\
\hline \multirow{2}{*}{ Cell-phone-switched off } & $\mathrm{M}$ & 3.07 & 1.45 & .76 & 1.93 & 3.07 & 1.45 \\
\hline & Mdn & 3.00 & 1.00 & 1.00 & 2.00 & 3.00 & 1.00 \\
\hline \multirow{2}{*}{$\begin{array}{l}\text { Reassuring question in helping } \\
\text { situation }\end{array}$} & $\mathrm{M}$ & 3.34 & 3.14 & 2.14 & 2.72 & 3.31 & 2.07 \\
\hline & Mdn & 4.00 & 3.00 & 2.00 & 3.00 & 3.00 & 2.00 \\
\hline \multirow{2}{*}{$\begin{array}{l}\text { Reassuring questions in other } \\
\text { situations* }\end{array}$} & $\mathrm{M}$ & 3.62 & 3.34 & 2.34 & 2.31 & 2.97 & 2.03 \\
\hline & Mdn & 4.00 & 3.00 & 3.00 & 2.00 & 3.00 & 2.00 \\
\hline \multirow{2}{*}{ Dysfluency of speech } & $\mathrm{M}$ & 3.55 & 2.10 & 1.72 & .72 & 1.04 & 3.14 \\
\hline & Mdn & 4.00 & 2.00 & 2.00 & .00 & .00 & 3.00 \\
\hline \multirow{2}{*}{ Negations (LIWC) } & $\mathrm{M}$ & 3.18 & 1.78 & 1.74 & 2.27 & 1.19 & 2.59 \\
\hline & Mdn & 4.00 & 2.00 & 2.00 & 2.00 & 1.00 & 2.00 \\
\hline \multirow{2}{*}{$\begin{array}{l}\text { Words related to anxiety and } \\
\text { depression }\end{array}$} & $\mathrm{M}$ & 4.34 & 2.03 & 1.14 & 1.07 & .96 & 3.90 \\
\hline & Mdn & 4.00 & 2.00 & 1.00 & 1.00 & 1.00 & 4.00 \\
\hline & & $\mathrm{N}$ & $\mathrm{E}$ & $\mathrm{O}$ & A & $\mathrm{C}$ & $\mathrm{D}$ \\
\hline \multicolumn{8}{|c|}{ Extraversion } \\
\hline \multirow{2}{*}{ Global behaviour } & $\mathrm{M}$ & 4.90 & 2.86 & 2.82 & 1.64 & 2.54 & 2.54 \\
\hline & Mdn & 5.00 & 3.00 & 3.00 & 2.00 & 3.00 & 3.00 \\
\hline \multirow{2}{*}{ Vision of future } & $\mathrm{M}$ & 2.39 & 4.10 & 3.04 & 2.30 & 1.68 & 2.39 \\
\hline & Mdn & 2.00 & 4.00 & 3.00 & 3.00 & 1.50 & 2.00 \\
\hline \multirow{2}{*}{ Global transcript } & $\mathrm{M}$ & 2.64 & 4.45 & 2.93 & 2.39 & 1.82 & 2.21 \\
\hline & Mdn & 3.00 & 5.00 & 3.50 & 3.00 & 1.00 & 2.50 \\
\hline Fxprescivity of facial expression & $\mathrm{M}$ & 3.19 & 4.41 & 2.26 & 2.59 & 1.04 & 3.37 \\
\hline Expressivity or racial expression & Mdn & 4.00 & 4.00 & 2.00 & 3.00 & 1.00 & 3.00 \\
\hline Loudness of yoice & $\mathrm{M}$ & 3.41 & 4.39 & 1.89 & 1.86 & 1.07 & 2.57 \\
\hline 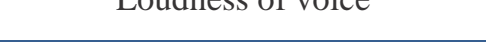 & Mdn & 3.00 & 5.00 & 2.00 & 2.00 & 1.00 & 3.00 \\
\hline Word count (I IWC) & $\mathrm{M}$ & 3.27 & 4.61 & 3.21 & 2.39 & 1.59 & 2.07 \\
\hline Wroid coumt (LIV) & Mdn & 4.00 & 5.00 & 4.00 & 3.00 & 1.00 & 2.00 \\
\hline Falce alarms in concentration tect & $\mathrm{M}$ & $\underline{4.14}$ & 3.48 & 1.36 & 1.69 & 3.14 & 1.79 \\
\hline raise ararms in concentration test & Mdn & 4.00 & 4.00 & 1.50 & 1.00 & 3.00 & 2.00 \\
\hline Own guestions in small talk & $\mathrm{M}$ & 3.50 & 4.62 & 3.07 & 2.76 & 2.66 & 1.59 \\
\hline Uwn questions in smantalk & Mdn & 4.00 & 5.00 & 3.00 & 3.00 & 3.00 & 1.00 \\
\hline Second-person pronouns (LIWC) & $\mathrm{M}$ & 2.29 & 3.68 & 1.86 & 2.50 & 1.00 & 1.32 \\
\hline second-person pronouns (Liwe) & Mdn & 2.00 & 4.00 & 2.00 & 3.00 & .00 & 1.00 \\
\hline Other references (IIWC) & $\mathrm{M}$ & 2.15 & 2.76 & 1.48 & 1.50 & .93 & 1.48 \\
\hline Uner rererences (Liwc) & Mdn & 2.00 & 3.00 & 1.00 & 1.00 & .00 & 1.00 \\
\hline Stvlish dress & $\mathrm{M}$ & 1.90 & 2.93 & 2.79 & 1.55 & 2.52 & 2.34 \\
\hline stynsh uress & Mdn & 2.00 & 3.00 & 3.00 & 1.00 & 3.00 & 3.00 \\
\hline Flashy dress & $\mathrm{M}$ & 2.71 & 4.45 & 2.86 & .93 & 1.17 & 3.24 \\
\hline rrasmy uress & Mdn & 3.00 & 5.00 & 3.00 & .00 & 1.00 & 4.00 \\
\hline
\end{tabular}




\begin{tabular}{|c|c|c|c|c|c|c|c|}
\hline & & $\mathrm{N}$ & $\mathrm{E}$ & $\mathrm{O}$ & A & $\mathrm{C}$ & $\mathrm{D}$ \\
\hline \multicolumn{8}{|c|}{ Openness to experience } \\
\hline \multirow{2}{*}{ Global short story } & $M$ & 2.86 & 3.10 & 4.69 & 1.86 & 1.59 & 2.59 \\
\hline & Mdn & 3.00 & 3.00 & 5.00 & 2.00 & 1.00 & 3.00 \\
\hline \multirow{2}{*}{ Global transcript } & $\mathrm{M}$ & 2.41 & 3.04 & 4.36 & 1.71 & 1.71 & 2.36 \\
\hline & Mdn & 3.00 & 3.00 & 4.50 & 2.00 & 1.00 & 2.00 \\
\hline \multirow{2}{*}{$\begin{array}{l}\text { Knowledge on test- multiple choice } \\
\text { question }\end{array}$} & $\mathrm{M}$ & 1.54 & 1.38 & 4.00 & 1.00 & 2.03 & 1.24 \\
\hline & Mdn & 1.00 & 1.00 & 4.00 & 1.00 & 2.00 & 1.00 \\
\hline \multirow{2}{*}{$\begin{array}{c}\text { Knowledge on test- open ended } \\
\text { questions }\end{array}$} & $\mathrm{M}$ & 2.18 & 1.66 & 4.45 & 1.31 & 1.86 & 1.55 \\
\hline & Mdn & 2.50 & 2.00 & 5.00 & 1.00 & 2.00 & 1.00 \\
\hline \multirow{2}{*}{ Eloquence } & $\mathrm{M}$ & 3.07 & 3.48 & 4.48 & 2.18 & 1.61 & 2.21 \\
\hline & Mdn & 3.00 & 4.00 & 5.00 & 2.00 & 2.00 & 2.00 \\
\hline \multirow{2}{*}{$\begin{array}{l}\text { Original and unusual brick } \\
\text { categories }\end{array}$} & $\mathrm{M}$ & 2.39 & 2.90 & 4.90 & 1.48 & 1.17 & 2.76 \\
\hline & Mdn & 3.00 & 3.00 & 5.00 & 1.00 & 1.00 & 3.00 \\
\hline \multirow{2}{*}{ Word count short story (LIWC) } & $M$ & 2.43 & 3.59 & 4.24 & 1.83 & 1.89 & 1.79 \\
\hline & Mdn & 3.00 & 4.00 & 4.00 & 2.00 & 2.00 & 1.50 \\
\hline \multirow{2}{*}{ Open answers in small talk } & M & 3.07 & 4.00 & 4.31 & 2.48 & 1.38 & 2.07 \\
\hline & Mdn & 3.00 & 4.00 & 5.00 & 2.00 & 1.00 & 2.00 \\
\hline \multicolumn{8}{|c|}{ Agreeableness } \\
\hline \multirow{2}{*}{$\begin{array}{l}\text { Global behaviour in helping } \\
\text { situation }\end{array}$} & $\mathrm{M}$ & 2.82 & 3.21 & 2.54 & 4.79 & 3.33 & 2.26 \\
\hline & Mdn & 3.00 & 3.50 & 3.00 & 5.00 & 3.00 & 3.00 \\
\hline \multirow{2}{*}{ Global transcript } & $\mathrm{M}$ & 2.00 & 3.00 & 2.43 & 4.39 & 3.00 & 1.89 \\
\hline & Mdn & 2.00 & 3.00 & 3.00 & 5.00 & 3.00 & 2.00 \\
\hline \multirow{2}{*}{ Quality of help } & $\mathrm{M}$ & 2.71 & 1.85 & 1.81 & 4.11 & 3.57 & 1.93 \\
\hline & Mdn & 3.00 & 2.00 & 2.00 & 4.00 & 4.00 & 2.00 \\
\hline \multirow{2}{*}{ Friendly voice in helping situation } & M & 2.59 & 3.55 & 2.28 & 4.76 & 2.66 & 2.21 \\
\hline & Mdn & 3.00 & 4.00 & 2.00 & 5.00 & 3.00 & 2.00 \\
\hline \multirow{3}{*}{ Friendly voice in small talk } & M & 2.90 & 4.14 & 2.07 & 4.79 & 2.31 & 2.38 \\
\hline & Mdn & 3.00 & 4.00 & 2.00 & 5.00 & 3.00 & 3.00 \\
\hline & & $\mathrm{N}$ & $\mathrm{E}$ & $\mathrm{O}$ & A & $\mathrm{C}$ & $\mathrm{D}$ \\
\hline \multicolumn{8}{|c|}{ Conscientiousness } \\
\hline \multirow{2}{*}{ Global transcript } & $M$ & 2.71 & 1.86 & 2.32 & 2.89 & 4.68 & 2.29 \\
\hline & Mdn & 3.00 & 2.00 & 3.00 & 3.00 & 5.00 & 2.00 \\
\hline \multirow{2}{*}{ Minutes late on the interview } & $\mathrm{M}$ & 2.36 & 1.25 & 1.36 & 3.18 & 4.52 & 1.75 \\
\hline & Mdn & 2.50 & 1.00 & 1.00 & 3.50 & 5.00 & 1.00 \\
\hline \multirow{2}{*}{$\begin{array}{c}\text { Lateness in sending back } \\
\text { questionnaire }\end{array}$} & $\mathrm{M}$ & 1.97 & .90 & 1.25 & 3.14 & 4.76 & 1.83 \\
\hline & Mdn & 2.00 & 1.00 & 1.00 & 3.00 & 5.00 & 2.00 \\
\hline \multirow{2}{*}{ Number of errors in short story } & $\mathrm{M}$ & 3.31 & .90 & 2.41 & 1.38 & 3.90 & 2.59 \\
\hline & Mdn & 3.00 & 1.00 & 2.00 & 1.00 & 4.00 & 2.00 \\
\hline \multirow[t]{2}{*}{ Understandability in small talk } & $\mathrm{M}$ & 3.34 & 2.17 & 2.41 & 2.38 & 3.10 & 3.11 \\
\hline & Mdn & 4.00 & 2.00 & 2.00 & 3.00 & 3.00 & 3.50 \\
\hline \multirow{2}{*}{$\begin{array}{c}\text { Number of errors in concentration } \\
\text { test }\end{array}$} & $\mathrm{M}$ & 3.50 & 1.31 & 1.55 & 1.38 & 3.55 & 3.03 \\
\hline & Mdn & 4.00 & 1.00 & 2.00 & 1.00 & 4.00 & 3.00 \\
\hline Sloucby body nocture & $\mathrm{M}$ & 2.62 & 2.55 & 1.55 & 1.93 & 2.83 & 2.17 \\
\hline Slouchy body posture & Mdn & 3.00 & 2.00 & 1.00 & 2.00 & 3.00 & 2.00 \\
\hline & $\mathrm{M}$ & 2.21 & 2.31 & 2.14 & 1.31 & 3.76 & 2.10 \\
\hline Formal dress & Mdn & 3.00 & 2.00 & 2.00 & 1.00 & 4.00 & 2.00 \\
\hline
\end{tabular}




\begin{tabular}{|c|c|c|c|c|c|c|c|}
\hline & & $\mathrm{N}$ & $\mathrm{E}$ & $\mathrm{O}$ & A & $\mathrm{C}$ & $\mathrm{D}$ \\
\hline \multicolumn{8}{|c|}{ Disintegration* } \\
\hline \multirow{2}{*}{ Global behaviour } & $\mathrm{M}$ & 3.54 & 1.96 & 2.11 & 2.08 & 1.96 & 4.55 \\
\hline & Mdn & 4.00 & 2.00 & 3.00 & 1.50 & 2.00 & 5.00 \\
\hline \multirow{2}{*}{ Global transcript } & $\mathrm{M}$ & 3.39 & 1.70 & 2.15 & 1.62 & 1.96 & 4.46 \\
\hline & Mdn & 3.00 & 2.00 & 3.00 & 2.00 & 2.00 & 5.00 \\
\hline \multirow{2}{*}{ Vision of future } & $\mathrm{M}$ & 3.19 & 1.54 & 2.23 & 1.28 & 1.35 & 4.59 \\
\hline & Mdn & 3.50 & 2.00 & 3.00 & 1.00 & 1.00 & 5.00 \\
\hline \multirow{2}{*}{ Inadequacy of facial expression } & $\mathrm{M}$ & 3.10 & 1.86 & 1.24 & 1.71 & 1.21 & 4.41 \\
\hline & Mdn & 4.00 & 2.00 & 1.00 & 1.50 & 1.00 & 5.00 \\
\hline \multirow{2}{*}{ Body posture } & $\mathrm{M}$ & 3.38 & 2.41 & 1.52 & 1.86 & 1.59 & 3.76 \\
\hline & Mdn & 4.00 & 3.00 & 1.00 & 2.00 & 1.00 & 4.00 \\
\hline \multirow{2}{*}{ Appearance - neglect, bizarre } & $\mathrm{M}$ & 2.59 & 2.07 & 1.52 & 1.54 & 2.72 & 4.71 \\
\hline & Mdn & 3.00 & 3.00 & 2.00 & 1.00 & 3.00 & 5.00 \\
\hline \multirow{2}{*}{ Concentration test-discrepancy } & $\mathrm{M}$ & 3.66 & 1.24 & 1.34 & 1.18 & 1.97 & 3.90 \\
\hline & Mdn & 4.00 & 1.00 & 1.00 & 1.00 & 2.00 & 4.00 \\
\hline \multirow{2}{*}{ Pantomime } & $\mathrm{M}$ & 3.28 & 2.66 & 2.90 & 1.68 & 1.38 & 3.83 \\
\hline & Mdn & 4.00 & 3.00 & 3.00 & 1.50 & 1.00 & 4.00 \\
\hline \multirow{2}{*}{ Short story-depressivness } & $\mathrm{M}$ & 3.48 & 1.69 & 2.45 & 1.57 & 1.79 & 4.24 \\
\hline & Mdn & 4.00 & 2.00 & 3.00 & 2.00 & 1.00 & 4.00 \\
\hline \multirow{2}{*}{ Behaviour in helping situation } & $\mathrm{M}$ & 3.00 & 1.93 & 1.52 & 3.07 & 2.76 & 3.76 \\
\hline & Mdn & 3.00 & 2.00 & 1.00 & 4.00 & 3.00 & 4.00 \\
\hline
\end{tabular}

Note: Indicators with * are added to original Back et al (2010) criteria.

The majority of the behavioural criteria were rated as prototypical for the specific trait. Exceptions were Silence during self-introduction (rated as more typical for Extraversion instead of Neuroticism) and False alarms in concentration test (rated as more typical for Neuroticism instead of Extraversion). Stylish dress, use of Secondperson pronouns, Understandability during interview, and Slouchy body posture were rated as almost equally prototypical for all the traits. However, in spite of the lower prototypicality of these indicators, they were used in order to compare the results of this study with that of Back et al. (2010).

After the assessment of prototypicality, the Cronbach alphas for the indicators and the Intraclass coefficients of correlation (absolute agreement of raters) were calculated for all the ratings. Results are presented in Table 15. 
Table 15 Reliability of indicators and intraclass coefficient of correlations of behavioural indicators

\begin{tabular}{|c|c|c|c|c|}
\hline Domain & $\begin{array}{c}\text { Number } \\
\text { of items }\end{array}$ & Reliability of indicators & $\begin{array}{c}\text { Number of } \\
\text { raters }\end{array}$ & $\begin{array}{c}\text { Intraclass coefficient of } \\
\text { correlation }\end{array}$ \\
\hline $\mathrm{N}_{\mathrm{B}}$ & 13 & .728 & 29 & .905 \\
\hline $\mathrm{E}_{\mathrm{B}}$ & 12 & .605 & 29 & .938 \\
\hline $\mathrm{O}_{\mathrm{B}}$ & 8 & .587 & 29 & .754 \\
\hline $\mathrm{A}_{\mathrm{B}}$ & 5 & .711 & 29 & .790 \\
\hline $\mathrm{C}_{\mathrm{B}}$ & 8 & .728 & 29 & .919 \\
\hline $\mathrm{D}_{\mathrm{B}}$ & 12 & .853 & 29 & .806 \\
\hline
\end{tabular}

Note: $\mathrm{N}_{\mathrm{B}}-\mathrm{D}_{\mathrm{B}}$-ratings by experts for basic six personality traits

These empirical data were in accord with the results of Back et al. (2010) and went in favour of including these criteria into the behavioural assessment (i.e., ratings by experts).

\subsection{Second Research Phase}

In the second phase, all the statistical analyses were performed on a sample of 224 and on a sub-sample of 99 subjects (from which the behavioural data and linguistic parameters were collected). These included analyses of the psychometric properties of all the instruments, correlation analyses, and structural equation modelling.

\subsubsection{Psychometric Properties of Implicit and Explicit Measures}

For all IAT scores, with RTT10G programme, the psychometric properties Kayser-Mayer-Olkin (KMO) measure of representativeness, internal consistencies (Cronbach $\alpha$ ), reliability of the first principal component (Lord-Kaiser-Caffrey $\beta$ ), and Momirovic's coefficient of Homogeneity (h2) were calculated on differential scores. For each attribute and each pronoun representing the target concepts in each IAT, differential scores were obtained (by subtracting from the RT of the stimulus in the sixth block, and RT of the same stimulus in the third block, e.g., IATShy141-IATShy41). Based 
on 60 differential scores calculated for each IAT representing one main domain (i.e., 30 differential scores for attributes, and 30 for pronouns), the psychometric properties were computed (Table 16).

Table 16 Psychometric properties of IAT scores of seven personality domains

\begin{tabular}{|c|c|c|c|c|}
\hline Domain & KMO & Cronbach $\alpha$ & L-K-C $\beta$ & h2 \\
\hline IAT $_{\mathrm{N}}-$ diff scores & .580 & .687 & .748 & .125 \\
\hline IAT $_{\mathrm{E}}-$ diff scores & .662 & .672 & .724 & .106 \\
\hline $\mathrm{IAT}_{\mathrm{O}}-$ diff scores & .751 & .795 & .823 & .183 \\
\hline $\mathrm{IAT}_{\mathrm{A}}-$ diff scores & .699 & .741 & .803 & .160 \\
\hline $\mathrm{IAT}_{\mathrm{C}}-$ diff scores & .688 & .762 & .787 & .147 \\
\hline $\mathrm{IAT}_{\mathrm{D}}-$ diff scores & .895 & .886 & .899 & .282 \\
\hline $\mathrm{IAT}_{\mathrm{I}}-$ diff scores & .703 & .780 & .808 & .163 \\
\hline
\end{tabular}

Note: IAT $_{\mathrm{N}}$ diff scores- IAT Neuroticism differential scores; IAT $_{\mathrm{E}}$ diff scores- IAT Extraversion differential scores; IAT $_{\mathrm{O}}$ diff scores- IAT Openness differential scores; IAT $_{\mathrm{A}}$ diff scores- IAT Agreeableness differential scores; IAT $_{\mathrm{C}}$

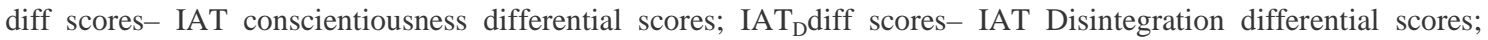
IAT $_{\text {I }}$ iff scores- IAT Intelligence differential scores; KMO - Kayser-Mayer-Olkin measure of representativeness; LK-C $\beta$ - Lord-Kaiser-Caffrey's $\beta$; h2- Momirovic's measure of homogeneity (h2)

Results showed that all the measures of psychometric properties were satisfactory (Table 16). Previous researches show that the internal consistencies of IATs range from 0.7 to 0.9 (Cunningham et al., 2001; Grumm \& van Collani, 2007; Hoffman et al., 2005). Results regarding the internal consistencies of IAT scores in this research were also satisfactory. The KMO measures of representativeness ranged from 0.580 (for IAT $_{\mathrm{N}}$ ) to 0.895 (for IAT $_{\mathrm{D}}$ ), internal consistencies (Cronbach's $\alpha$ ) of differential scores ranged from 0.672 (for $\mathrm{IAT}_{\mathrm{E}}$ ) to 0.886 (for $\mathrm{IAT}_{\mathrm{D}}$ ), reliabilities of the first principal component ranged from 0.724 (for $\operatorname{IAT}_{\mathrm{E}}$ ) to 0.899 (for $\mathrm{IAT}_{\mathrm{D}}$ ), and the coefficients of homogeneity ranged from 0.106 (for $\mathrm{IAT}_{\mathrm{E}}$ ) to 0.282 (for $\mathrm{IAT}_{\mathrm{D}}$ ).

Although all participants were psychology students, in order to exclude possibility that respondents did not share scientific understanding of all stimuli representing personality traits in IATs we analysed error rates for all stimuli in third, fourth, sixth and seventh block for all personality traits measured with IAT. Error rate 
was calculated as percentage of correct responses for all stimuli for each personality trait where more than $90 \%$ of respondents answered correctly on first attempt. This percentage ranged from $77 \%$ (for Neuroticism IAT) to $90 \%$ (for Agreeableness IAT) and we could exclude possibility that respondents did not comprehend meaning of the stimuli.

As shown in Table 17, all self-report scores also had satisfying psychometric properties. In Appendix 3, Appendix 4, Appendix 5, the psychometrical characteristics of the facets of six basic personality traits, assessed through self-reports and ratings by close others, are presented.

The KMO measure of representativeness ranged from 0.940 (for Agreeableness) to 0.999 (for Disintegration), Cronbach $\alpha$ from 0.847 (for Extraversion) to 0.936 (for Disintegration), L-K-C's $\beta$ from 0.874 (for Agreeableness) to 0.952 (for Disintegration), while h2 ranged from 0.162 (for Disintegration) to 0.331 (for Neuroticism).

Table 17 Psychometric properties of self-report measures of six basic personality domains

\begin{tabular}{|c|c|c|c|c|}
\hline Domain & KMO & Cronbach $\alpha$ & L-K-C $\beta$ & h2 \\
\hline Neuroticism $\left(\mathrm{N}_{\mathrm{SR}}\right)$ & .952 & .882 & .904 & .331 \\
\hline Extraversion $\left(\mathrm{O}_{\mathrm{SR}}\right)$ & .941 & .847 & .896 & .316 \\
\hline Openness $\left(\mathrm{E}_{\mathrm{SR}}\right)$ & .956 & .851 & .905 & .326 \\
\hline Agreeableness $\left(\mathrm{A}_{\mathrm{SR}}\right)$ & .940 & .854 & .874 & .259 \\
\hline Conscientiousness $\left(\mathrm{C}_{\mathrm{SR}}\right)$ & .954 & .883 & .903 & .322 \\
\hline Disintegration $\left(\mathrm{D}_{\mathrm{SR}}\right)$ & .999 & .936 & .952 & .162 \\
\hline
\end{tabular}

Note: $\mathrm{N}_{\mathrm{SR}^{-}} \mathrm{D}_{\mathrm{SR}^{-}}$self-report measures of big six personality traits on NEO PIR and DELTA 10

The female observer ratings also showed good metrical characteristics. The KMO measure of representativeness ranged from 0.900 (for Openness) to 0.978 (for Disintegration), internal consistency from 0.737 (for Openness) to 0.918 (for Disintegration), L-K-C's $\beta$ from 0.880 (for Extraversion) to 0.945 (for Disintegration), while homogeneity ranged from 0.259 (for Openness) to 0.380 (for Neuroticism) (Table $18)$. 
Table 18 Psychometric properties of female observer ratings measures of six basic personality domains

\begin{tabular}{|c|c|c|c|c|}
\hline Domain & KMO & Cronbach $\alpha$ & L-K-C $\beta$ & h2 \\
\hline Neuroticism $\left(\mathrm{N}_{\mathrm{F}}\right)$ & .965 & .904 & .920 & .380 \\
\hline Extraversion $\left(\mathrm{O}_{\mathrm{F}}\right)$ & .915 & .840 & .880 & .296 \\
\hline Openness $\left(\mathrm{E}_{\mathrm{F}}\right)$ & .900 & .737 & .861 & .259 \\
\hline Agreeableness $\left(\mathrm{A}_{\mathrm{F}}\right)$ & .944 & .842 & .889 & .301 \\
\hline Conscientiousness $\left(\mathrm{C}_{\mathrm{F}}\right)$ & .964 & .906 & .921 & .375 \\
\hline Disintegration $\left(\mathrm{D}_{\mathrm{F}}\right)$ & .978 & .918 & .945 & .260 \\
\hline
\end{tabular}

Note: $\mathrm{N}_{\mathrm{F}^{-}} \mathrm{D}_{\mathrm{F}^{-}}$rating by close female others of big six personality traits on NEO PIR and DELTA 10

Male observer ratings also showed good psychometric characteristics. The KMO measure of representativeness ranged from 0.902 (for Extraversion) to 0.971 (for Disintegration), internal consistency ranged from 0.780 (for Openness) to 0.910 (for Disintegration), L-K-C's $\beta$ from 0.850 (for Openness) to 0.940 (for Disintegration), while homogeneity ranged from 0.235 (for Openness) to 0.375 (for Conscientiousness) (Table 19).

Table 19 Psychometric properties of male observer ratings measures of six basic personality domains

\begin{tabular}{|c|c|c|c|c|}
\hline Domain & KMO & Cronbach $\alpha$ & L-K-C $\beta$ & h2 \\
\hline Neuroticism $\left(\mathrm{N}_{\mathrm{M}}\right)$ & .961 & .882 & .906 & .342 \\
\hline Extraversion $\left(\mathrm{O}_{\mathrm{M}}\right)$ & .902 & .823 & .874 & .285 \\
\hline Openness $\left(\mathrm{E}_{\mathrm{M}}\right)$ & .903 & .780 & .850 & .235 \\
\hline Agreeableness $\left(\mathrm{A}_{\mathrm{M}}\right)$ & .938 & .847 & .874 & .290 \\
\hline Conscientiousness $\left(\mathrm{C}_{\mathrm{M}}\right)$ & .964 & .906 & .924 & .375 \\
\hline Disintegration $\left(\mathrm{D}_{\mathrm{M}}\right)$ & .971 & .910 & .940 & .278 \\
\hline
\end{tabular}

Note: $\mathrm{N}_{\mathrm{M}^{-}}-\mathrm{D}_{\mathrm{M}^{-}}$rating by close male others of big six personality traits on NEO PIR and DELTA 10

The short scale of attributes (DOCEAN) showed satisfying psychometric characteristics. The KMO measure of representativeness ranged from 0.625 (for Openness) to 0.975 (for Extraversion), internal consistency ranged from 0.637 (for Openness) to 0.897 (for Extraversion), L-K-C's $\beta$ from 0.664 (for Openness) to 0.898 (for Extraversion), while homogeneity ranged from 0.518 (for Openness) to 0.820 (for Extraversion) (Table 20). 
Table 20 Psychometric properties of Short Attribute Scale (DOCEAN) of six basic personality domains

\begin{tabular}{|c|c|c|c|c|}
\hline Domain & KMO & Cronbach $\alpha$ & L-K-C $\beta$ & h2 \\
\hline Neuroticism $\left(\mathrm{SSA}_{\mathrm{N}}\right)$ & .902 & .796 & .805 & .681 \\
\hline Extraversion $\left(\mathrm{SSA}_{\mathrm{O}}\right)$ & .975 & .897 & .898 & .820 \\
\hline Openness $\left(\mathrm{SSA}_{\mathrm{E}}\right)$ & .625 & .637 & .664 & .518 \\
\hline Agreeableness $\left(\mathrm{SSA}_{\mathrm{A}}\right)$ & .952 & .851 & .855 & .853 \\
\hline Conscientiousness $\left(\mathrm{SSA}_{\mathrm{C}}\right)$ & .969 & .886 & .888 & .809 \\
\hline Disintegration $\left(\mathrm{SSA}_{\mathrm{D}}\right)$ & .912 & .764 & .789 & .802 \\
\hline
\end{tabular}

Note: $\mathrm{SSA}_{\mathrm{N}^{-}} \mathrm{SSA}_{-\mathrm{D}^{-}}$self-reported measure of big six personality traits on SSA DOCEAN

For the assessment of reliability of Back et al. (2010) and the behavioural indicators of this research, the intra-class correlation coefficients- ICC (absolute agreement of raters) were calculated. The analyses showed that the ratings of four experts for the majority of behavioural indicators had a high inter-rater reliability. The lowest intraclass correlation coefficient was 0.716 for Transcript (Conscientiousness) while the highest was for Checking out room in waiting situation (Openness) 0.968 (Table 21).

Table 21 Intraclass correlation coefficients for behavioural criteria

\begin{tabular}{|c|c|c|}
\hline Domain & Behavioural criteria & $\mathrm{ICC}$ \\
\hline \multirow{7}{*}{ Neuroticism } & Global behaviour vision of the future (rating) & .890 \\
\hline & Global behaviour SI (rating) & .884 \\
\hline & Gaze aversion SI (counting) & .874 \\
\hline & Tense body posture SI (rating) & .873 \\
\hline & Global transcript SI (rating) & .863 \\
\hline & Silence during SI (rating) & .842 \\
\hline & Tense leg posture SI (rating) & .822 \\
\hline \multirow{7}{*}{ Extraversion } & Stylish dress (rating) & .935 \\
\hline & Loudness of voice SI (rating) & .923 \\
\hline & Flashy dress (rating) & .919 \\
\hline & Expressivity of facial expression SI (rating) & .907 \\
\hline & Global behaviour SI (rating) & .895 \\
\hline & Global behaviour vision of the future (rating) & .891 \\
\hline & Global transcript SI (rating) & .880 \\
\hline \multirow{5}{*}{ Openness } & Pantomime - originality (rating) & .958 \\
\hline & Open answers in small-talk situation (rating) & .933 \\
\hline & Global short story (rating) & .919 \\
\hline & Verbal eloquence SI (rating) & .883 \\
\hline & Global transcript SI (rating) & .831 \\
\hline \multirow{6}{*}{ Agreeableness } & Checking out room in waiting situation (rating) & .968 \\
\hline & Friendly voice in small talk (rating) & .910 \\
\hline & Attentive body posture in small talk (rating) & .898 \\
\hline & Global behaviour in helping situation (rating) & .895 \\
\hline & Friendly voice in helping situation (rating) & .872 \\
\hline & Global transcript SI (rating) & .808 \\
\hline
\end{tabular}




\begin{tabular}{|c|c|c|}
\hline \multirow{4}{*}{ Conscientiousness } & Understandability in small talk (rating) & .916 \\
\cline { 2 - 3 } & Formal dress (rating) & .908 \\
\cline { 2 - 3 } & Slouching body posture SI (rating) & .788 \\
\cline { 2 - 3 } & Global transcript SI (rating) & .716 \\
\hline \multirow{5}{*}{ Disintegration } & Depression - short story (rating) & .949 \\
\cline { 2 - 3 } & Appearance - squalor, bizarreness (rating) & .942 \\
\cline { 2 - 3 } & Global transcript SI (rating) & .938 \\
\cline { 2 - 3 } & Helping situation (rating) & .924 \\
\cline { 2 - 3 } & Coherence - short story (rating) & .905 \\
\cline { 2 - 3 } & Global behaviour vision of the future (rating) & .885 \\
\cline { 2 - 3 } & Global behaviour SI (rating) & .884 \\
\cline { 2 - 3 } & Facial expression - inadequacy (rating) & .868 \\
\cline { 2 - 3 } & Pantomime - bizarreness (rating) & .867 \\
\cline { 2 - 3 } & Perseverance - short story (rating) & .845 \\
\cline { 2 - 3 } & Body posture (rating) & \\
\hline
\end{tabular}

As against Back et al. (2010), it was decided to separate the behavioural and linguistic indicators and make new composite measures for each domain of the six big personality traits consisting of LIWC parameters. It is important to say that in the analysis of the verbal material, three separate files with quantitative data were made for each subject. Two parts of the interview were oral - Introduction and Vision of the Future, while one was written - Short story. In preliminary analyses, we tried to verify if the verbal behaviour was consistent irrespective of the topic or the form (oral or written). Preliminary analyses indicated a consistent tendency to use words belonging to similar categories (from the point of automatic text analysis) in self-introduction, vision of the future, and written short story. Based on these results, all the three sources were agglomerated into one total measure for each LIWC category (e.g., Word Count total $=\mathrm{WC}$ introduction $+\mathrm{WC}$ vision of future $+\mathrm{WC}$ short story).

Several regression analyses provided specific LIWC parameters best predicting the traits measured by IAT. The parameters best predicting the personality traits (i.e., those who had the highest coefficients on one trait and, at the same time, low coefficients on others) were selected. In addition, for composite linguistic measures, the 
selected standardized parameters were not weighted, but added (with attention to sign)

(Table 22). List of LIWC abbreviations is provided in Appendix 6.

Table 22 Composite LIWC measures for each of big six personality domains

\begin{tabular}{|c|c|}
\hline LIWC $_{\mathrm{ZN}}$ & $\begin{array}{c}\text {-zfuncttotal-zauxverbtotal+zangertotal+zheartotal-zingesttotal+zfillertotal-zqmarktotal- } \\
\text { zapostrototal. }\end{array}$ \\
\hline LIWC $_{\mathrm{ZE}}$ & $\begin{array}{l}\text {-zyoutotal+zfuturetotal-zadverbtotal+zquanttotal+zfriendtotal-zperiodtotal+zcommatotal- } \\
\text { zqmarktotal-zallpcttotal. }\end{array}$ \\
\hline $\mathrm{LIWC}_{\mathrm{ZO}}$ & $\begin{array}{l}\text { zwctotal+zwpstotal-zpprontotal-zshehetotal+zconjtotal-znumbertotal-zsociatotal-zfamilytotal- } \\
\text { znegemototal+zinhibtotal-zpercepttotal-zseetotal-zbiototal-zbodytotal-zrelativtotal- } \\
\text { zmotiontotal-zparenthtotal. }\end{array}$ \\
\hline LIWC $_{\mathrm{ZA}}$ & $\begin{array}{c}\text { zsixltrtotal-ztheytotal+zarticletotal-zverbtotal-zpasttotal- } \\
\text { zsweartotal+zhumanstotal+zcogmechtotal+zexcltotal+zsexualtotal+zachievetotal+zhometotal- } \\
\text { zdeathtotal-zassenttotal-zapostrototal. }\end{array}$ \\
\hline LIWC $_{\mathrm{ZC}}$ & $\begin{array}{l}\text {-zpronountotal-zitotal-zwetotal-zpresenttotal+zprepstotal-znegatetotal-zsweartotal+zanxtotal- } \\
\text { zinsighttotal-zdiscreptotal+ztentattotal-zdeathtotal+zperiodtotal-zexclamtotal+zallpcttotal. }\end{array}$ \\
\hline LIWC $_{\mathrm{ZD}}$ & $\begin{array}{l}\text { +zaffecttotal+zposemototal-zsadtotal-zcausetotal+ztentattotal+zincltotal- } \\
\text { ztimetotal+zworktotal+zleisuretotal-zdashtotal. }\end{array}$ \\
\hline
\end{tabular}

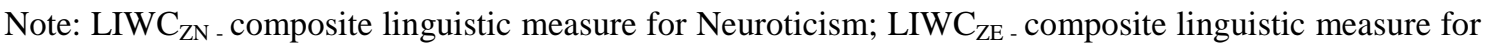
Extraversion; $\mathrm{LIWC}_{\mathrm{ZO}}$ - composite linguistic measure for Openness; LIWC $\mathrm{ZA}_{\mathrm{A}}$ - composite linguistic measure for Agreeableness; LIWC $\mathrm{ZC}$ - composite linguistic measure for Conscientiousness; LIWC $_{\mathrm{ZD}}$ composite linguistic measure for Disintegration.

In spite of the fact that the LIWC parameters were based on their relations with the IAT measures (circularity is obvious), it was not considered a trivial maneuver. The reason is that when the LIWC parameters are included as the predictors of IAT measures, multiple regression coefficients are substantial even when only some of them are utilized. In the absence of enough experience, knowledge, and theoretical expectations of what the LIWC parameters should indicate about a particular trait, the empirical solution to this problem seems to be justified. Furthermore, the LIWC score for a particular trait was not calculated with regression weights, but as a simple sum of the predictors (consequently, with a good chance to preserve the correlations with IAT measures on new samples). This is of special importance in the light of the fact that no matter how many self-reported predictors (traits, facets, or even items) are included in the prediction of IAT scores, the multiple regression coefficients always remain trivially small (i.e., the same result is obtained when the ratings by others or by experts are 
utilized). It speaks much about the fundamental gap between the self-report domain and IAT. For this reason, it was important to investigate the nature of relations between IAT and LIWC, since LIWC measures prove to be the only type of measures showing substantial correlations with IAT. Even if methodologically dubious, this step facilitated a better understanding of the nature of IAT measures.

The analysis of the psychometric properties of newly constructed composite linguistic measures showed satisfying results (Table 23).

Table 23 Psychometric properties of composite linguistic measures of six basic personality domains, subsample of 99 subjects

\begin{tabular}{|c|c|c|c|c|}
\hline Domain & KMO & Cronbach $\alpha$ & L-K-C $\beta$ & h2 \\
\hline LIWC $_{\text {ZN }}$ & .549 & .532 & .571 & .596 \\
\hline LIWC $_{\text {ZE }}$ & .936 & .616 & .672 & .726 \\
\hline LIWC $_{\text {ZO }}$ & .758 & .642 & .654 & .415 \\
\hline LIWC $_{\text {ZA }}$ & .691 & .628 & .673 & .512 \\
\hline LIWC $_{\text {ZC }}$ & .897 & .764 & .807 & .828 \\
\hline LIWC $_{Z D}$ & .871 & .610 & .639 & .782 \\
\hline
\end{tabular}

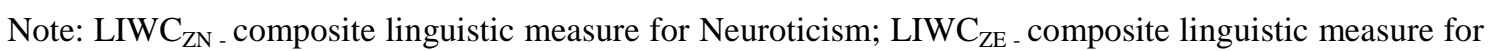
Extraversion; $\mathrm{LIWC}_{\mathrm{ZO}}$ - composite linguistic measure for Openness; LIWC $\mathrm{ZA}_{\mathrm{ZA}}$ - composite linguistic measure for Agreeableness; LIWC $_{\mathrm{ZC}}$ - composite linguistic measure for Conscientiousness; $\mathrm{LIWC}_{\mathrm{ZD}}$ composite linguistic measure for Disintegration.

\subsection{Descriptive Statistics for Implicit and Explicit Measures}

\subsubsection{Implicit Measures - "Data Trimming" in IAT}

Before conducting other analyses that included IAT, the distributions of these measures were examined. The data was "cleaned" of the usual speeded task impurities. According to the general agreement among scholars (Greenwald et al., 2003), we screened the data in order to exclude the RTs longer than $10000 \mathrm{~ms}$ and shorter than 300ms. These RTs were considered the consequence of prolonged responses after "too much thinking", or responses initiated prior to perceiving the stimulus and momentary inattention, respectively. In addition, if more than $10 \%$ of the response latencies were 
longer than $10000 \mathrm{~ms}$ or shorter than $300 \mathrm{~ms}$, the concerned subjects were to be excluded from further analysis. However, in the preliminary analyses, no subjects from the sample met this criterion and none of them were excluded from the sample.

The research verifies that the differential treatment of errors (adding the sum of block mean and $600 \mathrm{~ms}, 2 \mathrm{SD}$ or $1 \mathrm{SD}$, respectively, to score on trial) and the tightening of criteria for the exclusion of trials (from $300 \mathrm{~ms}$ to $400 \mathrm{~ms}$ ), does not lead to differences in results. The basic descriptive statistics of the IAT data, obtained after differential data treatment, are provided in Appendix 7. Since the results did not show any improvement in the correlations between the $\mathrm{D}$ scores and explicit measures, the $\mathrm{D}$ measures were calculated with improved scoring algorithm (i.e., replacement of error with sum of block mean and $600 \mathrm{~ms}$, and elimination of trials faster than $300 \mathrm{~ms}$ ) (Greenwald et al., 2003).

\subsubsection{Implicit Measures - Descriptive Statistics}

The descriptive statistics on IATs revealed that, on an average, the subjects showed a strong preference for a positive combination of paired categories. The mean differential values were above zero and indicated that the subjects sorted the stimuli representing the self and positive attributes faster (i.e., had positive associations between the self and positive words) (Table 24). The lowest differential scores were obtained on Extraversion (0.19), while the largest differences were on Disintegration (0.68), showing that the subjects had very strong preference for positive attributes in self-associating. 
Table 24 Descriptive statistics for main seven domains on IAT, sample 224 respondents

\begin{tabular}{|c|c|c|c|c|c|c|c|c|}
\hline Domain & $\mathrm{D}_{\text {Min }}$ & $\mathrm{D}_{\text {Max }}$ & $\mathrm{D}_{\mathrm{M}}$ & $\mathrm{D}_{\mathrm{SD}}$ & $\mathrm{D}_{\text {Skew }}$ & $\mathrm{D}_{\text {Skew SE }}$ & $\mathrm{D}_{\text {Kurt }}$ & $\mathrm{D}_{\text {Kurt SE }}$ \\
\hline $\mathrm{IAT}_{\mathrm{N}}$ & -.35 & 1.33 & $\mathbf{. 3 4}$ & .29 & .305 & .163 & .430 & .324 \\
\hline $\mathrm{IAT}_{\mathrm{E}}$ & -1.09 & 1.06 & $\mathbf{. 1 9}$ & .30 & -.451 & .163 & 1.182 & .324 \\
\hline $\mathrm{IAT}_{\mathrm{O}}$ & -.46 & 1.54 & $\mathbf{. 3 9}$ & .34 & .150 & .163 & .192 & .324 \\
\hline $\mathrm{IAT}_{\mathrm{A}}$ & -.50 & 1.21 & $\mathbf{. 5 3}$ & .30 & -.226 & .163 & .147 & .324 \\
\hline $\mathrm{IAT}_{\mathrm{C}}$ & -.80 & 1.37 & $\mathbf{. 5 0}$ & .33 & -.087 & .163 & .676 & .324 \\
\hline $\mathrm{IAT}_{\mathrm{D}}$ & -.15 & 1.84 & $\mathbf{. 6 8}$ & .40 & .436 & .163 & -.037 & .324 \\
\hline $\mathrm{IAT}_{\mathrm{I}}$ & -.29 & 1.44 & $\mathbf{. 4 7}$ & .30 & .380 & .163 & .139 & .324 \\
\hline
\end{tabular}

Note: $\mathrm{IAT}_{\mathrm{N}}-\mathrm{IAT}_{\mathrm{I}}$ - implicit association tests assessing big six personality traits and cognitive abilities

D-D measure in IAT

There were few subjects whose results on the IAT, or self-reports, could be treated as extreme, outlier analysis and subsequent correlation and regression analyses showed that exclusion of these subjects did not lead to different results. Therefore, all the analyses were carried out on the total sample of 224 respondents.

\subsubsection{Explicit Measures - Descriptive Statistics}

The basic descriptive statistics for the self-report measures of six basic personality traits are displayed in Table 25. In Appendix 8, Appendix 9, and Appendix 10, the descriptive statistics for all the facets of the six personality traits are presented, both for self-reports and the ratings by close others.

Table 25 Descriptive statistics for main six domains on self-reports, sample 224 respondents

\begin{tabular}{|c|c|c|c|c|c|c|c|c|}
\hline Domain & Min & Max & M & SD & Skew & Skew SE & Kurt & Kurt SE \\
\hline Neuroticism $\left(\mathrm{N}_{\mathrm{SR}}\right)$ & 16.00 & 154.00 & 94.06 & 23.63 & -.304 & .163 & .755 & .324 \\
\hline Extraversion $\left(\mathrm{O}_{\mathrm{SR}}\right)$ & 41.00 & 162.00 & 110.58 & 20.44 & -.450 & .163 & .425 & .324 \\
\hline Openness $\left(\mathrm{E}_{\mathrm{SR}}\right)$ & 69.00 & 174.00 & 124.39 & 20.70 & .143 & .163 & -.787 & .324 \\
\hline Agreeableness $\left(\mathrm{A}_{\mathrm{SR}}\right)$ & 35.00 & 172.00 & 112.45 & 19.49 & -.455 & .163 & 1.412 & .324 \\
\hline Conscientiousness $\left(\mathrm{C}_{\mathrm{SR}}\right)$ & 60.00 & 174.00 & 123.39 & 20.42 & -.183 & .163 & .423 & .324 \\
\hline Disintegration $\left(\mathrm{D}_{\mathrm{SR}}\right)$ & 1.18 & 3.35 & 2.08 & .45 & .269 & .163 & -.425 & .324 \\
\hline
\end{tabular}

Note: $\mathrm{N}_{\mathrm{SR}}-\mathrm{D}_{\mathrm{SR}}-$ self-report measures assessing big six personality traits on NEO PI R and DELTA 10

Table 26 shows basic descriptive statistics for the six main domains on female observer ratings for the sample of 224 respondents. 
Table 26 Descriptive statistics for main six domains on female observer ratings, sample 224 respondents

\begin{tabular}{|c|c|c|c|c|c|c|c|c|}
\hline Domain & Min & Max & M & SD & Skew & Skew SE & Kurt & Kurt SE \\
\hline Neuroticism $\left(\mathrm{N}_{\mathrm{F}}\right)$ & 16.00 & 159.00 & 84.07 & 24.39 & -.056 & .163 & -.049 & .324 \\
\hline Extraversion $\left(\mathrm{O}_{\mathrm{F}}\right)$ & 47.00 & 155.00 & 110.79 & 19.49 & -.450 & .163 & .285 & .324 \\
\hline Openness $\left(\mathrm{E}_{\mathrm{F}}\right)$ & 68.00 & 163.00 & 116.10 & 14.36 & .123 & .163 & .440 & .324 \\
\hline Agreeableness $\left(\mathrm{A}_{\mathrm{F}}\right)$ & 52.00 & 160.43 & 117.97 & 19.92 & -.425 & .163 & .447 & .324 \\
\hline Conscientiousness $\left(\mathrm{C}_{\mathrm{F}}\right)$ & 75.00 & 181.00 & 134.05 & 22.50 & -.013 & .163 & -.621 & .324 \\
\hline Disintegration $\left(\mathrm{D}_{\mathrm{F}}\right)$ & .82 & 3.76 & 1.96 & .50 & .228 & .163 & .040 & .324 \\
\hline
\end{tabular}

Note: $\mathrm{N}_{\mathrm{F}}-\mathrm{D}_{\mathrm{F}}-$ female rating by close others assessing big six personality traits on NEO PI R and DELTA 10

Table 27 shows basic descriptive statistics for the six main domains on male observer ratings for the sample of 224 respondents.

Table 27 Descriptive statistics for six main domains on male observer ratings, sample 224 respondents

\begin{tabular}{|c|c|c|c|c|c|c|c|c|}
\hline Domain & Min & Max & M & SD & Skew & Skew SE & Kurt & Kurt SE \\
\hline Neuroticism $\left(\mathrm{N}_{\mathrm{M}}\right)$ & 13.00 & 176.00 & 83.65 & 22.29 & -.138 & .163 & .884 & .324 \\
\hline Extraversion $\left(\mathrm{O}_{\mathrm{M}}\right)$ & 46.00 & 161.00 & 110.11 & 17.26 & -.317 & .163 & .855 & .324 \\
\hline Openness $\left(\mathrm{E}_{\mathrm{M}}\right)$ & 44.00 & 161.00 & 112.44 & 15.41 & -.265 & .163 & 1.995 & .324 \\
\hline Agreeableness $\left(\mathrm{A}_{\mathrm{M}}\right)$ & 17.00 & 172.00 & 117.12 & 18.89 & -.585 & .163 & 2.972 & .324 \\
\hline Conscientiousness $\left(\mathrm{C}_{\mathrm{M}}\right)$ & 65.00 & 180.00 & 131.15 & 22.40 & -.041 & .163 & -.377 & .324 \\
\hline Disintegration $\left(\mathrm{D}_{\mathrm{M}}\right)$ & 1.00 & 3.21 & 1.96 & .47 & .342 & .163 & -.169 & .324 \\
\hline
\end{tabular}

Note: $\mathrm{N}_{\mathrm{M}^{-}}-\mathrm{D}_{\mathrm{M}}$ - male rating by close others assessing big six personality traits on NEO PI R and DELTA 10

In Table 28, descriptive scores for all the tests in the battery KOG9 are

displayed. Keeping in mind that the norms exist only for battery KOG3, and not for

KOG9, the principal component was extracted, and was taken to represent the score.

Table 28 Descriptive statistics of KOG9 scores, sample 224 respondents

\begin{tabular}{|c|c|c|c|c|c|c|c|c|}
\hline Cognitive test & Min & Max & M & SD & Skew & Skew SE & Kurt & Kurt SE \\
\hline AL4 & 3.00 & 21.00 & 19.30 & 2.52 & -2.718 & .166 & 10.734 & .331 \\
\hline ALF7 & .00 & 32.00 & 23.89 & 4.02 & -1.380 & .166 & 5.500 & .331 \\
\hline GSN & .00 & 38.00 & 25.62 & 4.69 & -1.565 & .166 & 7.746 & .331 \\
\hline IT1 & .00 & 37.00 & 26.23 & 6.22 & -1.992 & .166 & 6.426 & .331 \\
\hline GT7 & .00 & 60.00 & 39.17 & 10.09 & -1.190 & .166 & 3.639 & .331 \\
\hline CF2 & .00 & 80.00 & 51.02 & 14.18 & -.897 & .166 & 2.110 & .331 \\
\hline S1 & .00 & 30.00 & 24.25 & 4.55 & -1.502 & .166 & 3.618 & .331 \\
\hline IT2 & 13.00 & 37.00 & 26.46 & 5.59 & -.303 & .166 & -.550 & .331 \\
\hline D48 & .00 & 37.00 & 27.21 & 5.50 & -.938 & .166 & 2.165 & .331 \\
\hline KOG9 - PC & -5.17 & 1.66 & .03 & .9 & -1.151 & .166 & 2.874 & .331 \\
\hline
\end{tabular}

The score distribution obtained was skewed to the left and most of the scores were grouped above the mean for this sample. 
On the subsample of 99 subjects, the composite behavioural measures (based on Back et al's (2010) suggestions of six basic personality traits) were calculated. Since the measures had different metrics (i.e., ratings, counting etc.), it was necessary to standardize all the behavioural variables. In Table 29 descriptive statistics of the standardized composite behavioural measures are presented.

Table 29 Descriptive statistics for main six domains on behavioural composite measures, subsample 99 respondents

\begin{tabular}{|c|c|c|c|c|c|c|}
\hline Domain & Min & Max & Skew & Skew SE & Kurt & Kurt SE \\
\hline Neuroticism $\left(\mathrm{N}_{\mathrm{B}}\right)$ & -6.92 & 16.22 & 1.215 & .251 & 1.599 & .498 \\
\hline Extraversion $\left(\mathrm{E}_{\mathrm{B}}\right)$ & -9.99 & 8.04 & -.302 & .251 & -.213 & .498 \\
\hline Openness $\left(\mathrm{O}_{\mathrm{B}}\right)$ & -9.32 & 8.37 & -.024 & .254 & -.310 & .503 \\
\hline Agreeableness $\left(\mathrm{A}_{\mathrm{B}}\right)$ & -8.36 & 8.12 & -.287 & .255 & -.342 & .506 \\
\hline Conscientiousness $\left(\mathrm{C}_{\mathrm{B}}\right)$ & -7.94 & 3.81 & -1.087 & .254 & 2.104 & .503 \\
\hline Disintegration $\left(\mathrm{D}_{\mathrm{B}}\right)$ & -5.80 & 21.86 & 1.864 & .255 & 3.364 & .506 \\
\hline
\end{tabular}

Note: $\mathrm{N}_{\mathrm{B}}-\mathrm{D}_{\mathrm{B}}-$ rating by experts assessing big six personality traits

\subsubsection{Descriptive Statistics - Self Assessment of Intellectual Abilities}

Table 30 shows the descriptive statistics of self-assessment measure of intellectual abilities.

Table 30 Descriptive statistics of self-assessment measure of intellectual abilities, sample 224 respondents

\begin{tabular}{|c|c|c|c|c|c|c|}
\hline & Min & Max & M & SD & Skew & Kurt \\
\hline IQ self & 3 & 7 & 5.07 & .825 & -.125 & -.333 \\
\hline
\end{tabular}

\subsubsection{Consistency of Traits (Subjective and Objective Measures)}

The self-reported global trait scores and the subjective measures of consistency for each trait were collected on a nine-point scale TSPROC (Appendix 2). The measures were collected for 196 subjects. The descriptive statistics are presented in Table 31 and Table 32. 
Table 31 Descriptive statistics of self-reported global trait score on TSPROC for six main domains

\begin{tabular}{|c|c|c|c|c|c|}
\hline Items & $\mathrm{N}$ & $\mathrm{Min}$ & $\mathrm{Max}$ & $\mathrm{M}$ & $\mathrm{SD}$ \\
\hline To what extent you consider yourself neurotic? & 196 & 1 & 9 & 4.26 & 2.22 \\
\hline To what extent you consider yourself extraverted? & 196 & 1 & 9 & 5.58 & 2.08 \\
\hline To what extent you consider yourself open to experience? & 196 & 2 & 9 & 7.14 & 1.52 \\
\hline To what extent you consider yourself agreeable? & 196 & 2 & 9 & 7.21 & 1.56 \\
\hline To what extent you consider yourself conscientious? & 196 & 2 & 9 & 7.67 & 1.42 \\
\hline $\begin{array}{c}\text { To what extent you consider yourself disintegrated? (absent, forgetful, } \\
\text { experience strange and unusual experiences, reactions, thoughts and } \\
\text { feelings) }\end{array}$ & 196 & 1 & 9 & 3.61 & 2.17 \\
\hline \begin{tabular}{c} 
felions \\
\hline
\end{tabular} & & & \\
\hline
\end{tabular}

Table 32 Descriptive statistics of self-reported consistency measures on TSPROC for six main domains

\begin{tabular}{|c|c|c|c|c|c|}
\hline Items & $\mathrm{N}$ & Min & Max & $\mathrm{M}$ & SD \\
\hline $\begin{array}{l}\text { How much is your behaviour related to trait Neuroticism consistent in } \\
\text { time? (Nsubj) }\end{array}$ & 196 & 1 & 9 & 4.42 & 2.39 \\
\hline $\begin{array}{l}\text { How much is your behaviour related to trait Extraversion consistent in } \\
\text { time? (Esubj) }\end{array}$ & 196 & 1 & 9 & 5.47 & 2.27 \\
\hline $\begin{array}{l}\text { How much is your behaviour related to trait Openness to experience } \\
\text { consistent in time? (Osubj) }\end{array}$ & 196 & 1 & 9 & 4.74 & 2.23 \\
\hline $\begin{array}{l}\text { How much is your behaviour related to trait Agreeableness consistent in } \\
\text { time? (Asubj) }\end{array}$ & 196 & 1 & 9 & 4.68 & 2.23 \\
\hline $\begin{array}{c}\text { How much is your behaviour related to trait Conscientiousness } \\
\text { consistent in time? (Csubj) }\end{array}$ & 196 & 1 & 9 & 3.64 & 2.34 \\
\hline $\begin{array}{l}\text { How much is your behaviour related to trait Disintegration consistent in } \\
\text { time? (Dsubj) }\end{array}$ & 195 & 1 & 9 & 3.62 & 2.20 \\
\hline
\end{tabular}

Table 33 shows the descriptive parameters of the objective measure of consistency (calculated as within subject standard deviation of S scores on Adjective Scale (DOCEAN adjectives), two observer ratings scores ( $\mathrm{R}$ scores) and self-reported global trait score (e.g. Nobj=zNF, zNM, zNatt, zTSPROC1).

Table 33 Descriptive statistics of objective measures of basic six personality trait consistencies

\begin{tabular}{|c|c|c|c|c|c|}
\hline Domain & N & Min & Max & M & SD \\
\hline Neuroticism (Nobjcons) & 219 & 4.76 & 276.72 & 80.14 & 48.64 \\
\hline Extraversion (Eobjcons) & 219 & 2.48 & 304.23 & 87.41 & 46.34 \\
\hline Openness (Oobjcons) & 219 & 2.37 & 372.28 & 105.26 & 57.37 \\
\hline Agreeableness (Aobjcons) & 219 & 2.51 & 245.87 & 90.35 & 46.77 \\
\hline Conscientiousness (Cobjcons) & 219 & 7.05 & 276.55 & 99.61 & 52.89 \\
\hline Disintegration (Dobjcons) & 219 & .00 & 6.28 & 2.16 & 1.27 \\
\hline
\end{tabular}

Note: *objcons-measure of objective consistency for each of big six personality traits

Results of moderator analyses shown that consistency measures did not moderate correlations between implicit and explicit measures. Results are displayed in Appendix 11. 


\subsubsection{Descriptive Statistics - Ipsatized S Measures}

The ipsatized scores for all the subjects from the sample were calculated. The descriptive statistics are presented in Table 34.

Table 34 Descriptive statistics of ipsatized scores for six personality traits, sample 224 respondents

\begin{tabular}{|c|c|c|c|c|c|c|c|c|}
\hline & Min & Max & M & SD & Skew & Skew SE & Kurt & Kurt SE \\
\hline $\mathrm{N}_{\text {IPS }}$ & -1.85 & 1.91 & .05 & .95 & -.166 & .163 & -1.020 & .324 \\
\hline $\mathrm{E}_{\text {IPS }}$ & -1.96 & 1.78 & .04 & .88 & -.298 & .163 & -.819 & .324 \\
\hline $\mathrm{O}_{\text {IPS }}$ & -2.01 & 1.71 & -.07 & .90 & -.132 & .163 & -.950 & .324 \\
\hline $\mathrm{A}_{\text {IPS }}$ & -1.89 & 1.91 & .02 & .86 & -.113 & .163 & -.507 & .324 \\
\hline $\mathrm{C}_{\text {IPS }}$ & -1.95 & 1.92 & -.01 & .90 & -.106 & .163 & -.689 & .324 \\
\hline $\mathrm{D}_{\text {IPS }}$ & -1.92 & 1.84 & -.04 & .98 & .045 & .163 & -1.049 & .324 \\
\hline
\end{tabular}

Note: $\mathrm{N}_{\text {IPS }}-\mathrm{D}_{\text {IPS }}$-ipsatized scores for big six personality traits

The results of all the analyses showed that the ipsatized scores did not have significant correlations with IATs, self-reports, and observer ratings. Therefore, these measures were also excluded from further analyses.

\subsection{Relations of IATs with Various Explicit Measures}

\subsubsection{Exploratory Factor Analysis - Latent Structure of Personality Traits Assessed by IAT}

In order to explore the latent structure of constructs assessed by the personality implicit association test, the factors from differential scores for each attribute used in the IAT were extracted. The Principal Component Analysis with Promax rotation extracted 6 factors, explaining $28 \%$ of the variance. Table 35 shows the pattern matrix with the loadings of differential scores. 
Table 35 Pattern matrix - PCA with Promax rotation with Kaiser Normalization - 6 factor solution

\begin{tabular}{|c|c|c|c|c|c|c|}
\hline & \multicolumn{6}{|c|}{ Component } \\
\hline & 1 & 2 & 3 & 4 & 5 & 6 \\
\hline Undiscerning $_{\text {diffscore }}$ & .638 & & & & & \\
\hline Volatile $_{\text {diffscore }}$ & .538 & & & & & \\
\hline Disorganised $_{\text {diffscore }}$ & -.536 & & .309 & & & \\
\hline Enthralled $_{\text {diffscore }}$ & .528 & & & & & .316 \\
\hline Balanced $_{\text {diffscore }}$ & .519 & & & & & \\
\hline Decisive $_{\text {diffscore }}$ & -.474 & & .358 & & & \\
\hline Normal $_{\text {diffscore }}$ & .471 & & & & & \\
\hline Wacky $_{\text {diffscore }}$ & .467 & & & & & \\
\hline Malicious $_{\text {diffscore }}$ & .460 & & & & & \\
\hline Devout $_{\text {diffscore }}$ & .442 & & & & & \\
\hline Generous $_{\text {diffscore }}$ & .430 & & & & & \\
\hline Dark $_{\text {diffscore }}$ & .401 & & & & & .330 \\
\hline Friendly $_{\text {diffscore }}$ & .357 & & -.310 & & .342 & \\
\hline Insensitive $_{\text {diffscore }}$ & .330 & & & & & \\
\hline Dogmatic $_{\text {diffscore }}$ & & .583 & & & & \\
\hline Creative $_{\text {diffscore }}$ & & .526 & & & & \\
\hline Complex $_{\text {diffscore }}$ & & .522 & & & & \\
\hline Practical $_{\text {diffscore }}$ & & .507 & & & & \\
\hline Curious $_{\text {diffscore }}$ & & .506 & & & & \\
\hline Unintrospective $_{\text {diffscore }}$ & & .503 & & & & \\
\hline Conventional $_{\text {diffscore }}$ & & .448 & & & & \\
\hline Traditional $_{\text {diffscore }}$ & & .405 & & & & \\
\hline Imaginative $_{\text {diffscore }}$ & & .324 & & & & \\
\hline \multicolumn{7}{|l|}{ Cold $_{\text {diffscore }}$} \\
\hline Calm diffscore & & & .575 & & & \\
\hline Stubborn $_{\text {diffscore }}$ & & & .515 & & & \\
\hline Quarrelsome $_{\text {diffscore }}$ & & & .510 & & & \\
\hline Tense $_{\text {diffscore }}$ & & & .447 & & & \\
\hline Nervous $_{\text {diffscore }}$ & & & .433 & & & \\
\hline Well-intentioned $_{\text {diffscore }}$ & & & .399 & & & \\
\hline Serene $_{\text {diffscore }}$ & & & .385 & & & \\
\hline Worried $_{\text {diffscore }}$ & & & .383 & & & \\
\hline Relaxed $_{\text {diffscore }}$ & & & .332 & & & \\
\hline \multicolumn{7}{|l|}{ Tough $_{\text {diffscore }}$} \\
\hline Careless $_{\text {diffscore }}$ & & & & .627 & & \\
\hline Efficient $_{\text {diffscore }}$ & & & & .590 & & \\
\hline Responsible $_{\text {diffscore }}$ & & & & .487 & & .330 \\
\hline Organised $_{\text {diffscore }}$ & & & & .466 & & \\
\hline Systematic $_{\text {diffscore }}$ & -.333 & & & .447 & & \\
\hline Lazy $_{\text {diffscore }}$ & & & & .356 & & \\
\hline Inefficient $_{\text {diffscore }}$ & & & & .314 & & \\
\hline Disciplined $_{\text {diffscore }}$ & & & & .306 & & \\
\hline \multicolumn{7}{|l|}{ Irresponsible $_{\text {diffscore }}$} \\
\hline \multicolumn{7}{|l|}{ Benign $_{\text {diffscore }}$} \\
\hline \multicolumn{7}{|l|}{ Cheerful $_{\text {diffscore }}$} \\
\hline \multicolumn{7}{|l|}{ Sympathetic $_{\text {diffscore }}$} \\
\hline Passive $_{\text {diffscore }}$ & & & & & .505 & \\
\hline Closed $_{\text {diffscore }}$ & & & & & .498 & \\
\hline Withdrawn $_{\text {diffscore }}$ & & & & & .473 & \\
\hline Vivacious $_{\text {diffscore }}$ & & & & & .447 & \\
\hline Talkative $_{\text {diffscore }}$ & & & & & .408 & \\
\hline Happy $_{\text {diffscore }}$ & & & & & .402 & \\
\hline
\end{tabular}




\begin{tabular}{|c|c|c|c|c|c|c|}
\hline & \multicolumn{6}{|c|}{ Component } \\
\hline & 1 & 2 & 3 & 4 & 5 & 6 \\
\hline Quiet $_{\text {diffscore }}$ & & & & & .358 & \\
\hline Shy diffscore & & & & & .335 & \\
\hline Philosophising $_{\text {diffscore }}$ & & & & & .331 & \\
\hline Ordinary $_{\text {diffscore }}$ & 329 & & & & & .564 \\
\hline Adapted $_{\text {diffscore }}$ & & & & & & .516 \\
\hline Weird $_{\text {diffscore }}$ & .364 & & & & & .424 \\
\hline Collected $_{\text {diffscore }}$ & & & & & & .404 \\
\hline Twisted $_{\text {diffscore }}$ & .333 & & & & & .378 \\
\hline
\end{tabular}

Note: Loadings lower than 0.30 are not displayed

Results showed that the four latent personality traits were well replicated in this solution. The differential scores for the attributes representing Openness, Neuroticism, Agreeableness, and Extraversion had clear loadings on the corresponding factors. Only the differential scores for the attributes for Agreeableness and Disintegration did not have clear loadings on the corresponding latent dimensions. This result suggests the existence of a latent structure describing the six basic personality traits. 


\subsubsection{Within method intercorrelations of personality traits}

In Table 36 are displayed intercorrelations between IATs measuring basic personality traits.

Table 36 Correlation matrix for IAT measures

\begin{tabular}{|c|c|c|c|c|c|c|c|}
\hline \multicolumn{2}{|c|}{ Domain } & IAT $_{\mathrm{N}}$ & IAT $_{\mathrm{E}}$ & $\mathrm{IAT}_{\mathrm{O}}$ & IAT $_{\mathrm{A}}$ & $\mathrm{IAT}_{\mathrm{C}}$ & $\mathrm{IAT}_{\mathrm{D}}$ \\
\hline \multirow{2}{*}{$\mathrm{IAT}_{\mathrm{N}}$} & $\mathrm{r}$ & 1 & .074 & .092 & .191 & .148 & .072 \\
\cline { 2 - 8 } & Sig. & & .271 & .169 & .004 & .027 & .284 \\
\hline \multirow{2}{*}{$\mathrm{IAT}_{\mathrm{E}}$} & $\mathrm{r}$ & .074 & 1 & .292 & .165 & .172 & .062 \\
\cline { 2 - 8 } & Sig. & .271 & & .000 & .013 & .010 & .359 \\
\hline \multirow{2}{*}{$\mathrm{IAT}_{\mathrm{O}}$} & $\mathrm{r}$ & .092 & .292 & 1 & .338 & .265 & .296 \\
\cline { 2 - 8 } & Sig. & .169 & .000 & & .000 & .000 & .000 \\
\hline \multirow{2}{*}{$\mathrm{IAT}_{\mathrm{A}}$} & $\mathrm{r}$ & .191 & .165 & .338 & 1 & .296 & .422 \\
\cline { 2 - 8 } & Sig. & .004 & .013 & .000 & & .000 & .000 \\
\hline \multirow{2}{*}{$\mathrm{IAT}_{\mathrm{C}}$} & $\mathrm{r}$ & .148 & .172 & .265 & .296 & 1 & .210 \\
\cline { 2 - 8 } & Sig. & .027 & .010 & .000 & .000 & & .002 \\
\hline \multirow{2}{*}{$\mathrm{IAT}_{\mathrm{D}}$} & $\mathrm{r}$ & .072 & .062 & .296 & .422 & .210 & 1 \\
\cline { 2 - 8 } & Sig. & .284 & .359 & .000 & .000 & .002 & \\
\hline
\end{tabular}

Note: $\mathrm{IAT}_{\mathrm{N}}-\mathrm{IAT}_{\mathrm{D}}-\mathrm{IAT}$ assessing big six personality traits

Between basic personality traits measured with IAT exist low to moderate correlations.

Intercorrelations of basic personality traits measured with self-reported NEO PI $\mathrm{R}$ and DELTA 10 are displayed in Table 37 and are similar to those obtained in literature (Knežević, 2011).

Table 37 Correlation matrix for self-report measures

\begin{tabular}{|c|c|c|c|c|c|c|c|}
\hline \multicolumn{2}{|c|}{ Domain } & $\mathrm{N}_{\mathrm{SR}}$ & $\mathrm{E}_{\mathrm{SR}}$ & $\mathrm{O}_{\mathrm{SR}}$ & $\mathrm{A}_{\mathrm{SR}}$ & $\mathrm{C}_{\mathrm{SR}}$ & $\mathrm{D}_{\mathrm{SR}}$ \\
\hline \multirow{2}{*}{$\mathrm{N}_{\mathrm{SR}}$} & $\mathrm{r}$ & 1 & .291 & .157 & .217 & .314 & .529 \\
\cline { 2 - 8 } & Sig. & & .000 & .018 & .001 & .000 & .000 \\
\hline \multirow{2}{*}{$\mathrm{E}_{\mathrm{SR}}$} & $\mathrm{r}$ & -.291 & 1 & .332 & .141 & .120 & .209 \\
\cline { 2 - 8 } & Sig. & .000 & & .000 & .035 & .073 & .002 \\
\hline \multirow{2}{*}{$\mathrm{O}_{\mathrm{SR}}$} & $\mathrm{r}$ & -.157 & .332 & 1 & .175 & .176 & .058 \\
\cline { 2 - 8 } & Sig. & .018 & .000 & & .009 & .008 & .391 \\
\hline \multirow{2}{*}{$\mathrm{A}_{\mathrm{SR}}$} & $\mathrm{r}$ & -.217 & .141 & .175 & 1 & .150 & .243 \\
\cline { 2 - 8 } & Sig. & .001 & .035 & .009 & & .024 & .000 \\
\hline $\mathrm{C}_{\mathrm{SR}}$ & $\mathrm{r}$ & -.314 & .120 & .176 & .150 & 1 & .177 \\
\cline { 2 - 8 } & Sig. & .000 & .073 & .008 & .024 & & .008 \\
\hline \multirow{2}{*}{$\mathrm{D}_{\mathrm{SR}}$} & $\mathrm{r}$ & .529 & -.209 & .058 & -.243 & -.177 & 1 \\
\cline { 2 - 7 } & Sig. & .000 & .002 & .391 & .000 & .008 & \\
& & & & & & \\
\end{tabular}

Note: $\mathrm{N}_{\mathrm{SR}}-\mathrm{D}_{\mathrm{SR}}-$ self-report measures assessing big six personality traits on NEO PI R and DELTA 10 
Intercorrelations between basic personality traits assessed with ratings by close female and male others are displayed in Table 38 and Table 39 and are in accordance with previous results (Knežević, 2011).

Table 38 Correlation matrix for ratings by close female others

\begin{tabular}{|c|c|c|c|c|c|c|c|}
\hline \multicolumn{2}{|c|}{ Domain } & $\mathrm{N}_{\mathrm{F}}$ & $\mathrm{E}_{\mathrm{F}}$ & $\mathrm{O}_{\mathrm{F}}$ & $\mathrm{A}_{\mathrm{F}}$ & $\mathrm{C}_{\mathrm{F}}$ & $\mathrm{D}_{\mathrm{F}}$ \\
\hline \multirow{2}{*}{$\mathrm{N}_{\mathrm{F}}$} & $\mathrm{r}$ & 1 & -.281 & -.030 & -.427 & -.466 & .531 \\
\cline { 2 - 8 } & Sig. & & .000 & .651 & .000 & .000 & .000 \\
\hline \multirow{2}{*}{$\mathrm{E}_{\mathrm{F}}$} & $\mathrm{r}$ & -.281 & 1 & .419 & .166 & .281 & -.251 \\
\cline { 2 - 8 } & Sig. & .000 & & .000 & .013 & .000 & .000 \\
\hline \multirow{2}{*}{$\mathrm{O}_{\mathrm{F}}$} & $\mathrm{r}$ & -.030 & .419 & 1 & .167 & .172 & -.042 \\
\cline { 2 - 8 } & Sig. & .651 & .000 & & .013 & .010 & .530 \\
\hline \multirow{2}{*}{$\mathrm{A}_{\mathrm{F}}$} & $\mathrm{r}$ & -.427 & .166 & .167 & 1 & .345 & -.341 \\
\cline { 2 - 8 } & Sig. & .000 & .013 & .013 & & .000 & .000 \\
\hline $\mathrm{C}_{\mathrm{F}}$ & $\mathrm{r}$ & -.466 & .281 & .172 & .345 & 1 & -.287 \\
\cline { 2 - 8 } & Sig. & .000 & .000 & .010 & .000 & & .000 \\
\hline \multirow{2}{*}{$\mathrm{D}_{\mathrm{F}}$} & $\mathrm{r}$ & .531 & -.251 & -.042 & -.341 & -.287 & 1 \\
\cline { 2 - 8 } & Sig. & .000 & .000 & .530 & .000 & .000 & \\
\hline
\end{tabular}

Note: $-\mathrm{N}_{\mathrm{F}}-\mathrm{D}_{\mathrm{F}}$ - ratings by close female others assessing big six personality traits on NEO PI R and DELTA 10

Table 39 Correlation matrix for ratings by close male others

\begin{tabular}{|c|c|c|c|c|c|c|c|}
\hline \multicolumn{2}{|c|}{ Domain } & $\mathrm{N}_{\mathrm{M}}$ & $\mathrm{E}_{\mathrm{M}}$ & $\mathrm{O}_{\mathrm{M}}$ & $\mathrm{A}_{\mathrm{M}}$ & $\mathrm{C}_{\mathrm{M}}$ & $\mathrm{D}_{\mathrm{M}}$ \\
\hline \multirow{2}{*}{$\mathrm{N}_{\mathrm{M}}$} & $\mathrm{r}$ & 1 & -.246 & -.062 & -.290 & -.417 & .389 \\
\cline { 2 - 8 } & Sig. & & .000 & .358 & .000 & .000 & .000 \\
\hline \multirow{2}{*}{$\mathrm{E}_{\mathrm{M}}$} & $\mathrm{r}$ & -.246 & 1 & .517 & .166 & -.016 & -.185 \\
\cline { 2 - 8 } & Sig. & .000 & & .000 & .013 & .815 & .005 \\
\hline \multirow{2}{*}{$\mathrm{O}_{\mathrm{M}}$} & $\mathrm{r}$ & -.062 & .517 & 1 & .237 & .065 & -.157 \\
\cline { 2 - 8 } & Sig. & .358 & .000 & & .000 & .330 & .019 \\
\hline \multirow{2}{*}{$\mathrm{A}_{\mathrm{M}}$} & $\mathrm{r}$ & -.290 & .166 & .237 & 1 & .354 & -.245 \\
\cline { 2 - 8 } & Sig. & .000 & .013 & .000 & & .000 & .000 \\
\hline \multirow{2}{*}{$\mathrm{C}_{\mathrm{M}}$} & $\mathrm{r}$ & -.417 & -.016 & .065 & .354 & 1 & -.334 \\
\cline { 2 - 8 } & Sig. & .000 & .815 & .330 & .000 & & .000 \\
\hline \multirow{2}{*}{$\mathrm{D}_{\mathrm{M}}$} & $\mathrm{r}$ & .389 & -.185 & -.157 & -.245 & -.334 & 1 \\
\cline { 2 - 8 } & Sig. & .000 & .005 & .019 & .000 & .000 & \\
\hline
\end{tabular}

Note: $-\mathrm{N}_{\mathrm{M}}-\mathrm{D}_{\mathrm{M}}$ - ratings by close male others assessing big six personality traits on NEO PI R and DELTA 10

Intercorrelations between basic personality traits assessed with Short Scale of Attributes DOCEAN are displayed in Table 40 are in accordance with previous results (Knežević \& Lazarević, 2011). 
Table 40 Correlation matrix for short scale of attributes

\begin{tabular}{|c|c|c|c|c|c|c|c|}
\hline \multicolumn{2}{|c|}{ Domain } & SSA $_{\mathrm{N}}$ & $\mathrm{SSA}_{\mathrm{E}}$ & $\mathrm{SSA}_{\mathrm{O}}$ & $\mathrm{SSA}_{\mathrm{A}}$ & $\mathrm{SSA}_{\mathrm{C}}$ & $\mathrm{SSA}_{\mathrm{D}}$ \\
\hline \multirow{2}{*}{$\mathrm{SSA}_{\mathrm{N}}$} & $\mathrm{r}$ & 1 & -.232 & .187 & -.152 & -.084 & .369 \\
\cline { 2 - 8 } & Sig. & & .004 & .021 & .063 & .304 & .000 \\
\hline $\mathrm{SSA}_{\mathrm{E}}$ & $\mathrm{r}$ & -.232 & 1 & .061 & .198 & .034 & -.172 \\
\cline { 2 - 8 } & Sig. & .004 & & .454 & .015 & .674 & .034 \\
\hline \multirow{2}{*}{$\mathrm{SSA}_{\mathrm{O}}$} & $\mathrm{r}$ & .187 & .061 & 1 & -.173 & -.192 & .583 \\
\cline { 2 - 8 } & Sig. & .021 & .454 & & .033 & .018 & .000 \\
\hline \multirow{2}{*}{$\mathrm{SSA}_{\mathrm{A}}$} & $\mathrm{r}$ & -.152 & .198 & -.173 & 1 & .291 & -.356 \\
\cline { 2 - 8 } & Sig. & .063 & .015 & .033 & & .000 & .000 \\
\hline $\mathrm{SSA}_{\mathrm{C}}$ & $\mathrm{r}$ & -.084 & .034 & -.192 & .291 & 1 & -.308 \\
\cline { 2 - 8 } & Sig. & .304 & .674 & .018 & .000 & & .000 \\
\hline $\mathrm{SSA}_{\mathrm{D}}$ & $\mathrm{r}$ & .369 & -.172 & .583 & -.356 & -.308 & 1 \\
\cline { 2 - 8 } & Sig. & .000 & .034 & .000 & .000 & .000 & \\
\hline
\end{tabular}

Note: $\mathrm{SSA}_{\mathrm{N}}-\mathrm{SSA}_{\mathrm{D}}$ - self-report measures assessing big six personality traits on SSA DOCEAN

Intercorrelations between basic personality traits assessed with ratings by experts are displayed in Table 41.

Table 41 Correlations matrix for ratings by experts

\begin{tabular}{|c|c|c|c|c|c|c|c|}
\hline & & $\mathrm{N}_{\mathrm{B}}$ & $\mathrm{E}_{\mathrm{B}}$ & $\mathrm{O}_{\mathrm{B}}$ & $\mathrm{A}_{\mathrm{B}}$ & $\mathrm{C}_{\mathrm{B}}$ & $\mathrm{D}_{\mathrm{B}}$ \\
\hline \multirow{2}{*}{$\mathrm{N}_{\mathrm{B}}$} & $\mathrm{r}$ & 1 & -.528 & -.326 & -.353 & -.392 & .545 \\
\cline { 2 - 8 } & Sig. & & .000 & .002 & .001 & .000 & .000 \\
\hline \multirow{2}{*}{$\mathrm{E}_{\mathrm{B}}$} & $\mathrm{r}$ & -.528 & 1 & .442 & .599 & .335 & -.343 \\
\cline { 2 - 8 } & Sig. & .000 & & .000 & .000 & .001 & .001 \\
\hline \multirow{2}{*}{$\mathrm{O}_{\mathrm{B}}$} & $\mathrm{r}$ & -.326 & .442 & 1 & .345 & .127 & -.088 \\
\cline { 2 - 8 } & Sig. & .002 & .000 & & .001 & .235 & .417 \\
\hline \multirow{2}{*}{$\mathrm{A}_{\mathrm{B}}$} & $\mathrm{r}$ & -.353 & .599 & .345 & 1 & .377 & -.396 \\
\cline { 2 - 8 } & Sig. & .001 & .000 & .001 & & .000 & .000 \\
\hline $\mathrm{C}_{\mathrm{B}}$ & $\mathrm{r}$ & -.392 & .335 & .127 & .377 & 1 & -.407 \\
\cline { 2 - 8 } & Sig. & .000 & .001 & .235 & .000 & & .000 \\
\hline \multirow{2}{*}{$\mathrm{D}_{\mathrm{B}} \mathrm{B}$} & $\mathrm{r}$ & .545 & -.343 & -.088 & -.396 & -.407 & 1 \\
\cline { 2 - 7 } & Sig. & .000 & .001 & .417 & .000 & .000 & \\
\hline
\end{tabular}

Note: $N_{B}-D_{B}-$ ratings by experts assessing big six personality traits

Intercorrelations between basic personality traits assessed with composite linguistic measures are displayed in Table 42. 
Table 42 Correlations matrix for linguistic measures

\begin{tabular}{|c|c|c|c|c|c|c|c|}
\hline & & $\mathrm{LIWCZ}_{\mathrm{N}}$ & LIWCZ $_{E}$ & $\mathrm{LIWCz}_{\mathrm{O}}$ & $\mathrm{LIWCz}_{\mathrm{A}}$ & $\mathrm{LIWCZ}_{\mathrm{C}}$ & $\mathrm{LIWCZ}_{\mathrm{D}}$ \\
\hline \multirow[t]{2}{*}{$\mathrm{LIWCz}_{\mathrm{N}}$} & $\mathrm{r}$ & 1 & .094 & .047 & .209 & .275 & .012 \\
\hline & Sig. & & .369 & .652 & .044 & .008 & .911 \\
\hline \multirow[t]{2}{*}{$\mathrm{LIWC}_{\mathrm{E}}$} & $\mathrm{r}$ & .094 & 1 & .118 & .195 & -.032 & .091 \\
\hline & Sig. & .369 & & .259 & .061 & .758 & .385 \\
\hline \multirow[t]{2}{*}{$\mathrm{LIWCz}_{\mathrm{O}}$} & $\mathrm{r}$ & .047 & .118 & 1 & .200 & .166 & .064 \\
\hline & Sig. & .652 & .259 & & .055 & .112 & .545 \\
\hline \multirow[t]{2}{*}{$\mathrm{LIWCz}_{\mathrm{A}}$} & $\mathrm{r}$ & .209 & .195 & .200 & 1 & .470 & .351 \\
\hline & Sig. & .044 & .061 & .055 & & .000 & .001 \\
\hline \multirow[t]{2}{*}{ LIWCZ $_{C}$} & $\mathrm{r}$ & .275 & -.032 & .166 & .470 & 1 & .128 \\
\hline & Sig. & .008 & .758 & .112 & .000 & & .222 \\
\hline \multirow[t]{2}{*}{$\mathrm{LIWCZ}_{\mathrm{D}}$} & $\mathrm{r}$ & .012 & .091 & .064 & .351 & .128 & 1 \\
\hline & Sig. & .911 & .385 & .545 & .001 & .222 & \\
\hline
\end{tabular}

Note: $\mathrm{LIWC}_{\mathrm{ZN}}-\mathrm{LIWC}_{\mathrm{ZD}}$ - composite linguistic measures assessing big six personality traits

\subsubsection{Correlations of IATs and Self-report Measures for Seven Basic Personality Domains}

All significance tests were conducted with $\alpha \leq 0.05$. Overall, the correlation coefficients obtained for the IATs and the corresponding explicit measures indicated that these assessment methods measured different constructs, or different aspects of the same construct. Only IATN and IATE weakly correlated with the corresponding selfreport measures (Table 43). However, these results are in accordance with previous researches that show weak and inconsistent correlations between IATs and self-report measures (Back et al., 2010; Steffens \& Schulze-König, 2006). Several hetero traithetero method correlations suggested problems with the construct validities of IATs. We can notice that the self-reported Openness had significant correlations with Agreeableness, Conscientiousness, Disintegration, and Intelligence IATs. 
Table 43 Correlations of IATs and self-report measuring corresponding personality traits

\begin{tabular}{|c|c|c|c|c|c|c|c|c|}
\hline \multicolumn{2}{|c|}{ Domain } & $\mathrm{N}_{\mathrm{SR}}$ & $\mathrm{E}_{\mathrm{SR}}$ & $\mathrm{O}_{\mathrm{SR}}$ & $\mathrm{A}_{\mathrm{SR}}$ & $\mathrm{S}_{\mathrm{SR}}$ & $\mathrm{D}_{\mathrm{SR}}$ & KOG9 \\
\hline \multirow{2}{*}{$\mathrm{IAT}_{\mathrm{N}}$} & $\mathrm{r}$ & $-.168^{*}$ & .037 & -.079 & -.019 & .109 & -.022 & -.071 \\
\cline { 2 - 10 } & $\mathrm{Sig}$. & .012 & .582 & .240 & .773 & .105 & .744 & .289 \\
\hline \multirow{2}{*}{$\mathrm{IAT}_{\mathrm{E}}$} & $\mathrm{r}$ & -.101 & $.155^{*}$ & -.076 & -.036 & .118 & -.070 & $.196^{* *}$ \\
\cline { 2 - 9 } & $\mathrm{Sig}$. & .134 & .020 & .259 & .597 & .077 & .294 & .003 \\
\hline \multirow{2}{*}{$\mathrm{IAT}_{\mathrm{O}}$} & $\mathrm{r}$ & .050 & .099 & -.081 & -.027 & .021 & .062 & .004 \\
\cline { 2 - 9 } & Sig. & .454 & .140 & .227 & .682 & .752 & .356 & .952 \\
\hline \multirow{2}{*}{$\mathrm{IAT}_{\mathrm{A}}$} & $\mathrm{r}$ & .059 & -.099 & $-.186^{* *}$ & -.017 & .028 & .059 & -.079 \\
\cline { 2 - 9 } & Sig. & .380 & .138 & .005 & .798 & .682 & .377 & .240 \\
\hline \multirow{2}{*}{$\mathrm{IAT}_{\mathrm{C}}$} & $\mathrm{r}$ & .022 & .026 & $-.157^{*}$ & -.050 & .000 & -.009 & -.031 \\
\cline { 2 - 9 } & Sig. & .748 & .703 & .019 & .457 & .998 & .892 & .642 \\
\hline \multirow{2}{*}{$\mathrm{IAT}_{\mathrm{D}}$} & $\mathrm{r}$ & .079 & -.046 & $-.134^{*}$ & .028 & -.025 & .053 & $-.224^{* *}$ \\
\cline { 2 - 9 } & Sig. & .240 & .489 & .046 & .677 & .706 & .428 & .001 \\
\hline \multirow{2}{*}{$\mathrm{IAT}_{\mathrm{I}}$} & $\mathrm{r}$ & .100 & -.112 & $-.216^{* *}$ & -.089 & -.042 & .037 & -.069 \\
\cline { 2 - 9 } & Sig. & .136 & .094 & .001 & .186 & .532 & .585 & .306 \\
\hline
\end{tabular}

*. Correlation is significant at the 0.05 level (2-tailed).

**. Correlation is significant at the 0.01 level (2-tailed).

Note: statistically significant validity coefficients are bolded, while hetero trait-hetero method correlations are in italics.

IAT $_{N}-$ IAT $_{I}-$ IATs measuring basic personality traits; $N_{S R}-D_{S R}-$ self-reported measures of big six personality traits on NEO PI R and DELTA 10; KOG9-objective measure of general cognitive ability

Partial correlation analyses showed that, when controlled for Openness, the correlations between IATN and IATE, and the corresponding self-report measures srose slightly (Table 44). A similar tendency was noticed in the relations between other IATs and the corresponding self-report measures, but these correlations were not sufficiently strong to reach statistical significance.

Table 44 Partial correlations of $\mathrm{IAT}_{\mathrm{N}}$ and $\mathrm{IAT}_{\mathrm{E}}$ and self-reports measuring corresponding traits, controlled for Openness (self-report)

\begin{tabular}{|c|c|c|c|}
\hline \multirow{4}{*}{$\mathrm{O}_{\mathrm{SR}}$} & \multicolumn{2}{|c|}{} & $\mathrm{N}_{\mathrm{SR}}$ \\
\cline { 2 - 4 } & \multirow{2}{*}{$\mathrm{IAT}_{\mathrm{N}}$} & $\mathrm{r}$ & -.186 \\
\cline { 2 - 4 } & & Sig. & .005 \\
\cline { 2 - 4 } & \multirow{2}{*}{$\mathrm{IAT}_{\mathrm{E}}$} & $\mathrm{r}$ & .194 \\
\cline { 3 - 4 } & & Sig. & .004 \\
\hline
\end{tabular}

Note: IAT $_{\mathrm{N}}-\mathrm{IAT}_{\mathrm{N}}$ measuring Neuroticism; $\mathrm{IAT}_{\mathrm{E}}$ - IAT measuring -Extraversion; $\mathrm{N}_{\mathrm{SR}}$-self-reported measures of Neuroticism on NEO PI R; $E_{S R}$ - self-reported measures of Extraversion on NEO PI R

Based on the results of partial correlations and regression analysis, a general tendency could be discerned in the subjects with higher scores on the self-reported 
Openness score, to automatically associate the negative attributes with the category $I$ and positive attributes with the category Others.

Since significant correlations between IATs and self-reports were observed only for Neuroticism and Extraversion, an attempt was made to verify if the specificity of the item formulation of self-report measures would have an impact on the correlations with IATs. Therefore, tests were carried out to see whether the IATs had larger correlations with self-report measure, formed as 60 item-attribute scale, representing big six personality traits (SSA DOCEAN) (Knežević \& Lazarević, 2011; Lazarević \& Knežević, 2012). Results of the tests are displayed in Table 45.

Table 45 Correlations of IATs and dimensions from Short Scale of Attributes (SSA) DOCEAN on 224 respondents

\begin{tabular}{|c|c|c|c|c|c|c|c|}
\hline & & $\mathrm{SSA}_{\mathrm{N}}$ & $\mathrm{SSA}_{\mathrm{E}}$ & $\mathrm{SSA}_{\mathrm{O}}$ & $\mathrm{SSA}_{\mathrm{A}}$ & $\mathrm{SSA}_{\mathrm{C}}$ & $\mathrm{SSA}_{\mathrm{D}}$ \\
\hline \multirow{2}{*}{ IATN } & $\mathrm{r}$ & -.004 & -.020 & -.067 & $-.167^{*}$ & .052 & -.015 \\
\hline & Sig. & .953 & .767 & .315 & .012 & .441 & .818 \\
\hline \multirow{2}{*}{ IATE } & $\mathrm{r}$ & -.024 & $.244^{* * *}$ & $.173^{* * *}$ & $-.195^{* *}$ & -.044 & -.025 \\
\hline & Sig. & .720 & .000 & .010 & .003 & .512 & .710 \\
\hline \multirow{2}{*}{ IATO } & $\mathrm{r}$ & .012 & .087 & $.192^{* * *}$ & -.101 & $.143^{*}$ & -.038 \\
\hline & Sig. & .863 & .195 & .004 & .133 & .033 & .576 \\
\hline \multirow{2}{*}{ IATA } & $\mathrm{r}$ & -.091 & .036 & $.154^{*}$ & -.021 & .085 & -.128 \\
\hline & Sig. & .173 & .588 & .021 & .756 & .205 & .056 \\
\hline \multirow{2}{*}{ IATC } & $\mathrm{r}$ & .010 & .055 & $.164^{*}$ & .025 & $.152^{*}$ & .016 \\
\hline & Sig. & .882 & .413 & .014 & .709 & .023 & .807 \\
\hline \multirow{2}{*}{ IATD } & $\mathrm{r}$ & -.095 & -.041 & .112 & -.032 & .095 & -.066 \\
\hline & Sig. & .157 & .540 & .094 & .639 & .154 & .329 \\
\hline
\end{tabular}

Note: IAT $_{N}-$ IAT $_{D^{-}}$IATs assessing basic six personality traits; $\mathrm{SSA}_{N}-\mathrm{SSA}_{\mathrm{D}}-$ Short scale of attributes assessing basic six personality traits

These results showed that the diverse item formulation in implicit and explicit measures was not a source of lower correlations displayed previously. 


\subsubsection{Correlations of IATs and Ratings by Close Others for Six basic Personality Domains}

While correlating the IATs and female observer ratings, no significant correlations were observed between the IATs and the corresponding explicit measures (i.e., validity coefficients) (Table 46). Significant hetero trait-hetero method correlations did not go in favour of the discriminant validity of IAT as an assessment method.

Table 46 Correlations of IATs and female observer ratings measuring corresponding traits

\begin{tabular}{|c|c|c|c|c|c|c|c|}
\hline \multicolumn{2}{|c|}{ Domain } & $\mathrm{N}_{\mathrm{F}}$ & $\mathrm{E}_{\mathrm{F}}$ & $\mathrm{O}_{\mathrm{F}}$ & $\mathrm{A}_{\mathrm{F}}$ & $\mathrm{S}_{\mathrm{F}}$ & $\mathrm{D}_{\mathrm{F}}$ \\
\hline \multirow{2}{*}{$\mathrm{IAT}_{\mathrm{N}}$} & $\mathrm{r}$ & -.099 & .020 & -.071 & -.029 & .010 & $-.133^{*}$ \\
\cline { 2 - 8 } & $\mathrm{Sig}$. & .139 & .771 & .290 & .666 & .883 & .046 \\
\hline \multirow{2}{*}{$\mathrm{IAT}_{\mathrm{E}}$} & $\mathrm{r}$ & -.061 & .065 & -.087 & $-.188^{* *}$ & -.037 & -.009 \\
\cline { 2 - 8 } & $\mathrm{Sig}$ & .366 & .336 & .194 & .005 & .586 & .892 \\
\hline \multirow{2}{*}{$\mathrm{IAT}_{\mathrm{O}}$} & $\mathrm{r}$ & .120 & .060 & .072 & -.096 & -.016 & .130 \\
\cline { 2 - 8 } & $\mathrm{Sig}$ & .072 & .371 & .285 & .150 & .809 & .051 \\
\hline \multirow{2}{*}{$\mathrm{IAT}_{\mathrm{A}}$} & $\mathrm{r}$ & .085 & $-.166^{*}$ & $-.150^{*}$ & -.091 & -.041 & .014 \\
\cline { 2 - 8 } & $\mathrm{Sig}$ & .204 & .013 & .025 & .176 & .537 & .835 \\
\hline \multirow{2}{*}{$\mathrm{IAT}_{\mathrm{C}}$} & $\mathrm{r}$ & .096 & -.121 & -.071 & -.047 & -.071 & .069 \\
\cline { 2 - 8 } & $\mathrm{Sig}$. & .152 & .071 & .289 & .486 & .287 & .303 \\
\hline \multirow{2}{*}{$\mathrm{IAT}_{\mathrm{D}}$} & $\mathrm{r}$ & $.175^{* *}$ & $-.154^{*}$ & -.102 & -.110 & -.085 & .095 \\
\cline { 2 - 8 } & $\mathrm{Sig}$. & .009 & .021 & .127 & .101 & .205 & .154 \\
\hline
\end{tabular}

* Correlation is significant at the 0.05 level (2-tailed).

** Correlation is significant at the 0.01 level (2-tailed).

Note: Heterotrait-heteromethod correlations are in italics.

Note: $\mathrm{IAT}_{\mathrm{N}}-\mathrm{IAT}_{\mathrm{D}^{-}}$IATs assessing basic six personality traits; $\mathrm{N}_{\mathrm{F}}-\mathrm{D}_{\mathrm{F}}$ - ratings by close female others assessing basic six personality traits

When correlating the IATs and male observer ratings, significant correlation was found only for IATA and Agreeableness assessed by the male observer ratings. Other IATs did not correlate significantly with other corresponding male observer ratings (Table 47). 
Table 47 Correlations of IATs and male observer ratings measuring corresponding traits

\begin{tabular}{|c|c|c|c|c|c|c|c|}
\hline \multicolumn{2}{|c|}{ Domain } & $\mathrm{N}_{\mathrm{M}}$ & $\mathrm{E}_{\mathrm{M}}$ & $\mathrm{O}_{\mathrm{M}}$ & $\mathrm{A}_{\mathrm{M}}$ & $\mathrm{S}_{\mathrm{M}}$ & $\mathrm{D}_{\mathrm{M}}$ \\
\hline \multirow{2}{*}{$\mathrm{IAT}_{\mathrm{N}}$} & $\mathrm{r}$ & -.065 & .046 & -.006 & -.104 & .043 & -.057 \\
\cline { 2 - 8 } & Sig. & .335 & .492 & .930 & .120 & .522 & .399 \\
\hline \multirow{2}{*}{$\mathrm{IAT}_{\mathrm{E}}$} & $\mathrm{r}$ & .018 & -.041 & -.078 & -.116 & -.054 & -.024 \\
\cline { 2 - 8 } & Sig. & .792 & .542 & .248 & .083 & .418 & .719 \\
\hline \multirow{2}{*}{$\mathrm{IAT}_{\mathrm{O}}$} & $\mathrm{r}$ & .064 & -.002 & .016 & $-.197^{* *}$ & -.095 & .033 \\
\cline { 2 - 8 } & Sig. & .339 & .982 & .807 & .003 & .155 & .620 \\
\hline \multirow{2}{*}{$\mathrm{IAT}_{\mathrm{A}}$} & $\mathrm{r}$ & .121 & -.012 & -.010 & $-.134^{*}$ & .051 & .051 \\
\cline { 2 - 8 } & Sig. & .071 & .861 & .877 & .046 & .447 & .449 \\
\hline \multirow{2}{*}{$\mathrm{IAT}_{\mathrm{C}}$} & $\mathrm{r}$ & .075 & -.127 & -.085 & $-.153^{*}$ & -.021 & -.003 \\
\cline { 2 - 8 } & Sig. & .265 & .058 & .205 & .022 & .755 & .963 \\
\hline \multirow{2}{*}{$\mathrm{IAT}_{\mathrm{D}}$} & $\mathrm{r}$ & .056 & -.037 & -.031 & -.023 & -.015 & .019 \\
\cline { 2 - 8 } & Sig. & .406 & .585 & .649 & .729 & .827 & .775 \\
\hline
\end{tabular}

* Correlation is significant at the 0.05 level (2-tailed).

** Correlation is significant at the 0.01 level (2-tailed).

Note: statistically significant validity coefficients are bolded, while heterotrait-heteromethod correlations are in italics.

Note: IAT $_{N}-$ IAT $_{D^{-}}$IATs assessing basic six personality traits; $N_{M}-D_{M}-$ ratings by close male others assessing basic six personality traits

The study also tried to test if the principal components extracted (with Promax rotation) from differential score on the attributes used in IAT (the RT for a specific attribute was divided with SD for that attribute and these scores were used for the Principal Component Analysis) would have higher correlations with self-reports and observer ratings. The basic assumption was that the factor would score better as reflecting the latent traits would increase the correlations between the explicit and implicit measures. Although the extracted factors were saturated with adequate attributes (pattern matrix is displayed in Appendix 12), it did not lead to an improvement in correlations between the implicit measures on the one hand, and selfreports and ratings by close others on the other. No significant correlations were found between the IAT factor scores and explicit measures. 


\subsubsection{Correlations of IAT and Measures of Intellectual Abilities}

Results from all the analyses showed that the strength of automatic associations in IATs measuring intellectual abilities did not have significant correlations with the objective (KOG9) and self-reported measure of intellectual abilities. However, the selfassessment measure had significant correlation with the objective cognitive measure (KOG9) (Table 48).

Table 48 Correlations of Self-assessment of intellectual abilities with principal component on

\begin{tabular}{|c|c|c|c|}
\multicolumn{3}{|c|}{ KOG9 and IATI } \\
\hline \multirow{2}{*}{ IQSelf } & r & $.172(*)$ & .006 \\
\cline { 2 - 4 } & Sig. & .010 & .929 \\
\hline
\end{tabular}

* Correlation is significant at the 0.05 level (2-tailed).

Note: IQSelf- self assessment of intellectual abilities; IATI-IAT for assessment of intellectual abilities; KOG9-objective measure of intellectual abilities

\subsubsection{Correlations of IATs and Behavioural Measures}

When correlating the IATs and composite behavioural measures, no significant validity coefficients were found (Table 49).

Table 49 Correlations of IATs and composite behavioural measures (behavioural indicators and LIWC), sample 99 respondents

\begin{tabular}{|c|c|c|c|c|c|c|c|}
\hline \multicolumn{2}{|c|}{} & NB & EB & OB & AB & CB & DB \\
\hline \multirow{2}{*}{$\mathrm{IAT}_{\mathrm{N}}$} & $\mathrm{r}$ & -.058 & .100 & .153 & .197 & .022 & -.032 \\
\cline { 2 - 8 } & Sig. & .583 & .342 & .150 & .065 & .833 & .769 \\
\hline \multirow{2}{*}{$\mathrm{IAT}_{\mathrm{E}}$} & $\mathrm{r}$ & -.100 & .008 & .166 & -.168 & -.010 & .074 \\
\cline { 2 - 8 } & Sig. & .344 & .940 & .118 & .115 & .923 & .493 \\
\hline \multirow{2}{*}{$\mathrm{IAT}_{\mathrm{O}}$} & $\mathrm{r}$ & -.082 & .155 & .032 & .048 & .039 & .059 \\
\cline { 2 - 8 } & Sig. & .439 & .139 & .764 & .654 & .718 & .583 \\
\hline \multirow{2}{*}{$\mathrm{IAT}_{\mathrm{A}}$} & $\mathrm{r}$ & .032 & -.054 & .145 & .013 & .022 & .052 \\
\cline { 2 - 8 } & Sig. & .764 & .608 & .174 & .906 & .835 & .629 \\
\hline \multirow{2}{*}{$\mathrm{IAT}_{\mathrm{C}}$} & $\mathrm{r}$ & -.070 & .049 & .052 & $.211^{*}$ & -.162 & -.075 \\
\cline { 2 - 8 } & Sig. & .507 & .642 & .624 & .047 & .128 & .485 \\
\hline \multirow{2}{*}{$\mathrm{IAT}_{\mathrm{D}}$} & $\mathrm{r}$ & .030 & .053 & .144 & .135 & .012 & -.070 \\
\cline { 2 - 8 } & Sig. & .779 & .615 & .176 & .206 & .913 & .515 \\
\hline
\end{tabular}

* Correlation is significant at the 0.05 level (2-tailed).

Note: IAT $_{N}-\mathrm{IAT}_{\mathrm{D}}-$ IATs measuring big six personality traits; $\mathrm{N}_{\mathrm{B}}-\mathrm{D}_{\mathrm{B}}$ - ratings by experts on big six personality traits 


\subsubsection{Correlations of IATs and LIWC Parameters}

Based on some previous results indicating correlations between the IAT and LIWC measures (Bosson et al., 2000; Cohen, Beck, Brown, \& Najolia, 2010), the relations between them were tested.

As already mentioned, the new composite LIWC personality measures were calculated with IATs as the dependent variables. These steps understandably led to a significant increase in correlations between the IAT and LIWC measures (Table 50).

Table 50 Correlations of IATs and standardized composite LIWC measures, sample of 99 respondents

\begin{tabular}{|c|c|c|c|c|c|c|c|}
\hline & & $\mathrm{LIWCZ}_{\mathrm{N}}$ & $\mathrm{LIWCZ}_{\mathrm{E}}$ & $\mathrm{LIWCz}_{\mathrm{O}}$ & $\mathrm{LIWCz}_{\mathrm{A}}$ & $\mathrm{LIWCz}_{\mathrm{C}}$ & LIWCZ $_{D}$ \\
\hline \multirow{2}{*}{$\mathrm{IAT}_{\mathrm{N}}$} & $\mathrm{r}$ & $.477^{* * *}$ & .101 & .057 & .198 & .030 & .096 \\
\hline & Sig. & .000 & .334 & .584 & .058 & .777 & .359 \\
\hline \multirow{2}{*}{$\mathrm{IAT}_{\mathrm{E}}$} & $r$ & .019 & $.486^{* *}$ & .080 & .087 & .016 & .109 \\
\hline & Sig. & .859 & .000 & .446 & .404 & .883 & .298 \\
\hline \multirow{2}{*}{$\mathrm{IAT}_{\mathrm{O}}$} & $r$ & .096 & .089 & $.521^{* *}$ & .080 & .153 & $.206^{*}$ \\
\hline & Sig. & .361 & .398 & .000 & .445 & .142 & .048 \\
\hline \multirow{2}{*}{$\mathrm{IAT}_{\mathrm{A}}$} & $\mathrm{r}$ & .175 & .163 & $.206^{*}$ & $.537^{* *}$ & $.262^{*}$ & $.206^{*}$ \\
\hline & Sig. & .094 & .119 & .048 & .000 & .011 & .047 \\
\hline \multirow{2}{*}{$\mathrm{IAT}_{\mathrm{C}}$} & $\mathrm{r}$ & .189 & .040 & .127 & $.263^{*}$ & $.463^{* * *}$ & $.262^{*}$ \\
\hline & Sig. & .070 & .705 & .225 & .011 & .000 & .011 \\
\hline \multirow{2}{*}{$\mathrm{IAT}_{\mathrm{D}}$} & $\mathrm{r}$ & .087 & -.032 & .146 & $.340^{* *}$ & $.218^{*}$ & $.565^{* *}$ \\
\hline & Sig. & .406 & .764 & .163 & .001 & .036 & .000 \\
\hline
\end{tabular}

*. Correlation is significant at the 0.05 level (2-tailed).

**. Correlation is significant at the 0.01 level (2-tailed).

Note: $\mathrm{IAT}_{\mathrm{N}}-\mathrm{IAT}_{\mathrm{D}}$ - personality IAT assessing big six personality traits; $\mathrm{LIWCZ}_{\mathrm{N}}-$ standardized LIWC Neuroticism measure; $\mathrm{LIWC}_{\mathrm{E}}$ - standardized LIWC Extraversion measure; $\mathrm{LIWCz}_{\mathrm{O}}$ - standardized LIWC Openness measure; $\mathrm{LIWCz}_{\mathrm{A}}$ - standardized LIWC Agreeableness measure; $\mathrm{LIWCz}_{\mathrm{C}}-$ standardized LIWC Conscientiousness measure; $\mathrm{LIWCz}_{\mathrm{D}}$ - standardized LIWC Disintegration measure.

\subsection{Correlations of Explicit Measures}

\subsubsection{Correlations of Self-reports and Ratings by Close Others}

Table 51 and Table 52 display the correlations between self-reports and the female and male observer ratings, respectively. Results indicated moderate correlations in accordance with several previous studies on the convergent validity of both the 
assessment methods (Conolly, Kavanagh, \& Viswesvaren, 2007; Funder, Kolar, \& Blackman, 1995; Vazire, 2006; Vazire \& Mehl, 2008; Knežević, 2011).

Table 51 Correlations of self-report and female observer ratings, sample of 224 respondents

\begin{tabular}{|c|c|c|c|c|c|c|c|}
\hline & & $\mathrm{N}_{\mathrm{F}}$ & $\mathrm{E}_{\mathrm{F}}$ & $\mathrm{O}_{\mathrm{F}}$ & $\mathrm{A}_{\mathrm{F}}$ & $\mathrm{C}_{\mathrm{F}}$ & $\mathrm{D}_{\mathrm{F}}$ \\
\hline \multirow{2}{*}{$\mathrm{N}_{\mathrm{SR}}$} & $\mathrm{r}$ & $\mathbf{. 4 2 9}^{* * *}$ & $-.180^{* *}$ & -.103 & $-.189^{* *}$ & -.111 & $.218^{* *}$ \\
\cline { 2 - 8 } & $\mathrm{Sig}$. & $\mathbf{. 0 0 0}^{*}$ & .007 & .126 & .004 & .096 & .001 \\
\hline \multirow{2}{*}{$\mathrm{E}_{\mathrm{SR}}$} & $\mathrm{r}$ & $-.213^{* *}$ & $\mathbf{. 6 3 7}^{* *}$ & $.176^{* *}$ & .017 & .055 & $-.189^{* *}$ \\
\cline { 2 - 8 } & $\mathrm{Sig}$. & .001 & $\mathbf{. 0 0 0}^{* *}$ & .008 & .797 & .415 & .005 \\
\hline \multirow{2}{*}{$\mathrm{O}_{\mathrm{SR}}$} & $\mathrm{r}$ & $-.335^{* *}$ & $.323^{* *}$ & $\mathbf{. 3 9 2}^{* *}$ & .086 & $.264^{* *}$ & -.092 \\
\cline { 2 - 8 } & $\mathrm{Sig}$. & .000 & .000 & $\mathbf{. 0 0 0}$ & .198 & .000 & .169 \\
\hline \multirow{2}{*}{$\mathrm{A}_{\mathrm{SR}}$} & $\mathrm{r}$ & $-.167^{*}$ & $.136^{*}$ & .043 & $\mathbf{. 4 3 4}$ & .062 & -.109 \\
\cline { 2 - 8 } & $\mathrm{Sig}$. & .012 & .042 & .517 & $\mathbf{. 0 0 0}$ & .353 & .104 \\
\hline \multirow{2}{*}{$\mathrm{C}_{\mathrm{SR}}$} & $\mathrm{r}$ & $-.184^{* *}$ & .098 & .048 & .049 & $\mathbf{. 5 1 5}$ & -.049 \\
\cline { 2 - 8 } & $\mathrm{Sig}$. & .006 & .142 & .473 & .467 & $\mathbf{. 0 0 0}$ & .466 \\
\hline \multirow{2}{*}{$\mathrm{D}_{\mathrm{SR}}$} & $\mathrm{r}$ & .124 & $-.132^{*}$ & .059 & $-.169^{*}$ & -.033 & $\mathbf{. 4 1 1}$ \\
\cline { 2 - 8 } & $\mathrm{Sig}$. & .063 & .049 & .376 & .011 & .621 & $\mathbf{. 0 0 0}$ \\
\hline
\end{tabular}

**. Correlation is significant at the 0.01 level (2-tailed).

*. Correlation is significant at the 0.05 level (2-tailed).

Note: $\mathrm{N}_{\mathrm{SR}}-\mathrm{D}_{\mathrm{SR}}-$ self-reported measures of big six personality traits on NEO PI R and DELTA 10; $\mathrm{N}_{\mathrm{F}}-$ $\mathrm{D}_{\mathrm{F}}$ - ratings by close female others assessing basic six personality traits

The male observer ratings showed lower correlations with self-reports on all the personality traits, except Disintegration, as compared to female ratings (Table 52).

Table 52 Correlations of self-report and male observer ratings, sample of 224 respondents

\begin{tabular}{|c|c|c|c|c|c|c|c|}
\hline & & $\mathrm{N}_{\mathrm{M}}$ & $\mathrm{E}_{\mathrm{M}}$ & $\mathrm{O}_{\mathrm{M}}$ & $\mathrm{A}_{\mathrm{M}}$ & $\mathrm{C}_{\mathrm{M}}$ & $\mathrm{D}_{\mathrm{M}}$ \\
\hline \multirow{2}{*}{$\mathrm{N}_{\mathrm{SR}}$} & $\mathrm{r}$ & $.298^{* * *}$ & $-.236^{* * *}$ & -.106 & -.033 & .017 & $.135^{*}$ \\
\hline & Sig. & .000 & .000 & .115 & .618 & .800 & .043 \\
\hline \multirow{2}{*}{$\mathrm{E}_{\mathrm{SR}}$} & $\mathrm{r}$ & $-.236^{* * *}$ & $.552^{* * *}$ & $.165^{*}$ & .015 & -.012 & $-.188^{* * *}$ \\
\hline & Sig. & .000 & .000 & .013 & .825 & .861 & .005 \\
\hline \multirow{2}{*}{$\mathrm{O}_{\mathrm{SR}}$} & $\mathrm{r}$ & $-.286^{* *}$ & $.202^{* *}$ & $.316^{* * *}$ & .111 & $.167^{*}$ & -.065 \\
\hline & Sig. & .000 & .002 & .000 & .097 & .012 & .334 \\
\hline \multirow{2}{*}{$\mathrm{A}_{\mathrm{SR}}$} & $\mathrm{r}$ & -.082 & $.201^{* *}$ & .118 & $.310^{* * *}$ & .076 & -.088 \\
\hline & Sig. & .222 & .003 & .079 & .000 & .260 & .190 \\
\hline \multirow{2}{*}{$\mathrm{C}_{\mathrm{SR}}$} & $\mathrm{r}$ & -.118 & -.039 & .021 & -.033 & $.405^{* * *}$ & -.070 \\
\hline & Sig. & .078 & .559 & .755 & .627 & .000 & .293 \\
\hline \multirow{2}{*}{$\mathrm{D}_{\mathrm{SR}}$} & $\mathrm{r}$ & $.145^{*}$ & $-.178^{* * *}$ & -.071 & $-.135^{*}$ & -.010 & $.440^{* * *}$ \\
\hline & Sig. & .030 & .008 & .289 & .044 & .878 & .000 \\
\hline
\end{tabular}

**. Correlation is significant at the 0.01 level (2-tailed).

*. Correlation is significant at the 0.05 level (2-tailed).

Note: $\mathrm{N}_{\mathrm{SR}}-\mathrm{D}_{\mathrm{SR}}-$ self-reported measures of big six personality traits on NEO PI R and DELTA $10 ; \mathrm{N}_{\mathrm{M}}-$ $\mathrm{D}_{\mathrm{M}}$ - ratings by close male others assessing basic six personality traits

The correlations of both the female and male observer ratings with self-reports showed lower correlations for the traits that are less visible in behaviour, or more 
difficult to rate (e.g., Neuroticism, Openness), which was consistent with some previous findings (Funder \& Colvin, 1988).

Results showed that female and male observer ratings (in this case, the parents' observer ratings) correlated moderately, which is again consistent with other previous findings (Table 53) (Funder et al., 1995; McCrae \& Costa, 1987).

Table 53 Correlations of female and male observer ratings, sample of 224 respondents

\begin{tabular}{|c|c|c|c|c|c|c|c|}
\hline \multicolumn{2}{|c|}{} & $\mathrm{N}_{\mathrm{M}}$ & $\mathrm{E}_{\mathrm{M}}$ & $\mathrm{O}_{\mathrm{M}}$ & $\mathrm{A}_{\mathrm{M}}$ & $\mathrm{C}_{\mathrm{M}}$ & $\mathrm{D}_{\mathrm{M}}$ \\
\hline \multirow{2}{*}{$\mathrm{N}_{\mathrm{F}}$} & $\mathrm{r}$ & $\mathbf{. 5 6 4}^{* * *}$ & $-.174^{* *}$ & -.114 & $-.186^{* *}$ & $-.296^{* *}$ & $.322^{* *}$ \\
\cline { 2 - 8 } & Sig. & $\mathbf{. 0 0 0}^{*}$ & .007 & .082 & .004 & .000 & .000 \\
\hline \multirow{2}{*}{$\mathrm{E}_{\mathrm{F}}$} & $\mathrm{r}$ & $-.191^{* *}$ & $\mathbf{. 5 3 7}^{* *}$ & $.232^{* *}$ & .114 & .031 & $-.151^{*}$ \\
\cline { 2 - 8 } & Sig. & .003 & $\mathbf{. 0 0 0}^{*}$ & .000 & .079 & .640 & .021 \\
\hline \multirow{2}{*}{$\mathrm{O}_{\mathrm{F}}$} & $\mathrm{r}$ & -.020 & $.198^{* *}$ & $\mathbf{. 3 3 8}^{* *}$ & .050 & .007 & .016 \\
\cline { 2 - 8 } & Sig. & .755 & .002 & $\mathbf{. 0 0 0}^{* *}$ & .443 & .911 & .806 \\
\multirow{2}{*}{$\mathrm{A}_{\mathrm{F}}$} & $\mathrm{r}$ & $-.250^{* *}$ & $.153^{*}$ & $.153^{*}$ & $\mathbf{. 4 7 3}^{* *}$ & $.184^{* *}$ & $-.246^{* *}$ \\
\cline { 2 - 8 } & Sig. & .000 & .019 & .018 & $\mathbf{. 0 0 0}^{* *}$ & .005 & .000 \\
\hline \multirow{2}{*}{$\mathrm{C}_{\mathrm{F}}$} & $\mathrm{r}$ & $-.379^{* *}$ & .031 & .014 & $.231^{* *}$ & $\mathbf{. 6 3}^{* *}$ & $-.264^{* *}$ \\
\cline { 2 - 8 } & Sig. & .000 & .638 & .834 & .000 & $\mathbf{. 0 0 0}^{* *}$ & .000 \\
\hline \multirow{2}{*}{$\mathrm{D}_{\mathrm{F}}$} & $\mathrm{r}$ & $.291^{* *}$ & $-.151^{*}$ & -.112 & -.120 & $-.162^{*}$ & $\mathbf{. 5 4 8}$ \\
\cline { 2 - 8 } & Sig. & .000 & .021 & .086 & .067 & .013 & $\mathbf{. 0 0 0}$ \\
\hline
\end{tabular}

**. Correlation is significant at the 0.01 level (2-tailed).

*. Correlation is significant at the 0.05 level (2-tailed).

Note: $\mathrm{N}_{\mathrm{F}}-\mathrm{D}_{\mathrm{F}}$ - ratings by close female others assessing basic six personality traits; $\mathrm{N}_{\mathrm{M}}-\mathrm{D}_{\mathrm{M}}-$ ratings by close male others assessing basic six personality traits

\subsubsection{Correlations of Self-reports and Ratings by Experts}

Table 54 displays correlations between the self-report measures of the six big personality traits and the composite behavioural measures, obtained on the subsample of 99 respondents. 
Table 54 Correlations of self-reports and composite behavioural measures, sample of 99 respondents

\begin{tabular}{|c|c|c|c|c|c|c|c|}
\hline \multicolumn{2}{|c|}{ Domain } & $\mathrm{NB}$ & $\mathrm{EB}$ & $\mathrm{OB}$ & $\mathrm{AB}$ & $\mathrm{CB}$ & $\mathrm{DB}$ \\
\hline \multirow{2}{*}{$\mathrm{N}_{\mathrm{SR}}$} & $\mathrm{r}$ & $.416^{* *}$ & $-.466^{* *}$ & -.111 & -.083 & $-.257 *$ & $.260^{*}$ \\
\cline { 2 - 8 } & $\mathrm{Sig}$. & .000 & .000 & .303 & .438 & .015 & .012 \\
\hline \multirow{2}{*}{$\mathrm{E}_{\mathrm{SR}}$} & $\mathrm{r}$ & -.175 & $.336^{* *}$ & .103 & .066 & .085 & .057 \\
\cline { 2 - 8 } & Sig. & .101 & .001 & .336 & .537 & .427 & .591 \\
\hline \multirow{2}{*}{$\mathrm{O}_{\mathrm{SR}}$} & $\mathrm{r}$ & -.090 & .043 & .188 & -.010 & .111 & .159 \\
\cline { 2 - 8 } & Sig. & .409 & .692 & .082 & .930 & .308 & .133 \\
\hline \multirow{2}{*}{$\mathrm{A}_{\mathrm{SR}}$} & $\mathrm{r}$ & .014 & .187 & -.016 & .140 & .109 & .068 \\
\cline { 2 - 8 } & Sig. & .901 & .085 & .883 & .200 & .319 & .525 \\
\hline \multirow{2}{*}{$\mathrm{C}_{\mathrm{SR}}$} & $\mathrm{r}$ & -.132 & $.305^{* *}$ & .095 & .125 & .015 & -.158 \\
\cline { 2 - 8 } & Sig. & .222 & .004 & .381 & .248 & .888 & .136 \\
\hline \multirow{2}{*}{$\mathrm{D}_{\mathrm{SR}}$} & $\mathrm{r}$ & $.321 * *$ & $-.460 * *$ & -.107 & $-.399 * *$ & -.184 & $.407 * *$ \\
\cline { 2 - 8 } & Sig. & .003 & .000 & .326 & .000 & .090 & .000 \\
\hline
\end{tabular}

**. Correlation is significant at the 0.01 level (2-tailed).

*. Correlation is significant at the 0.05 level (2-tailed).

Note: $\mathrm{N}_{\mathrm{SR}}-\mathrm{D}_{\mathrm{SR}}-$ self-reported measures of big six personality traits on NEO PI R and DELTA $10 ; \mathrm{N}_{\mathrm{B}}-$ $D_{B}$ - ratings by experts assessing basic six personality traits

Results indicated a moderate convergent-discriminative validity of the selfreports and behavioural measures on Neuroticism, Extraversion and Disintegration. There was a lack of significant correlation for Conscientiousness, Agreeableness and Openness.

\subsubsection{Correlations of Behavioural Indicators and Self-reports}

Results on correlations between the behavioural indicators and corresponding self-reports (NEO PIR and DELTA 10) are displayed in Table 55. Abbreviations of names of behavioural indicators are provided in Appendix 13.

Table 55 Correlations of self-reported Neuroticism and behavioural indicators, sample of 99 respondents

\begin{tabular}{|l|c|c|c|c|c|c|c|c|c|}
\hline & & globbeh & globVF & gazeaver & tensebody & tenseleg & silence & cell-phone & reassquest \\
\hline \multirow{2}{*}{$\mathrm{N}_{\mathrm{SR}}$} & $\mathrm{r}$ & $.393^{* *}$ & $.424^{* *}$ & $.305^{* *}$ & $.277^{* *}$ & $.225^{*}$ & $.314^{* *}$ & $-.247^{*}$ & .102 \\
\cline { 2 - 11 } & Sig. & .000 & .000 & .004 & .009 & .034 & .003 & .040 & .349 \\
\hline
\end{tabular}

**. Correlation is significant at the 0.01 level (2-tailed).

*. Correlation is significant at the 0.05 level (2-tailed).

Note: $\mathrm{N}_{\mathrm{SR}}$-self-reported measures of Neuroticism on NEO PI R 
All the indicators, except reassuring questions in the helping situation, correlated significantly with self-reported Neuroticism. Table 56 shows correlations between the behavioural indicators of Extraversion and the self-reported measure of the same trait.

Table 56 Correlations of self-reported Extraversion and behavioural indicators, sample of 99 respondents

\begin{tabular}{|c|c|c|c|c|c|c|c|c|c|}
\hline & & globbeh & globVF & faceexpres & loudvoice & stylish & flashy & falsealarms & $\begin{array}{c}\text { questsmallt } \\
\text { alk }\end{array}$ \\
\hline \multirow{2}{*}{$\mathrm{E}_{\mathrm{SR}}$} & $\mathrm{r}$ & $.335^{* *}$ & $.270^{*}$ & $.318^{* *}$ & $.320^{* *}$ & .054 & .013 & -.158 & .128 \\
\cline { 2 - 11 } & $\mathrm{Sig}$. & .001 & .011 & .002 & .002 & .612 & .901 & .139 & .231 \\
\hline
\end{tabular}

**. Correlation is significant at the 0.01 level (2-tailed).

*. Correlation is significant at the 0.05 level (2-tailed).

Note: $\mathrm{E}_{\mathrm{SR}}$-self-reported measures of Extraversion on NEO PI R

As for behavioural indicators of Extraversion, four indicators correlated moderately, while stylish dress, flashy dress, false alarms in concentration test, and questions in small talk did not correlate with self-reported measure. Table 57 gives correlations between the self-reported measure of Openness and the behavioural indicators of the same trait.

Table 57 Correlations of self-reported Openness and behavioural indicators, sample of 99 respondents

\begin{tabular}{|c|c|c|c|c|c|c|c|}
\hline & & eloquence & freeranswers & pantomorig & multiplechoice & openended & originalsolutions \\
\hline \multirow{2}{*}{ OSR $_{\text {SR }}$} & $\mathrm{r}$ & $.302 * *$ & .088 & .084 & -.045 & .067 & .125 \\
\cline { 2 - 8 } & Sig. & .004 & .411 & .434 & .672 & .526 & .242 \\
\hline
\end{tabular}

**. Correlation is significant at the 0.01 level (2-tailed).

Note: $\mathrm{O}_{\mathrm{SR}}$-self-reported measures of Openness on NEO PI R

Results show that only verbal eloquence correlates significantly with selfreported measure of Openness. Table 58 shows correlations between the behavioural indicators and self-reported measure of Agreeableness.

Table 58 Correlations of self-reported Agreeableness and behavioural indicators, sample of 99 respondents

\begin{tabular}{|c|c|c|c|c|c|c|c|}
\hline & & behhelp & friendlyvoice & friendlynonform & attentbody & checkingout & aggresdestr \\
\hline \multirow{2}{*}{$\mathrm{A}_{\mathrm{SR}}$} & $\mathrm{r}$ & $.381^{*}$ & $.261 *$ & .051 & .090 & $-.246^{*}$ & -.045 \\
\cline { 2 - 8 } & Sig. & .000 & .014 & .637 & .401 & .022 & .678 \\
\hline
\end{tabular}

**. Correlation is significant at the 0.01 level (2-tailed).

*. Correlation is significant at the 0.05 level (2-tailed).

Note: $\mathrm{A}_{\mathrm{SR}}$-self-reported measures of Agreeableness on NEO PI R 
Behaviour in helping situation, friendly voice in helping situation, and checking out room in waiting situation correlated significantly with the self-reported measure of Agreeableness, while the other three indicators did not. Table 59 gives the correlations between behavioural indicators and the self-reported measure of Conscientiousness.

Table 59 Correlations of self-reported Conscientiousness and behavioural indicators, sample of 99 respondents

\begin{tabular}{|c|c|c|c|c|c|c|c|}
\hline & & understand & slouchy & formal & lateinterview & latequestion & errorconc \\
\hline \multirow{2}{*}{$\mathrm{C}_{\mathrm{SR}}$} & $\mathrm{r}$ & .043 & -.065 & -.168 & .021 & -.173 & -.090 \\
\cline { 2 - 8 } & Sig. & .692 & .542 & .115 & .848 & .100 & .400 \\
\hline
\end{tabular}

Note: $\mathrm{C}_{\mathrm{SR}}$-self-reported measures of Conscientiousness on NEO PI R

Results show that none of the indicators correlate significantly with self-reports.

Table 60 displays correlations between behavioural indicators and the self-report measure of Disintegration.

Table 60 Correlations of self-reported Disintegration and behavioural indicators, sample of 99 respondents

\begin{tabular}{|c|c|c|c|c|c|c|c|c|c|c|}
\hline & & globbeh & globVF & $\begin{array}{c}\text { facial } \\
\text { inadequ }\end{array}$ & $\begin{array}{c}\text { body } \\
\text { posture }\end{array}$ & $\begin{array}{c}\text { bizarre } \\
\text { appear }\end{array}$ & concent & $\begin{array}{c}\text { pantom } \\
\text { bizzare }\end{array}$ & helpsit & waitsit \\
\hline \multirow{2}{*}{$\mathrm{D}_{\mathrm{SR}}$} & $\mathrm{r}$ & $.327^{*}$ & $.305^{*}$ & $.352^{* *}$ & $.299^{* *}$ & $.207^{*}$ & $.231^{*}$ & .135 & $.247^{*}$ & $.274^{*} *$ \\
\cline { 2 - 27 } & Sig. & .001 & .003 & .001 & .004 & .048 & .027 & .199 & .018 \\
\hline
\end{tabular}

**. Correlation is significant at the 0.01 level (2-tailed).

*. Correlation is significant at the 0.05 level (2-tailed).

Note: DSR -self-reported measures of Disintegration on DELTA 10

Results demonstrate that all the indicators, except the assessment of pantomime, were significantly correlated with the self-reported measure of Disintegration.

\subsubsection{Correlations of Ratings by Close Others and Ratings by Experts}

Correlations between ratings by female close others and the composite behavioural measures give evidence for the convergent validity of Neuroticism, Extraversion and Disintegration traits, while for the rest of the traits, only nonsignificant correlations were obtained (Table 61). 
Table 61 Correlations of female observer ratings and composite behavioural measures

\begin{tabular}{|c|c|c|c|c|c|c|c|}
\hline & & $\mathrm{N}_{\mathrm{B}}$ & $\mathrm{E}_{\mathrm{B}}$ & $\mathrm{O}_{\mathrm{B}}$ & $A_{B}$ & $\mathrm{C}_{\mathrm{B}}$ & $\mathrm{D}_{\mathrm{B}}$ \\
\hline \multirow{2}{*}{$\mathrm{N}_{\mathrm{F}}$} & $\mathrm{r}$ & $.252 *$ & -.188 & -.015 & -.092 & -.120 & .170 \\
\hline & Sig. & .018 & .080 & .890 & .392 & .264 & .116 \\
\hline \multirow{2}{*}{$\mathrm{E}_{\mathrm{F}}$} & $\mathrm{r}$ & -.028 & $.245^{*}$ & .174 & -.026 & .074 & -.105 \\
\hline & Sig. & .797 & .022 & .104 & .810 & .492 & .333 \\
\hline \multirow{2}{*}{$\mathrm{O}_{\mathrm{F}}$} & $\mathrm{r}$ & -.140 & .067 & .189 & -.034 & .175 & -.076 \\
\hline & Sig. & .197 & .539 & .080 & .757 & .105 & .489 \\
\hline \multirow{2}{*}{$A_{F}$} & $r$ & -.151 & .121 & .094 & .039 & .103 & -.194 \\
\hline & Sig. & .168 & .271 & .391 & .723 & .349 & .077 \\
\hline \multirow{2}{*}{$\mathrm{C}_{\mathrm{F}}$} & $r$ & -.042 & $.240 *$ & -.062 & .170 & .056 & -.005 \\
\hline & Sig. & .700 & .026 & .574 & .117 & .610 & .962 \\
\hline \multirow{2}{*}{$\mathrm{D}_{\mathrm{F}}$} & $\mathrm{r}$ & $.405 * *$ & $-.308 * *$ & .061 & $-.392 * *$ & $-.313 * *$ & $.335 * *$ \\
\hline & Sig. & .000 & .004 & .580 & .000 & .004 & .002 \\
\hline
\end{tabular}

**. Correlation is significant at the 0.01 level (2-tailed).

*. Correlation is significant at the 0.05 level (2-tailed).

Note: $N_{F}-D_{F}$ - ratings by close female others assessing basic six personality traits; $N_{B}-D_{B}-$ ratings by experts assessing basic six personality traits

Correlations between ratings by male close others and the composite behavioural measures give evidence for convergent validity of Extraversion and the Disintegration trait, while for the rest of the traits, no significant correlations were obtained (Table 62).

Table 62 Correlations of male observer ratings and composite behavioural measures

\begin{tabular}{|c|c|c|c|c|c|c|c|}
\hline & & $\mathrm{N}_{\mathrm{B}}$ & $\mathrm{E}_{\mathrm{B}}$ & $\mathrm{O}_{\mathrm{B}}$ & $\mathrm{A}_{\mathrm{B}}$ & $\mathrm{C}_{\mathrm{B}}$ & $\mathrm{D}_{\mathrm{B}}$ \\
\hline \multirow{2}{*}{$\mathrm{N}_{\mathrm{M}}$} & $\mathrm{r}$ & .167 & -.183 & .143 & .100 & .039 & .119 \\
\cline { 2 - 8 } & $\mathrm{Sig}$. & .117 & .086 & .182 & .351 & .719 & .271 \\
\hline \multirow{2}{*}{$\mathrm{E}_{\mathrm{M}}$} & $\mathrm{r}$ & -.008 & $.236^{*}$ & .050 & .033 & -.107 & .026 \\
\cline { 2 - 8 } & Sig. & .941 & .026 & .643 & .761 & .319 & .811 \\
\hline \multirow{2}{*}{$\mathrm{O}_{\mathrm{M}}$} & $\mathrm{r}$ & -.020 & .085 & -.068 & -.173 & .004 & .016 \\
\cline { 2 - 8 } & Sig. & .855 & .434 & .532 & .108 & .974 & .887 \\
\hline \multirow{2}{*}{$\mathrm{A}_{\mathrm{M}}$} & $\mathrm{r}$ & .028 & .119 & -.044 & .006 & -.011 & .066 \\
\cline { 2 - 8 } & Sig. & .797 & .274 & .685 & .956 & .920 & .547 \\
\hline \multirow{2}{*}{$\mathrm{C}_{\mathrm{M}}$} & $\mathrm{r}$ & -.109 & .128 & $-.225 *$ & .003 & -.076 & -.043 \\
\cline { 2 - 8 } & Sig. & .316 & .237 & .037 & .981 & .482 & .691 \\
\hline \multirow{2}{*}{$\mathrm{D}_{\mathrm{M}}$} & $\mathrm{r}$ & $.306^{* *}$ & $-.438^{* *}$ & -.066 & $-.363 * *$ & -.095 & $.350 * *$ \\
\cline { 2 - 8 } & Sig. & .004 & .000 & .546 & .001 & .383 & .001 \\
\hline
\end{tabular}

**. Correlation is significant at the 0.01 level (2-tailed).

*. Correlation is significant at the 0.05 level (2-tailed).

Note: $N_{M}-D_{M}$ - ratings by close male others assessing basic six personality traits; $N_{B}-D_{B}-$ ratings by experts assessing basic six personality traits

\subsubsection{Correlations of LIWC Measures and Self-reports}

Between LIWC composite measures and self-reports, low significant correlations were obtained on Agreeableness and Conscientiousness (Table 63). 
Table 63 Correlations of LIWC composite measures and self-reports

\begin{tabular}{|c|c|c|c|c|c|c|c|}
\hline & & $\mathrm{N}_{\mathrm{SR}}$ & $\mathrm{E}_{\mathrm{SR}}$ & $\mathrm{O}_{\mathrm{SR}}$ & $\mathrm{A}_{\mathrm{SR}}$ & $\mathrm{C}_{\mathrm{SR}}$ & $\mathrm{D}_{\mathrm{SR}}$ \\
\hline \multirow{2}{*}{ LIWC $_{\mathrm{ZN}}$} & $\mathrm{r}$ & -.072 & .028 & -.099 & .083 & .182 & .034 \\
\cline { 2 - 8 } & $\mathrm{Sig}$. & .499 & .791 & .355 & .439 & .087 & .743 \\
\hline \multirow{2}{*}{ LIWC $_{\mathrm{ZE}}$} & $\mathrm{r}$ & -.148 & .047 & .004 & .013 & .111 & .056 \\
\cline { 2 - 8 } & $\mathrm{Sig}$. & .163 & .660 & .971 & .903 & .297 & .597 \\
\hline \multirow{2}{*}{ LIWC $_{\mathrm{ZO}}$} & $\mathrm{r}$ & -.005 & .061 & .155 & -.058 & .080 & .169 \\
\cline { 2 - 8 } & $\mathrm{Sig}$. & .962 & .567 & .144 & .589 & .453 & .105 \\
\hline \multirow{2}{*}{ LIWC $_{\mathrm{ZA}}$} & $\mathrm{r}$ & .028 & .117 & .118 & $.208^{*}$ & .163 & .104 \\
\cline { 2 - 8 } & $\mathrm{Sig}$. & .795 & .271 & .269 & .049 & .126 & .323 \\
\cline { 2 - 8 } & $\mathrm{r}$ & -.013 & .164 & .119 & .111 & $.231 *$ & -.090 \\
\hline \multirow{2}{*}{ LIWC $_{\mathrm{ZD}}$} & $\mathrm{Sig}$. & .903 & .123 & .262 & .297 & .029 & .391 \\
\cline { 2 - 8 } & $\mathrm{r}$ & -.026 & .095 & .006 & .184 & .138 & -.048 \\
\cline { 2 - 8 } & Sig. & .807 & .373 & .953 & .083 & .196 & .648 \\
\hline
\end{tabular}

*. Correlation is significant at the 0.05 level (2-tailed).

Note: $\mathrm{LIWCZ}_{\mathrm{N}}-\mathrm{LIWCZ}_{\mathrm{D}}$ - standardized LIWC measures of big six personality traits; $\mathrm{N}_{\mathrm{SR}}-\mathrm{D}_{\mathrm{SR}}-$ selfreported measures of big six personality traits on NEO PI R and DELTA 10.

\subsubsection{Correlations of LIWC Measures and Ratings by Close Others}

Between linguistic measures and ratings by female close others, no significant correlations were obtained (Table 64 and Table 65).

Table 64 Correlations of LIWC composite measures and ratings by close female others

\begin{tabular}{|c|c|c|c|c|c|c|c|}
\hline & & $\mathrm{N}_{\mathrm{F}}$ & $\mathrm{E}_{\mathrm{F}}$ & $\mathrm{O}_{\mathrm{F}}$ & $\mathrm{A}_{\mathrm{F}}$ & $\mathrm{C}_{\mathrm{F}}$ & $\mathrm{D}_{\mathrm{F}}$ \\
\hline \multirow{2}{*}{ LIWC $_{\mathrm{ZN}}$} & $\mathrm{r}$ & -.096 & -.026 & -.161 & -.031 & -.017 & .025 \\
\cline { 2 - 8 } & $\mathrm{Sig}$. & .370 & .807 & .132 & .776 & .877 & .815 \\
\hline \multirow{2}{*}{ LIWC $_{\mathrm{ZE}}$} & $\mathrm{r}$ & -.061 & .015 & .136 & -.122 & .039 & .171 \\
\cline { 2 - 8 } & $\mathrm{Sig}$. & .568 & .891 & .204 & .255 & .717 & .111 \\
\hline \multirow{2}{*}{ LIWC $_{\mathrm{ZO}}$} & $\mathrm{r}$ & .047 & -.040 & .163 & -.146 & .023 & .119 \\
\cline { 2 - 8 } & $\mathrm{Sig}$. & .660 & .707 & .128 & .171 & .828 & .269 \\
\hline \multirow{2}{*}{ LIWC $_{\mathrm{ZA}}$} & $\mathrm{r}$ & .070 & -.058 & .108 & -.116 & .004 & .189 \\
\cline { 2 - 8 } & $\mathrm{Sig}$. & .516 & .592 & .315 & .281 & .972 & .078 \\
\cline { 2 - 8 } & $\mathrm{r}$ & -.033 & .037 & .161 & -.068 & .204 & -.015 \\
\cline { 2 - 8 } LIWC $_{\mathrm{ZD}}$ & $\mathrm{Sig}$. & .758 & .729 & .131 & .525 & .055 & .891 \\
\cline { 2 - 8 } & $\mathrm{r}$ & .015 & -.123 & -.052 & .001 & .092 & .095 \\
\cline { 2 - 8 } & $\mathrm{Sig}$. & .890 & .250 & .626 & .989 & .390 & .380 \\
\hline
\end{tabular}

Note: $\mathrm{LIWC}_{\mathrm{N}}-\mathrm{LIWC} \mathrm{z}_{\mathrm{D}}$ - standardized LIWC measures of big six personality traits; $\mathrm{N}_{\mathrm{F}}-\mathrm{D}_{\mathrm{F}}$-ratings by close female others of big six personality traits on NEO PI R and DELTA 10. 
Table 65 Correlations of LIWC composite measures and ratings by close male others

\begin{tabular}{|c|c|c|c|c|c|c|c|}
\hline & & NM & EM & OM & AM & CM & DM \\
\hline \multirow{2}{*}{ LIWC $_{\text {ZN }}$} & $\mathrm{r}$ & .020 & .122 & .113 & -.096 & -.006 & .002 \\
\cline { 2 - 8 } & Sig. & .850 & .250 & .290 & .368 & .955 & .985 \\
\hline \multirow{2}{*}{ LIWC $_{\text {ZE }}$} & $\mathrm{r}$ & -.037 & .003 & .035 & -.098 & .090 & .067 \\
\cline { 2 - 8 } & Sig. & .727 & .976 & .744 & .357 & .401 & .533 \\
\hline \multirow{2}{*}{ LIWC $_{\text {ZO }}$} & $\mathrm{r}$ & .056 & -.018 & .013 & -.087 & .005 & .143 \\
\cline { 2 - 8 } & Sig. & .597 & .869 & .904 & .417 & .966 & .182 \\
\hline \multirow{2}{*}{ LIWC $_{\text {ZA }}$} & $\mathrm{r}$ & .042 & .053 & -.031 & -.018 & .057 & .064 \\
\cline { 2 - 8 } & Sig. & .695 & .620 & .772 & .868 & .594 & .553 \\
\hline \multirow{2}{*}{ LIWC $_{Z \mathrm{ZC}}$} & $\mathrm{r}$ & -.017 & .127 & .135 & .101 & .171 & -.170 \\
\cline { 2 - 8 } & Sig. & .871 & .235 & .206 & .345 & .106 & .111 \\
\hline \multirow{2}{*}{ LIWC $_{\mathrm{ZD}}$} & $\mathrm{r}$ & -.040 & -.145 & -.173 & .016 & .206 & -.091 \\
\cline { 2 - 8 } & Sig. & .708 & .174 & .103 & .879 & .051 & .394 \\
\hline
\end{tabular}

Note: $\mathrm{LIWC}_{\mathrm{N}}-\mathrm{LIWCz_{ \textrm {D } }}$ - standardized LIWC measures of big six personality traits; $\mathrm{N}_{\mathrm{M}}-\mathrm{D}_{\mathrm{M}}-$ ratings by close male others of big six personality traits on NEO PI R and DELTA 10.

\subsubsection{Correlations of LIWC Measures and Ratings by Experts}

Table 66 displays correlations between the linguistic and behavioural measures.

A significant correlation was obtained only for Neuroticism.

Table 66 Correlations of LIWC composite measures and ratings by experts

\begin{tabular}{|c|c|c|c|c|c|c|c|}
\hline & & $\mathrm{N}_{\mathrm{B}}$ & $\mathrm{E}_{\mathrm{B}}$ & $\mathrm{O}_{\mathrm{B}}$ & $\mathrm{A}_{\mathrm{B}}$ & $\mathrm{C}_{\mathrm{B}}$ & $\mathrm{D}_{\mathrm{B}}$ \\
\hline \multirow{2}{*}{ LIWC $_{\mathrm{ZN}}$} & $\mathrm{r}$ & $-.212^{*}$ & .161 & .098 & $.210^{*}$ & .063 & $-.229^{*}$ \\
\cline { 2 - 8 } & $\mathrm{Sig}$. & .042 & .125 & .360 & .048 & .558 & .031 \\
\hline \multirow{2}{*}{ LIWC $_{\mathrm{ZE}}$} & $\mathrm{r}$ & -.001 & .039 & .123 & -.185 & -.069 & .032 \\
\cline { 2 - 8 } & $\mathrm{Sig}$. & .990 & .713 & .247 & .083 & .518 & .766 \\
\hline \multirow{2}{*}{ LIWC $_{\mathrm{ZA}}$} & $\mathrm{r}$ & $-.221 *$ & .169 & .176 & .176 & .117 & .055 \\
\cline { 2 - 8 } & $\mathrm{Sig}$. & .034 & .108 & .097 & .099 & .272 & .609 \\
\cline { 2 - 8 } & $\mathrm{r}$ & -.147 & -.013 & .117 & .090 & .033 & -.134 \\
\hline \multirow{2}{*}{ LIWC $_{\mathrm{ZC}}$} & $\mathrm{r}$ & .162 & .904 & .272 & .402 & .756 & .211 \\
\cline { 2 - 8 } & $\mathrm{Sig}$. & .284 & .833 & .658 & .167 & .339 & .053 \\
\hline \multirow{2}{*}{ LIWC $_{\mathrm{ZD}}$} & $\mathrm{r}$ & -.040 & -.153 & .029 & .090 & .041 & -.181 \\
\cline { 2 - 8 } & $\mathrm{Sig}$. & .707 & .145 & .784 & .403 & .701 & .091 \\
\hline
\end{tabular}

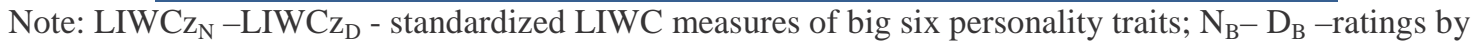
experts of big six personality traits. 


\subsection{Multi-Trait Multi-Method Validation}

\subsubsection{Multi-Trait Multi-Method Validation of IAT -first part}

Based on the theoretical background and previous analyses, first the model in which all the latent personality factors have loadings from each assessment method was tested. In other words, it was hypothesised that the self-reports, ratings by close others, and IATs measuring the six basic personality traits load on the corresponding latent factors. Besides, it was assumed that the IATI, KOG9, and self-assessment of intellectual abilities load on the latent factor of cognitive abilities. While creating the model, the suggestions of Marsh, Byrne, \& Craven (1992) were followed, and a CTCU model was designed which posits the Correlated Trait factors (CT) and methods, against the Correlated Uniquenesses (CU). This was done as a large body of evidence suggests that this model typically results in proper solutions in comparison with other models, especially the CTCM model (Correlated Traits and Correlated Method Factors). The CTCU model has three important advantages over the CTCM model (Marsh et al., 1992):

1. It is relatively immune to ill-defined solutions,

2. It provides a way to test the implicit assumption that all the correlated uniquenesses associated with one method of assessment can be explained in terms of single unidimensional method factor,

3. The interpretations based on the CTCU model tend to be more valid.

Therefore, correlated uniquenesses have been postulated in this model which is displayed in Figure 8. 


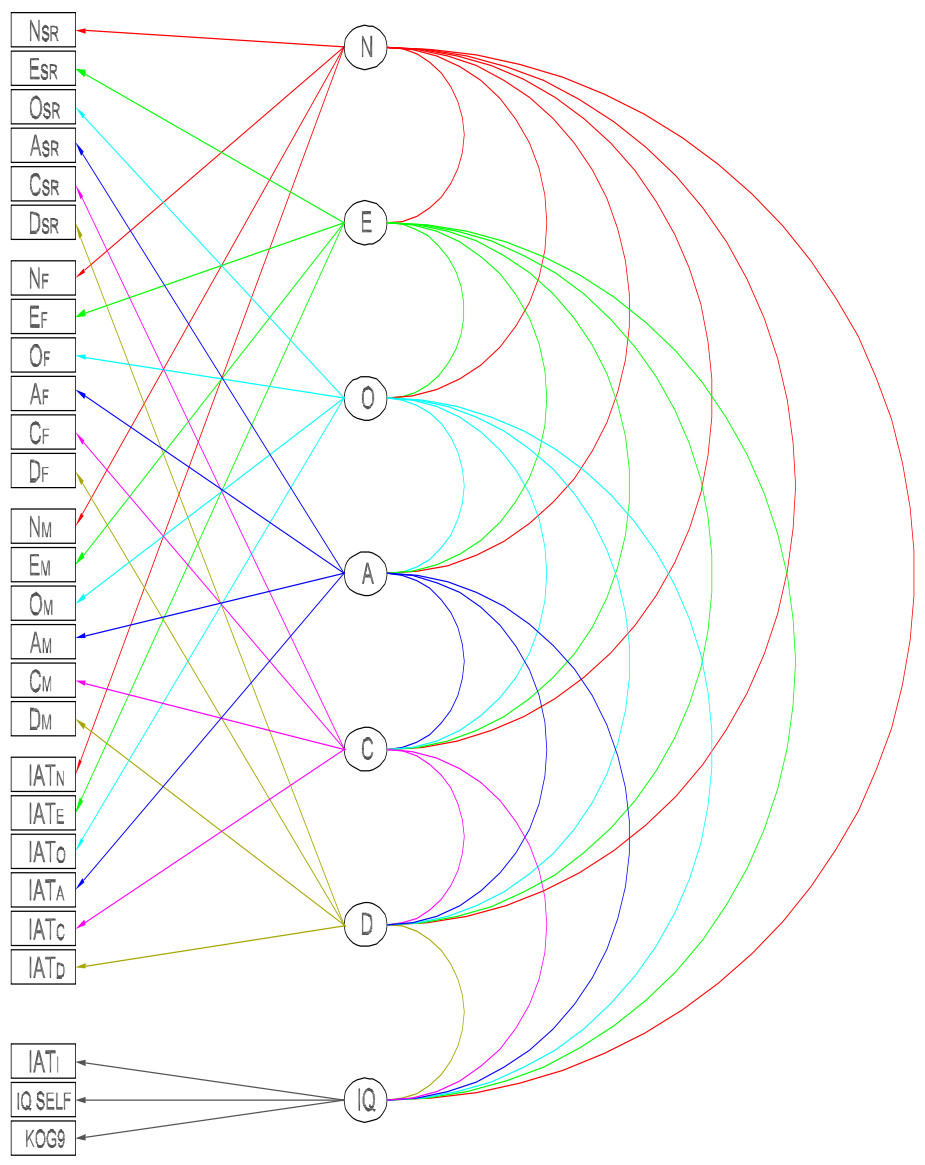

Figure 8. Structural Model Tested on 224 Subjects

Note: $\mathrm{N}_{\mathrm{SR}}-\mathrm{D}_{\mathrm{SR}}$ - self report measures of six basic personality traits; $\mathrm{N}_{\mathrm{F}}-\mathrm{D}_{\mathrm{F}}$-ratings by close female others of six basic personality traits; $\mathrm{N}_{\mathrm{M}^{-}} \mathrm{D}_{\mathrm{M}}$-ratings by close male others of six basic personality traits; IAT $_{\mathrm{N}^{-}}$ IAT $_{\mathrm{I}^{-}}$IAT measuring seven basic personality traits; IQself-self-assessment of intellectual abilities; KOG9principal component on the KOG9 battery of intellectual abilities. N-D- latent factors of six basic personality traits; IQ - latent factor of cognitive abilities.

This model was tested on 224 respondents, and the results showed that it had a very good fit, with $\chi^{2}=338.18(\mathrm{df}=231), \mathrm{p}=0.00 ; \mathrm{RMSEA}=0.042$ (90\% CI RMSEA 0.031-0.053), RMR=0.067, SRMR=0.066, and $\mathrm{CFI}=0.96$. Other fit indices are displayed in Appendix 14.

All the latent factors representing the six basic personality traits had strong loadings on self-reports and ratings by close others (Table 67, Table 68 and Table 69) which supported the construct validity of the basic personality traits when measured 
with self-reports and observer ratings. This was in accordance with previous researches

(Borkenau \& Liebner, 1993; Conolly et al., 2007).

Table 67 Factor loadings of self-reports on corresponding latent factors, sample 224 respondents

\begin{tabular}{|c|c|c|c|c|c|c|}
\hline \multirow{yyyyyn}{*}{ Factor } & \multirow{2}{*}{$\mathrm{N}$} & $\mathrm{E}$ & $\mathrm{O}$ & $\mathrm{A}$ & $\mathrm{C}$ & $\mathrm{D}$ \\
\cline { 1 - 5 } Measure & & & & & & \\
\hline $\mathrm{N}_{\mathrm{SR}}$ & 0.62 & & & & & \\
\hline $\mathrm{E}_{\mathrm{SR}}$ & & 0.81 & & & & \\
\hline $\mathrm{O}_{\mathrm{SR}}$ & & & 0.82 & & & \\
\hline $\mathrm{A}_{\mathrm{SR}}$ & & & & 0.53 & & \\
\hline $\mathrm{C}_{\mathrm{SR}}$ & & & & & 0.67 & \\
\hline $\mathrm{D}_{\mathrm{SR}}$ & & & & & & 0.62 \\
\hline
\end{tabular}

Note: $\mathrm{N}_{\mathrm{SR}}-\mathrm{D}_{\mathrm{SR}}$ - self report measures of basic six personality traits; N-D - latent factors of six basic personality traits

Table 68 Factor loadings of female ratings on corresponding latent factors, sample 224 respondents

\begin{tabular}{|c|c|c|c|c|c|c|}
\hline \multirow{2}{*y}{ Factor } & \multirow{2}{*}{$\mathrm{N}$} & $\mathrm{E}$ & $\mathrm{O}$ & $\mathrm{A}$ & $\mathrm{C}$ & $\mathrm{D}$ \\
\cline { 1 - 6 } Measure & & & & & & \\
\hline $\mathrm{N}_{\mathrm{F}}$ & 0.77 & & & & & \\
\hline $\mathrm{E}_{\mathrm{F}}$ & & 0.77 & & & & \\
\hline $\mathrm{O}_{\mathrm{F}}$ & & & 0.47 & & & \\
\hline $\mathrm{A}_{\mathrm{F}}$ & & & & 0.81 & & \\
\hline $\mathrm{C}_{\mathrm{F}}$ & & & & & 0.81 & \\
\hline $\mathrm{D}_{\mathrm{F}}$ & & & & & & 0.69 \\
\hline
\end{tabular}

Note: $\mathrm{N}_{\mathrm{F}}-\mathrm{D}_{\mathrm{F}}$ - female observer ratings of six basic personality traits; $\mathrm{N}-\mathrm{D}$ - latent factors of six basic personality traits

Table 69 Factor loadings of male ratings on corresponding latent factors, sample 224 respondents

\begin{tabular}{|c|c|c|c|c|c|c|}
\cline { 1 - 5 } Factor & \multirow{2}{*}{$\mathrm{N}$} & $\mathrm{E}$ & $\mathrm{O}$ & $\mathrm{A}$ & $\mathrm{C}$ & $\mathrm{D}$ \\
\cline { 1 - 5 } Measure & & & & & & \\
\hline $\mathrm{N}_{\mathrm{M}}$ & 0.60 & & & & & \\
\hline $\mathrm{E}_{\mathrm{M}}$ & & 0.65 & & & & \\
\hline $\mathrm{O}_{\mathrm{M}}$ & & & 0.42 & & & \\
\hline $\mathrm{A}_{\mathrm{M}}$ & & & & 0.53 & & \\
\hline $\mathrm{C}_{\mathrm{M}}$ & & & & & 0.65 & \\
\hline $\mathrm{D}_{\mathrm{M}}$ & & & & & & 0.75 \\
\hline
\end{tabular}

Note: $\mathrm{N}_{\mathrm{M}}-\mathrm{D}_{\mathrm{M}}-$ male observer ratings of six basic personality traits; $\mathrm{N}-\mathrm{D}$ - latent factors of six basic personality traits. 
The preliminary correlation analyses showed that the IATN and IATE have significant correlations with the self-reported Neuroticism and Extraversion. However, when placed in the structural model, the implicit measures did not have significant loadings on the latent personality factors (Table 70).

Table 70 Factor loadings of IATs on corresponding latent factors, sample 224 respondents

\begin{tabular}{|c|c|c|c|c|c|c|}
\cline { 1 - 5 } Factor & \multirow{2}{*}{$\mathrm{N}$} & $\mathrm{E}$ & $\mathrm{O}$ & $\mathrm{A}$ & $\mathrm{C}$ & $\mathrm{D}$ \\
\cline { 1 - 6 } Measure & & & & & & \\
\hline $\mathrm{IAT}_{\mathrm{N}}$ & -0.14 & & & & & \\
\cline { 1 - 5 } $\mathrm{IAT}_{\mathrm{E}}$ & & 0.13 & & & & \\
\hline $\mathrm{IAT}_{\mathrm{O}}$ & & & 0.07 & & & \\
\hline $\mathrm{IAT}_{\mathrm{A}}$ & & & & -0.02 & & \\
\hline $\mathrm{IAT}_{\mathrm{C}}$ & & & & & -0.02 & \\
\hline $\mathrm{IAT}_{\mathrm{D}}$ & & & & & & -0.04 \\
\hline
\end{tabular}

Note: $\mathrm{IAT}_{\mathrm{N}}-\mathrm{IAT}_{\mathrm{D}}$ - IATs measuring basic personality traits; N-D - latent factors of six basic personality traits

Self-assessment of the intellectual abilities and KOG9 scores had significant loadings on the latent factor of intellectual abilities while IATI had only an insignificant loading of -0.07 (Table 71).

Table 71 Factor loadings of intellectual abilities measures on latent factor of intellectual abilities, sample 224 respondents

\begin{tabular}{|c|c|}
\hline Factor & \multirow{2}{*}{ IQF } \\
\cline { 1 - 1 } Measure & \\
\hline IQself & 0.43 \\
\hline KOG9 $^{\text {KOn }}$ & 0.42 \\
\hline IAT $_{\text {I }}$ & -0.07 \\
\hline
\end{tabular}

Note: IQself - self-assessment of intellectual abilities, KOG9- principal component from KOG9 battery, IAT $_{\mathrm{I}^{-}}$IAT measuring intellectual abilities

Inter-correlations between the latent personality dimensions and personality factors, and the latent factor of General Intellectual Abilities (Table 72), were slightly higher than the correlations reported in literature (DeYoung, 2011; Knežević, 2011). 
Table 72 Inter-correlations of latent factors, sample 224 respondents

\begin{tabular}{|c|c|c|c|c|c|c|}
\hline Factors & $\mathrm{N}$ & $\mathrm{E}$ & $\mathrm{O}$ & $\mathrm{A}$ & $\mathrm{C}$ & $\mathrm{D}$ \\
\hline $\mathrm{N}$ & 1 & & & & & \\
\hline $\mathrm{E}$ & -0.44 & 1 & & & & \\
\hline $\mathrm{O}$ & -0.49 & 0.45 & 1 & & & \\
\hline $\mathrm{A}$ & -0.42 & 0.13 & 0.19 & 1 & & \\
\hline $\mathrm{C}$ & -0.48 & 0.12 & 0.31 & 0.26 & 1 & \\
\hline $\mathrm{D}$ & 0.48 & -0.37 & -0.20 & -0.36 & -0.28 & 1 \\
\hline $\mathrm{IQ}$ & -0.42 & 0.51 & 0.41 & -0.10 & 0.24 & -0.32 \\
\hline
\end{tabular}

Note: Values in italic are not significant.

Note: N-D - latent factors of six basic personality traits

The study made an attempt to design a Correlated Traits Orthogonal Methods model (CTOM) and a Correlated Traits Correlated Methods (CTCM) models. The CTOM model assumes that a single latent factor underlies each method, and these factors are uncorrelated, while the CTCM assumes that a single latent factor underlies each method and also provides estimates of the relationships among those method factors (Biesanz \& West, 2004). However, both CTOM and CTCM model did not converge on admissible solutions.

\subsubsection{Multi-trait Multi-method Validation of IAT- second part}

In the second part of the construct validity testing, several structural models were designed on the sample of 99 subjects. These models included behavioural measures, in addition to all the previously mentioned measures. As with the previously tested models (on the sample of 224 respondents), these models were CTCU, and the existence of latent factors for all the measured traits was assumed. The model that had the best fit had separate loadings on the behavioural indicators and composite LIWC measures. Each latent factor had loadings on each of the assessment methods (i.e., selfreports, ratings by close others, ratings by experts, IAT, LIWC) respectively (Figure 9). 


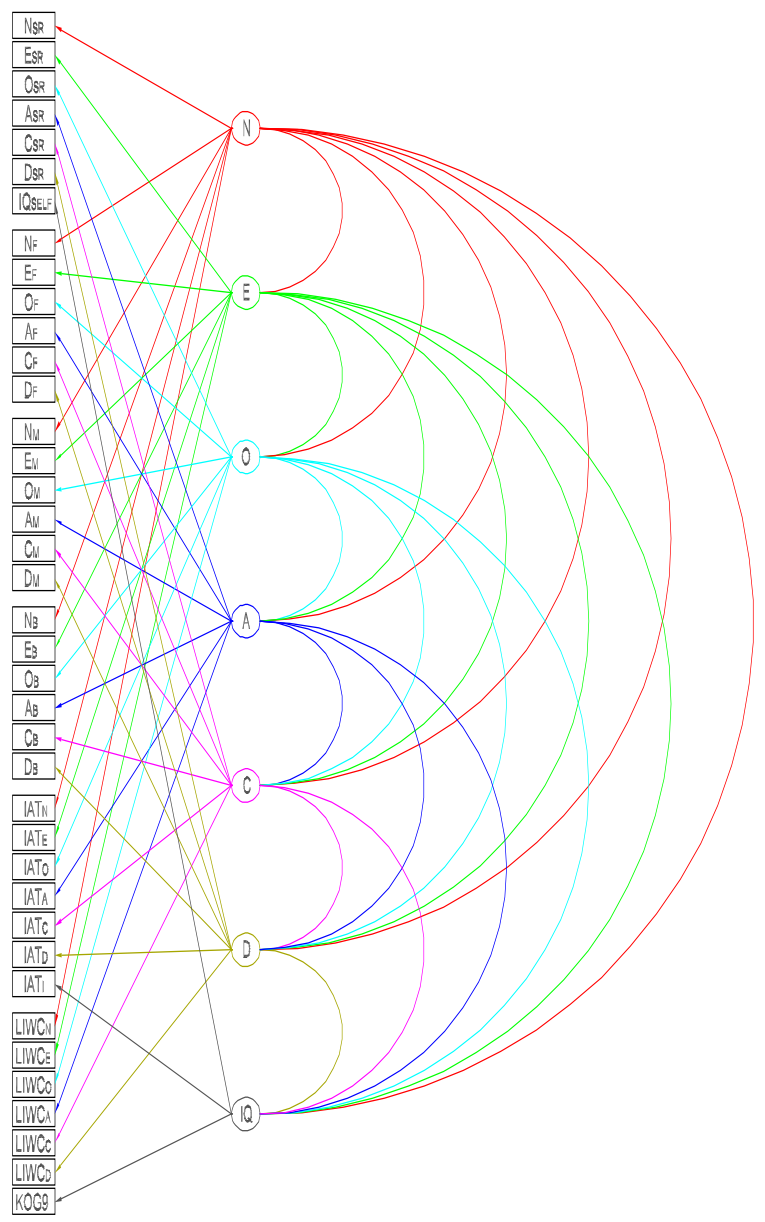

Figure 9. Structural Model Tested on 99 subjects

Note: $\mathrm{N}_{\mathrm{SR}}-\mathrm{D}_{\mathrm{SR}}$ - self report measures of six basic personality traits; $\mathrm{N}_{\mathrm{F}}-\mathrm{D}_{\mathrm{F}}$-ratings ratings by close female others of six basic personality traits; $\mathrm{N}_{\mathrm{M}}-\mathrm{D}_{\mathrm{M}}$-ratings by close male others of six basic personality traits; $\mathrm{N}_{\mathrm{B}}-\mathrm{D}_{\mathrm{B}}$-ratings by experts of six basic personality traits; $\mathrm{IAT}_{\mathrm{N}}-\mathrm{IAT}_{\mathrm{D}}-\mathrm{IAT}$ assessing six basic personality traits, KOG9-principal component on KOG9 battery, IQself-self-assessment of intellectual abilities; IAT $_{\mathrm{I}^{-}}$IAT assessing intellectual abilities; N-D - latent factors of six basic personality traits; IQlatent factors of intellectual abilities.

The model had a lower fit with $\chi^{2}=827.10(\mathrm{df}=585), \mathrm{p}=0.00 ; \mathrm{RMSEA}=0.065$ (90\% CI RMSEA 0.054-0.075), RMR=0.11, SRMR=0.11 and CFI=0.80. Other fit indices for this model are displayed in Appendix 15. However, one caveat must be made about the model. Since the total sample size was smaller than the number of parameters, the parameter estimates could be unreliable. Still, the model provided some important information about the relations among the methods used. Table 73, Table 74 and Table 
75 display the loadings of self-reports, female observer ratings, and male observer ratings on corresponding latent trait factors.

Table 73 Factor loadings of self-reports on corresponding latent factors, sample 99 respondents

\begin{tabular}{|c|c|c|c|c|c|c|}
\hline \multicolumn{1}{|c|}{ Factor } & \multirow{2}{*}{$\mathrm{N}$} & $\mathrm{E}$ & $\mathrm{O}$ & $\mathrm{A}$ & $\mathrm{C}$ & $\mathrm{D}$ \\
\cline { 1 - 5 } Measure & & & & & & \\
\hline $\mathrm{N}_{\mathrm{SR}}$ & .64 & & & & & \\
\hline $\mathrm{E}_{\mathrm{SR}}$ & & .83 & & & & \\
\hline $\mathrm{O}_{\mathrm{SR}}$ & & & .83 & & & \\
\hline $\mathrm{A}_{\mathrm{SR}}$ & & & & .63 & & \\
\hline $\mathrm{C}_{\mathrm{SR}}$ & & & & & .61 & \\
\hline $\mathrm{D}_{\mathrm{SR}}$ & & & & & & .77 \\
\hline
\end{tabular}

Note: $\mathrm{N}_{\mathrm{SR}}-\mathrm{D}_{\mathrm{SR}}$ - self report measures of basic six personality traits; $\mathrm{N}-\mathrm{D}$ - latent factors of six basic personality traits.

Table 74 Factor loadings of female ratings on corresponding latent factors, sample 99 respondents

\begin{tabular}{|c|c|c|c|c|c|c|}
\cline { 1 - 1 } Factor & \multirow{2}{*}{ N } & E & O & A & C & D \\
\cline { 1 - 5 } $\mathrm{N}_{\mathrm{F}}$ & .66 & & & & & \\
\hline $\mathrm{E}_{\mathrm{F}}$ & & 0.69 & & & & \\
\hline $\mathrm{O}_{\mathrm{F}}$ & & & 0.50 & & & \\
\hline $\mathrm{A}_{\mathrm{F}}$ & & & & 0.72 & & \\
\hline $\mathrm{C}_{\mathrm{F}}$ & & & & & 0.75 & \\
\hline $\mathrm{D}_{\mathrm{F}}$ & & & & & & 0.45 \\
\hline
\end{tabular}

Note: $\mathrm{N}_{\mathrm{F}}-\mathrm{D}_{\mathrm{F}}$-ratings by close female others of six basic personality traits; N-D - latent factors of six basic personality traits

Table 75 Factor loadings of male ratings on corresponding latent factors, sample 99 respondents

\begin{tabular}{|c|c|c|c|c|c|c|}
\hline Factor & \multirow{2}{*}{$\mathrm{N}$} & \multirow{2}{*}{$\mathrm{E}$} & \multirow{2}{*}{$\mathrm{O}$} & \multirow{2}{*}{ A } & \multirow{2}{*}{$\mathrm{C}$} & \multirow{2}{*}{ D } \\
\hline Measure & & & & & & \\
\hline $\mathrm{N}_{\mathrm{M}}$ & 0.69 & & & & & \\
\hline$E_{M}$ & & 0.76 & & & & \\
\hline $\mathrm{O}_{\mathrm{M}}$ & & & 0.39 & & & \\
\hline$A_{M}$ & & & & 0.64 & & \\
\hline $\mathrm{C}_{\mathrm{M}}$ & & & & & 0.60 & \\
\hline $\mathrm{D}_{\mathrm{M}}$ & & & & & & 0.62 \\
\hline
\end{tabular}

Note: $\mathrm{N}_{\mathrm{M}}-\mathrm{D}_{\mathrm{M}}$-ratings by close male others of six basic personality traits; $\mathrm{N}-\mathrm{D}$ - latent factors of six basic personality traits.

As in the model tested on 224 subjects, the implicit measures did not have significant loadings on the latent personality factors (Table 76). 
Table 76 Factor loadings of IATs on corresponding latent factors, sample 99 respondents

\begin{tabular}{|c|c|c|c|c|c|c|}
\hline Factor & \multirow{2}{*}{$\mathrm{N}$} & \multirow{2}{*}{$\mathrm{E}$} & \multirow{2}{*}{$\mathrm{O}$} & \multirow{2}{*}{ A } & \multirow{2}{*}{$\mathrm{C}$} & \multirow{2}{*}{ D } \\
\hline Measure & & & & & & \\
\hline $\mathrm{IAT}_{\mathrm{N}}$ & -0.09 & & & & & \\
\hline $\mathrm{IAT}_{\mathrm{E}}$ & & 0.06 & & & & \\
\hline $\mathrm{IAT}_{\mathrm{O}}$ & & & 0.16 & & & \\
\hline $\mathrm{IAT}_{\mathrm{A}}$ & & & & -0.10 & & \\
\hline $\mathrm{IAT}_{\mathrm{C}}$ & & & & & 0.14 & \\
\hline $\mathrm{IAT}_{\mathrm{D}}$ & & & & & & -0.02 \\
\hline
\end{tabular}

Note: $\mathrm{IAT}_{\mathrm{N}}-\mathrm{IAT}_{\mathrm{D}}$ - IATs measuring basic personality traits; N-D - latent factors of six basic personality traits.

Note: Non-significant correlations are displayed in italics.

The measures consisting of behavioural indicators for the six basic personality traits had significant loadings on Neuroticism, Extraversion and Disintegration latent factors. For Openness, Agreeableness, and Conscientiousness, loadings were nonsignificant (Table 77).

Table 77 Factor loadings of behavioural measures on corresponding latent factors, sample of 99 respondents

\begin{tabular}{|c|c|c|c|c|c|c|}
\cline { 1 - 5 } Factor & \multirow{2}{*}{$\mathrm{N}$} & $\mathrm{E}$ & $\mathrm{O}$ & $\mathrm{A}$ & $\mathrm{C}$ & $\mathrm{D}$ \\
\cline { 1 - 5 } Measure & & & & & & \\
\hline $\mathrm{N}_{\mathrm{B}}$ & 0.32 & & & & & \\
\hline $\mathrm{E}_{\mathrm{B}}$ & & 0.20 & & & & \\
\hline $\mathrm{O}_{\mathrm{B}}$ & & & 0.16 & & & \\
\hline $\mathrm{A}_{\mathrm{B}}$ & & & & 0.04 & & \\
\hline $\mathrm{C}_{\mathrm{B}}$ & & & & & -0.04 & \\
\hline $\mathrm{D}_{\mathrm{B}}$ & & & & & & 0.61 \\
\hline
\end{tabular}

Note: $\mathrm{N}_{\mathrm{B}}-\mathrm{D}_{\mathrm{B}}$ - ratings by experts of basic six personality traits; N-D - latent factors of six basic personality traits

Note: Non-significant correlations are displayed in italics.

The measures consisting of linguistic indicators for the six basic personality traits had significant loadings only on Conscientiousness latent factor, while on Neuroticism, Extraversion, Openness, Agreeableness, and Disintegration, loadings were non- significant (Table 78). 
Table 78 Factor loadings of linguistic measures on corresponding latent factors, sample 99 respondents

\begin{tabular}{|c|c|c|c|c|c|c|}
\hline Factor & \multirow{2}{*}{ N } & E & O & A & C & D \\
\cline { 1 - 5 } Measure & & & & & & \\
\hline LIWC $_{\mathrm{ZN}}$ & -0.13 & & & & & \\
\hline LIWC $_{\mathrm{ZE}}$ & & 0.03 & & & & \\
\hline LIWC $_{\mathrm{ZO}}$ & & & 0.16 & & & \\
\hline LIWC $_{\mathrm{ZA}}$ & & & & 0.02 & & \\
\hline LIWC $_{\mathrm{ZC}}$ & & & & & $0.31^{*}$ & \\
\hline LIWC $_{\mathrm{ZD}}$ & & & & & & -0.14 \\
\hline
\end{tabular}

Note: $\mathrm{LIWC}_{\mathrm{ZN}}-\mathrm{LIWC} \mathrm{ZD}_{\mathrm{ZD}}$ - linguistic measures of basic six personality traits; N-D - latent factors of six basic personality traits

Note: Non-significant correlations are displayed in italics.

Table 79 shows loadings of cognitive measures on the latent factor of intellectual abilities.

Table 79 Factor loadings of KOG9 processors on corresponding latent factor, sample 99 respondents

\begin{tabular}{|c|c|}
\hline \multirow{2}{*}{ Factor } & \multirow{2}{*}{ IQ } \\
\cline { 1 - 2 } Measure & \\
\hline KOG9 & 0.52 \\
\hline IQSelf $^{*}$ & 0.07 \\
\hline IAT $_{\mathrm{I}}$ & 0.26 \\
\hline
\end{tabular}

Note: IQself - self-assessment of intellectual abilities, KOG9- principal component from KOG9 battery, IAT $_{\mathrm{I}^{-}}$IAT measuring intellectual abilities

The results of correlations between the latent factors are in accordance with previous researches (DeYoung, 2011; Knežević, 2011) and similarly, although somewhat lower, to those obtained in the model tested on 224 subjects (Table 80).

Table 80 Inter-correlations of latent factors, sample 99 respondents

\begin{tabular}{|c|c|c|c|c|c|c|c|}
\hline Factors & $\mathrm{N}$ & $\mathrm{E}$ & $\mathrm{O}$ & $\mathrm{A}$ & $\mathrm{C}$ & $\mathrm{D}$ & $\mathrm{IQ}$ \\
\hline $\mathrm{N}$ & 1 & & & & & & \\
\hline $\mathrm{E}$ & $-0.57^{*}$ & 1 & & & & & \\
\hline $\mathrm{O}$ & $-0.29 *$ & $0.51^{*}$ & 1 & & & & \\
\hline $\mathrm{A}$ & $-0.46^{*}$ & $0.33^{*}$ & 0.10 & 1 & & & \\
\hline $\mathrm{C}$ & $-0.27^{*}$ & 0.12 & 0.18 & 0.14 & 1 & & \\
\hline $\mathrm{D}$ & $0.70^{*}$ & $-0.49^{*}$ & -0.06 & $-0.64^{*}$ & $-0.35^{*}$ & 1 & \\
\hline $\mathrm{IQ}$ & $-0.41^{*}$ & 0.10 & $0.60^{*}$ & -0.02 & 0.26 & -0.19 & 1 \\
\hline
\end{tabular}

*. Correlation is significant at the 0.05 level.

Note: N-D - latent factors of six basic personality traits; IQ - latent factor of cognitive abilities.

Note: Non-significant correlations are displayed in italics. 


\subsubsection{Model Testing Only Method Factors}

Previous researches in the field of implicit assessment indicate that the implicit techniques (e.g., IAT) contain method specific individual differences that are independent of the measured content (Mierke \& Klauer, 2003; Nosek, 2005; Nosek \& Smyth, 2007; Ranganath, Tucker Smith, \& Nosek, 2008). In other words, previous studies have shown that agglomerating the indicators of implicit and explicit measures into a single latent factor leads to an inferior model fit. In order to test whether only method factors (i.e., non-trait factors) influence the structure of relations among the measured constructs, the basic model was tested assuming the existence of only method factors (for self-reports, female observer ratings, male observer ratings, expert ratings, implicit measures (IAT), and the factors consisting of linguistic indicators (LIWC)). (Figure 10). 


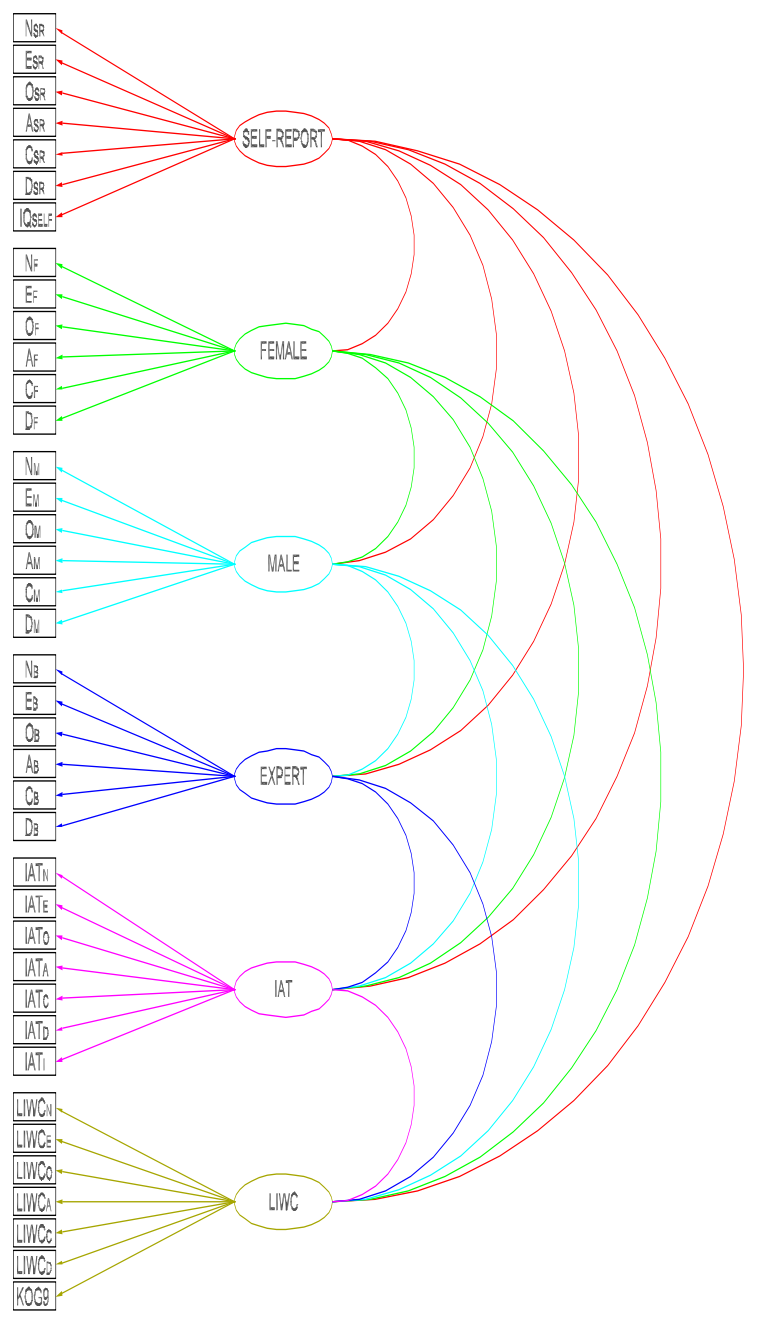

Figure 10. Structural Model Testing Only Latent Method Factors on 99 subjects

Note: $\mathrm{N}_{\mathrm{SR}}-\mathrm{D}_{\mathrm{SR}}$ - self report measures of six basic personality traits; $\mathrm{N}_{\mathrm{F}}-\mathrm{D}_{\mathrm{F}}$ - ratings by close female others of six basic personality traits; $\mathrm{N}_{\mathrm{M}^{-}} \mathrm{D}_{\mathrm{M}}$-ratings by close male others of six basic personality traits; $\mathrm{N}_{\mathrm{B}}-\mathrm{D}_{\mathrm{B}}$ - ratings by experts of six basic personality traits; IAT $_{\mathrm{N}}-\mathrm{IAT}_{\mathrm{D}}-\mathrm{IAT}$ assessing six big personality traits, KOG9-principal component on KOG9 battery, IQself-self-assessment of intellectual abilities; SELF-REPORT - latent method factor for self-report measures; FEMALE- latent method factor of ratings by close female others; MALE- latent method factor of ratings by close male others; EXPERTlatent method factor of ratings by experts; IAT-latent method factor of implicit measures; LIWC- latent method factor of linguistic parameters.

This model, as expected, did not have acceptable fit with $\chi^{2}=1241.73(\mathrm{df}=650)$, $\mathrm{p}=0.00 ; \mathrm{RMSEA}=0.096(90 \%$ CI RMSEA 0.088-0.10), RMR=0.12, SRMR=0.12 and $\mathrm{CFI}=0.61$. 
Appendix 16 Appendix16 presents other fit indices for this model. However, it clearly indicated a strong correlation between the latent IAT and LIWC method factors $(\mathrm{r}=0.75)$, which suggests that these two assessment methods share at least 50 per cent of the common method variance. In addition, these two method factors did not have significant correlations with other latent method factors (Table 81).

Table 81 Correlations of latent method factors, sample 99 respondents

\begin{tabular}{|c|c|c|c|c|c|c|}
\hline Factors & Self & Female & Male & Expert & IAT & LIWC \\
\hline Self & 1 & & & & & \\
\hline Female & .53 & 1 & & & & \\
\hline Male & .46 & .63 & 1 & & & \\
\hline Expert & .45 & .29 & .10 & 1 & & \\
\hline IAT & .08 & .20 & .12 & -.04 & 1 & \\
\hline LIWC & -.15 & .07 & -.08 & -.21 & .75 & 1 \\
\hline
\end{tabular}

* Significant correlation on .05 level

Non-significant correlations are displayed in italics.

Note: SELF-REPORT - latent method factor for self-report measures; FEMALE- latent method factor of ratings by close female others; MALE- latent method factor of ratings by close male others; EXPERTlatent method factor of ratings by experts; IAT-latent method factor of implicit measures; LIWC- latent method factor of linguistic parameters

This result demonstrated a strong divergence between the implicit and explicit methods of assessment. 


\section{DISCUSSION}

Before discussing the results in detail, it would be desirable to briefly summarize all the results obtained in previous analyses. The Implicit Association Test did not prove to be a sufficiently valid method for the assessment of basic personality traits, at least not for the assessment of those aspects that are mostly tapped by explicit methods. Weak correlations were obtained only on Neuroticism and Extraversion measured using IAT and self-reports, and on Agreeableness using IAT and ratings by male close others (but the last one in the "wrong" direction). Thus, the results of this research do not go in favour of the discriminative and convergent validity of IAT in the assessment of basic personality traits. Moreover, the structural equation modelling provided definite evidence that the obtained correlations were not the consequence of IAT tapping the latent traits assessed with traditional methods.

\subsection{On the Quality of IAT Stimuli and Relations between IAT and Explicit Measures in Assessment of Basic Personality Traits}

The first steps in analysing data were to test the quality of stimuli, and of the software used in the IATs. This phase included a thorough selection of attributes for the personality IAT, with the intention to ensure that the most central concepts of the measured traits were captured. It also included two pilot testings.

Factor analyses performed on all the attributes resulted in a very good five-factor solution (i.e., where the extracted factors described the "big five" personality traits), while the six-factor solution was found to be less good. For example, in the six-factor solution, Disintegration attributes did not converge on one factor, and some had higher 
loadings on the Openness factor. However, because of the constraints of time, and the possibility that the selection of extreme attributes (probably indicating Disintegration more efficiently) would lead to uniformly strong positive D measure, it was decided to proceed with the stimuli.

The pilot testing consisted of two IATs, one for the assessment of implicit attitudes towards homosexuality, and the other for basic personality traits. Results indicated moderate correlations between the implicit and explicit attitudes towards homosexuality (Bjekic et al., unpublished manuscript), and lack of correlations between personality IAT and self-report measures. However, since the sample in the pilot testing was rather small, and since some previous findings had indicated weak but inconsistent correlations between personality IAT and explicit measures (Banse et al., 2001; Egloff \& Schmukle, 2002; Schmukle \& Egloff, 2005; Steffens \& Schulze-König, 2006), results from the preliminary analyses were not taken as discouraging. Assured of the fact that it would lead to the detection of the population correlation of 0.20 with 0.85 power at 0.05 alpha level, it was decided to proceed with the study.

The major findings, in correlation analyses, indicated some convergent (only for Neuroticism and Extraversion assessed by self-reports), and very low discriminant validity of the six basic personality traits, measured with IAT, which was consistent with some previous researches (Back et al., 2010; Steffens \& Schulze-König, 2006). To some extent, it confirmed the hypothesis that non-zero correlations exist between the implicit and explicit measures (Hypothesis 1). Results showed that the correlations between IAT and explicit measures were weak and significant correlations existed only between the Implicit Association Test and NEO PIR self-reports, but not with the short scale of attributes (containing the same attributes as IAT), ratings by close others or 
behavioural measures. These, and the results of some previous researches (e.g., Steffens \& Schulze-König, 2006; Grumm \& van Collani, 2007), showing weak and inconsistent patters of correlations did not go in the favour of considering IAT as a stable and valid measure of basic personality traits.

Based on the theoretical assumption that the implicit measures grasp automatic, less controlled, and less intentional aspects of personality (DeHouwer, 2006), it was hypothesised (Hypothesis 2) that the ratings by close others, and by experts, would have similar or higher correlations with IATs in comparison with self-reports. This assumption was founded on the results of previous researches showing moderate correlations between self-reports and ratings by close others, and between self-reports and zero-acquaintance ratings (Costa \& McCrae, 2008; Gosling, Rentfrow, \& Swann, 2003; Vazire, 2006). Observer ratings are considered to entangle, at least partially, different aspects of behaviour in comparison with self-reports (including those less controlled, expressive aspects that a person is not fully aware of). If this were true, then the implicit measures would have incremental validity in the observer ratings. However, results from both correlation and regression analyses showed that IAT and ratings by close others, or experts, did not overlap at all. Thus, these results also did not go in favour of the construct and discriminant validity of IAT.

In order to investigate whether the item formulation had an impact on the correlations between IAT and explicit measures, D measures from the Implicit Association Test were correlated with scores from the Short Scale of Attributes DOCEAN (which consisted of the same attributes that are used in the IAT as stimuli). Results demonstrated low correlations only for Extraversion (when correlating IAT and 
NEO PIR) and Openness. Therefore, we could rule out the possibility of the use of disparate instruments being the reason for low convergent validity coefficients of IATs.

Concerning the correlations of the IAT measuring automatic associations related to cognitive abilities (IATI), and other measures of intelligence, the results did not confirm the Hypothesis 3 that implicit measures would have incremental validity over self-report of intellectual abilities in objective scores on KOG9 battery. Moreover, the direct correlation between the IATI and the score on KOG9 battery was zero. In other words, results concerning the efficacy of cognitive functioning demonstrated that the implicit measure taps something entirely different in comparison to either self-assessed or objectively measured abilities ${ }^{8}$.

\subsection{On the Effect of Moderators on Correlations between IAT and Explicit Measures}

We have tested the effects of moderator variables (i.e., consistency of traits in behaviour) on correlations between the IATs and explicit measures. Some researches show that Extraversion, Agreeableness, and Conscientiousness tend to be more visible traits in behaviour, in comparison with Neuroticism, Openness, and Disintegration (Gosling et al., 1998; John \& Robins, 1993; Heyes \& Dunning, 1997; Szarota et al., 2002; Vazire, 2010). Following these findings, the study investigated if the trait consistency (self-reported and objectively measured) would also moderate correlations between the IATs and explicit measures. However, all analyses demonstrated that the chosen moderators do not influence correlations and they were excluded from further

\footnotetext{
${ }^{8}$ The only interesting result dealing with relations between IAT measuring automatic association related to cognitive abilities and other measures of cognitive functioning was that the efficiency of cognitive processes was significantly correlated with the sorting speed on all IATs (i.e., correlation between KOG9 and total time in IAT was -0.352 , $\mathrm{p}=0.000$ ).
} 
analyses, and were not going in favour of Hypotheses 4 that consistency would moderate relations between implicit and explicit measures. In other words, results suggested that either self-reported or objectively measured consistency do not have impact on strength of relations between implicit measures and self-report or rating measure.

\subsection{On Relations between IAT and Ipsatized Measures}

A major reason for the development of implicit techniques was the need to overcome the problem of social desirability in responding, seen while using traditional methods, such as self-reports. Several studies advocate the use of implicit measures as less sensitive to SDR in comparison with self-report measures (Greenwald et al., 1998; Greenwald et al., 2003). However, some previous studies have shown that social desirability does not moderate the relationship between the implicit and explicit measures of anxiety, and stressed that additional research is required to generalize this result, and apply it to other personality constructs. "The results suggest that, at least concerning the construct of anxiety, the magnitude of the implicit-explicit correspondence is not moderated by social desirability (...) social desirability might moderate the relationship between implicit and explicit measures of other constructs“" (Egloff \& Schmukle, 2003; p.1704).

While using explicit measures, such as self-reports, one possibility to overcome the problem of SDR is to use ipsatized scores. If the implicit measures allow diminishing tendency for SDR, we can presume that, between IAT and ipsatized scores, correlations would be higher than the correlations between implicit and normative scores (Hypothesis 5). This expectation is the consequence of the fact that ipsatized 
scores are less prone to SDR, and the assumption that SDR in self-report measures could be responsible for the low correlation between IAT and normative self-report measures. However, results showed a drastic reduction in correlations between the implicit and ipsatized scores, compared to those with normative scores. These results do not favour the interpretation that the low correlations between IAT and self-report measures were the consequence of the latter being influenced by SDR.

\subsection{On Relations between Explicit Measures in Assessment of Basic Personality Traits}

Results of the research confirmed a high convergent and discriminative validity of self-reports and ratings by close others, which is in accordance with previous results (Vazire, 2006; Costa \& McCrae, 2008; Watson et al., 2000). Although both the male and female observer ratings had moderate correlations with self-reports, the male observer ratings showed slightly lower correlations on all personality traits except on Disintegration, in comparison with female ratings. Some previous results show that the level of acquaintance influences the correlations between self-reports and observer ratings (Funder \& Colvin, 1988; Kurtz \& Sherker, 2003). It seems that one of the reasons for lower coefficients for male ratings in this research is that fathers (since the majority of male observers were the respondents' fathers) are less able to assess their children's personality traits, possibly because of their lower involvement in the upbringing of a child.

Self-reports and expert ratings had significant correlations. In comparison with correlations between self-reports and observer ratings, these coefficients were somewhat lower, but still indicated a moderate convergent validity. Some previous researches have 
demonstrated moderate to strong correlations between self-reports and zeroacquaintance ratings, when identical instruments are used (Gosling, Rentfrow, \& Swann, 2003). Results of this research also demonstrated convergent validity between self-reports and zero-acquaintance ratings, even though different instruments were used.

Regarding convergent coefficients between the ratings by close-others and by experts, results showed significant correlations only for Extraversion and Disintegration trait. The SEM demonstrated that the expert assessments of Extraversion, Disintegration and Neuroticism were valid indicators of these latent traits, but the other three (Openness, Agreeableness and Conscientiousness) were not. Lack of significant correlations for Openness, Agreeableness and Conscientiousness is a probable consequence of the lower reliability coefficients of behavioural measures of these traits. In the next section, we will discuss this in more detail.

\subsubsection{On Behavioural Indicators}

The reliability analysis of behavioural indicators brought out the strengths and shortcomings of certain behavioural indicators, and pointed to the directions for possible improvements of expert assessment. Behavioural indicators of Neuroticism, Extraversion, and Disintegration demonstrated satisfactory reliability coefficients, and convergent validity with other explicit measures. Specifically, all the behavioural indicators of Neuroticism showed a high internal consistency and a significant correlation with self-reported measure (from 0.225 for leg tension to 0.424 for global vision of future). Of all the behavioural indicators of Extraversion, only those related to appearance (i.e., flashy and stylish dress), concentration test, and reassuring question did not have significant correlations with other Extraversion indicators or with self-report 
measures. Other Extraversion indicators correlated with the self-reported measure from 0.270 for vision of future to 0.335 for global behaviour. When it came to Disintegration indicators, all but one (i.e. pantomime) correlated significantly with other indicators and with the self-reported measure, from 0.207 (for appearance) to 0.352 (for facial inadequacy).

However, behavioural indicators for latent traits Openness, Agreeableness, and Conscientiousness had lower coefficients of internal consistencies, and the coefficient for Conscientiousness was the lowest. The reasons for this can be found both in the number of indicators designed for the assessment of $\mathrm{O}, \mathrm{A}$ and $\mathrm{C}$, and in the internal consistencies of indicators. The indicators mapping Conscientiousness were related to being late on the interview or in sending back questionnaire, the number of errors in concentration task and short story, slouchy body posture, and formal dress. However, the principal component analysis indicated very low loadings of almost all the indicators, and none of them was significantly correlated with the self-reported measure. It seems that these indicators were not tapping orderliness, responsibility or selfdiscipline, and that it is necessary to design tasks that are more difficult and yield indicators converging more on one factor.

The indicators for the latent trait Openness were not correlated with the selfreported measure, and showed a lower internal consistency (only eloquence was correlated with the self-reported measure). In principal component analyses indicators related to general and actual knowledge and eloquence did not have high loadings on first extracted principal component.

Analysis showed that the correlations between the indicators designed for behavioural assessment of Agreeableness and self-reported measure were low (for 
global behaviour in helping situation 0.381 , friendly voice in helping situation 0.261 , and checking out room -0.246) or non-significant (friendly voice, attentive body posture). In the task named helping situation, the respondents had to cooperate and help the interviewer. However, it seems that the purpose of the task itself was too obvious for the respondents and, therefore, the experts had more difficulty in rating Agreeableness of the respondents. These results hint at the necessity of redesigning the Agreeableness indicators.

\subsection{On Relations between IAT and Spontaneous Verbal Behaviour}

The study yielded some very important results on the relations between IAT and spontaneous behaviour assessed through automatic text analysis. That is, the results demonstrated the fact that measures of spontaneous verbal behaviour could be constructed to have strong correlations with implicit measures (unlike self-report measures). Implicit measures were related to content and grammatical aspects of language recorded in the interview. In other words, the results showed that both the IAT and LIWC measures share significant amounts of common method variance. This result is even more interesting, considering that the sample of speech processed was relatively small.

Scholars are not unanimous as to whether the automatic text analysis (specifically LIWC) is strictly an implicit or explicit method, but they agree that the processes underlying verbal production are, at least in part, automatic (Buckley \& Cameron, 2011; Schultheiss \& Brunstein, 2001; Tausczik \& Pennebaker, 2010). Theoretically speaking, the analysis of verbal material could be considered as implicit, having in mind that people cannot easily control word selection, and that it is a fast and 
not-completely-intentional process (Chung \& Pennebaker, 2007). Results of this study support that, irrespective of the fact that interview is a structured situation, the verbal output is very spontaneous, and that the processes underlying verbal behaviour, even in controlled situations, are a lot similar to automatic processes assessed in the personality IAT.

So far, the results on correlations between the IAT and LIWC had been scarce and inconsistent (Bosson et al., 2000; Cohen et al., 2010). This study finds substantial reasons to hypothesise the similarity of processes underlying both, spontaneous verbal behaviour and personality IAT, since there were high correlations between the personality IAT and linguistic indicators. If IAT is efficient in the assessment of spontaneous, non-controlled processes (Greenwald et al., 1998; Greenwald \& Farnham, 2000), and if the verbal output is considered as one aspect of behaviour (i.e., spontaneous behaviour) (Tausczik \& Pennebaker, 2010), these findings provide evidence to support the possibilities of IAT in the prediction of spontaneous behaviour.

\subsection{On Aspects of Verbal Behaviour Explaining Individual Differences in Personality}

A detailed analysis of relations between the IAT and LIWC demonstrated that function words (counted in LIWC analysis) convey a large part of information in describing the individual differences in IAT. This finding is in line with some previous researches pointing out that function words reflect differences in the ways individuals think about, and relate to the world (Chung \& Pennebaker, 2007; Newman, Groom, Handelman, \& Pennebaker, 2008). These groups of words are processed differently in the brain, and are found to be related to different emotional states such as depression, 
social connections with others, and with the way people think about the world around them (Chung \& Pennebaker, 2007; Rude, Gortner, \& Pennebaker, 2004).

The results showed lack of significant correlations between the LIWC parameters and explicit measures (i.e., self-reports and observer ratings), except for Conscientiousness. Primarily, it is the consequence of the fact that LIWC trait measures are constructed to have correlations with IAT, not explicit measures. But, it seems that other reasons could be present as well. It is possible that the low base rate of words in experimental situation leads to non-significant correlations with explicit measures. In other words, in a small sample of speech, psychologically relevant words tend to be low in number, while the number of function words is higher (Chung \& Pennebaker, 2007; Pennebaker \& King, 1999; Pennebaker et al., 2003). This probably leads to range restriction and low correlations between the LIWC parameters and personality domains. In addition, we should note that, in free speech, individual differences are more pronounced in words marking psychological processes than in function words (Groom \& Pennebaker, 2002; Mehl et al., 2006). Results of this study support the previous studies in the field, and show larger differences in function words in experimental situations.

\subsection{On Possibilities of IAT in Assessment of Basic Personality Traits}

The structural equation modelling in this study provided an extensive view on the relations between implicit and various explicit measures. The model in which the latent trait factors had paths from each assessment method had excellent fit. However, none of the paths from personality IAT to the corresponding latent traits in CorrelatedTraits-Correlated-Uniqueness-MTMM-Model were significant. The important result 
was that the significant correlations between IAT and self-report on Neuroticism and Extraversion were lost when the IAT measures were related to the latent factors of Neuroticism and Extraversion instead. Therefore, these analyses did not confirm the construct validity of personality traits measured by IAT. Sporadic, very low, and inconsistent correlations between the implicit and explicit measures suggest that implicit and explicit techniques measure completely different aspects of personality constructs. In other words, this analysis demonstrated that, whatever the type of personality measured by IAT, the traits that come out have little in common with the personality traits traditionally measured through self-report inventories or rating scales.

However, before discarding IAT as a valid method for the assessment of basic personality traits, it is imperative to have a look on the significant findings related to the latent structure of differential scores, derived from IATs. Thus, the exploratory factor analysis demonstrated that it was possible to clearly distinguish four personality dimensions (i.e., Neuroticism, Extraversion, Openness, and Conscientiousness), while the differential scores derived from the attributes for Agreeableness and Disintegration did not have clear loadings on the corresponding latent dimensions. This result provides some evidence that the Implicit Association Test taps certain aspects of our personalities. However, it seems that the personality assessed with IAT, and the one assessed with traditional explicit techniques, have an isomorphic structure.

An important observation is that this study did not replicate the results of Back et al. (2010) even though the same procedure for behavioural assessment was used. The result is even more peculiar if we take into account that IAT is supposed to tap the lesscontrolled processes and that, in behavioural observation, the research had access to those less controlled behavioural manifestations (e.g., prosody, body posture, expressive 
aspects of behaviour, movements, etc.). As Grumm \& Van Collani (2007) state, every time we assess someone's behaviour irrespective of the task or situation, a large part of it can be described as spontaneous behaviour. Previous researches have reported significant correlations between the implicit measures and spontaneous behaviours, but not between implicit measures and controlled behaviours (Asendorpf et al., 2002; Steffens \& Schulze-König, 2006). Back et al. (2010) showed that the implicitly measured Neuroticism and Extraversion predicted actual behaviour. Still, the fact that this study did not replicate the findings of Back and his colleagues raises doubts over the possibilities of the personality IAT in the prediction of controlled behaviour assessed through ratings. However, results of this study do shed some light on the relations between IAT measures and the spontaneous verbal behaviour assessed by automatic text analysis. If we analyse the measures collected in this study (apart from the IAT) on the dimension of spontaneity of underlying processes, on one side of the continnum would be self-reports (assessing mostly controlled aspects of behaviour), and on the other spontaneous verbal behaviour (assessing almost completely spontaneous behaviour). Results showed that IAT has significant relations only with spontaneous behaviour related to basic personality traits. This supports the model of double dissociation, proposing that IAT has a predictive validity for spontaneous behaviours, but not for controlled.

It seems that IAT correlations with explicit measures in case of attitudes are well established phenomenon (Hofman et al., 2005) in spite of some contrary voices (Bosson et al., 2000; Fazio \& Olson, 2003). However, when it comes to IAT personality measures, data seem more inconsistent and correlations considerably lower (Back et al., 2010; Schmukle et al., 2008). This study in which IAT relations with latent personality 
factors were investigated (not just relations with a particular assessment method) did not find support for the claim that IAT in the present form could be the valid way to measure personality.

A possible explanation for the lower validity coefficients of IAT in personality assessment in comparison with attitude assessment could be that the process of selfassociating (i.e., implicit personality assessment) is different from implicit attitudes assessment. Stimuli in attitudes assessment could be more emotionally provoking (especially if visual stimuli are utilized instead of verbal) than in self-associating. It could be that the contents of attitudes are more emotionally arousing than selfassociations.

\subsubsection{Automatic Self-associations are Predominately Positive}

Results of this study demonstrate that automatic self-associations are predominantely positive, and this is in congruence with some previous studies (Back et al., 2010; Steffens \& Schulze-König, 2006).

Self-evaluations assessed thorough IAT are considered to be a part of implicit self-esteem, and they occur without any explicit encouragement to engage in selfevaluative activity. Besides, people lack introspective awareness when they are exhibiting implicit self-esteem, which suggests that implicit self-esteem is a form of self-evaluation that occurs in the absence of conscious self-reflection (Koole, Dijksterhuis, \& Knippenberg, 2001). It is very justifiable to ask how people can have a subset of self-evaluations of which they are not aware. One stream of researchers states that self-evaluations are formed from the childhood, and they are consolidated into the person's cognitive-affective architecture. Also, when activated repeatedly, their easy 
retrieval increases and they can spring to the mind unwittingly, and in this way these self-evaluations may become an integral part of the automatic self.

Scholars tried to explain the mechanism of acquisition of positive selfassociations. Self-enhancement is very easily accomplished through positive feedback; when self-reflective information is positively reinforced, it is acquired, and when it is negative, it is rejected (Swann, Hixon, Stein-Seroussi, \& Gilbert, 1990). Throughout the process development, a continuous activation of positive self-relevant associations will give rise to a positive bias in the people's evaluations of self-associated stimuli. Therefore, self-descriptions tend to be positive and, with their continuous repetition, there is a tendency to yield a positive automatic self that requires less attention to generate (Paulhus, 1993; Swann et al., 1990). However, empirical evidences suggest that there is a divergence between the implicit and explicit self-associations and, in terms of content, implicit associations are more positive than explicit. It was suspected that the explicit self-associations are a result of more sophisticated cognitive judgment of the self, and that these two kinds of self-evaluative judgments involve qualitatively different kinds of self-evaluation. This view also assumes that there is a highly dynamic and complex relationship between implicit and explicit self-evaluations. Thus, when people process information with sufficient motivation and capacity, their selfassociations tend to reflect a more deliberate evaluation, and this is what is grasped by explicit measures. However, when the motivation or capacity is lacking, implicit automatic self-associations are predominant, and this is why there is a discrepancy between these kinds of evaluations (Swann et al., 1990). Empirical evidence, both coming form previous researches and this one, gives a certain support to the viewpoint that the implicit self-evalutions are an integral part of the automatic self, and that when 
there is no deliberative engagement in self-reflection, the implicit and explicit selfevaluations are divergent. In the situations where the conscious attention of the respondent is directed elsewhere, the implicit automatic self-evaluations are activated.

\subsection{On the Strength and Shortcomings of this Study}

The design of this study provided extensive investigation of the possibilities of Implicit Association Test in the assessment of basic personality traits. The use of practically all the explicit methods in personality assessment (i.e., self-reports, ratings by close others, and rating by experts) demonstrated a low convergent and discriminative validity of personality IAT. The major strength of the study is possibility to find out the correlations of IAT with latent traits, based on several assessment methods, not traits contaminated with a particular method of assessment (which is not yet done, to the best of our knowledge).

It is important to mention that the results of the study are based on highly reliable measures (except some expert ratings), with the introduction of some new promissing measures, such as spontaneous verbal behaviour. It seems that spontaneous verbal behaviour could be treated as an easily quantifiable measure of spontaneous behaviour - which is not unimportant in the context of questioning "spontaneity" of some behavioural measures previously used (Grumm \& Van Collani, 2007). So, this field of research is worth further exploration. The inclusion of verbal behaviour extracted in spontaneous, everyday, speech (using for example the Electronically Activated Recorder (Mehl et al., 2001)) would probably give even clearer perspective on the automatic processes related to the basic personality traits. 
Major drawback of this study was the way linguistic parameters for personality traits have been chosen. Namely, the selection of LIWC parameters was based on their relations with IAT measures. As already mentioned, it was very difficult to define a priori specific relations between IAT and LIWC, since clear guidelines about relations do not exist yet. The interesting point was that in spite of the fact that LIWC measures where constructed to optimize their relations with IAT, the correlation with C selfreported measure appeared. This suggests that it is probably possible to construct LIWC measures for other traits that would have correlation with both IAT and explicit measures. Anyway, beyond the important fact that personality IAT and LIWC converge, the meaning of both measures remains to be established, since we still cannot exactly say what is the meaning of the implicit personality measures that do not correlate with explicit measures at all. If it turns out that LIWC measures correlate both with IAT and explicit measures it could help in understanding the nature of automatic processes that makes them more or less similar to explicit measures. 


\section{CONCLUSION}

Assessment in the field of individual differences, particularly in the basic personality traits, is usually performed with various explicit measures. However, due to several serious limitations (e.g., the response set and response style), a lot of effort was invested in the development of new assessment methods - the implicit methods -among which the Implicit Association Test is said to have the best psychometric characteristics (Greenwald et al., 2003). In the field of attitude assessment, a large body of evidence showed that IAT is efficient in overcoming the limitations of explicit methods (Greenwald et al., 2009). When it came to the theoretical background of the implicit methods, researchers still disagreed, to some extent, about the nature of processes underlying the measured constructs. Some stated that the implicit methods measured unconscious aspects, while some were more inclined to label these processes as automatic (DeHouwer, 2006).

The basic goal of this research was to test IAT as an assessment method of the basic personality traits, and to provide some insight into the nature of the underlying processes. Besides, the research results provided information on whether it is possible to substitute self-reports, or other explicit methods, with IAT, or perhaps use it as a complementary method in personality assessment.

However, based on all the results, the study did not find enough evidence to claim that IAT is efficient in the assessment of basic personality traits, at least of those aspects that can be measured with traditional, explicit methods. The main finding was that the personality IAT does not show convergent and discriminant validity. The results suggested that the personality measures assessed with IAT and those with explicit 
measures are divergent, but that patterns (factorial structures) obtained by each of the methods seem to be isomorphic. The results demonstrated relations between the IAT measures and the measures of spontaneous behaviour (i.e., verbal behaviour), and supported the model of double dissociation (Asendorpfet al., 2002; Egloff \& Schmuckle, 2002; Steffens \& Schulze-König, 2006), indicating that the implicit measures have predictive validity only in the domain of spontaneous behaviour. 


\section{References}

1. Arcuri, L., Castelli, L., Galdi, S., Zogmaister, C. \& Amadori, A. (2008). Predicting the Vote: Implicit Attitudes as Predictors of the Future Behavior of Decided and Undecided Voters. Political Psychology, 29, 369 - 387.

doi: 10.1111/j.1467-9221.2008.00635.x

2. Asendorpf, J. B. (1988). Individual response profiles in the behavioural assessment of personality. European Journal of Personality, 2, 155-167. doi: 10.1002/per.2410020209

3. Asendorpf, J. B., Banse, R. \& Mücke, D. (2002). Double dissociation between implicit and explicit personality self-concept: The case of shy behavior. Journal of Personality and Social Psychology, 83, 380-393.

doi: $10.1037 / 0022-3514.83 .2 .380$

4. Ashton, M. C. \& Lee, K. (2008). The HEXACO model of personality structure. In Boyle, G. J., Matthews, G. \& Saklofske, D. H. (Eds.). The SAGE Handbook of Personality Theory and Assessment - Vol 2 Personality Measurement and Testing (pp.239-260). Los Angeles: SAGE

5. Back, M. D., Schmukle, S. C. \& Egloff, B. (2010). Predicting actual behavior from the explicit and implicit self-concept of personality. Journal of Personality and Social Psychology, 97, 533-548.

doi: 10.1037/a0016229

6. Banse, R., Seise, J., \& Zerbes, N. (2001). Implicit attitudes towards homosexuality: Reliability, validity, and controllability of the IAT. Zeitschrift für Experimentelle Psychologie, 48 (2), 145-160.

7. Bargh, J. A., \& Tota, M. E. (1988). Context-dependent automatic processing in depression: Accessibility of negative constructs with regard to self but not others. Journal of Personality and Social Psychology, 54 (6), 925-939.

8. Barrick, M. R. \& Mount, M. K. (1991). The Big five personality dimensions and job performance: A meta-analysis. Personnel Psychology, 44, 1-26. doi: 10.1111/j.1744-6570.1991.tb00688.x

9. Bele-Potočnik, Ž. (1983). Test Domino “D48” - Priručnik. (Domino test manual). Ljubljana, Zavod SR Slovenije za produktivnost dela - Centar za psihodijagnostička sredstva.

10. Bem, D. J. \& Allen, A. (1974). On predicting some of the people some of the time: The search for cross-situational consistencies in behavior. Psychological Review, 81 (6), 506-520. 
11. Biesanz, J. C. \& West, S. G. (2004). Towards understanding assessments of the big five: multitrait-multimethod analyses of convergent and discriminant validity across measurement occasion and type of observer. Journal of Personality, 72 (4), 845-876.

12. Bjekic, J., Živanović, M. \& Žeželj, I. (unpublished manuscript). Linguistic markers of attitudes toward homosexuality

13. Bluemke, M. \& Friese, M. (2006). Do features of stimuli influence IAT effects? Journal of Experimental Social Psychology, 42, 163-176.

doi:10.1016/j.jesp.2005.03.004

14. Bosson, J. K., Swann, Jr. W. B., \& Pennebaker, J. W. (2000). Stalking the perfect measure of implicit self-esteem: The blind men and the elephant revisited? Journal of Personality and Social Psychology, 79, 631-643.

doi: 10.1037//0022-3514.79.4.631

15. Bornstein, R. F. (1995). Sex differences in objective and projective dependency tests: A meta-analytic review. Assessment, 2, 319-331.

doi:10.1177/1073191195002004003

16. Borkenau, P., \& Liebner, A. (1993). Convergence of Stranger Ratings of Personality and Intelligence with Self/Ratings, Partner Ratings, an Measured Intelligence. Journal of Personality and Social Psychology, 65, 546-553 doi: 0022-3514/93/\$3.00

17. Boysen, G. A., Vogel, D. L., \& Madon, S. (2006). A public versus private administration of the Implicit Association Test. European Journal of Social Psychology, 36, 845-856.

doi: $10.1002 /$ ejsp.318

18. Buckley, J. \& Cameron, L. D. (2011). Automaticity of exercise self-regulatory efficacy beliefs in adults with high and low experience in exercise selfregulation. Journal of Sport and Exercise Psychology, 33, 325-348.

19. Bukvić, A., Štajberger, I. i Dragićević, Č. (1976). Revizija i standardizacija revidirane serije "Beta". (Revision and standardization of Beta series tests). Psihološka istraživanja. Beograd: Institut za psihologiju.

20. Chen, S. \& Chaiken, S. (1999). The Heuristic-Systematic Model in Its Broader Context. In Chaiken, S. \& Trope, Y. (Eds.). Dual-process theories in social psychology (pp.73-96). New York: The Guilford Press

21. Chissom, B. S., \& Hoenes, R. L. (1976). A Comparison of the Ability of the D48 Test and the IPAT Culture Fair Intelligence Test to Predict SRA 
Achievement Test Scores for 8th and 9th Grade Students, Educational and Psychological Measurement, 36 (2), 561-564.

22. Chissom, B. S., \& Lightsey, R. (1971). A Comparison of the D48 and the Otis Quick Score for High School Dropouts. Educational and Psychological Measurement, 31 (2), 525-527.

23. Chung, C. \& Pennebaker, J. (2007). The psychological functions of function words. In Fielder, K. (Ed.). Social communication (pp.343-359). New York: Psychology Press.

24. Cohen, A. S., Beck, M. R., Brown, L. A., \& Najolia, G. M. (2010). Decoupling implicit measures of pleasant and unpleasant social attitudes. Journal of Behaviour Therapy and Experimental Psychiatry, 41, 24-30. doi:10.1016/j.jbtep.2009.08.007

25. Colom, R., Flores-Mendoza, C., Angeles Quiroga, M., \& Privado, J. (2005). Working memory and general intelligence: The role of short-term storage. Personality and Individual Differences, 39, 1005-1014.

doi:10.1016/j.paid.2005.03.02

26. Conolly, J. J., Kavanagh, E. J. \& Viswesvaran, C. (2007). The convergent validity between self and observer ratings of personality: A meta-analytic review. International Journal of Selection and Assessment, 15, 110-117.

doi: 10.1111/j.1468-2389.2007.00371.x

27. Costa, P.T. \& McCrae, R. R. (1995). Domains and facets: Hierarchical personality assessment using the revised NEO Personality Inventory. Journal of Personality Assessment, 64 (1), 21-50.

28. Costa, P. T. \& McCrae, R. R. (2008). The Revised NEO Personality Inventory (NEO-PI-R). In Boyle, G. J., Matthews, G. \& Saklofske, D. H. (Eds.). The SAGE Handbook of Personality Theory and Assessment - Vol. 2 Personality Measurement and Testing (pp.179-198). Los Angeles: SAGE

29. Craik, K. H. (2007). Taxonomies, Trends, and Integrations. In Robins, R. W., Fraley, R. C. \& Krueger, R. F. (Eds.). Handbook of Research Methods in Personality Psychology (pp.209-223). New York: The Guilford Press

30. Cunningham, W. A., Johnson, M. K., Raye, C. L., Gatenby, J. C., Gore, J. C. \& Banaji, M. R. (2004). Separable neural components in the processing of Black and White faces. Psychological Science, 15, 806-813.

doi: 10.1111/j.0956-7976.2004.00760.x

31. Cunningham, W. A., Preacher, K. J. \& Banaji, M. R. (2001). Implicit attitude measures: Consistency, stability and convergent validity. Psychological Science, 12 (2), 163-170 
32. Darley, J. M., Glucksberg, S., \& Kinchla, R. A. (1986). Psychology, $3^{\text {rd }}$ Edition. New Jersey: Prentice-Hall, Inc.

33. Das, J. P., Kirby, J. R. \& Jarman, R. F. (1975). Simultaneous and successive syntheses: An alternative model for cognitive abilities. Psychological Bulletin, $82,87-103$.

34. DeHouwer, J. (2001). A Structural and Process Analysis of the Implicit Association Test. Journal of Experimental Social Psychology, 37, 443-451. doi:10.1006/jesp.2000.1464

35. DeHouwer, J. (2003). A Structural Analysis of Indirect Measures of Attitudes. In Musch, J. \& Klauer, K. C. (Eds.). The Psychology of Evaluation: Affective Processes in Cognition and Emotion (pp.219-244). Mahwah, NJ: Lawrence Erlbaum

36. DeHouwer, J. (2006). What are implicit measures and why are we using them. In Wiers, R. W. \& Stacy, A. W. (Eds.). The Handbook of Implicit Cognition and Addiction (pp.11-28). Thousand Oaks, CA: SAGE Publishers

37. DeHouwer, J. \& Moors, A. (2007). How to Define and Examine the Implicitness of Implicit Measures. In Wittenbrink, B. \& Schwarz, N. (Eds.). Implicit Measures of Attitudes (pp.179-194). New York: The Guilford Press

38. DeHouwer, J., Teige-Mocigemba, S., Spruyt, A. \& Moors, A. (2009). Implicit Measures: A Normative Analysis and Review. Psychological Bulletin, 135, 347368.

doi: 10.1037/a0014211

39. DeYoung, C. G. (2011). Intelligence and personality. In R. J. Sternberg \& S. B. Kaufman (Eds.). The Cambridge handbook of intelligence. New York: Cambridge University Press.

40. Domino, G. (2001). The D48 application in Mexican-American children of a Culture Fair Test. School Psychology International, 22, 253-257.

41. Domino, G., \& Morales, A. (2000). Reliability and Validity of the D-48 with Mexican American College Students. Hispanic Journal of Behavioral Sciences, 22, 382-389.

doi:10.1177/0739986300223007

42. Đurić-Jočić, D., Knežević, G., Džamonja-Ignjatović, T. (2004). NEO PI R primena $i$ interpretacija.(NEO PIR - application and interpretation). Beograd: Centar za primenjenu psihologiju i Društvo psihologa Srbije

43. Egloff, B., \& Schmukle, S. C. (2002). Predictive validity of an Implicit Association Test for assessing anxiety. Journal of Personality and Social Psychology, 83, 1441-1455. 
doi: 10.1037//0022-3514.83.6.1441

44. Fast, L. A. \& Funder, D. C. (2008). Personality as manifest in word use: correlations with self-report, acquaintance report and behaviour. Journal of Personality and Social Psychology, 94, 334-346.

doi: 10.1037/0022-3514.94.2.334

45. Fazio, R. H.\& Olson, M. A. (2003). Implicit measures in social cognition research: Their meaning and use. Annual Review of Psychology, 54, 297-327. doi: 10.1146/annurev.psych.54.101601.145225

46. Fazio, R. H. \& Towles-Schwen, T. (1999). The MODE model of attitudebehavior processes. In Chaiken, S. \& Trope, Y. (Eds.). Dual-process theories in social psychology (pp.97-116). New York: The Guilford Press

47. Fiske, S. T. \& Taylor, S. E. (2008). Social cognition - From Brains to Culture. Boston, McGraw-Hill

48. Frojd, S. (1969). Uvod u psihoanalizu (Introduction to psychoanalysis). Novi Sad, Matica srpska

49. Frojd, S. (1970). Tumačenje snova (Interpretation of dreams). Novi Sad, Matica srpska

50. Funder, D. \& Colvin, C. (1988). Friends and strangers: acquaintanceship, agreement, and the accuracy of personality judgment. Journal of Personality and Social Psychology, 55, 149-158.

doi: 0022-351/88/\$00.75

51. Funder, D., Kolar, D., \& Blackman, M. (1995). Agreement among judges of personality: interpersonal relations, similarity and acquaintanceship. Journal of Personality and Social Psychology, 69, 656-672.

doi: 0022-35I4/95/S3.00

52. Furr, R. M. \& Funder, D. C. (2007). Behavioural observation. In R. W. Robins, R. C. Fraley \& R. F. Kruger (Eds.). Handbook of research methods in personality psychology (pp. 273-291). New York: The Guilford Press.

53. Gilbert, D. T. (1998). Ordinary personology. In Gilbert, D. T., Fiske, S. T. \& Lindzey, G. (Eds.). The Handbook of Social Psychology, $4^{\text {th }}$ Edition (pp.89-150). New York, McGraw-Hill

54. Gill, A.J. and Oberlander, J. (2002). Taking care of the linguistic features of Extraversion. In Proceedings of the 24th Annual Conference of the Cognitive Science Society (pp. 363-368). Fairfax, VA, August 2002. 
55. Goldberg, 1. (1990). An alternative "description of personality": The big five factor structure. Journal of Personality and Social Psychology, 59, 1216-1229. doi: 0022-3514/90/\$00.75

56. Gosling, S. D., John, O. P., Craik, K. H. \& Robins, R. W. (1998). Do People Know How They Behave? Self- Reported Act Frequencies Compared With OnLine Codings by Observers. Journal of Personality and Social Psychology, 74 (5), 1337-1349

57. Gosling, S. D., Rentfrow, P. J., \& Swann, W. B. Jr. (2003). A very brief measure of the Big-five personality domains. Journal of Research in Personality, 37, 504-528.

doi: 10.1016/S0092-6566(03)00046-1

58. Gough, H. G., \& Domino, G. (1963). The D48 test as a measure of general ability among grade school children. Journal of Consulting Psychology, 27, 344349

59. Govan, C. L., \& Williams, K. D. (2004). Changing the affective valence of the stimulus items influences the IAT by re-defining the category labels, Journal of Experimental Social Psychology, 40, 357-365.

doi:10.1016/j.jesp.2003.07.002

60. Greenwald, A. G., \& Banaji, M. R. (1995). Implicit social cognition: Attitudes, self-esteem, and stereotypes. Psychological Review, 102 (1), 4-27

61. Greenwald, A. G, Banaji, M. R., Rudman, L. A., Farnham, S. D., Nosek, B. A. \& Mellott, D. S. (2002). A Unified Theory of Implicit Attitudes, Stereotypes, Self-Esteem, and Self-Concept. Psychological Review, 109, 3-25

doi: 10.1037//0033-295X.109.1.3

62. Greenwald, A. G. \& Farnham, S. D. (2000). Using the Implicit Association Test to Measure Self-Esteem and Self-Concept. Journal of Personality and Social Psychology, 79, 1022-1038.

doi: 10.1037//0022-3514.79.6.1022

63. Greenwald, A. G., McGhee, D. E., \& Schwartz, J. L. K. (1998). Measuring individual differences in implicit cognition: The Implicit Association Test. Journal of Personality and Social Psychology, 74 (6), 1464-1480.

64. Greenwald, A. G., Nosek, B. A. \& Banaji, M. R. (2003). Understanding and Using the Implicit Association Test: I. An Improved Scoring Algorithm. Journal of Personality and Social Psychology, 85, 197-216

doi: 10.1037/0022-3514.85.2.197 
65. Greenwald, A. G., Poehlman, T. A., Uhlmann, E., \& Banaji, M. R. (2009). Understanding and using the Implicit Association Test III. Meta-analysis of predictive validity. Journal of Personality and Social Psychology, 97, 17-41. doi: $10.1037 / \mathrm{a} 0015575$

66. Groom, C. J., \& Pennebaker, J. W. (2002). Words. Journal of Research in Personality, 36, 615-621.

doi: 0092-6566/02/\$

67. Grumm, M. \& van Collani, G. (2007). Measuring Big-five personality dimensions with the implicit association test - Implicit personality traits or selfesteem? Personality and Individual Differences, 43, 2205-2217.

doi:10.1016/j.paid.2007.06.032

68. Hart, R. P. (2001). Redeveloping DICTION: Theoretical Considerations. In West, M. D. (Ed.). Theory, method and practice in computer content analysis (pp.43-60). New York: Ablex

69. Hayes, A. F. \& Dunning, D. (1997). Construal processes and trait ambiguity: implications for self-peer agreement in personality judgment. Journal of Personality and Social Psychology, 72 (3), 664-677.

70. Heylighen, F., \& Dewaele, J. M. (2002). Variation in the contextuality of language: and empirical measure. Context in context, Special Issue of foundations of Science, 7, 293-240.

71. Hirsh, J. B., \& Peterson, J. B. (2009). Personality and language use in selfnarratives. Journal of Research in Personality, 43, 524-527.

doi: 10.1016/j.jrp.2009.01.006

72. Hofmann, W., Gawronski, B., Gschwender, T., Le, H. \& Schmitt, M. (2005). A meta-analysis on the correlation between the Implicit Association Test and explicit self-report measures. Personality and Social Psychology Bulletin, 31, 1369-1385.

doi: $10.1177 / 0146167205275613$

73. Huffman, K., Vernoy, M., \& Vernoy, J. (1994). Psychology in Action, $3^{\text {rd }}$ Edition. New York: John Wiley \& Sons, Inc.

74. Hofstee, W. K. B. (1994). Who should own the definition of personality? European Journal of Personality, 8, 149-162

75. Ignjatović, I. i Bukvić, A. (1966). GVERTOS - Grupna verzija verbalnog dela Vekslerovog testa inteligencije za odrasle.(GVERTOS- group version of verbal scale of Weschlers Adult Intelligence Scale). Beograd: Institut za kriminološka i kriminalistička istraživanja. 
76. John, O. P., Naumann, L. P. \& Soto, C. J. (2008). Paradigm shift to the Integrative Big Five Trait Taxonomy. In John, O. P., Robins, R. W. \& Pervin, L. A. (Eds.) Handbook of Personality - Theory and Research, $3^{\text {rd }}$ Edition (pp.114158). New York: The Guilford Press

77. John, O. P. \& Robins, R. W. (1993). Determinants of Interjudge Agreement on Personality Traits: Big Five Domains, Observability, Evaluativeness, and the Unique Perspective of the Self. Journal of Personality, 61, 521-551.

78. John, O. P. \& Robins, R. W. (1994). Accuracy and bias in self-perception: Individual differences in self-enhancement and the role of narcissism. Journal of Personality and Social Psychology, 66 (1), 206-219.

79. John, O. P. \& Soto, C. J. (2007). The importance of being valid: reliability and the process of construct validation. In Robins, R. W., Fraley, R. C. \& Krueger, R. F. (Eds.). Handbook of Research Methods in Personality Psychology (pp.461494). New York: The Guilford Press

80. John, O. P.\& Srivastava, S. (1999). The Big-Five Trait Taxonomy: History, Measurement and Theoretical Perspectives. In Pervin, L. A. \& John, O. P. (Eds.). Handbook of personality (pp.102-138). New York: The Guilford Press

81. Johnson, J. A. (1997). Units of Analysis for the Description and Explanation of Personality. In Hogan, R., Johnson, J. \& Briggs, S. (Eds.). Handbook of personality psychology (pp.73-93). San Diego: Academic Press

82. Jordan, C. H., Spencer, S. J., Zanna, M. P., Hoshino-Browne, E., \& Correll, J. (2003). Secure and defensive high self-esteem. Journal of Personality and Social Psychology, 85, 969-978.

doi: 10.1037/0022-3514.85.5.969

83. Kagan, J. (2007). A trio of concerns. Perspective on Psychological Science, 2, 361-376.

84. Karpinski, A. (2004). Measuring Self-Esteem Using the Implicit Association Test: The Role of the Other. Personality and Social Psychology Bulletin, 30, 2234.

doi: $10.1177 / 0146167203258835$

85. Kim, D. Y. (2003). Voluntary controllability of the Implicit Association Test (IAT). Social Psychology Quarterly, 66 (1), 83-96.

86. Kline, P. (1993). Personality: The psychometric view. London: Routledge.

87. Knežević, G. (2003). Koreni amoralnosti. (Roots of amorality). Beograd: Centar za primenjenu, Institut za psihooška i kriminiloška istraživanja i Institut za psihologiju 
88. Knežević, G. (2011). Further evidence favoring Disintegration as a basic personality trait: A multi-trait multi-informant study. ISSID 2011, London, 2528 July, (pp. 8). In: http://www.issid2011.com/program/symposia.pdf

89. Knežević, G., Džamonja-Ignjatović, T. \& Đurić-Jočić, D. (2004). Petofaktorski model ličnosti. (The Five-Factor model of personality). Beograd, Centar za primenjenu psihologiju

90. Knežević, G. \& Lazarević, Lj. (2011). Kratka, balansirana, pridevska skala za procenu "Velikih pet" (Short, balanced, attribute scale for the assessment of Big five). XVII Naučni skup Empirijska istraživanja u psihologiji (pp. 199-200). Beograd: Institut za psihologiju i Laboratorija za eksperimentalnu psihologiju, Filozofski fakultet, Univerzitet u Beogradu

91. Knežević, G. \& Momirović, K. (1996). RTT9G i RTT10G: Dva programa za analizu metrijskih karakteristika kompozitnih mernih instrumenata. (RTT9G and RTT10G: Two softwares for analysis of metrical characteristics of composite instruments). U Kostić, P (Ur.). Merenje u psihologiji 2. Primena računara $u$ psihologiji. Beograd: Institut za kriminološka i sociološka istraživanja

92. Knežević, G. \& Opačić, G. (2009). PSIHO software

93. Knežević, G., Radović, B., Opačić, G. (1997). Evaluacija "Velikih pet" modela ličnosti kroz analizu inventara ličnosti NEO PI R (Evaluation of "Big Five" models of personality through analysis of NEO PI R questionnaire), Psihologija $1-2,7-40$

94. Knežević, G., Savić, D., Kutlešić, V., Jović, V., Opačić, G. \& Šaula, B. (submitted). Disintegration: A basic personality trait - A reconceptualization of psychosis as a personality trait.

95. Kolar, D. W., Funder, D. C. \& Colvin, C. R. (1996). Comparing the accuracy of personality judgments by the self and knowledgeable others. Journal of Personality, 64, 311-337.

doi: 10.1111/j.1467-6494.1996.tb00513.x

96. Koole, S. L., Dijksterhuis, A.\& van Knippenberg, A. (2001). What's in a name: Implicit self-esteem and the automatic self. Journal of Personality and Social Psychology, 80, 669-685.

doi: 10.1037//0022-3514.80.4.669

97. Kurtz, J. \& Sherker, J. (2003). Relationship quality, trait similarity, and selfother agreement on personality ratings in college roommates. Journal of Personality, 71, 21-48.

98. Lalović, D. (2000). Povezanost inteligencije i brzine kognitivne obrade reči srpskog jezika. Psihologija, 33 (1-2), 53-74. 
99. Lane, K. A., Banaji, M. R., Nosek, B. A. \& Greenwald, A. G. (2007). Understanding and using the Implicit Association Test: What we know (so far) about the method. In Wittenbrink, B. \& Schwarz, N. (Eds.). Implicit Measures of Attitudes (pp.59-102). New York: The Guilford Press

100. Larsen, R. J. \& Buss, D. M. (2008). Personality psychology. Boston, McGraw Hill

101. Lazarević, Lj. B. \& Knežević, G. (2008). Provera faktorske strukture baterije za procenu intelektualnih sposobnosti KOG9. Psihologija, 41, 489-505. doi: 10.2298/PSI0804489L

102. Lazarević, Lj. \& Knežević, G. (2012). Da li se ipsativnim merama mogu zameniti inventari u formi prisilnog izbora (Is it possible to substitute forced choice scores with ipsatized measures). XVIII Naučni skup Empirijska istraživanja u psihologiji (pp. 160-161). Beograd: Institut za psihologiju i Laboratorija za eksperimentalnu psihologiju, Filozofski fakultet, Univerzitet u Beogradu

103. Luria, A. R. (1983). Osnovi neuropsihologije. (The working brain: An Introduction to neuropsychology). Beograd: Nolit

104. Mairesse, F., \& Walker, M. (2006). Words Mark the Nerds: Computational Models of Personality Recognition through Language. In Proceedings of the 28th Annual Conference of the Cognitive Science Society (CogSci 2006), Vancouver, July 2006 (pp. 543-548).

105. Mairesse, F., Walker, M. A., Mehl, M. R. \& Moore, R. K. (2007). Using linguistic cues for the automatic recognition of personality in conversation and text. Journal of Artificial Intelligence Research, 30, 457-500.

106. Matthews, G., Deary, I. J. \& Whiteman, M. C. (2003). Personality traits, $2^{\text {nd }}$ Edition. Cambridge, Cambridge University Press

107. Marsh, H. W., Byrne, B. M., \& Craven, R. (1992). Overcoming problems in confirmatory factor analyses of MTMM data: The correlated uniqueness model and factorial invariance. Multivariate Behavioural Research, 27 (4), 489-507

108. McAdams, D. P. (1992). The Five-Factor Model in Personality: A Critical Appraisal. Journal of Personality, 60, 329-361

109. McCrae, R. R. \& Costa, P. T. (1987). Validation of the five-factor model of personality across instruments and observers. Journal of Personality and Social Psychology, 52 (1), 81-90.

110. McCrae, R. R. \& Costa, P. T. (1997). Personality Trait Structure as a Human Universal. American Psychologist, 52 (5), 509-516 
111. McCrae, R. R. \& Costa, P. T. (1999). A five-factor theory of personality. In Pervin, L. A. \& John, O. P. (Eds.). Handbook of personality (pp. 139-154). New York: The Guilford Press

112. McCrae, R. R. \& Costa, P. T. (2003). Personality in Adulthood - A Five Factor Theory of Personality, $2^{\text {nd }}$ Edition. New York: The Guilford Press.

113. McCrae, R. R. \& Costa, P. T. (2008). The Five-Factor Theory of Personality. In John, O. P., Robins, R. W. \& Pervin, L. A. (Eds.). Handbook of Personality - Theory and Research, $3^{\text {rd }}$ Edition (pp. 159-181). New York: The Guilford Press

114. McCrae, R. R., Terracciano, A. \& 78 Members of the Personality Profiles of Cultures Project (2005). Universal features of personality traits from the observer's perspective: Data from 50 cultures. Journal of Personality and Social Psychology, 88, 547-561.

doi: 10.1037/0022-3514.88.3.547

115. McCrae, R. R. \& Weiss, A. (2007). Observer Ratings of Personality. In Robins, R. W., Fraley, R. C. \& Krueger, R. F. (Eds.). Handbook of Research Methods in Personality Psychology (pp. 259-272). New York: The Guilford Press

116. McDaniel, M. J., Beier, M. E., Perkins, A. W., Goggin, S. \& Frankel, B. (2009). An assessment of the fakeability of self-report and implicit personality measures. Journal of Research in Personality, 43, 682-685. doi:10.1016/j.jrp.2009.01.011

117. McGregor, I., Nail, P. R., Marigold, D. C., \& Kang, S.-J. (2005). Defensive pride and consensus: Strength in imaginary numbers. Journal of Personality and Social Psychology, 89, 978-996.

doi: 10.1037/0022-3514.89.6.978

118. McLaurin, W. A., Pendergrass, P., \& Kennedy, S. (1973). Relationship of the D48 with Otis IQ and Grade Point Average. Educational and Psychological Measurement, 33, 453-457.

119. Mehl, M. R.\& Gill, A. J. (2010). Automatic text analysis. In S. D. Gosling \& J. A. Johnson (Eds.). Advanced methods in conducting online behavioural research (pp. 109-127). Washington, DC: American Psychological Association

120. Mehl, M. R., Gosling, S. D. \& Pennebaker, J. W. (2006). Personality in its natural habitat: manifestations and implicit folk theories of personality in daily life. Journal of Personality and Social Psychology, 90, 862-877.

doi: 10.1037/0022-3514.90.5.862 
121. Mehl, M. R., Pennebaker, J. W., Crow, M. D., Dabbs, J., \& Price, J. H. (2001). The electronically activated recorder (EAR): a device for sampling naturalistic daily activities and conversations. Behaviour Research Methods, Instruments Computers, 33, 517-523.

122. Mehl, M. R. \& Pennebaker, J. W. (2003). The social dynamics of a cultural upheaval: social interactions surrounding September 11, 2001. Psychological Science, 14, 579-585.

123. Mitchell, J. P., Nosek, B. A., \& Banaji, M. R. (2003). Contextual Variations in Implicit Evaluation, Journal of Experimental Psychology, 132, 455-469

doi: 10.1037/0096-3445.132.3.455

124. Mierke, J. \& Klauer, K. C. (2003). Method-Specific Variance in the Implicit Association Test. Journal of Personality and Social Psychology, 85, 1180-1192.

doi: 10.1037/0022-3514.85.6.1180

125. Moskowitz, G. B. (2005). Social cognition - Understanding self and others. New York: The Guilford Press

126. Naumann, L. P., Vazire, S., Rentfrow, P. J. \& Gosling, S. D. (2009). Personality judgments based on physical appearance. Personality and Social Psychology Bulletin, 35, 1661-1671.

doi: 10.1177/0146167209346309.

127. Newman, M. L., Groom, C. J., Handelman, L. D., \& Pennebaker, J. W. (2008). Gender Differences in language use: an analysis of 14000 text samples. Discourse Processes, 45, 211-236.

doi: 10.1080/01638530802073712

128. Nisbett, R.E., \& Wilson, T.D. (1977). The halo effect: Evidence for unconscious alteration of judgments. Journal of Personality and Social Psychology, 35 (4), 250-256.

129. Nosek, B. A. (2005). Moderators of the relationship between implicit and explicit evaluation. Journal of Experimental Psychology: General, 134, 565584.

doi: 10.1037/0096-3445.134.4.565

130. Nosek, B. A. (2007). Implicit-Explicit Relations. Current Directions in Psychological Science, 16, 65-69 
131. Nosek, B. A., Greenwald, A. G. \& Banaji, M. R. (2005). Understanding and using the Implicit Association Test: II. Method variables and construct validity. Personality and Social Psychology Bulletin, 31, 166-180.

doi: $10.1177 / 0146167204271418$

132. Nosek, B. A., Greenwald, A. G. \& Banaji, M. R. (2007). The Implicit Association Test at age 7: A methodological and conceptual review. In Bargh, J. A. (Ed.). Automatic processes in social thinking and behavior (pp. 265-292). Psychological Press

133. Nosek, B. A., Hawkins, C. B., \& Frazier, R. S. (in press). Implicit Social Cognition. In S., Fiske \& C. N., McCrae (Eds.). Handbook of Social Cognition. New York, NY: Sage.

134. Nosek, B. A. \& Smyth, F. L. (2007). A multitrait-multimethod validation of the Implicit Association Test: Implicit and explicit attitudes are related but distinct constructs. Experimental psychology, 54, 14-29.

doi: 10.1027/1618-3169.54.1.14

135. Nosek, B. A. \& Hansen, J. J. (2008). Personalizing the Implicit Association Test Increases Explicit Evaluation of Target Concepts. European Journal of Psychological Assessment, 24, 226-236.

doi: 10.1080/02699930701438186

136. Oh, I., Wang, G. \& Mount, M. K. (2011). Validity of observer ratings of the Five-Factor Model of personality traits: A meta-analysis. Journal of Applied Psychology, 96, 762-773.

doi: $10.1037 / \mathrm{a} 0021832$

137. Olson, M. A.\& Fazio, R. H. (2004). Reducing the influence of extrapersonal associations on the Implicit Association Test: Personalizing the IAT. Journal of Personality and Social Psychology, 86, 653-667.

doi: 10.1037/0022-3514.86.5.653

138. Paulhus, D. P. (1991). Measurement and control of response bias. In J. P. Robins, P. R. Shaver, \& L. S. Wrightsman (Eds.). Measures of personality and social psychological attitudes (pp. 17-59). San Diego: Academic Press.

139. Paulhus, D. L. (1993). Bypassing the will. In Wegner, D. M. \& Pennebaker, J. W. (Eds.). Handbook of Mental Control. Hillsdale (pp. 573-587). NJ

140. Paulhus, D. L. (2002). Socially Desirable Responding: the evolution of the construct. In Braun, H. I., Jackson, D. N. \& Wiley, D. E. (Eds.). The role of constructs in psychological and educational measurement (pp. 67-88). Mahvah, NJ: Erlbaum 
141. Paulhus, D. L. \& Vazire, S. (2007). The Self-Report Method. In Robins, R. W., Fraley, R. C. \& Krueger, R. F. (Eds.). Handbook of Research Methods in Personality Psychology (pp. 224-239). New York: The Guilford Press

142. Pennebaker, J. W. \& King, L. A. (1999). Linguistic styles: language use as an individual difference. Journal of Personality and Social Psychology, 77 (6), 1296-1312

143. Pennebaker, J. W., Chung, C. K., Ireland, M., Gonzales, A. \& Booth, R. J. (2007). The Development and Psychometric Properties of LIWC2007, Manual. The University of Texas at Austin and The University of Auckland, New Zealand

144. Pennebaker, J. W., Francis, M. E., \& Booth, R. J. (2001). Linguistic Inquiry and Word Count 2001, Mahwah, NJ: Erlbaum Publishers

145. Pennebaker, J. W. \& Graybeal, A. (2001). Patterns of natural language use: disclosure, personality, and social integration. Current Directions, 10 (3), 90-93

146. Pennebaker, J. W., Mehl, M. R. \& Niederhoffer, K. G. (2003). Psychological aspects of natural language use: our words, our selves. Annual Review of Psychology, 54, 547-577.

doi: 10.1146/annurev.psych.54.10161.145041.

147. Pervin, L. A. (1999). Epilogue: constancy and change in personality theory and research. In L. A. Pervin \& O. P. John (Eds.). Handbook of personality: Theory and research $2^{\text {nd }}$ Edition (pp. 689-704). London: Guilford Press

148. Petty, R. E. \& Cacioppo, J. T. (1986). The elaboration likelihood model of persuasion. In Berkowitz, L. (Ed.). Advances in experimental social psychology (Vol. 19) (pp. 123-205). New York: Academic Press

149. Petty, R. E. \& Wegener, D. T. (1999). The elaboration likelihood model: Current status and controversies. In Chaiken, S. \& Trope, Y. (Eds.). Dualprocess theories in social psychology (pp. 37-72). New York: The Guilford Press

150. Perugini, M. (2005). Predictive models of implicit and explicit attitudes. British Journal of Social Psychology, 44, 29-45.

doi:10.1348/014466604X23491

151. Pinter, B. \& Greenwald, A. G. (2005). Clarifying the Role of the "Other" Category in the Self-Esteem IAT. Experimental Psychology, 52, 74-79.

doi: 10.1027/1618-3169.52.1.74 
152. Pucel, D. J., \& Nelson, H. F. (1969). General Aptitude Test Battery (B1002 Form B) Training Success Norms. US Department of Health, Education and Welfare, Office of Education. Minneapolis, University of Minnesota. Retreived from (08.03.2008)

\section{http://eric.ed.gov/ERICDocs/data/ericdocs2sq1/content_storage $\underline{01 / 0000019 b / 80 / 36 / 0 \mathrm{e} / \mathrm{ca} . p d f}$}

153. Ranganath, K. A., Tucker Smith, C., \& Nosek, B. A. (2008). Distinguishing automatic and controlled components of attitude from direct and indirect measurement methods. Journal of Experimental Social Psychology, 44, 386-396.

doi: 10.1016/j.jesp.2006.12.008

154. Roediger, H.L. (1990). Implicit memory: Retention without remembering. American Psychologist, 45 (9), 1043-1056.

155. Rogers, T. B., Kuiper, N. A., \& Kirker, W. S. (1977). Self-reference and the encoding of personal information. Journal of Personality and Social Psychology, 35 (9), 677-688.

156. Rude, S. S., Gortner, E. M., \& Pennebaker, J. W. (2004). Language use of depressed and depression-vulnerable college students. Cognition and Emotion, 18, 1121-1133.

doi: 10.1080/02699930441000030

157. Sharp, H. C., \& Pickett, L. M. (1959). The General Aptitude Test Battery as a Predictor of College Success. Educational and Psychological Measurement, 19, 617-623.

158. Saucier, G. (2008). Measures of the Personality Factors Found Recurrently in Human Lexicon. In Boyle, G. J., Matthews, G. \& Saklofske, D. H. (Eds.) The SAGE Handbook of Personality Theory and Assessment - Vol. 2 Personality Measurement and Testing (pp.29-54). Los Angeles: SAGE

159. Schmukle, S. C. \& Egloff, B. (2005). A Latent State-Trait Analysis of Implicit and Explicit Personality Measures. European Journal of Psychological Assessment, 21, 100-107.

doi: 10.1027/1015-5759.21.2.100

160. Schnabel, K, Asendorpf, J. B. \& Greenwald, A. G. (2007). Using Implicit Association Tests for the assessment of implicit personality selfconcept. In Boyle, G. J., Matthews, G., \& Saklofske, H. (Eds.). Handbook of Personality Theory and Testing (pp.508-528). London: Sage 
161. Schnabel, K, Asendorpf, J. B. \& Greenwald, A. G. (2008). Assessment of individual differences in implicit cognition. A review of IAT measures. European Journal of Psychological Assessment, 24, 210-217.

doi: 10.1027/1015-5759.24.4.210

162. Schnabel, K., Banse, R., \& Asendorpf, J. B. (2006a). Assessment of implicit personality self-concept using the Implicit Association Test (IAT): Concurrent assessment of anxiousness and angriness. British Journal of Social Psychology, 45, 373-396.

doi:10.1348/014466605X49159

163. Schnabel, K., Banse, R., \& Asendorpf, J. B. (2006b). Employing automatic approach and avoidance tendencies for the assessment of implicit personality self-concept: The Implicit Association Procedure (IAP). Experimental Psychology, 53, 69-76.

doi: 10.1027/1618-3169.53.1.69

164. Schultheiss, O. C., \& Brunstein, J. C. (2001). Assessment of implicit motives with a research version of the TAT: picture profiles, gender differences, and relations to other personality measures. Journal of Personality Assessment, 77 (1), 71-86.

165. Schröder-Abé, M., Rudolph, A., Wiesner, A., \& Schütz, A. (2007). Selfesteem discrepancies and defensive reactions to social feedback. International Journal of Psychology, 42, 174-183.

doi:10.1080/00207590601068134

166. Smederevac, S. \& Mitrović, D. (2006). Ličnost - metode $i$ modeli. (Personality-methods and models). Beograd: Centar za primenjenu psihologiju.

167. Steffens, M. C. (2004). Is the implicit association test immune to faking? Experimental Psychology, 51, 165-179.

doi: 10.1027/1618-3169.51.3.165

168. Steffens, M. C. \& Plewe, I. (2001). Items' Cross-Category Associations as a Confounding Factor in the Implicit Association Test. Zeitschrift für Experimentelle Psychologie, 48 (2),123-134

169. Steffens, M. C. \& Schulze-König, S. (2006). Predicting Spontaneous Big Five Behavior with Implicit Association Tests. European Journal of Psychological Assessment, 22, 13-20.

doi:10.1027/1015-5759.22.1.13

170. Szarota, P., Zawadzki, B. \& Strelau, J. (2002). Big five domain and gender as determinants of rater agreement: a comparison based on self- and 
peer-rating on the Polish Adjective List. Personality and Individual Differences, 33 (8), 1265-1277

171. Swann, W. B. Jr., Hixon, G., Stein-Seroussi, A., \& Gilbert, D. T. (1990). Thee fleeting gleam of praise: Cognitive processes underlying behavioural reactions to self-relevant feedback. Journal of Personality and Social Psychology, 59, 17-26.

doi: 0022-3514/90/S00.75

172. Tausczik, Y. R. \& Pennebaker, J. W. (2010). The psychological meaning of words: LIWC and computerized text analysis methods. Journal of Language and Social Psychology, 29, 24-54.

doi: 10.1177/0261927X09351676

173. Thomas, S., Burton Smith, R. \& Ball, P. (2007). Implicit Attitudes in Very Young Children: An Adaptation of the IAT. Current Research in Social Psychology, 13 (7), 75-85

174. Touron, J. (1983). The determination of factors related to academic achievement in the university: Implications for the selection and counseling of students. Higher Education, 12, 399-410.

175. Trope, Y. \& Gaunt, R. (1999). A dual-process model of overconfident attributional inferences. In Chaiken, S. \& Trope, Y. (Eds.). Dual-process theories in social psychology (pp. 161-178). New York: The Guilford Press

176. Tupes, E. C., \& Christal, R. C. (1992). Recurrent personality factors based on trait ratings. Journal of Personality, 60, 225-251.

177. Vazire, S. (2006). Informant reports: A cheap, fast and easy method for personality assessment. Journal of Research in Personality, 40, 472-481. doi:10.1016/j.jrp.2005.03.003

178. Vazire, S. (2010). Who knows what about a person? The self-other knowledge asymmetry (SOKA) Model. Journal of Personality and Social Psychology, 98, 281-300.

doi: $10.1037 / \mathrm{a} 0017908$

179. Vazire, S. \& Carlson, E. N. (2010). Self-knowledge of personality: Do people know themselves? Social and Personality Psychology Compass, 4/8, 605-620.

doi:10.1111/j.1751-9004.2010.00280.x

180. Vazire, S. \& Mehl, M. R. (2008). Knowing me, knowing you: The accuracy and unique predictive validity of self-ratings and other-ratings of daily behavior. Journal of Personality and Social Psychology, 95, 1201-1216. doi:10.1037/a0013314 
181. Waller, N. G. (1999). Evaluating the structure of personality. In Cloninger, C. R. (Ed.). Personality and psychopathology (pp. 155-197). Washington, D.C.: American Psychiatric Press

182. Watson, D., Hubbard, B. \& Wiese, D. (2000). Self-other agreement in personality and affectivity: the role of acquaintanceship, trait visibility and assumed similarity. Journal of Personality and Social Psychology, 78, 546-558. doi: 10.1037//0022-3514.78.3.546.

183. Wechsler, D. (2008) - Wechsler Adult Intelligence Scale-Fourth Edition (WAIS-IV). Pearson Corp

184. Wilson, T. D., Lindsey, S. \& Schooler, T. Y. (2000). A Model of Dual Attitudes. Psychological Review, 107, 101-126.

doi: 10.1037//0033-295X.107.1.101

185. Wittenbrink, B. (2007). Measuring Attitudes through Priming. In Wittenbrink, B. \& Schwarz, N. (Eds.). Implicit Measures of Attitudes (pp. 1758). New York: The Guilford Press

186. Wittenbrink, B. \& Schwarz, N. (2007). Introduction. In Wittenbrink, B. \& Schwarz, N. (Eds.). Implicit Measures of Attitudes (pp. 1-13). New York, The Guilford Press

187. Wolf, B., Momirović, K. \& Džamonja, Z. (1992). KOG3 - Baterija testova inteligencije. (KOG3 - Battery of intelligence tests). Beograd: Centar za primenjenu psihologiju

188. Zuckerman, M., Koestner, R., DeBoy, T., Garcia, T., Maresca, B. C, \& Sartoris, J. M. (1988). To predict some of the people some of the time: A reexamination of the moderator variable approach in personality theory. Journal of Personality and Social Psychology, 54 (6), 1006-1019 


\section{Appendices}

Appendix 1 Questionnaire for self-assessment of intellectual abilities

On cognitive abilities tests, my achievement is grouped into category (select appropriate number) (Na testovima sposobnosti, moje postignuće spada u kategoriju (zaokružite jedan od ponuđenih odgovora)):

- 0-2\% with lowest scores among psychology students (sa najnižim skorom među studentima psihologije)

$-\quad 3-16 \%$

$-17-30 \%$

- $31-70 \%$

$-71-84 \%$

$-\quad 85-97 \%$

- 98-100\% better than other psychology students (boljih od drugih studenata psihologije). 
Appendix 2 Questionnaire for assessment of consistency and visibility of basic personality traits

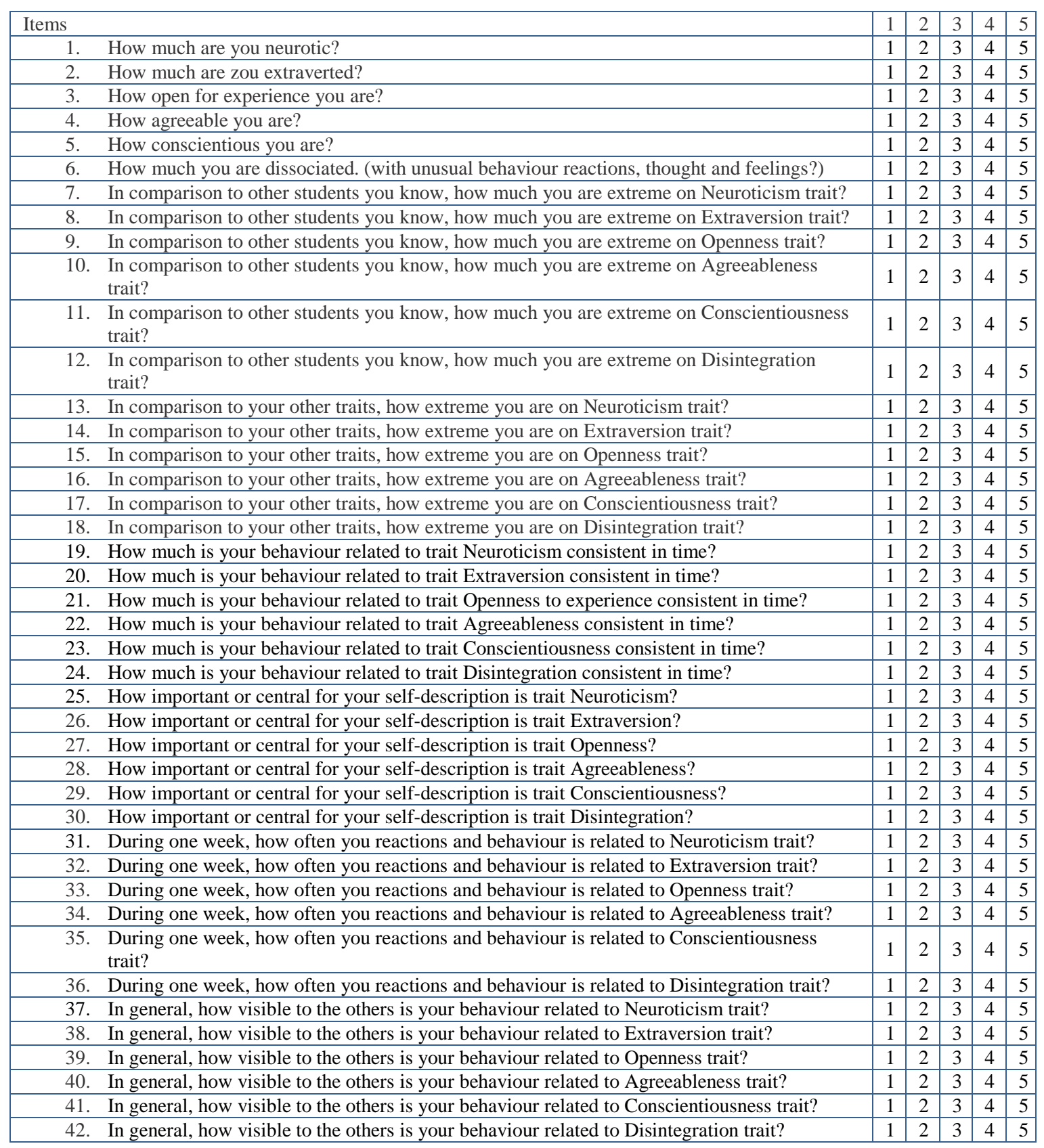


Appendix 3 Metrical characteristics of self-report measures - facets and main domains

Neuroticism

\begin{tabular}{|c|c|c|c|}
\hline & KMO & $\alpha$ & h2 \\
\hline Anxiety & 0.831 & .713 & .675 \\
\hline Hostility & .729 & .631 & .617 \\
\hline Depression & .899 & .763 & .729 \\
\hline Self-consciousness & .673 & .542 & .699 \\
\hline Impulsiveness & .539 & .519 & .588 \\
\hline Vulnerability & .927 & .708 & .788 \\
\hline Neuroticism & .952 & .882 & .331 \\
\hline
\end{tabular}

Extraversion

\begin{tabular}{|c|c|c|c|}
\hline & KMO & $\alpha$ & h2 \\
\hline Warmth & .839 & .603 & .759 \\
\hline Gregariousness & .838 & .667 & .504 \\
\hline Assertiveness & .583 & .524 & .524 \\
\hline Activity & .819 & .566 & .737 \\
\hline Excitement seeking & .736 & .558 & .786 \\
\hline Positive emotions & .769 & .655 & .535 \\
\hline Extraversion & .941 & .847 & .316 \\
\hline
\end{tabular}

Openness

\begin{tabular}{|c|c|c|c|}
\hline & KMO & $\alpha$ & h2 \\
\hline Fantasy & .948 & .787 & .633 \\
\hline Aesthetics & .789 & .681 & .503 \\
\hline Feelings & .824 & .648 & .596 \\
\hline Actions & .618 & .477 & .498 \\
\hline Ideas & .907 & .731 & .484 \\
\hline Values & .454 & .465 & .441 \\
\hline Openness & .956 & .851 & .326 \\
\hline
\end{tabular}

Agreeableness

\begin{tabular}{|c|c|c|c|}
\hline & KMO & $\alpha$ & h2 \\
\hline Trust & .928 & .778 & .782 \\
\hline Straightforwardness & .786 & .479 & .699 \\
\hline Altruism & .689 & .723 & .685 \\
\hline Compliance & .646 & .546 & .613 \\
\hline Modesty & .776 & .609 & .585 \\
\hline Tender-mindedness & .703 & .538 & .731 \\
\hline Agreeableness & .940 & .854 & .259 \\
\hline
\end{tabular}

Conscientiousness

\begin{tabular}{|c|c|c|c|}
\hline & KMO & $\alpha$ & $\mathrm{h} 2$ \\
\hline Competence & .778 & .600 & .661 \\
\hline Order & .752 & .451 & .468 \\
\hline Dutifulness & .801 & .626 & .763 \\
\hline Achievement striving & .777 & .682 & .581 \\
\hline Self-discipline & .867 & .744 & .687 \\
\hline Deliberation & .882 & .679 & .750 \\
\hline Conscientiousness & .954 & .883 & .322 \\
\hline
\end{tabular}

Disintegration

\begin{tabular}{|c|c|c|c|}
\hline & KMO & $\alpha$ & h2 \\
\hline $\begin{array}{c}\text { General Executive } \\
\text { dysfunction }\end{array}$ & .809 & .705 & .718 \\
\hline Perceptive Distortion & .969 & .886 & .829 \\
\hline Paranoia & .904 & .809 & .711 \\
\hline Depression & .971 & .889 & .867 \\
\hline Flattened Affect & .758 & .701 & .491 \\
\hline $\begin{array}{c}\text { Somatoform } \\
\text { Dysregulation }\end{array}$ & .918 & .813 & .752 \\
\hline Enhanced Awareness & .945 & .845 & .824 \\
\hline Magical Thinking & .950 & .856 & .771 \\
\hline Mania & .893 & .788 & .690 \\
\hline Social Anhedonia & .948 & .856 & .780 \\
\hline Disintegration & .978 & .918 & .260 \\
\hline
\end{tabular}


Appendix 4 Metrical characteristics of female observer ratings measures - facets and main domains

Neuroticism

\begin{tabular}{|c|c|c|c|}
\hline & KMO & $\alpha$ & h2 \\
\hline Anxiety F & .800 & .676 & .675 \\
\hline Hostility F & .818 & .706 & .676 \\
\hline Depression F & .885 & .756 & .789 \\
\hline Self-consciousness F & .545 & .511 & .527 \\
\hline Impulsiveness F & .560 & .505 & .507 \\
\hline Vulnerability F & .960 & .795 & .829 \\
\hline Neuroticism F & .965 & .904 & .380 \\
\hline
\end{tabular}

Extraversion

\begin{tabular}{|c|c|c|c|}
\hline & KMO & $\alpha$ & $\mathrm{h} 2$ \\
\hline Warmth F & .852 & .592 & .834 \\
\hline Gregariousness F & .821 & .650 & .531 \\
\hline Assertiveness F & .373 & .427 & .392 \\
\hline Activity F & .752 & .561 & .792 \\
\hline Excitement seeking F & .531 & .485 & .632 \\
\hline Positive emotions F & .672 & .601 & .516 \\
\hline Extraversion F & .915 & .840 & .296 \\
\hline
\end{tabular}

Openness

\begin{tabular}{|c|c|c|c|}
\hline & KMO & $\alpha$ & h2 \\
\hline Fantasy F & .773 & .666 & .670 \\
\hline Aesthetics F & .702 & .633 & .521 \\
\hline Feelings F & .719 & .570 & .479 \\
\hline Actions F & .690 & .552 & .633 \\
\hline Ideas F & .691 & .655 & .537 \\
\hline Values F & .542 & -.018 & .642 \\
\hline Openness F & .900 & .737 & .259 \\
\hline
\end{tabular}

Agreeableness

\begin{tabular}{|c|c|c|c|}
\hline & KMO & $\alpha$ & h2 \\
\hline Trust F & .932 & .795 & .756 \\
\hline Straightforwardness F & .878 & .540 & .796 \\
\hline Altruism F & .845 & .684 & .577 \\
\hline Compliance F & .650 & .596 & .623 \\
\hline Modesty F & .755 & .618 & .620 \\
\hline Tender-mindedness F & .742 & .572 & .752 \\
\hline Agreeableness F & .944 & .842 & .301 \\
\hline
\end{tabular}

Conscientiousness

\begin{tabular}{|c|c|c|c|}
\hline & KMO & $\alpha$ & h2 \\
\hline Competence F & .760 & .651 & .558 \\
\hline Order F & .768 & .435 & .566 \\
\hline Dutifulness F & .806 & .668 & .787 \\
\hline Achievement striving F & .811 & .672 & .553 \\
\hline Self-discipline F & .822 & .692 & .659 \\
\hline Deliberation F & .835 & .699 & .766 \\
\hline Conscientiousness F & .964 & .906 & .375 \\
\hline
\end{tabular}

Disintegration

\begin{tabular}{|c|c|c|c|}
\hline $\begin{array}{c}\text { General } \\
\text { Executive } \\
\text { dysfunction F }\end{array}$ & .826 & .740 & .715 \\
\hline $\begin{array}{c}\text { Perceptive } \\
\text { Distortion F }\end{array}$ & .955 & .876 & .814 \\
\hline Paranoia F & .891 & .796 & .686 \\
\hline Depression F & .943 & .859 & .806 \\
\hline $\begin{array}{c}\text { Flattened Affect } \\
\text { F }\end{array}$ & .862 & .784 & .625 \\
\hline $\begin{array}{c}\text { Somatoform } \\
\text { Dysregulation F }\end{array}$ & .898 & .795 & .654 \\
\hline $\begin{array}{c}\text { Enhanced } \\
\text { Awareness F }\end{array}$ & .953 & .854 & .802 \\
\hline $\begin{array}{c}\text { Magical Thinking } \\
\text { F }\end{array}$ & .923 & .830 & .723 \\
\hline Mania F & .948 & .849 & .750 \\
\hline $\begin{array}{c}\text { Social Anhedonia } \\
\text { F }\end{array}$ & .924 & .817 & .819 \\
\hline Disintegration F & .978 & .918 &. .260 \\
\hline
\end{tabular}


Appendix 5 Metrical characteristics of male observer ratings measures - facets and main domains

Neuroticism

\begin{tabular}{|c|c|c|c|}
\hline & KMO & $\alpha$ & h2 \\
\hline Anxiety M & .732 & .618 & .657 \\
\hline Hostility M & .773 & .624 & .636 \\
\hline Depression M & .823 & .706 & .698 \\
\hline Self-consciousness M & .499 & .402 & .578 \\
\hline Impulsiveness M & .754 & .561 & .674 \\
\hline Vulnerability M & .960 & .755 & .821 \\
\hline Neuroticism M & .961 & .882 & .342 \\
\hline
\end{tabular}

Agreeableness

\begin{tabular}{|c|c|c|c|}
\hline & KMO & $\alpha$ & h2 \\
\hline Trust M & .869 & .703 & .696 \\
\hline Straightforwardness M & .858 & .479 & .756 \\
\hline Altruism M & .844 & .702 & .597 \\
\hline Compliance M & .589 & .555 & .579 \\
\hline Modesty M & .785 & .617 & .582 \\
\hline Tender-mindedness M & .691 & .486 & .694 \\
\hline Agreeableness M & .938 & .847 & .290 \\
\hline
\end{tabular}

Extraversion

\begin{tabular}{|c|c|c|c|}
\hline & KMO & $\alpha$ & h2 \\
\hline Warmth M & .868 & .532 & .828 \\
\hline Gregariousness M & .699 & .578 & .439 \\
\hline Assertiveness M & .545 & .485 & .470 \\
\hline Activity M & .788 & .554 & .762 \\
\hline Excitement seeking M & .589 & .521 & .657 \\
\hline Positive emotions M & .604 & .560 & .538 \\
\hline Extraversion M & .902 & .823 & .285 \\
\hline
\end{tabular}

Openness

\begin{tabular}{|c|c|c|c|}
\hline & KMO & $\alpha$ & h2 \\
\hline Fantasy M & .739 & .619 & .621 \\
\hline Aesthetics M & .668 & .608 & .488 \\
\hline Feelings M & .735 & .588 & .540 \\
\hline Actions M & .785 & .615 & .710 \\
\hline Ideas M & .747 & .642 & .559 \\
\hline Values M & .291 & .271 & .359 \\
\hline Openness M & .903 & .780 & .235 \\
\hline
\end{tabular}

Conscientiousness

\begin{tabular}{|c|c|c|c|}
\hline & KMO & $\alpha$ & h2 \\
\hline Competence M & .785 & .609 & .551 \\
\hline Order M & .890 & .455 & .617 \\
\hline Dutifulness M & .880 & .695 & .880 \\
\hline Achievement striving M & .732 & .616 & .549 \\
\hline Self-discipline M & .843 & .717 & .652 \\
\hline Deliberation M & .814 & .688 & .672 \\
\hline Conscientiousness M & .971 & .908 & .394 \\
\hline
\end{tabular}

Disintegration

\begin{tabular}{|c|c|c|c|}
\hline & KMO & $\alpha$ & $\mathrm{h} 2$ \\
\hline $\begin{array}{c}\text { General Executive } \\
\text { dysfunction M }\end{array}$ & .859 & .757 & .737 \\
\hline Perceptive Distortion M & .955 & .859 & .829 \\
\hline Paranoia M & .918 & .825 & .705 \\
\hline Depression M & .925 & .836 & .811 \\
\hline Flattened Affect M & .892 & .794 & .720 \\
\hline $\begin{array}{c}\text { Somatoform } \\
\text { Dysregulation M }\end{array}$ & .896 & .805 & .691 \\
\hline Enhanced Awareness M & .964 & .874 & .875 \\
\hline Magical Thinking M & .945 & .846 & .725 \\
\hline Mania M & .916 & .837 & .683 \\
\hline Social Anhedonia M & .938 & .839 & .825 \\
\hline Disintegration M & .971 & .910 & .278 \\
\hline
\end{tabular}


Appendix 6 List of parameters and their abbreviations in LIWC (Pennebaker et al, 2007) ${ }^{9}$

\begin{tabular}{|c|c|c|}
\hline Category & Abbreviation & Examples \\
\hline \multicolumn{3}{|c|}{ Linguistic processes } \\
\hline Word count & $\mathrm{wc}$ & \\
\hline Words/sentence & Wps & \\
\hline Dictionary words & Dic & \\
\hline Words $>6$ letters & Sixltr & \\
\hline Total function words & Funct & \\
\hline Total pronouns & pronoun & $\mathrm{I}$, them, itself \\
\hline Personal pronouns & ppron & I, them, her \\
\hline $1^{\text {st }}$ person singular & I & I, me, mine \\
\hline $1^{\text {st }}$ person plural & we & We, us, our \\
\hline $2^{\text {nd }}$ person & You & You, your, thou \\
\hline $3^{\text {rd }}$ person singular & Shehe & She, her, him, he \\
\hline $3^{\text {rd }}$ person plural & They & They, their \\
\hline Impersonal pronouns & Ipron & It, it's, those \\
\hline Articles & article & A, an, the \\
\hline (Common verbs) & verb & Walk, went, see \\
\hline Auxiliary verbs & auxverb & Am, will, have \\
\hline Past tense & past & Went, ran, had \\
\hline Present tense & present & Is, does, hear \\
\hline Future tense & Future & Will, gonna \\
\hline Adverbs & Adverb & Very, really, quickly \\
\hline Propositions & Prep & To, with, above \\
\hline Conjunctions & Conj & And, but, whereas \\
\hline Negations & Negate & No, not, never \\
\hline Quantifiers & Quant & Few, many, much \\
\hline Numbers & Number & Second, thousand \\
\hline Swear words & swear & Damn, piss, fuck \\
\hline \multicolumn{3}{|c|}{ Psychological processes } \\
\hline Social processes & social & Mate, talk, they, child \\
\hline Family & family & Daughter, husband, aunt \\
\hline Friends & friend & buddy, friend, neighbor \\
\hline Humans & human & adult, baby, boy \\
\hline Affective processes & affect & happy, cried, abandon \\
\hline Positive emotion & posemo & love, nice, sweet \\
\hline Negative emotion & negemo & hurt, ugly, nasty \\
\hline Anxiety & anx & worried, fearful, nervous \\
\hline Anger & anger & hate, kill, annoyed \\
\hline Sadness & sad & crying, grief, sad \\
\hline Cognitive processes & cogmech & cause, know, ought \\
\hline Insight & insight & think, know, consider \\
\hline Causation & cause & because, effect, hence \\
\hline Discrepancy & discrep & should, would, could \\
\hline Tentative & tentat & maybe, perhaps, guess \\
\hline Certainty & certain & always, never \\
\hline Inhibition & inhib & block, constrain, stop \\
\hline Inclusive & incl & and, with, include \\
\hline Exclusive & excl & but, without, exclude \\
\hline Perceptual processes & percept & observed, heard, feeling \\
\hline See & see & view, saw, seen \\
\hline Hear & hear & listen, hearing \\
\hline Feel & feel & feels, touch \\
\hline
\end{tabular}

9 Table continues on next page 


\begin{tabular}{|c|c|c|}
\hline Category & Abbreviation & Examples \\
\hline Biological processes & bio & eat, blood, pain \\
\hline Body & body & cheek, hands, spit \\
\hline Health & health & clinic, flu, pill \\
\hline Sexual & sexual & horny, love, incest \\
\hline Ingestion & ingest & dish, eat, pizza \\
\hline Relativity & relativ & area, band, exit, stop \\
\hline Motion & motion & arrive, car, go \\
\hline Space & space & down, in, thin \\
\hline Time & time & end, until, season \\
\hline \multicolumn{3}{|c|}{ Personal concerns } \\
\hline Work & work & job, majors, xerox \\
\hline Achievement & achieve & earn, hero, win \\
\hline Leisure & leisure & cook, chat, movie, kitchen \\
\hline Home & home & family \\
\hline Money & money & audit, cash, owe \\
\hline Religion & relig & altar, church, mosque \\
\hline Death & death & bury, coffin, kill \\
\hline \multicolumn{3}{|c|}{ Spoken categories } \\
\hline Assent & assent & agree, $\mathrm{OK}$, yes \\
\hline Non fluencies & nonfl & er, hm, umm \\
\hline Fillers & filler & blah, Imean, youknow \\
\hline
\end{tabular}


Appendix 7 Basic descriptive statistics of IAT data - different error-correction treatments

MBlock + 600 ms

\begin{tabular}{|c|c|c|c|c|c|}
\hline & $\mathrm{N}$ & $\mathrm{Min}$ & $\mathrm{Max}$ & $\mathrm{M}$ & $\mathrm{SD}$ \\
\hline IATN & 224 & -.35 & 1.33 & .343 & .29 \\
\hline IATE & 224 & -1.09 & 1.06 & .192 & .30 \\
\hline IATO & 224 & -.46 & 1.54 & .387 & .34 \\
\hline IATA & 224 & -.50 & 1.21 & .527 & .30 \\
\hline IATC & 224 & -.80 & 1.37 & .504 & .33 \\
\hline IATD & 224 & -.15 & 1.84 & .678 & .40 \\
\hline IATI & 224 & -.29 & 1.44 & .466 & .30 \\
\hline
\end{tabular}

MBlock+600 ms (excluded below 400ms)

\begin{tabular}{|c|c|c|c|c|c|}
\hline & $\mathrm{N}$ & Min & $\mathrm{Max}$ & $\mathrm{M}$ & $\mathrm{SD}$ \\
\hline IATN & 224 & -.35 & 1.33 & .343 & .29 \\
\hline IATE & 224 & -1.09 & 1.06 & .192 & .30 \\
\hline IATO & 224 & -.46 & 1.54 & .387 & .34 \\
\hline IATA & 224 & -.50 & 1.21 & .527 & .30 \\
\hline IATC & 224 & -.80 & 1.37 & .504 & .33 \\
\hline IATD & 224 & -.15 & 1.84 & .678 & .40 \\
\hline IATI & 224 & -.29 & 1.44 & .466 & .30 \\
\hline
\end{tabular}

MBlock + 2SDBlock

\begin{tabular}{|c|c|c|c|c|c|}
\hline & $\mathrm{N}$ & $\mathrm{Min}$ & $\mathrm{Max}$ & $\mathrm{M}$ & $\mathrm{SD}$ \\
\hline IATN & 224 & -.44 & 1.43 & .408 & .36 \\
\hline IATE & 224 & -1.20 & 1.25 & .222 & .35 \\
\hline IATO & 224 & -.57 & 1.81 & .443 & .42 \\
\hline IATA & 224 & -.56 & 1.34 & .594 & .34 \\
\hline IATC & 224 & -.83 & 1.59 & .587 & .38 \\
\hline IATD & 224 & -.18 & 2.40 & .794 & .46 \\
\hline IATI & 224 & -.26 & 1.93 & .545 & .37 \\
\hline
\end{tabular}

MBlock + 2SDBlock (excluded below 400ms)

\begin{tabular}{|c|c|c|c|c|c|}
\hline & $\mathrm{N}$ & $\mathrm{Min}$ & $\mathrm{Max}$ & $\mathrm{M}$ & $\mathrm{SD}$ \\
\hline IATN & 224 & -.45 & 1.46 & .412 & .36 \\
\hline IATE & 224 & -1.18 & 1.20 & .218 & .36 \\
\hline IATO & 224 & -.57 & 1.99 & .461 & .42 \\
\hline IATA & 224 & -.56 & 1.57 & .605 & .35 \\
\hline IATC & 224 & -1.00 & 1.55 & .589 & .39 \\
\hline IATD & 224 & -.17 & 2.41 & .806 & .47 \\
\hline IATI & 224 & -.30 & 1.81 & .545 & .37 \\
\hline
\end{tabular}

MBlock + 1SDBlock

\begin{tabular}{|c|c|c|c|c|c|}
\hline & $\mathrm{N}$ & Min & Max & $\mathrm{M}$ & $\mathrm{SD}$ \\
\hline IATN & 224 & -.36 & 1.36 & .349 & .31 \\
\hline IATE & 224 & -1.13 & 1.08 & .199 & .31 \\
\hline IATO & 224 & -.45 & 1.63 & .404 & .35 \\
\hline IATA & 224 & -.53 & 1.21 & .536 & .31 \\
\hline IATC & 224 & -.77 & 1.42 & .505 & .33 \\
\hline IATD & 224 & -.18 & 2.02 & .704 & .42 \\
\hline IATI & 224 & -.32 & 1.50 & .480 & .32 \\
\hline
\end{tabular}

MBlock + 1SDBlock (excluded below 400ms)

\begin{tabular}{|c|c|c|c|c|c|}
\hline & $\mathrm{N}$ & Min & Max & $\mathrm{M}$ & $\mathrm{SD}$ \\
\hline IATN & 224 & -.36 & 1.36 & .349 & .31 \\
\hline IATE & 224 & -1.13 & 1.08 & .199 & .31 \\
\hline IATO & 224 & -.45 & 1.63 & .404 & .35 \\
\hline IATA & 224 & -.53 & 1.21 & .536 & .31 \\
\hline IATC & 224 & -.77 & 1.42 & .505 & .33 \\
\hline IATD & 224 & -.18 & 2.02 & .704 & .42 \\
\hline IATI & 224 & -.32 & 1.50 & .480 & .32 \\
\hline
\end{tabular}


Appendix 8 Descriptive statistics for facets of six basic personality traits - self-reports

Descriptive statistics of Neuroticism facets - self-reports

\begin{tabular}{|c|c|c|c|c|c|c|c|c|c|}
\hline & $\mathrm{N}$ & Min & Max & $\mathrm{M}$ & $\mathrm{SD}$ & Skew & $\begin{array}{c}\text { Skew } \\
\text { SE }\end{array}$ & Kurt & $\begin{array}{c}\text { Kurt } \\
\text { SE }\end{array}$ \\
\hline Anxiety & 224 & 0.00 & 32.00 & 16.23 & 5.88 & .400 & .163 & .489 & .324 \\
\hline Hostility & 224 & 0.00 & 29.00 & 14.62 & 5.40 & -.031 & .163 & .134 & .324 \\
\hline Depression & 224 & 1.00 & 32.00 & 14.13 & 6.07 & .425 & .163 & -.019 & .324 \\
\hline Self-consciousness & 224 & 3.00 & 32.00 & 16.56 & 4.69 & -.224 & .163 & .294 & .324 \\
\hline Impulsiveness & 224 & 3.00 & 38.00 & 18.55 & 4.83 & .171 & .163 & 1.026 & .324 \\
\hline Vulnerability & 224 & 0.00 & 25.00 & 13.69 & 5.85 & -.221 & .163 & -.678 & .324 \\
\hline Neuroticism & 224 & 16.00 & 154.00 & 94.06 & 23.63 & -.304 & .163 & .755 & .324 \\
\hline
\end{tabular}

Descriptive statistics of Extraversion facets - self-reports

\begin{tabular}{|c|c|c|c|c|c|c|c|c|c|}
\hline & $\mathrm{N}$ & Min & Max & $\mathrm{M}$ & SD & Skew & $\begin{array}{c}\text { Skew } \\
\text { SE }\end{array}$ & Kurt & $\begin{array}{c}\text { Kurt } \\
\text { SE }\end{array}$ \\
\hline Warmth & 224 & 8.00 & 28.00 & 19.95 & 4.25 & -.376 & .163 & -.471 & .324 \\
\hline Gregariousness & 224 & 2.00 & 32.87 & 17.49 & 5.94 & -.229 & .163 & -.164 & .324 \\
\hline Assertiveness & 224 & 2.00 & 29.00 & 16.84 & 4.56 & -.297 & .163 & .199 & .324 \\
\hline Activity & 224 & 5.00 & 30.00 & 17.88 & 4.64 & -.119 & .163 & -.132 & .324 \\
\hline Excitement seeking & 224 & 0.00 & 30.00 & 18.06 & 5.29 & -.390 & .163 & .001 & .324 \\
\hline Positive emotions & 224 & 1.00 & 32.00 & 20.45 & 5.58 & -.595 & .163 & .937 & .324 \\
\hline Extraversion & 224 & 41.00 & 162.00 & 110.58 & 20.44 & -.450 & .163 & .425 & .324 \\
\hline
\end{tabular}

Descriptive statistics of Openness facets - self-reports

\begin{tabular}{|c|c|c|c|c|c|c|c|c|c|}
\hline & $\mathrm{N}$ & Min & Max & M & SD & Skew & $\begin{array}{c}\text { Skew } \\
\text { SE }\end{array}$ & Kurt & $\begin{array}{c}\text { Kurt } \\
\text { SE }\end{array}$ \\
\hline Fantasy & 224 & 4.84 & 32.00 & 20.35 & 6.41 & -.108 & .163 & -.818 & .324 \\
\hline Aesthetics & 224 & 4.00 & 32.00 & 22.07 & 5.75 & -.194 & .163 & -.412 & .324 \\
\hline Feelings & 224 & 10.00 & 32.00 & 23.43 & 4.92 & -.070 & .163 & -.964 & .324 \\
\hline Actions & 224 & 3.00 & 29.00 & 16.47 & 4.63 & -.140 & .163 & -.002 & .324 \\
\hline Ideas & 224 & 5.00 & 32.00 & 21.51 & 5.95 & -.079 & .163 & -.652 & .324 \\
\hline Values & 224 & 9.00 & 32.00 & 20.44 & 4.15 & .123 & .163 & -.159 & .324 \\
\hline Openness & 224 & 69.00 & 174.00 & 124.39 & 20.70 & .143 & .163 & -.787 & .324 \\
\hline
\end{tabular}


Descriptive statistics of Agreeableness facets - self-reports

\begin{tabular}{|c|c|c|c|c|c|c|c|c|c|}
\hline & $\mathrm{N}$ & Min & Max & $\mathrm{M}$ & $\mathrm{SD}$ & Skew & $\begin{array}{c}\text { Skew } \\
\text { SE }\end{array}$ & $\begin{array}{c}\text { Kurt } \\
\text { Kurt } \\
\text { SE }\end{array}$ \\
\hline Trust & 224 & 4.00 & 32.00 & 18.47 & 5.66 & -.108 & .163 & -.120 & .324 \\
\hline Straightforwardness & 224 & 6.00 & 28.00 & 18.45 & 4.89 & -.165 & .163 & -.639 & .324 \\
\hline Altruism & 224 & 6.00 & 32.00 & 22.01 & 4.78 & -.159 & .163 & -.008 & .324 \\
\hline Compliance & 224 & .00 & 30.00 & 16.41 & 5.10 & -.238 & .163 & .558 & .324 \\
\hline Modesty & 224 & .00 & 29.00 & 15.93 & 4.94 & -.206 & .163 & .252 & .324 \\
\hline Tender-mindedness & 224 & 6.00 & 30.00 & 21.27 & 4.04 & -.847 & .163 & 1.353 & .324 \\
\hline Agreeableness & 224 & 35.00 & 172.00 & 112.45 & 19.49 & -.455 & .163 & 1.412 & .324 \\
\hline
\end{tabular}

Descriptive statistics of Conscientiousness facets - self-reports

\begin{tabular}{|c|c|c|c|c|c|c|c|c|c|}
\hline & $\mathrm{N}$ & $\operatorname{Min}$ & $\mathrm{Max}$ & $\mathrm{M}$ & $\mathrm{SD}$ & Skew & $\begin{array}{c}\text { Skew } \\
\text { SE }\end{array}$ & Kurt & $\begin{array}{c}\text { Kurt } \\
\text { SE }\end{array}$ \\
\hline Competence & 224 & 9.00 & 31.00 & 21.37 & 4.07 & -.296 & .163 & .189 & .324 \\
\hline Order & 224 & 7.00 & 32.00 & 18.89 & 4.60 & .113 & .163 & -.127 & .324 \\
\hline Dutifulness & 224 & 9.00 & 36.61 & 23.97 & 4.03 & -.433 & .163 & .638 & .324 \\
\hline $\begin{array}{c}\text { Achievement } \\
\text { striving }\end{array}$ & 224 & 7.00 & 32.00 & 20.83 & 4.99 & -.176 & .163 & -.663 & .324 \\
\hline Self-discipline & 224 & 4.00 & 32.00 & 19.80 & 5.41 & -.400 & .163 & .164 & .324 \\
\hline Deliberation & 224 & .00 & 31.00 & 18.45 & 5.02 & -.448 & .163 & .503 & .324 \\
\hline Conscientiousness & 224 & 60.00 & 174.00 & 123.39 & 20.42 & -.183 & .163 & .423 & .324 \\
\hline
\end{tabular}

Descriptive statistics of Disintegration facets - self-reports

\begin{tabular}{|c|c|c|c|c|c|c|c|c|c|}
\hline & $\mathrm{N}$ & Min & Max & $\mathrm{M}$ & $\mathrm{SD}$ & Skew & $\begin{array}{c}\text { Skew } \\
\text { SE }\end{array}$ & $\begin{array}{c}\text { Kurt } \\
\text { Kurt } \\
\text { SE }\end{array}$ \\
\hline GEI & 224 & 1.00 & 4.67 & 2.12 & .60 & .645 & .163 & .866 & .324 \\
\hline PD & 224 & .93 & 3.92 & 1.63 & .66 & 1.361 & .163 & 1.470 & .324 \\
\hline P & 224 & 1.00 & 3.33 & 1.67 & .477 & .842 & .163 & .463 & .324 \\
\hline D & 224 & 1.00 & 4.82 & 1.76 & .70 & 1.448 & .163 & 2.434 & .324 \\
\hline FA & 224 & 1.00 & 3.78 & 2.00 & .59 & .452 & .163 & -.082 & .324 \\
\hline SOD & 224 & 1.00 & 3.77 & 1.73 & .57 & .791 & .163 & .103 & .324 \\
\hline EA & 224 & 1.00 & 5.00 & 3.01 & .89 & -.093 & .163 & -.568 & .324 \\
\hline MT & 224 & 1.00 & 4.62 & 2.10 & .80 & .608 & .163 & -.180 & .324 \\
\hline M & 224 & 1.11 & 4.67 & 2.73 & .74 & -.076 & .163 & -.354 & .324 \\
\hline SA & 224 & 1.00 & 4.80 & 2.04 & .70 & .817 & .163 & .542 & .324 \\
\hline DELTATOT & 224 & 1.18 & 3.35 & 2.08 & .45 & .269 & .163 & -.425 & .324 \\
\hline
\end{tabular}

Note: GEI-general executive dysfunction; PD-perceptive distortions; EA-enhanced awareness; Ddepression; P-paranoia; M-mania; SA-social anhedonia; FA-flattened affect; SD-somatoform disregulation; MT-magical thinking; DELTATOT-Delta total score. 
Appendix 9 Descriptive statistics for facets of six basic personality traits - female observer ratings

Descriptive statistics of Neuroticism facets - female observer ratings

\begin{tabular}{|c|c|c|c|c|c|c|c|c|c|}
\hline & $\mathrm{N}$ & $\mathrm{Min}$ & $\mathrm{Max}$ & $\mathrm{M}$ & $\mathrm{SD}$ & Skew & $\begin{array}{c}\text { Skew } \\
\text { SE }\end{array}$ & Kurt & $\begin{array}{c}\text { Kurt } \\
\text { SE }\end{array}$ \\
\hline Anxiety F & 224 & .00 & 32.00 & 14.24 & 5.30 & .265 & .163 & .932 & .324 \\
\hline Hostility F & 224 & .00 & 33.73 & 14.44 & 6.04 & .125 & .163 & -.148 & .324 \\
\hline Depression F & 224 & .00 & 28.00 & 11.92 & 5.55 & .272 & .163 & -.188 & .324 \\
\hline $\begin{array}{c}\text { Self-consciousness } \\
\text { F }\end{array}$ & 224 & 2.00 & 32.00 & 14.81 & 4.35 & .222 & .163 & 1.332 & .324 \\
\hline Impulsiveness F & 224 & 3.00 & 27.28 & 16.53 & 4.62 & -.125 & .163 & -.049 & .324 \\
\hline Vulnerability F & 224 & .00 & 27.00 & 11.72 & 6.16 & .301 & .163 & -.733 & .324 \\
\hline Neuroticism F & 224 & 16.00 & 159.00 & 84.07 & 24.39 & -.056 & .163 & -.049 & .324 \\
\hline
\end{tabular}

Descriptive statistics of Extraversion facets - female observer ratings

\begin{tabular}{|c|c|c|c|c|c|c|c|c|c|}
\hline & $\mathrm{N}$ & Min & Max & $\mathrm{M}$ & $\mathrm{SD}$ & Skew & $\begin{array}{c}\text { Skew } \\
\text { SE }\end{array}$ & $\begin{array}{c}\text { Kurt } \\
\text { SE }\end{array}$ \\
\hline Warmth F & 224 & 7.00 & 32.00 & 20.66 & 4.23 & -.455 & .163 & .635 & .324 \\
\hline Gregariousness F & 224 & 3.00 & 31.00 & 18.72 & 5.38 & -.454 & .163 & .027 & .324 \\
\hline Assertiveness F & 224 & 4.00 & 32.00 & 16.62 & 4.34 & .173 & .163 & .571 & .324 \\
\hline Activity F & 224 & 4.00 & 31.00 & 18.3 & 4.69 & -.186 & .163 & .217 & .324 \\
\hline $\begin{array}{c}\text { Excitement seeking } \\
\text { F }\end{array}$ & 224 & 5.00 & 32.00 & 16.91 & 4.88 & -.031 & .163 & -.035 & .324 \\
\hline Positive emotions F & 224 & .00 & 31.00 & 19.35 & 4.93 & -.541 & .163 & 1.041 & .324 \\
\hline Extraversion F & 224 & 47.00 & 155.00 & 110.79 & 19.49 & -.450 & .163 & .285 & .324 \\
\hline
\end{tabular}

Descriptive statistics of Openness facets - female observer ratings

\begin{tabular}{|c|c|c|c|c|c|c|c|c|c|}
\hline & $\mathrm{N}$ & Min & Max & $\mathrm{M}$ & SD & Skew & $\begin{array}{c}\text { Skew } \\
\text { SE }\end{array}$ & Kurt & $\begin{array}{c}\text { Kurt } \\
\text { SE }\end{array}$ \\
\hline Fantasy F & 224 & 4.00 & 41.03 & 17.11 & 5.30 & .401 & .163 & 1.947 & .324 \\
\hline Aesthetics F & 224 & 4.00 & 32.00 & 21.32 & 4.87 & -.244 & .163 & .184 & .324 \\
\hline Feelings F & 224 & 10.00 & 31.00 & 22.04 & 4.09 & -.148 & .163 & .092 & .324 \\
\hline Actions F & 224 & 4.00 & 32.00 & 15.61 & 4.32 & .152 & .163 & .745 & .324 \\
\hline Ideas F & 224 & 9.00 & 32.00 & 21.72 & 4.69 & .107 & .163 & -.392 & .324 \\
\hline Values F & 224 & 11.00 & 27.00 & 18.55 & 3.19 & .163 & .163 & -.218 & .324 \\
\hline Openness F & 224 & 68.00 & 163.00 & 116.10 & 14.36 & .123 & .163 & .440 & .324 \\
\hline
\end{tabular}


Descriptive statistics of Agreeableness facets - female observer ratings

\begin{tabular}{|c|c|c|c|c|c|c|c|c|c|}
\hline & $\mathrm{N}$ & Min & Max & M & SD & Skew & $\begin{array}{c}\text { Skew } \\
\text { SE }\end{array}$ & Kurt & $\begin{array}{c}\text { Kurt } \\
\text { SE }\end{array}$ \\
\hline Trust F & 224 & 3.00 & 32.00 & 20.39 & 5.71 & -.460 & .163 & .125 & .324 \\
\hline Straightforwardness F & 224 & 5.00 & 31.00 & 20.83 & 5.12 & -.458 & .163 & -.278 & .324 \\
\hline Altruism F & 224 & 7.00 & 34.19 & 23.08 & 5.02 & -.200 & .163 & -.431 & .324 \\
\hline Compliance F & 224 & 4.00 & 31.00 & 16.88 & 5.23 & -.174 & .163 & -.271 & .324 \\
\hline Modesty F & 224 & 4.00 & 28.00 & 15.35 & 4.94 & .054 & .163 & -.431 & .324 \\
\hline Tender-mindedness F & 224 & 7.00 & 32.29 & 21.47 & 4.10 & -.443 & .163 & .499 & .324 \\
\hline Agreeableness F & 224 & 52.00 & 160.43 & 117.97 & 19.92 & -.425 & .163 & .447 & .324 \\
\hline
\end{tabular}

Descriptive statistics of Consciousness facets - female observer ratings

\begin{tabular}{|c|c|c|c|c|c|c|c|c|c|}
\hline & $\mathrm{N}$ & Min & Max & $\mathrm{M}$ & $\mathrm{SD}$ & Skew & $\begin{array}{c}\text { Skew } \\
\text { SE }\end{array}$ & $\begin{array}{c}\text { Kurt } \\
\text { Kurt } \\
\text { SE }\end{array}$ \\
\hline Competence F & 224 & 14.00 & 34.46 & 24.72 & 4.21 & -.183 & .163 & -.683 & .324 \\
\hline Order F & 224 & 5.00 & 32.00 & 18.14 & 4.85 & -.115 & .163 & -.180 & .324 \\
\hline Dutifulness F & 224 & 14.00 & 32.00 & 25.61 & 3.80 & -.307 & .163 & -.401 & .324 \\
\hline Achievement striving F & 224 & 9.00 & 32.00 & 22.56 & 4.74 & -.270 & .163 & -.520 & .324 \\
\hline Self-discipline F & 224 & 7.00 & 32.00 & 21.95 & 5.10 & -.239 & .163 & .042 & .324 \\
\hline Deliberation F & 224 & 6.00 & 32.00 & 21.18 & 4.94 & -.279 & .163 & .009 & .324 \\
\hline Conscientiousness F & 224 & 75.00 & 181.00 & 134.05 & 22.50 & -.013 & .163 & -.621 & .324 \\
\hline
\end{tabular}

Descriptive statistics of Disintegration facets - female observer ratings

\begin{tabular}{|c|c|c|c|c|c|c|c|c|c|}
\hline & $\mathrm{N}$ & Min & Max & $\mathrm{M}$ & SD & Skew & $\begin{array}{c}\text { Skew } \\
\text { SE }\end{array}$ & Kurt & $\begin{array}{c}\text { Kurt } \\
\text { SE }\end{array}$ \\
\hline GEI F & 224 & .69 & 3.89 & 1.68 & .54 & 1.011 & .163 & 1.138 & .324 \\
\hline PD F & 224 & .82 & 3.83 & 1.65 & .66 & .892 & .163 & -.137 & .324 \\
\hline P F & 224 & .87 & 4.09 & 1.72 & .58 & 1.076 & .163 & 1.477 & .324 \\
\hline D F & 224 & .42 & 4.80 & 1.63 & .62 & 1.490 & .163 & 3.319 & .324 \\
\hline FA F & 224 & 1.00 & 3.91 & 1.81 & .61 & .581 & .163 & -.193 & .324 \\
\hline SOD F & 224 & 1.00 & 4.40 & 2.70 & .73 & -.425 & .163 & -.099 & .324 \\
\hline EA F & 224 & 1.00 & 4.00 & 2.01 & .67 & .473 & .163 & -.249 & .324 \\
\hline MT F & 224 & .64 & 4.60 & 2.03 & .69 & .593 & .163 & .299 & .324 \\
\hline M F & 224 & -.16 & 4.00 & 1.90 & .63 & .388 & .163 & .435 & .324 \\
\hline SA F & 224 & .34 & 4.57 & 2.44 & .85 & .046 & .163 & -.453 & .324 \\
\hline DELTATOT F & 224 & .82 & 3.76 & 1.96 & .50 & .228 & .163 & .040 & .324 \\
\hline
\end{tabular}

Note: GEI-general executive dysfunction; PD-perceptive distortions; EA-enhanced awareness; Ddepression; P-paranoia; M-mania; SA-social anhedonia; FA-flattened affect; SD-somatoform disregulation; MT-magical thinking; DELTATOT-Delta total score 
Appendix 10 Descriptive statistics for facets of six basic personality traits - male observer ratings

Descriptive statistics of Neuroticism facets - male observer ratings

\begin{tabular}{|c|c|c|c|c|c|c|c|c|c|}
\hline & $\mathrm{N}$ & Min & Max & $\mathrm{M}$ & $\mathrm{SD}$ & Skew & $\begin{array}{c}\text { Skew } \\
\text { SE }\end{array}$ & Kurt & $\begin{array}{c}\text { Kurt } \\
\text { SE }\end{array}$ \\
\hline Anxiety M & 224 & .00 & 31.00 & 14.49 & 4.85 & .275 & .163 & .798 & .324 \\
\hline Hostility M & 224 & .00 & 30.00 & 14.34 & 5.16 & -.092 & .163 & -.093 & .324 \\
\hline Depression M & 224 & .00 & 31.00 & 11.69 & 4.81 & .196 & .163 & .576 & .324 \\
\hline Self-consciousness M & 224 & 6.00 & 28.00 & 15.13 & 4.01 & .454 & .163 & .227 & .324 \\
\hline Impulsiveness M & 224 & .00 & 30.00 & 15.88 & 4.69 & -.148 & .163 & .602 & .324 \\
\hline Vulnerability M & 224 & .00 & 27.00 & 11.88 & 5.61 & .267 & .163 & -.720 & .324 \\
\hline Neuroticism M & 224 & 13.00 & 176.00 & 83.65 & 22.29 & -.138 & .163 & .884 & .324 \\
\hline
\end{tabular}

Descriptive statistics of Extraversion facets - male observer ratings

\begin{tabular}{|c|c|c|c|c|c|c|c|c|c|}
\hline & $\mathrm{N}$ & Min & Max & $\mathrm{M}$ & $\mathrm{SD}$ & Skew & $\begin{array}{c}\text { Skew } \\
\text { SE }\end{array}$ & $\begin{array}{c}\text { Kurt } \\
\text { SE }\end{array}$ & $\begin{array}{c}\text { Kurt } \\
\text { SE }\end{array}$ \\
\hline Warmth M & 224 & 4.00 & 30.56 & 20.59 & 3.91 & -.537 & .163 & 1.377 & .324 \\
\hline Gregariousness M & 224 & 4.00 & 30.00 & 18.48 & 4.96 & -.510 & .163 & .060 & .324 \\
\hline Assertiveness M & 224 & 6.00 & 30.00 & 16.85 & 4.15 & .142 & .163 & .477 & .324 \\
\hline Activity M & 224 & 4.00 & 28.00 & 18.34 & 4.43 & -.276 & .163 & .144 & .324 \\
\hline Excitement seeking M & 224 & 4.00 & 30.00 & 16.64 & 4.64 & -.199 & .163 & .040 & .324 \\
\hline Positive emotions M & 224 & 8.00 & 31.00 & 19.28 & 4.36 & -.268 & .163 & -.172 & .324 \\
\hline Extraversion M & 224 & 46.00 & 161.00 & 110.11 & 17.26 & -.317 & .163 & .855 & .324 \\
\hline
\end{tabular}

Descriptive statistics of Openness facets - male observer ratings

\begin{tabular}{|c|c|c|c|c|c|c|c|c|c|}
\hline & $\mathrm{N}$ & Min & Max & $\mathrm{M}$ & $\mathrm{SD}$ & Skew & $\begin{array}{c}\text { Skew } \\
\text { SE }\end{array}$ & $\begin{array}{c}\text { Kurt } \\
\text { Kurt } \\
\text { SE }\end{array}$ \\
\hline Fantasy M & 224 & .00 & 30.00 & 17.21 & 4.54 & -.083 & .163 & .706 & .324 \\
\hline Aesthetics M & 224 & 4.00 & 32.00 & 20.45 & 4.69 & -.186 & .163 & 1.028 & .324 \\
\hline Feelings M & 224 & .00 & 31.02 & 20.56 & 4.17 & -.528 & .163 & 1.974 & .324 \\
\hline Actions M & 224 & 1.00 & 28.00 & 15.12 & 4.56 & .009 & .163 & .394 & .324 \\
\hline Ideas M & 224 & 5.00 & 33.16 & 20.97 & 4.67 & .080 & .163 & .483 & .324 \\
\hline Values M & 224 & 9.00 & 30.00 & 18.56 & 3.47 & .074 & .163 & .424 & .324 \\
\hline Openness M & 224 & 44.00 & 161.00 & 112.44 & 15.41 & -.265 & .163 & 1.995 & .324 \\
\hline
\end{tabular}


Descriptive statistics of Agreeableness facets - male observer ratings

\begin{tabular}{|c|c|c|c|c|c|c|c|c|c|}
\hline & $\mathrm{N}$ & Min & Max & $\mathrm{M}$ & $\mathrm{SD}$ & Skew & $\begin{array}{c}\text { Skew } \\
\text { SE }\end{array}$ & Kurt & $\begin{array}{c}\text { Kurt } \\
\text { SE }\end{array}$ \\
\hline Trust M & 224 & 3.00 & 32.00 & 20.02 & 4.83 & -.120 & .163 & .396 & .324 \\
\hline $\begin{array}{c}\text { Straightforwardness } \\
\text { M }\end{array}$ & 224 & 4.00 & 30.47 & 20.40 & 4.81 & -.351 & .163 & .003 & .324 \\
\hline Altruism M & 224 & 1.00 & 32.00 & 22.99 & 4.65 & -.395 & .163 & 1.254 & .324 \\
\hline Compliance M & 224 & 2.00 & 32.00 & 16.76 & 4.79 & .021 & .163 & .543 & .324 \\
\hline Modesty M & 224 & 4.00 & 28.00 & 15.86 & 4.78 & -.004 & .163 & -.254 & .324 \\
\hline Tender-mindedness M & 224 & .00 & 32.00 & 21.19 & 3.87 & -.587 & .163 & 3.494 & .324 \\
\hline Agreeableness M & 224 & 17.00 & 172.00 & 117.12 & 18.89 & -.585 & .163 & 2.972 & .324 \\
\hline
\end{tabular}

Descriptive statistics of Conscientiousness facets - male observer ratings

\begin{tabular}{|c|c|c|c|c|c|c|c|c|c|}
\hline & $\mathrm{N}$ & Min & Max & $\mathrm{M}$ & SD & Skew & $\begin{array}{c}\text { Skew } \\
\text { SE }\end{array}$ & Kurt & $\begin{array}{c}\text { Kurt } \\
\text { SE }\end{array}$ \\
\hline Competence M & 224 & 14.00 & 73.00 & 24.36 & 5.15 & 3.719 & .163 & 34.480 & .324 \\
\hline Order M & 224 & 6.00 & 28.00 & 17.95 & 4.64 & -.308 & .163 & -.376 & .324 \\
\hline Dutifulness M & 224 & 11.00 & 32.02 & 25.13 & 4.08 & -.680 & .163 & .510 & .324 \\
\hline Achievement striving M & 224 & 9.00 & 32.00 & 21.92 & 4.46 & -.182 & .163 & -.116 & .324 \\
\hline Self-discipline M & 224 & 6.37 & 32.00 & 21.53 & 5.30 & -.219 & .163 & -.519 & .324 \\
\hline Deliberation M & 224 & 5.00 & 32.00 & 20.88 & 4.77 & -.183 & .163 & .141 & .324 \\
\hline Conscientiousness M & 224 & 65.00 & 180.00 & 131.15 & 22.40 & -.041 & .163 & -.377 & .324 \\
\hline
\end{tabular}

Descriptive statistics of Disintegration facets - male observer ratings

\begin{tabular}{|c|c|c|c|c|c|c|c|c|c|}
\hline & $\mathrm{N}$ & Min & Max & $\mathrm{M}$ & SD & Skew & $\begin{array}{c}\text { Skew } \\
\text { SE }\end{array}$ & Kurt & $\begin{array}{c}\text { Kurt } \\
\text { SE }\end{array}$ \\
\hline GEI M & 224 & .81 & 3.50 & 1.74 & .50 & .819 & .163 & .959 & .324 \\
\hline PD M & 224 & .62 & 3.25 & 1.61 & .60 & .889 & .163 & -.157 & .324 \\
\hline P M & 224 & .70 & 3.92 & 1.79 & .59 & .936 & .163 & .873 & .324 \\
\hline D M & 224 & .70 & 3.27 & 1.57 & .52 & 1.140 & .163 & 1.053 & .324 \\
\hline FA M & 224 & 1.00 & 4.11 & 1.97 & .59 & .811 & .163 & .904 & .324 \\
\hline SOD M & 224 & 1.00 & 3.38 & 1.73 & .56 & .600 & .163 & -.516 & .324 \\
\hline EA M & 224 & 1.00 & 5.00 & 2.62 & .75 & -.052 & .163 & .156 & .324 \\
\hline MT M & 224 & 1.00 & 4.23 & 1.97 & .68 & .456 & .163 & -.343 & .324 \\
\hline M M & 224 & .20 & 4.67 & 2.44 & .77 & .037 & .163 & -.041 & .324 \\
\hline SA M & 224 & .73 & 4.80 & 2.11 & .69 & .789 & .163 & .967 & .324 \\
\hline DELTATOT M & 224 & 1.00 & 3.21 & 1.96 & .47 & .342 & .163 & -.169 & .324 \\
\hline
\end{tabular}

Note: GEI-general executive dysfunction; PD-perceptive distortions; EA-enhanced awareness; Ddepression; P-paranoia; M-mania; SA-social anhedonia; FA-flattened affect; SD-somatoform disregulation; MT-magical thinking; DELTATOT-Delta total score. 
Appendix 11 Hierarchical linear regression analyses- testing of effects of moderator variables on correlations between implicit and explicit measures

Neuroticism - objectively measured consistency

\begin{tabular}{|c|c|c|c|c|c|c|}
\hline Model & $\mathrm{R}$ & $\mathrm{R}$ Square & $\begin{array}{c}\text { Adjusted R } \\
\text { Square }\end{array}$ & $\begin{array}{c}\text { SE of the } \\
\text { Estimate }\end{array}$ & $\begin{array}{c}\text { R Square } \\
\text { change }\end{array}$ & $\begin{array}{c}\text { Sig. F } \\
\text { Change }\end{array}$ \\
\hline 1 & $.172 \mathrm{a}$ & .030 & .025 & .285 & .030 & .011 \\
\hline 2 & $.173 \mathrm{~b}$ & .030 & .021 & .286 & .000 & .788 \\
\hline
\end{tabular}

a. Predictors: (Constant), NSR

b. Predictors: (Constant), NSR, Nobjcons x IATN

Neuroticism - subjective consistency

\begin{tabular}{|c|c|c|c|c|c|c|}
\hline Model & $\mathrm{R}$ & $\mathrm{R}$ Square & $\begin{array}{c}\text { Adjusted R } \\
\text { Square }\end{array}$ & $\begin{array}{c}\text { SE of the } \\
\text { Estimate }\end{array}$ & $\begin{array}{c}\text { R Square } \\
\text { change }\end{array}$ & $\begin{array}{c}\text { Sig. F } \\
\text { Change }\end{array}$ \\
\hline 1 & $.184 \mathrm{a}$ & .034 & .029 & .283 & .034 & .010 \\
\hline 2 & $.184 \mathrm{~b}$ & .034 & .024 & .283 & .000 & .807 \\
\hline
\end{tabular}

a. Predictors: (Constant), NSR

b. Predictors: (Constant), NSR, Nsubjx IATN

Extraversion - objectively measured consistency

\begin{tabular}{|c|c|c|c|c|c|c|}
\hline Model & $\mathrm{R}$ & $\begin{array}{c}\mathrm{R} \\
\text { Square }\end{array}$ & $\begin{array}{c}\text { Adjusted R } \\
\text { Square }\end{array}$ & $\begin{array}{c}\text { SE of the } \\
\text { Estimate }\end{array}$ & $\begin{array}{c}\text { R Square } \\
\text { change }\end{array}$ & $\begin{array}{c}\text { Sig. F } \\
\text { Change }\end{array}$ \\
\hline 1 & $.141 \mathrm{a}$ & .020 & .015 & .978 & .020 & .037 \\
\hline 2 & $.160 \mathrm{~b}$ & .026 & .017 & .978 & .006 & .259 \\
\hline
\end{tabular}

a. Predictors: (Constant), ESR

b. Predictors: (Constant), ESR, Eobjcons x IATE

Extraversion - subjective consistency

\begin{tabular}{|c|c|c|c|c|c|c|}
\hline Model & $\mathrm{R}$ & $\begin{array}{c}\mathrm{R} \\
\text { Square }\end{array}$ & $\begin{array}{c}\text { Adjusted R } \\
\text { Square }\end{array}$ & $\begin{array}{c}\text { SE of the } \\
\text { Estimate }\end{array}$ & $\begin{array}{c}\text { R Square } \\
\text { change }\end{array}$ & $\begin{array}{c}\text { Sig. F } \\
\text { Change }\end{array}$ \\
\hline 1 & $.161 \mathrm{a}$ & .026 & .021 & .956 & .026 & .025 \\
\hline 2 & $.161 \mathrm{~b}$ & .026 & .016 & .959 & .000 & .920 \\
\hline
\end{tabular}

a. Predictors: (Constant), ESR

b. Predictors: (Constant), ESR, Esubj x IATE

Openness - objectively measured consistency

\begin{tabular}{|c|c|c|c|c|c|c|}
\hline Model & $\mathrm{R}$ & $\begin{array}{c}\mathrm{R} \\
\text { Square }\end{array}$ & $\begin{array}{c}\text { Adjusted R } \\
\text { Square }\end{array}$ & $\begin{array}{c}\text { SE of the } \\
\text { Estimate }\end{array}$ & $\begin{array}{c}\text { R Square } \\
\text { change }\end{array}$ & $\begin{array}{c}\text { Sig. F } \\
\text { Change }\end{array}$ \\
\hline 1 & $.074 \mathrm{a}$ & .006 & .001 & .996 & .006 & .274 \\
\hline 2 & $.107 \mathrm{~b}$ & .012 & .002 & .995 & .006 & .253 \\
\hline
\end{tabular}

a. Predictors: (Constant), OSR

b. Predictors: (Constant), OsR, Oobjcons x IATO

Openness - subjective consistency

\begin{tabular}{|c|c|c|c|c|c|c|}
\hline Model & $\mathrm{R}$ & $\begin{array}{c}\mathrm{R} \\
\text { Square }\end{array}$ & $\begin{array}{c}\text { Adjusted R } \\
\text { Square }\end{array}$ & $\begin{array}{c}\text { SE of the } \\
\text { Estimate }\end{array}$ & $\begin{array}{c}\text { R Square } \\
\text { change }\end{array}$ & $\begin{array}{c}\text { Sig. F } \\
\text { Change }\end{array}$ \\
\hline 1 & $.084 \mathrm{a}$ & .007 & .002 & 1.018 & .007 & .247 \\
\hline 2 & $.161 \mathrm{~b}$ & .026 & .016 & 1.011 & .019 & .056 \\
\hline
\end{tabular}

a. Predictors: (Constant), OSR

b. Predictors: (Constant), OsR, Osubj x IATO 
Agreeableness - objectively measured consistency

\begin{tabular}{|c|c|c|c|c|c|c|}
\hline Model & $\mathrm{R}$ & $\begin{array}{c}\mathrm{R} \\
\text { Square }\end{array}$ & $\begin{array}{c}\text { Adjusted R } \\
\text { Square }\end{array}$ & $\begin{array}{c}\text { SE of the } \\
\text { Estimate }\end{array}$ & $\begin{array}{c}\text { R Square } \\
\text { change }\end{array}$ & $\begin{array}{c}\text { Sig. F } \\
\text { Change }\end{array}$ \\
\hline 1 & $.013 \mathrm{a}$ & .000 & -.004 & 1.007 & .000 & .850 \\
\hline 2 & $.070 \mathrm{~b}$ & .005 & -.004 & 1.006 & .005 & .309 \\
\hline
\end{tabular}

a. Predictors: (Constant), ASR

b. Predictors: (Constant), AsR, Aobjcons x IATA

Agreeableness - subjective consistency

\begin{tabular}{|c|c|c|c|c|c|c|}
\hline Model & $\mathrm{R}$ & $\begin{array}{c}\mathrm{R} \\
\text { Square }\end{array}$ & $\begin{array}{c}\text { Adjusted R } \\
\text { Square }\end{array}$ & $\begin{array}{c}\text { SE of the } \\
\text { Estimate }\end{array}$ & $\begin{array}{c}\text { R Square } \\
\text { change }\end{array}$ & $\begin{array}{c}\text { Sig. F } \\
\text { Change }\end{array}$ \\
\hline 1 & $.037 \mathrm{a}$ & .001 & -.004 & 1.010 & .001 & .606 \\
\hline 2 & $.088 \mathrm{~b}$ & .008 & -.003 & 1.009 & .006 & .271 \\
\hline
\end{tabular}

a. Predictors: (Constant), ASR

b. Predictors: (Constant), Asr, Asubj x IATA

Conscientiousness - objectively measured consistency

\begin{tabular}{|c|c|c|c|c|c|c|}
\hline Model & $\mathrm{R}$ & $\begin{array}{c}\mathrm{R} \\
\text { Square }\end{array}$ & $\begin{array}{c}\text { Adjusted R } \\
\text { Square }\end{array}$ & $\begin{array}{c}\text { SE of the } \\
\text { Estimate }\end{array}$ & $\begin{array}{c}\text { R Square } \\
\text { change }\end{array}$ & $\begin{array}{c}\text { Sig. F } \\
\text { Change }\end{array}$ \\
\hline 1 & $.008 \mathrm{a}$ & .000 & -.005 & .999 & .000 & .905 \\
\hline 2 & $.117 \mathrm{~b}$ & .014 & .005 & .995 & .014 & .085 \\
\hline
\end{tabular}

a. Predictors: (Constant), CSR

b. Predictors: (Constant), CSR, Cobjcons x IATC

Conscientiousness - subjective consistency

\begin{tabular}{|c|c|c|c|c|c|c|}
\hline Model & $\mathrm{R}$ & $\begin{array}{c}\mathrm{R} \\
\text { Square }\end{array}$ & $\begin{array}{c}\text { Adjusted R } \\
\text { Square }\end{array}$ & $\begin{array}{c}\text { SE of the } \\
\text { Estimate }\end{array}$ & $\begin{array}{c}\text { R Square } \\
\text { change }\end{array}$ & $\begin{array}{c}\text { Sig. F } \\
\text { Change }\end{array}$ \\
\hline 1 & $.034 \mathrm{a}$ & .001 & -.004 & 1.001 & .001 & .633 \\
\hline 2 & $.034 \mathrm{~b}$ & .001 & -.009 & 1.004 & .000 & .988 \\
\hline
\end{tabular}

a. Predictors: (Constant), CSR

b. Predictors: (Constant), CSR, Csubj x IATC

Disintegration - objectively measured consistency

\begin{tabular}{|c|c|c|c|c|c|c|}
\hline Model & $\mathrm{R}$ & $\begin{array}{c}\mathrm{R} \\
\text { Square }\end{array}$ & $\begin{array}{c}\text { Adjusted R } \\
\text { Square }\end{array}$ & $\begin{array}{c}\text { SE of the } \\
\text { Estimate }\end{array}$ & $\begin{array}{c}\text { R Square } \\
\text { change }\end{array}$ & $\begin{array}{c}\text { Sig. F } \\
\text { Change }\end{array}$ \\
\hline 1 & $.049 \mathrm{a}$ & .002 & -.002 & .983 & .002 & .474 \\
\hline 2 & $.110 \mathrm{~b}$ & .012 & .003 & .981 & .010 & .151 \\
\hline
\end{tabular}

a. Predictors: (Constant), DSR

b. Predictors: (Constant), DSR, Dobjcons x IATD

Disintegration - subjective consistency

\begin{tabular}{|c|c|c|c|c|c|c|}
\hline Model & $\mathrm{R}$ & $\begin{array}{c}\mathrm{R} \\
\text { Square }\end{array}$ & $\begin{array}{c}\text { Adjusted R } \\
\text { Square }\end{array}$ & $\begin{array}{c}\text { SE of the } \\
\text { Estimate }\end{array}$ & $\begin{array}{c}\text { R Square } \\
\text { change }\end{array}$ & $\begin{array}{c}\text { Sig. F } \\
\text { Change }\end{array}$ \\
\hline 1 & $.049 \mathrm{a}$ & .002 & -.002 & .983 & .002 & .474 \\
\hline 2 & $.110 \mathrm{~b}$ & .012 & .003 & .981 & .010 & .151 \\
\hline
\end{tabular}

a. Predictors: (Constant), DSR

b. Predictors: (Constant), DsR, Dsubj x IATD 
Appendix 12 Exploratory factor analysis- Principal component analysis on IAT differential scores

\section{KMO and Bartlett's Test}

Kaiser-Meyer-Olkin Measure of Sampling Adequacy. Bartlett's Test of Sphericity

\begin{tabular}{|c|c|}
\hline Approx. Chi-Square & 2015.901 \\
\hline df & 1225 \\
\hline Sig. & .000 \\
\hline
\end{tabular}

\begin{tabular}{|c|c|c|c|c|c|c|c|}
\hline \multicolumn{8}{|c|}{ Total Variance Explained } \\
\hline \multirow[t]{2}{*}{ Component } & \multicolumn{3}{|c|}{ Initial Eigenvalues } & \multicolumn{3}{|c|}{$\begin{array}{c}\text { Extraction Sums of Squared } \\
\text { Loadings }\end{array}$} & \multirow{2}{*}{$\begin{array}{c}\begin{array}{c}\text { Rotation Sums } \\
\text { of Squared } \\
\text { Loadings }\end{array} \\
\text { Total }\end{array}$} \\
\hline & Total & $\begin{array}{c}\% \text { of } \\
\text { Variance }\end{array}$ & $\begin{array}{c}\text { Cumulative } \\
\%\end{array}$ & Total & $\%$ of Variance & $\begin{array}{c}\text { Cumulative } \\
\%\end{array}$ & \\
\hline 1 & 3.961 & 7.922 & 7.922 & 3.961 & 7.922 & 7.922 & 3.245 \\
\hline 2 & 3.263 & 6.525 & 14.448 & 3.263 & 6.525 & 14.448 & 2.957 \\
\hline 3 & 2.190 & 4.379 & 18.827 & 2.190 & 4.379 & 18.827 & 2.865 \\
\hline 4 & 2.071 & 4.143 & 22.970 & 2.071 & 4.143 & 22.970 & 2.585 \\
\hline 5 & 1.873 & 3.747 & 26.716 & 1.873 & 3.747 & 26.716 & 2.529 \\
\hline 6 & 1.681 & 3.362 & 30.078 & & & & \\
\hline
\end{tabular}

\begin{tabular}{|c|c|c|c|c|c|}
\hline \multicolumn{6}{|c|}{ Pattern Matrix ${ }^{a}$} \\
\hline & \multicolumn{5}{|c|}{ Component } \\
\hline & 1 & 2 & 3 & 4 & 5 \\
\hline Undiscerning $_{\text {diffscore }}$ & .689 & & & & \\
\hline Volatile $_{\text {diffscore }}$ & .537 & & & & \\
\hline Malicious $_{\text {diffscore }}$ & .506 & & & & \\
\hline Generous $_{\text {diffscore }}$ & .472 & & & & \\
\hline Disorganised $_{\text {diffscore }}$ & -.457 & & & & \\
\hline Faithful $_{\text {diffscore }}$ & .412 & & & & \\
\hline Insensitive $_{\text {diffscore }}$ & .410 & & & & \\
\hline Benign $_{\text {diffscore }}$ & .357 & & & & \\
\hline Irresponsible $_{\text {diffscore }}$ & .340 & & & & \\
\hline Cold $_{\text {diffscore }}$ & .161 & & & & \\
\hline Calm diffscore & & .608 & & & \\
\hline Stubborn $_{\text {diffscore }}$ & & .506 & & & \\
\hline Quarrelsome $_{\text {diffscore }}$ & & .471 & & & \\
\hline Tense $_{\text {diffscore }}$ & & .443 & & & \\
\hline Well-intentioned $_{\text {diffscore }}$ & & .435 & & & \\
\hline Decisive $_{\text {diffscore }}$ & & .434 & & & \\
\hline Worried $_{\text {diffscore }}$ & & .425 & & & \\
\hline Nervous $_{\text {diffscore }}$ & & .403 & & & \\
\hline Serene $_{\text {diffscore }}$ & & .355 & & & \\
\hline Relaxed $_{\text {diffscore }}$ & & .344 & & & \\
\hline Sympathetic $_{\text {diffscore }}$ & & .255 & & & \\
\hline Toughdiffscore & & .237 & & & \\
\hline Dogmatic $_{\text {diffscore }}$ & & & .589 & & \\
\hline Unintrospective $_{\text {diffscore }}$ & & & .551 & & \\
\hline Complex $_{\text {diffscore }}$ & & & .517 & & \\
\hline Practical $_{\text {diffscore }}$ & & & .512 & & \\
\hline Creative $_{\text {diffscore }}$ & & & .508 & & \\
\hline Curious $_{\text {diffscore }}$ & & & .473 & & \\
\hline Traditional $_{\text {diffscore }}$ & & & .472 & & \\
\hline
\end{tabular}




\begin{tabular}{|c|c|c|c|}
\hline \multicolumn{4}{|c|}{ Pattern Matrix ${ }^{a}$} \\
\hline Conventional $_{\text {diffscore }}$ & .431 & & \\
\hline Imaginative $_{\text {diffscore }}$ & .302 & & \\
\hline Careless $_{\text {diffscore }}$ & & .648 & \\
\hline Efficient $_{\text {diffscore }}$ & & .565 & \\
\hline Systematic $_{\text {diffscore }}$ & & .514 & \\
\hline Responsible $_{\text {diffscore }}$ & & .510 & \\
\hline Organised diffscore & & .429 & \\
\hline Disciplined $_{\text {diffscore }}$ & & .337 & \\
\hline Lazy $_{\text {diffscore }}$ & & .324 & \\
\hline Inefficient $_{\text {diffscore }}$ & & .315 & \\
\hline Cheerful $_{\text {diffscore }}$ & & .219 & \\
\hline Withdrawn $_{\text {diffscore }}$ & & & .490 \\
\hline Closed $_{\text {diffscore }}$ & & & .488 \\
\hline Passive $_{\text {diffscore }}$ & & & .475 \\
\hline Vivacious $_{\text {diffscore }}$ & & & .443 \\
\hline Talkative $_{\text {diffscore }}$ & & & .419 \\
\hline Happy $_{\text {diffscore }}$ & & & .403 \\
\hline Friendly diffscore $_{\text {en }}$ & & & .376 \\
\hline Quiet $_{\text {diffscore }}$ & & & .344 \\
\hline Shy $y_{\text {diffscore }}$ & & & .340 \\
\hline Philosophising $_{\text {diffscore }}$ & & & .338 \\
\hline \multicolumn{4}{|c|}{$\begin{array}{l}\text { Extraction Method: Principal Component Analysis. } \\
\text { Rotation Method: Promax with Kaiser Normalization. }\end{array}$} \\
\hline \multicolumn{4}{|c|}{ a. Rotation converged in 9 iterations. } \\
\hline
\end{tabular}


Appendix 13 List of abbreviations of behavioural criteria

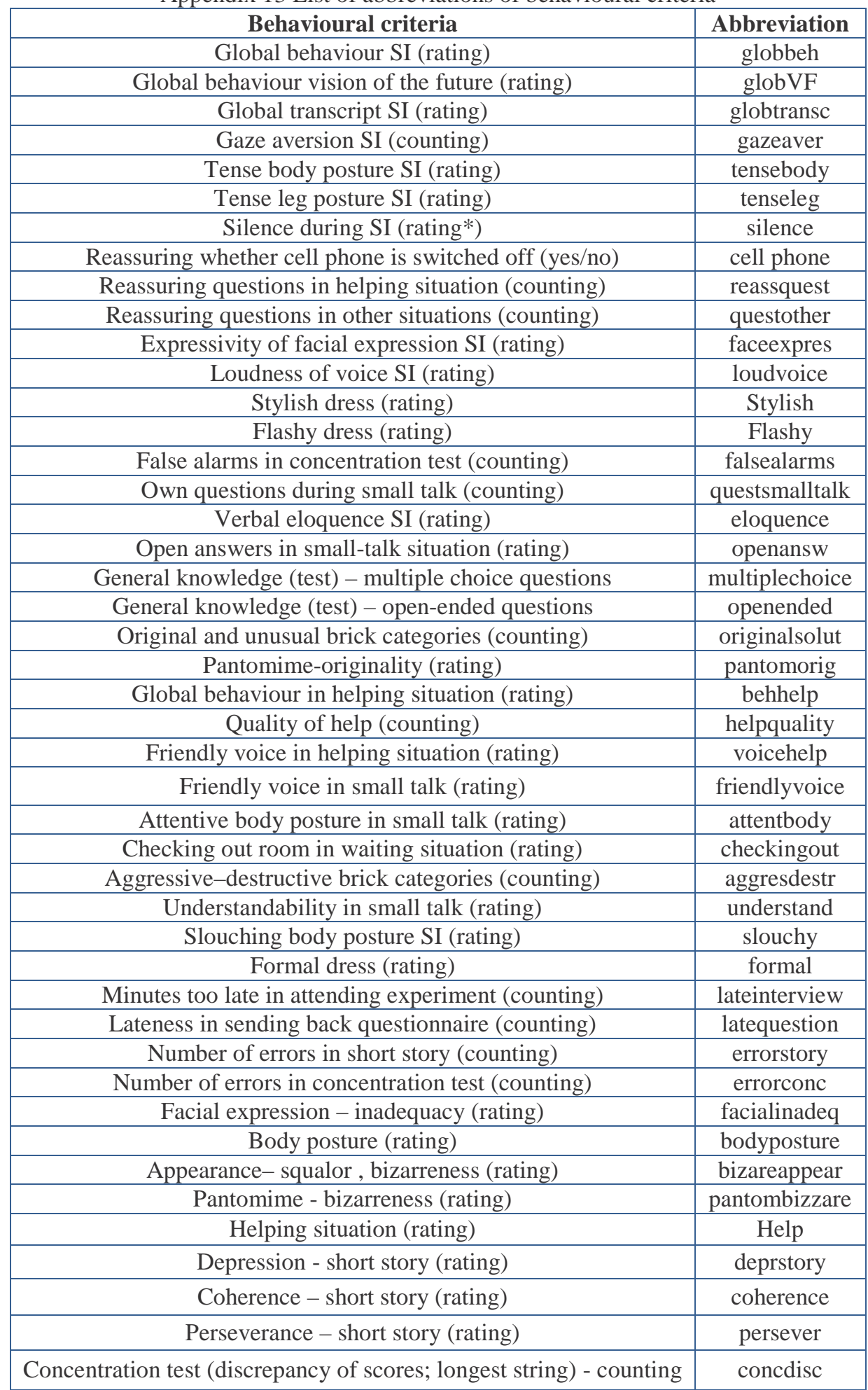


Appendix 14 Goodness of Fit statistics - MTMM model tested on 224 respondents

\begin{tabular}{|c|}
\hline Degrees of Freedom $=231$ \\
\hline Minimum Fit Function Chi-Square $=338.18$ \\
$(\mathrm{P}=0.00)$
\end{tabular}

\begin{tabular}{|c|}
\hline Minimum Fit Function Value $=1.52$ \\
\hline Population Discrepancy Function Value $(\mathrm{F} 0)=0.42$ \\
\hline 90 Percent CI for F0 $=(0.22 ; 0.65)$ \\
\hline RMSEA $=0.042$ \\
\hline 90 Percent CI for RMSEA $=(0.031 ; 0.053)$ \\
\hline P-Value for Test of Close Fit $($ RMSEA $<0.05)=$ \\
0.88
\end{tabular}

\begin{tabular}{|c|}
\hline Expected Cross-Validation Index $(\mathrm{ECVI})=2.77$ \\
\hline 90 Percent CI for ECVI $=(2.58 ; 3.00)$ \\
\hline ECVI for Saturated Model $=3.39$ \\
\hline ECVI for Independence Model $=12.88$ \\
\hline $\begin{array}{c}\text { Chi-Square for Independence Model } \\
\text { with 378 Degrees of Freedom }=2818.26\end{array}$ \\
\hline Independence AIC $=2872.26$ \\
\hline Model AIC $=617.87$ \\
\hline Saturated AIC $=756.00$ \\
\hline Independence CAIC $=2991.38$ \\
\hline Model CAIC $=1266.38$ \\
\hline Saturated CAIC $=2423.60$ \\
\hline
\end{tabular}

\begin{tabular}{|c|}
\hline Normed Fit Index (NFI) $=0.88$ \\
\hline Non-Normed Fit Index (NNFI) $=0.93$ \\
\hline Parsimony Normed Fit Index (PNFI) $=0.58$ \\
\hline Comparative Fit Index (CFI) $=0.96$ \\
\hline Incremental Fit Index (IFI) $=0.96$ \\
\hline Relative Fit Index (RFI) $=0.82$ \\
\hline
\end{tabular}

\begin{tabular}{|c|}
\hline Critical N $(\mathrm{CN})=188.22$ \\
\hline Root Mean Square Residual (RMR) $=0.067$ \\
\hline Standardized RMR $=0.066$ \\
\hline Goodness of Fit Index (GFI) $=0.90$ \\
\hline Adjusted Goodness of Fit Index $($ AGFI $)=0.84$ \\
\hline Parsimony Goodness of Fit Index (PGFI) $=0.55$ \\
\hline
\end{tabular}


Appendix 15 Goodness of Fit statistics - MTMM model tested on 99 respondents

\begin{tabular}{|c|}
\hline Degrees of Freedom $=585$ \\
\hline Minimum Fit Function Chi-Square $=937.10$ \\
$(\mathrm{P}=0.00)$
\end{tabular}

\begin{tabular}{|c|}
\hline Minimum Fit Function Value $=9.56$ \\
\hline Population Discrepancy Function Value $(\mathrm{F} 0)=2.47$ \\
\hline 90 Percent CI for F0 $=(1.74 ; 3.29)$ \\
\hline RMSEA $=0.065$ \\
\hline 90 Percent CI for RMSEA $=(0.054 ; 0.075)$ \\
\hline P-Value for Test of Close Fit $($ RMSEA $<0.05)=0.011$ \\
\hline
\end{tabular}

\begin{tabular}{|c|}
\hline Expected Cross-Validation Index $($ ECVI $)=12.42$ \\
\hline 90 Percent CI for ECVI $=(11.68 ; 13.24)$ \\
\hline ECVI for Saturated Model = 15.92 \\
\hline ECVI for Independence Model $=26.58$ \\
\hline $\begin{array}{c}\text { Chi-Square for Independence Model } \\
\text { with } 378 \text { Degrees of Freedom }=2526.38\end{array}$ \\
\hline Independence $\mathrm{AIC}=2604.38$ \\
\hline Model AIC = 1217.11 \\
\hline Saturated AIC $=1560.00$ \\
\hline Independence CAIC = 2744.59 \\
\hline Model CAIC $=1918.16$ \\
\hline Saturated CAIC $=4364.19$ \\
\hline
\end{tabular}

\begin{tabular}{|c|}
\hline Normed Fit Index $(\mathrm{NFI})=0.63$ \\
\hline Non-Normed Fit Index (NNFI) $=0.75$ \\
\hline Parsimony Normed Fit Index (PNFI) $=0.50$ \\
\hline Comparative Fit Index $(\mathrm{CFI})=0.80$ \\
\hline Incremental Fit Index $(\mathrm{IFI})=0.82$ \\
\hline Relative Fit Index $(\mathrm{RFI})=0.53$ \\
\hline
\end{tabular}

\begin{tabular}{|c|}
\hline Critical N $(\mathrm{CN})=70.81$ \\
\hline Root Mean Square Residual $(\mathrm{RMR})=0.11$ \\
\hline Standardized RMR $=0.11$ \\
\hline Goodness of Fit Index $(\mathrm{GFI})=0.70$ \\
\hline Adjusted Goodness of Fit Index $(\mathrm{AGFI})=0.60$ \\
\hline Parsimony Goodness of Fit Index (PGFI) $=0.52$ \\
\hline
\end{tabular}


Appendix 16 Goodness of Fit statistics - model testing only method factors

\begin{tabular}{|c|}
\hline Degrees of Freedom $=650$ \\
\hline Minimum Fit Function Chi-Square $=1325.52$ \\
$(\mathrm{P}=0.00)$
\end{tabular}

\begin{tabular}{|c|}
\hline Minimum Fit Function Value $=13.53$ \\
\hline Population Discrepancy Function Value $(\mathrm{F} 0)=6.04$ \\
\hline 90 Percent CI for F0 $=(5.06 ; 7.09)$ \\
\hline RMSEA $=0.096$ \\
\hline 90 Percent CI for RMSEA $=(0.088 ; 0.010)$ \\
\hline P-Value for Test of Close Fit $($ RMSEA $<0.05)=0.00$ \\
\hline
\end{tabular}

\begin{tabular}{|c|}
\hline Expected Cross-Validation Index $(\mathrm{ECVI})=14.53$ \\
\hline 90 Percent CI for ECVI $=(13.55 ; 15.58)$ \\
\hline ECVI for Saturated Model $=15.12$ \\
\hline ECVI for Independence Model $=25.67$ \\
\hline $\begin{array}{c}\text { Chi-Square for Independence Model } \\
\text { with 378 Degrees of Freedom }=2439.73\end{array}$ \\
\hline Independence AIC $=2515.73$ \\
\hline Model AIC $=1423.73$ \\
\hline Saturated AIC $=1482.00$ \\
\hline Independence CAIC $=2652.34$ \\
Model CAIC $=1750.88$ \\
\hline Saturated CAIC $=4145.98$ \\
\hline
\end{tabular}

\begin{tabular}{|c|}
\hline Normed Fit Index $(\mathrm{NFI})=0.46$ \\
\hline Non-Normed Fit Index (NNFI) $=0.58$ \\
\hline Parsimony Normed Fit Index (PNFI) $=0.42$ \\
\hline Comparative Fit Index $(\mathrm{CFI})=0.61$ \\
\hline Incremental Fit Index $(\mathrm{IFI})=0.62$ \\
\hline Relative Fit Index $(\mathrm{RFI})=0.41$ \\
\hline
\end{tabular}

\begin{tabular}{|c|}
\hline Critical N $(\mathrm{CN})=55.48$ \\
\hline Root Mean Square Residual (RMR) $=0.12$ \\
\hline Standardized RMR $=0.12$ \\
\hline Goodness of Fit Index $(\mathrm{GFI})=0.60$ \\
\hline Adjusted Goodness of Fit Index $(\mathrm{AGFI})=0.54$ \\
\hline Parsimony Goodness of Fit Index (PGFI) $=0.53$ \\
\hline
\end{tabular}


Curriculum Vitae

\section{Ljiljana B. Lazarević}

Ljiljana B. Lazarević was born on 29 December 1981 in Belgrade, Serbia. She graduated from X Belgrade Gymnasium on 2000. On the same year started studying at the Department of Psychology, University of Belgrade, graduated on 2006 and in 2007 finished master studies (module: Researcher) at the same department under supervision of Prof. Goran Knežević, Phd. In 2007 she enrolled in PhD studies at the same department under supervision of Prof. Goran Knežević, Phd. Her main field of interest are individual differences, specifically basic personality traits and problems of personality assessment.

From 2008 to 2010 she was awarded with scholarship for Young researchers $\mathrm{PhD}$ students by the Ministry of Education and Science of Serbia.

From 2008-2009 she worked as teaching assistant at the courses Social perception and interaction and Socialization. From 2010 she is employed at the Institute of Psychology, University of Belgrade as a researcher.

From 2008 with small group of colleagues participates in international collaborative network of the Project Implicit (principal investigator: Prof. Brian Nosek, PhD, University of Virginia, USA). From 2008 to 2009 participated in the project "Psychological Problems in the Context of Social Changes" (supported by Ministry of Science and Environmental Protection of Serbia, 2006-2010, No. 149018D), and since 2011 participates in the project „Identification, measurement and development of the 
cognitive and emotional competences important for a Europe-oriented society (supported by Ministry of Education and Science of Serbia, 2011-2014; No. 179018.

She speaks fluently English, and has good knowledge of Spanish and Italian. She has published seven refereed papers and participated in a dozen domestic and international conferences. 
Прилог 1.

\section{Изјава о ауторству}

\section{Потписани-а Љиљана Б. Лазаревић}

број уписа 4P070017

\section{Изјављујем}

да је докторска дисертација под насловом

Relations between implicit and explicit measures of personality - Prospects of Implicit Association Test (IAT) in assessment of basic personality traits

- резултат сопственог истраживачког рада,

- да предложена дисертација у целини ни у деловима није била предложена за добијање било које дипломе према студијским програмима других високошколских установа,

- да су резултати коректно наведени и

- да нисам кршио/ла ауторска права и користио интелектуалну својину других лица.

Потпис докторанда

У Београду, 01. 04. 2012.

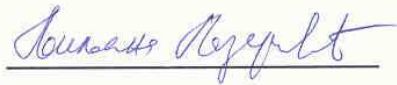


Прилог 2.

\section{Изјава о истоветности штампане и електронске верзије докторског рада}

Име и презиме аутора: Љиљана Б. Лазаревић

Број уписа 4 P 070017

Студијски програм: Психологија

Наслов рада: Relations between implicit and explicit measures of personality Prospects of Implicit Association Test (IAT) in assessment of basic personality traits Ментор: Проф. др Горан Кнежевић

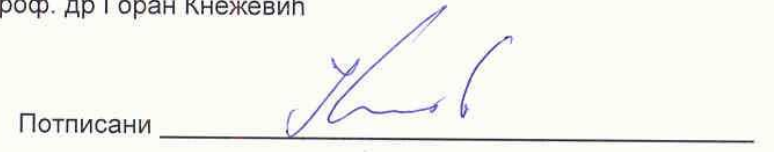

изјављујем да је штампана верзија мог докторског рада истоветна електронској верзији коју сам предао/ла за објављивање на порталу Дигиталног репозиторијума Универзитета у Београду.

Дозвољавам да се објаве моји лични подаци везани за добијање академског звања доктора наука, као што су име и презиме, година и место рођења и датум одбране рада.

Ови лични подаци могу се објавити на мрежним страницама дигиталне библиотеке, у електронском каталогу и у публикацијама Универзитета у Београду.

\section{Потпис докторанда}

у Београду, 01. 04. 2012.

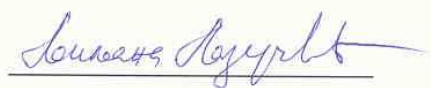


Прилог 3.

\section{Изјава о коришћењу}

Овлашћујем Универзитетску библиотеку „Светозар Марковић“ да у Дигитални репозиторијум Универзитета у Београду унесе моју докторску дисертацију под насловом:

Relations between implicit and explicit measures of personality - Prospects of Implicit Association Test (IAT) in assessment of basic personality traits

која је моје ауторско дело.

Дисертацију са свим прилозима предао/ла сам у електронском формату погодном за трајно архивирање.

Моју докторску дисертацију похрањену у Дигитални репозиторијум Универзитета у Београду могу да користе сви који поштују одредбе садржане у одабраном типу лиценце Креативне заједнице (Creative Commons) за коју сам се одлучио/ла.

1. Ауторство

2. Ауторство - некомерцијално

3. Ауторство - некомерцијално - без прераде

4. Ауторство - некомерцијално - делити под истим условима

5. Ауторство - без прераде

6. Ауторство - делити под истим условима

(Молимо да заокружите само једну од шест понуђених лиценци, кратак опис лиценци дат је на полеђини листа).

Потпис докторанда

у Београду, 01. 04. 2012.

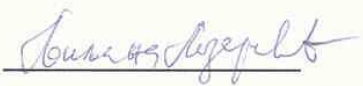


1. Ауторство - Дозвољавате умножавање, дистрибуцију и јавно саопштавање дела, и прераде, ако се наведе име аутора на начин одређен од стране аутора или даваоца лиценце, чак и у комерцијалне сврхе. Ово је најслободнија од свих лиценци.

2. Ауторство - некомерцијално. Дозвољавате умножавање, дистрибуцију и јавно саопштавање дела, и прераде, ако се наведе име аутора на начин одређен од стране аутора или даваоца лиценце. Ова лиценца не дозвољава комерцијалну употребу дела.

3. Ауторство - некомерцијално - без прераде. Дозвољавате умножавање дистрибуцију и јавно саопштавање дела, без промена, преобликовања или употребе дела у свом делу, ако се наведе име аутора на начин одређен од стране аутора или даваоца лиценце. Ова лиценца не дозвољава комерцијалну употребу дела. У односу на све остале лиценце, овом лиценцом се ограничава највећи обим права коришћења дела.

4. Ауторство - некомерцијално - делити под истим условима. Дозвољавате умножавање, дистрибуцију и јавно саопштавање дела, и прераде, ако се наведе име аутора на начин одређен од стране аутора или даваоца лиценце и ако се прерада дистрибуира под истом или сличном лиценцом. Ова лиценца не дозвољава комерцијалну употребу дела и прерада.

5. Ауторство - без прераде. Дозвољавате умножавање, дистрибуцију и јавно саопштавање дела, без промена, преобликовања или употребе дела у свом делу, ако се наведе име аутора на начин одређен од стране аутора или даваоца лиценце. Ова лиценца дозвољава комерцијалну употребу дела.

6. Ауторство - делити под истим условима. Дозвољавате умножавање, дистрибуцију и јавно саопштавање дела, и прераде, ако се наведе име аутора на начин одређен од стране аутора или даваоца лиценце и ако се прерада дистрибуира под истом или сличном лиценцом. Ова лиценца дозвољава комерцијалну употребу дела и прерада. Слична је софтверским лиценцама, односно лиценцама отвореног кода. 